Portland State University

PDXScholar

Spring 1-1-2013

\title{
Characterization of Nano-scale Aluminum Oxide Transport Through Porous Media
}

Sasha Norien Norwood

Portland State University

Follow this and additional works at: https://pdxscholar.library.pdx.edu/open_access_etds

Part of the Environmental Engineering Commons, and the Other Environmental Sciences Commons Let us know how access to this document benefits you.

\section{Recommended Citation}

Norwood, Sasha Norien, "Characterization of Nano-scale Aluminum Oxide Transport Through Porous Media" (2013). Dissertations and Theses. Paper 981.

https://doi.org/10.15760/etd.981

This Thesis is brought to you for free and open access. It has been accepted for inclusion in Dissertations and Theses by an authorized administrator of PDXScholar. Please contact us if we can make this document more accessible: pdxscholar@pdx.edu. 
Characterization of Nano-scale Aluminum Oxide Transport Through Porous Media

by

Sasha Norien Norwood

A thesis submitted in partial fulfillment of the requirements for the degree of

Master of Science

in

Civil and Environmental Engineering

Thesis Committee:

Gwynn R. Johnson, Chair

Dean B. Atkinson

William Fish

Portland State University

2013 


\section{ABSTRACT}

Land application of biosolids has become common practice in the United States as an alternative to industrial fertilizers. Although nutrient rich, biosolids have been found to contain high concentrations of unregulated and/or unrecognized emerging contaminants (e.g., pharmaceuticals, personal care products) while containing a significant fraction of inorganic nano-scale colloidal materials such as oxides of iron, titanium, and aluminum. Given their reactivity and small size, there are many questions concerning the potential migration of these nano-sized colloidal materials through the soil column and into our surface and groundwater bodies. Transport of emerging pollutants of concern through the soil column, at minimum, is impacted by colloidal properties (e.g., chemical composition, shape, aggregation kinetics), solution chemistry (e.g., $\mathrm{pH}$, ionic strength, natural organic matter), and water flow velocity. The purpose of this current research was to characterize the long-term transport behavior of aluminum oxide nanoparticles $\left(\mathrm{Al}_{2} \mathrm{O}_{3}\right)$ through a natural porous media with changes in $\mathrm{pH}$, aqueous-phase concentration, pore-water velocity and electrolyte valence. Additionally, deposition rates during the initial stages of deposition were compared to several models developed based on colloid filtration theory and DLVO stability theory. Benchtop column laboratory experiments showed that, under environmentally relevant groundwater conditions, $\mathrm{Al}_{2} \mathrm{O}_{3}$ nanoparticles are mobile through saturated porous media. Mobility increased under conditions in which the nanoparticles and porous media were of like charge ( $\mathrm{pH} 9)$. Changes in linear pore water velocity, under these same high $\mathrm{pH}$ conditions, showed similar transport behavior with little mass retained in the system. Deposition is believed to be kinetically controlled at 
$\mathrm{pH}$ 9, as evidenced by the slightly earlier breakthrough as flow rate increased and was further supported by observed concentration effects on the arrival wave following several stop flows. While lower aqueous-phase concentrations resulted in significantly longer breakthrough times, the total mass retained in the system was found to be independent of concentration. Additionally, experimental deposition rate coefficients $\left(k_{d}\right)$, used to describe deposition kinetics under "clean bed" conditions, were similar across the aqueous-phase concentrations studied. The use of calcium chloride electrolyte solution in transport studies resulted in enhanced mobility relative to potassium chloride suggesting that changes in groundwater solution chemistry could impact mobility of contaminants associated with biosolids. Predicted deposition rate coefficients, using three different models, were found to under- or over-predict values relative to those experimentally determined values depending on the model. This current research has shown that nanocolloids associated with biosolids, specifically $\mathrm{Al}_{2} \mathrm{O}_{3}$, are mobile through saturated porous media. Given the ubiquity of nanocolloidal materials, particularly engineered nanomaterials, coupled with the expected increase in land-application of biosolids, a clear understanding of their transport and fate is prudent to understanding the potential impact these emerging pollutants may have on our surface and groundwater bodies. 


\section{TABLE OF CONTENTS}

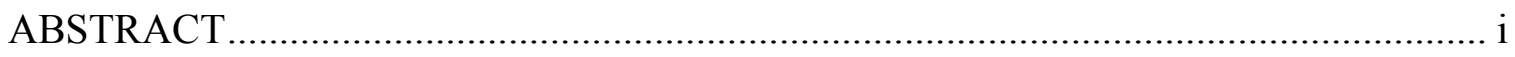

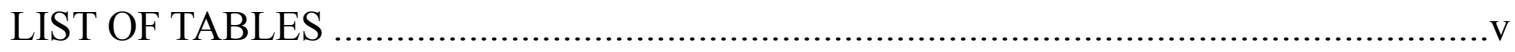

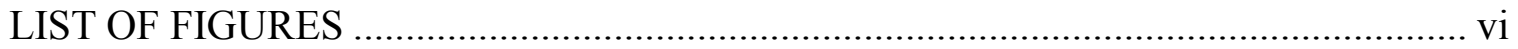

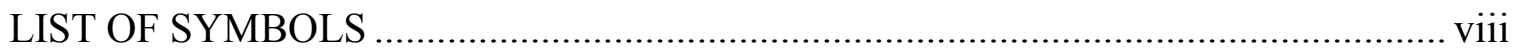

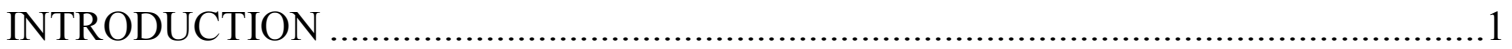

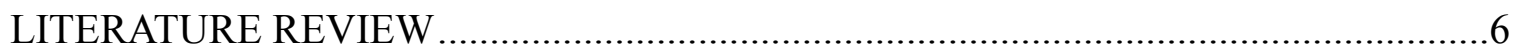

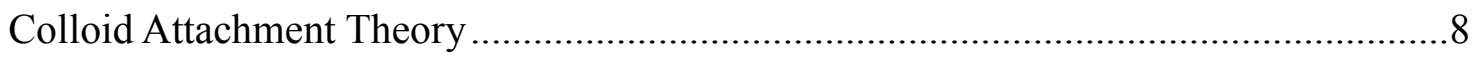

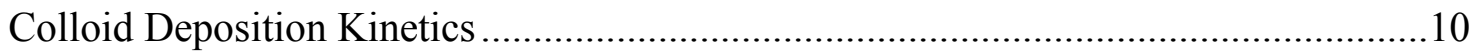

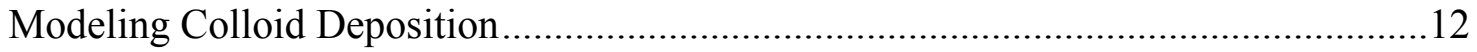

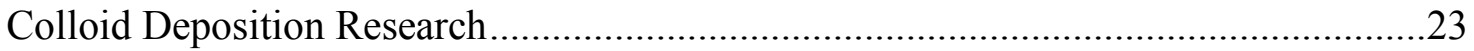

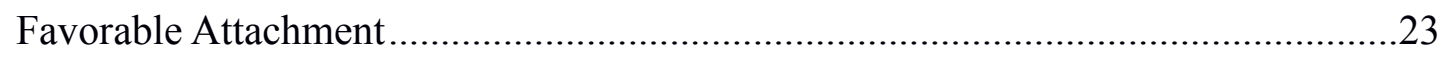

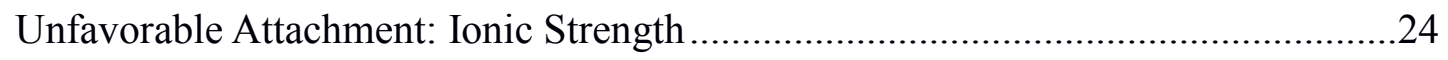

Unfavorable Attachment: Colloid Size...................................................................27

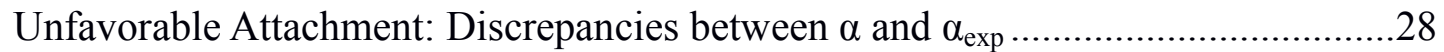

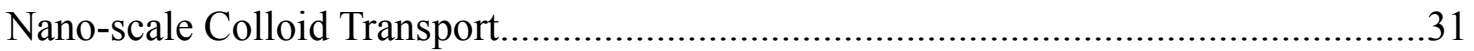

Nano-scale Metal Oxide Transport .....................................................................35

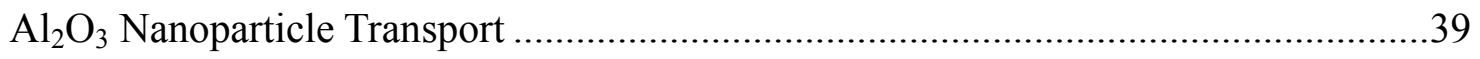

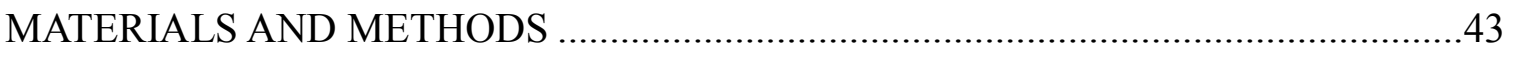

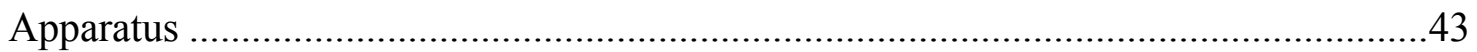

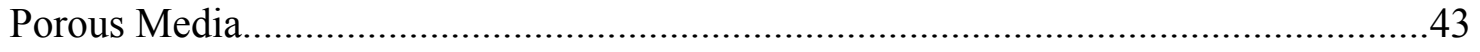

Aluminum Oxide Nanoparticles................................................................45

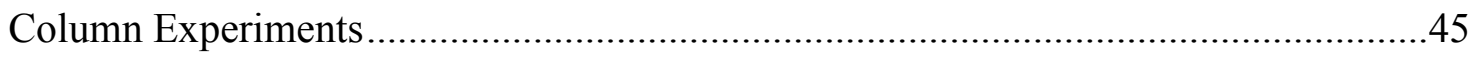

Collector Efficiency and Deposition Rate Coefficients .........................................48

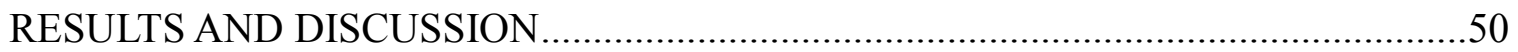


Physical Heterogeneity - Non-reactive Tracer..........................................................50

Physical and Chemical Heterogeneity.................................................................51

Favorable and Unfavorable Attachment Conditions ( $\mathrm{pH} 6$ and $\mathrm{pH}$ 9).........................53

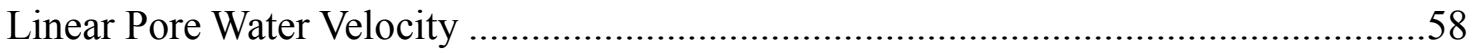

Aqueous-Phase Concentration ...............................................................................62

Electrolyte - Monovalent Versus Divalent Cation .......................................................65

Collector Efficiency/First-order Reaction Rate Coefficient...........................................68

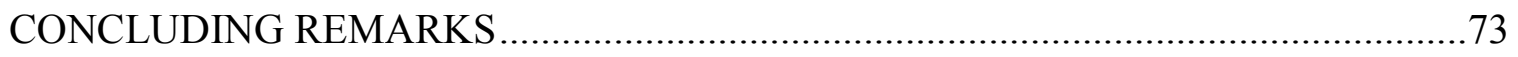

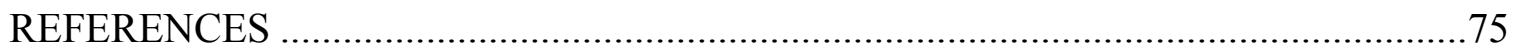

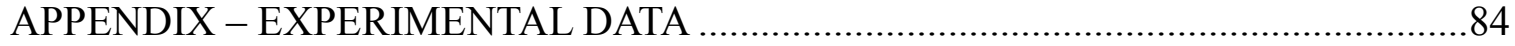




\section{LIST OF TABLES}

Table 1: Tufenkji and Elimelech (2004) dimensionless parameters .............................. 17

Table 2: Nelson and Ginn (2011) dimensionless parameters ....................................... 19

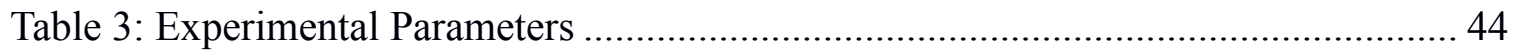

Table 4: Theoretical single-collector efficiencies $(\eta)$ compared to experimental singlecollector efficiencies $\left(\eta_{\text {exp }}\right)$ from $\mathrm{Al}_{2} \mathrm{O}_{3} \mathrm{pH} 6$ nanoparticle transport experiments ........... 70

Table 5: Theoretical collector efficiencies $(\eta)$ compared to experimental collector efficiencies $\left(\eta_{\text {exp }}\right)$ from $\mathrm{Al}_{2} \mathrm{O}_{3} \mathrm{pH} 6$ nanoparticle transport experiments ........................ 71

Table 6: Experimental and Theoretical Reaction Rate Coefficients - Favorable

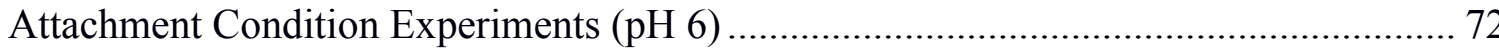




\section{LIST OF FIGURES}

Figure 1: Particle transport mechanisms to the collector surface ...................................... 6

Figure 2: Relative contribution of diffusion, sedimentation, and interception to overall transport as a function of particle size …………….................................................... 7

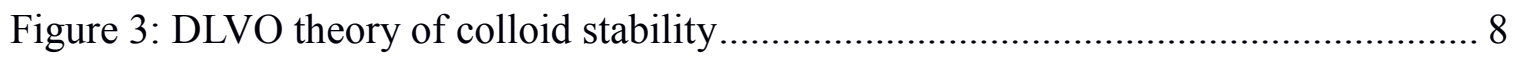

Figure 4: Breakthrough Curve of Silica Coated Zirconia - Favorable Attachment ..........11

Figure 5: Breakthrough curves of $489 \mathrm{~nm}$ latex colloids as a function of aqueous-phase concentration and time- Favorable Attachment .......................................................... 12

Figure 6: Single-collector efficiency model compared to experimental values................ 15

Figure 7: Tufenkji and Elimelech and Yao collector efficiency model performance ....... 18

Figure 8: Nelson and Ginn and Tufenkji and Elimelech collector efficiency model

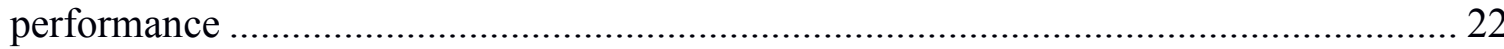

Figure 9: Latex colloid breakthrough curves with approach velocity of $8.2 \mathrm{~cm} / \mathrm{min}$

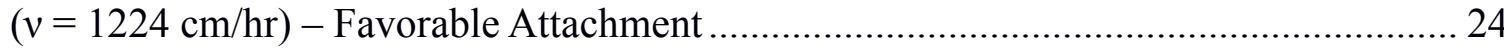

Figure 10: Colloid-collector interaction energy profiles for a representative negatively

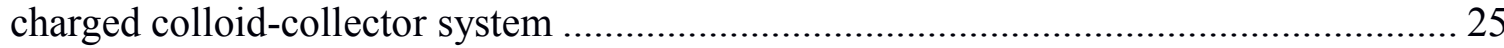

Figure 11: Particle breakthrough curves of $753 \mathrm{~nm}$ negatively charged latex colloids illustrating an increase in deposition with increasing ionic strength ............................... 26

Figure 12: Interaction energy profiles for 50,110 , and $1500 \mathrm{~nm}$ negatively charged latex colloids in $0.001-0.1 \mathrm{M}$ electrolyte solutions ......................................................... 27

Figure 13: Discrepancies between theoretical and experimental attachment efficiencies

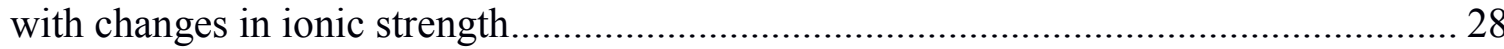

Figure 14: Increasing deposition of silica colloids due to collector patchwise charge

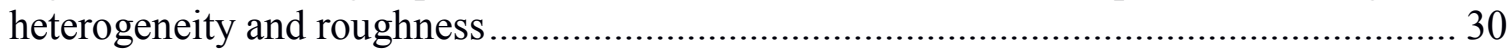

Figure 15: Nanoparticle classification: Size and representative natural colloids ............. 31

Figure 16: Engineered Nanoparticle Breakthrough Curves - Unfavorable Attachment .. 33

Figure 17: Impact of solution $\mathrm{pH}$ on hematite $\left(\alpha-\mathrm{Fe}_{2} \mathrm{O}_{3}\right)$ nanoparticle aggregation rate and hydrodynamic diameter.

Figure 18: Breakthrough Curves of $100 \mathrm{~nm} \mathrm{Fe}_{2} \mathrm{O}_{3}$ Particles - Unfavorable Attachment 38 
Figure 19: Alumina $\left(\mathrm{Al}_{2} \mathrm{O}_{3}\right)$ breakthrough curves with approach velocity Transport Experiments - Favorable Attachment

Figure 20: Representative Non-reactive Tracer Studies Illustrating Physical

Heterogeneity 50

Figure 21: $\mathrm{Al}_{2} \mathrm{O}_{3}$ Arrival Waves Illustrating Physical and Chemical Heterogeneity

Relative to NRT Physical Heterogeneity.... 52

Figure 22: $\mathrm{Al}_{2} \mathrm{O}_{3}$ Arrival Waves- Favorable ( $\mathrm{pH}$ 6) and Unfavorable Attachment (pH 9).....

Figure 23: High velocity $\mathrm{Al}_{2} \mathrm{O}_{3}$ Nanoparticle Breakthrough Curve $(v=217 \mathrm{~cm} / \mathrm{h})-$

Favorable Attachment

Figure 24: Characterization of Velocity Effects on Transport Behavior of $\mathrm{Al}_{2} \mathrm{O}_{3}-$ Unfavorable Conditions ( $\mathrm{pH} 9$ ) 59

Figure 25: Concentration effects upon stop flow events - Unfavorable Attachment ....... 61

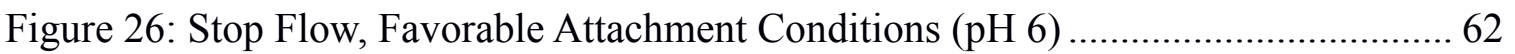

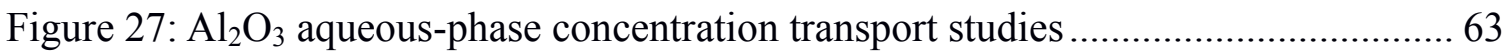

Figure 28: Total mass $\mathrm{Al}_{2} \mathrm{O}_{3}$ nanoparticles retained relative to the total mass injected at three different aqueous phase concentrations 65

Figure 29: Comparison of $\mathrm{Al}_{2} \mathrm{O}_{3}$ transport using a monovalent $(\mathrm{KCl})$ and divalent $\left(\mathrm{CaCl}_{2}\right)$ electrolyte solution. 66

Figure 30: Comparison of $\mathrm{Al}_{2} \mathrm{O}_{3}$ Transport Study in $\mathrm{KCl}$ to a Higher Ionic Strength Study using $\mathrm{CaCl}_{2}$ 68

Figure 31: $\mathrm{Al}_{2} \mathrm{O}_{3}$ Early Transport Behavior - Favorable Attachment Conditions 69 


\section{LIST OF SYMBOLS}

$\begin{array}{ll}A & \text { Hamaker constant } \\ a_{p} & \text { radius of a particle } \\ C & \text { particle concentration } \\ C_{o} & \text { fluid-phase particle concentration } \\ D & \text { hydrodynamic dispersion coefficient } \\ D_{\infty}, D_{B M} & \text { diffusion coefficient in an infinite medium, } D_{\infty}=D_{B M}=k T / 6 \pi \mu a_{p} \\ d_{c} & \text { diameter of spherical collector } \\ d_{p} & \text { diameter of particle } \\ f & \text { porosity of porous medium } \\ g & \text { gravitational constant } \\ k_{d} & \text { particle deposition (filtration) rate coefficient } \\ k & \text { Boltzmann constant, 1.3805 } \mathrm{x} 10^{-23} \mathrm{~J} / \mathrm{K} \\ L & \text { filter bed packed length or column length } \\ S & \text { retained particle concentration } \\ T & \text { absolute temperature } \\ t & \text { time } \\ U & \text { approach (superficial) velocity of fluid; darcy velocity } \\ x & \text { distance along column length }\end{array}$

\section{Greek Letters}

$\alpha \quad$ single-collector attachment efficiency

$\eta \quad$ single-collector removal (collection) efficiency or collection efficiency

$\eta_{o} \quad$ single-collector contact efficiency

$\eta_{D} \quad$ single-collector contact efficiency for deposition by diffusion

$\eta_{G} \quad$ single-collector contact efficiency for deposition by gravity

$\eta_{I} \quad$ single-collector contact efficiency for deposition by interception 


$\begin{array}{ll}\mu & \text { absolute viscosity of fluid } \\ v & \text { linear pore-water velocity, } v=U / f \text { for saturated porous media } \\ \rho_{b} & \text { porous medium bulk density } \\ \rho_{p} & \text { density of particle } \\ \rho_{f} & \text { density of fluid } \\ \gamma & \gamma=(1-f)^{1 / 3}\end{array}$




\section{INTRODUCTION}

The production, use, and disposal of anthropogenic compounds has resulted in the detection of compounds in the environment whose distribution and input sources may be largely unknown. These compounds, many with unknown human and environmental health risks, are increasingly being recognized as emerging pollutants of concern. Pharmaceuticals and personal care products (PPCPs) and other anthropogenic waste indicators (e.g., nanomaterials, halogenated compounds, pesticides, flame retardants, plasticizers) have been found in wastewater effluent and surface runoff that feed into our nation's surface waters: waters that provide fish and wildlife habitat, drinking water supplies and recreational resources $(1-7)$.

Modern nanotechnology, with a projected market value of $\$ 1.5$ trillion by 2015 , seeks to fabricate nano-scale materials for a variety of applications including medical devices, consumer products, electronic devices, and wastewater treatment $(8,9)$. Although nanotechnology serves to improve our quality of life, there is concern that the ubiquity of nano-scale materials, in particular nano-particles, have the potential to negatively impact human health and natural ecosystems via uptake through groundwater, surface water, plants and animals. More specifically, given their reactivity and small size, there are many questions concerning the potential migration of these nano-sized particulates through the soil column and their potential participation in the facilitated transport of contaminants, such as heavy metals and other pollutants of concern. 
While research points to wastewater effluent and stormwater runoff as input sources of emerging pollutants of concern, the land-application of biosolids is an exposure pathway of considerable interest among many researchers. Treated sewage sludge, termed biosolids, is increasingly being land applied and marketed as a sustainable solution to incineration or disposal in a land-fill. Of the 7.1 million dry tons generated in the United States in 2004, it is estimated that 55\% were land applied where they were spread on the land surface, mechanically incorporated or injected $(10,11)$. While providing nutrients and improving soil properties of agricultural and reclaimed lands, forests, and parks, biosolids also contain high concentrations of unregulated and/or unrecognized emerging contaminants; including pharmaceuticals, personal care products, and other anthropogenic waste indicators $(12-15)$. Additionally biosolids contain a significant amount of inorganic material including heavy metals and metal oxides $(12,14$, 16, 17). For example, Jaynes and Zartman (2005) found oxides of iron, aluminum, silicon, and magnesium in their analysis of New York City municipal biosolids (16). Additionally, anthropogenic nano-scale titanium dioxide, commonly used as a whitener and strong UV absorber in consumer products, is believed to have contributed to the titanium found in these same biosolids (16).

Land-application of biosolids presents a possible exposure pathway for these nano-scale emerging pollutants resulting from consumer product usage and disposal of nanoparticle-incorporated products. For example, several studies have shown the migration of pollutants of concern from land-applied biosolids into tile drains used in 
agricultural fields $(18-20)$. Gottschall et al. (2012) showed that several of the compounds (e.g., bacteriocides and fluoroquinolones) were detected up to a year postapplication with four compounds (ibuprofen, triclosan, triclocarbon, and odesmethylvenlafaxine) also detected in shallow groundwater after the first rain event two days post-application (20).Furthermore in-situ colloid generation and transport through biosolid-amended soils has been shown to occur and has the potential to facilitate transport of heavy metals and those emerging pollutants of concern found in biosolids $(17,21-24)$.

As generation of biosolids from wastewater treatment plants has increased, so have costs of disposal. Disposal via landfill and incineration has become less cost effective such that biosolids slated for beneficial use (e.g., land-application) is expected to continuously grow. Given the ubiquitous nature of many emerging pollutants of concern in the environment coupled with the expected increases in biosolid generation and land-application, a clear understanding of their transport and fate is necessary. Furthermore, a characterization of mechanisms and/or processes potentially facilitating the transport and affecting the fate of these toxins is necessary.

Transport of emerging pollutants of concern through the soil column, at minimum, is impacted by colloidal properties (e.g., chemical composition, shape, aggregation kinetics), solution chemistry (e.g., $\mathrm{pH}$, ionic strength, natural organic matter), and water flow velocity. Colloidal transport and deposition, commonly described using colloid filtration theory in conjunction with Derjaguin - Landau - Verwey - Overbeek 
(DLVO) colloid stability theory, typically considers mono-disperse model colloid solutions (e.g., spherical latex particles in mono-valent electrolytes) in model porous media (e.g., glass beads or silica sand). In contrast, variations in surface reactivity and the propensity to form poly-disperse aggregates may result in nanoparticle transport behavior much different than that measured in these model systems. A laboratory assessment of nanoparticle mobility, conducted by Lecoanet et al. (2004) used glass beads to simulate a sandy groundwater aquifer and found markedly different transport behavior among the eight engineered nanoparticles examined, indicating mobility of nanoparticles through soils may be highly variable (25).

Questions concerning the transport and fate of nano-colloidal emerging pollutants through the soil column, particularly those associated with land-applied biosolids, is an important area of concern within our research group. This current research attempts to characterize transport of metal oxide nanoparticles, specifically aluminum oxide nanoparticles, under variable and environmentally relevant groundwater conditions. While ecotoxicity of aluminum oxide nanoparticles, manufactured for use as an abrasive, insulator, and in personal care products, has not been well established, some research indicates a higher conferred toxicity to some plants and animals $(26,27)$. Benchtop column transport studies were conducted to characterize aluminum oxide nanoparticle transport through a natural porous media using large input pulses and pore-water velocities typical of groundwater flow. While research typically focuses on the initial stages of deposition using short input pulses and significantly higher flow velocities 
paramount to colloid filtration theory, this research aims to characterize long-term transport behavior with changes in $\mathrm{pH}$, ionic strength, aqueous-phase concentration, and pore-water velocity. Deposition rates during the initial stages of deposition were examined and compared to models developed utilizing colloid filtration and DLVO colloid stability theory. Given the ubiquitous nature of these emerging pollutants of concern in the environment, a clear understanding of their transport and fate is necessary to assess the potential for contaminant transport and the facilitated transport of toxins through the subsurface and into our surface and groundwater bodies. 


\section{LITERATURE REVIEW}

Colloidal particles, with at least one linear dimension between $1 \mathrm{~nm}$ and $1 \mu \mathrm{m}$, are ubiquitous in the natural environment $(28,29)$. Transport and fate of these particles through saturated porous media is described as a two step process consisting of particle transport to the collector surface followed by attachment (29). While advective flow transports particles through porous media, contact or collision with the media or collector surface occurs via three mechanisms: interception, sedimentation, and/or diffusion, also termed Brownian diffusion (30, 31, Figure 1). Interception is the result of direct contact with the collector as colloids are transported along a streamline of flow. Sedimentation occurs through gravitational settling of colloids flowing along a different trajectory than the aqueous solution. Diffusion is transport through the random motion of particles quantified as a thermal kinetic energy. The extent that diffusion, interception, and

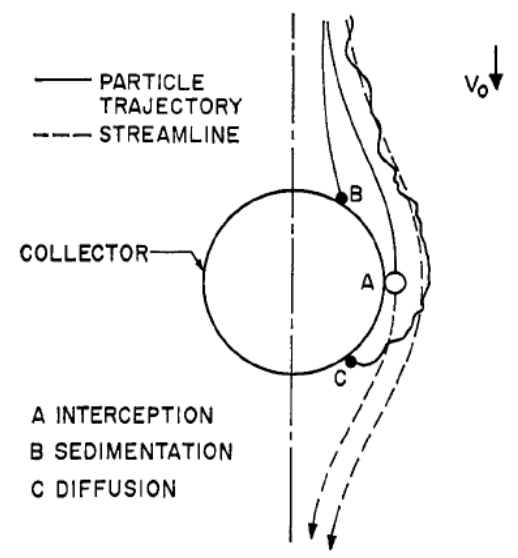

Figure 1: Particle transport mechanisms to the collector surface (Source: Yao et al. (30)) 
sedimentation operate in overall colloid transport to the collector surface is dependent, in part, on particle diameter. For particles smaller than $1 \mu \mathrm{m}$, diffusion is the dominant filtration mechanism with its contribution increasing as particle size decreases as illustrated in Figure $2(30-33)$. This behavior is in contrast to particles greater than $1 \mu \mathrm{m}$ in diameter whose transport to collector surfaces is increasingly controlled by interception and sedimentation.

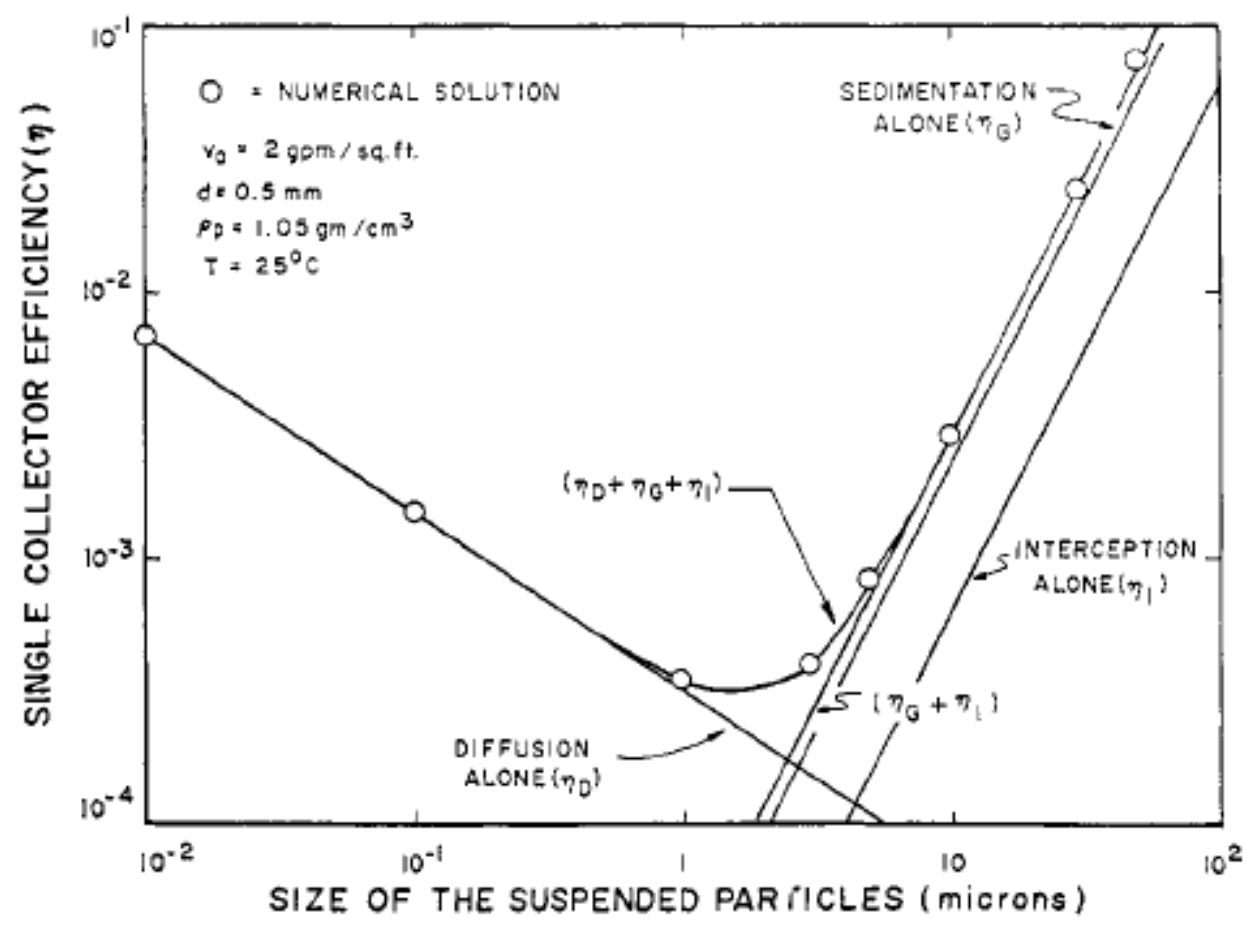

Figure 2: Relative contribution of diffusion, sedimentation, and interception to overall transport as a function of particle size

(Source: Yao et al. (30)) 


\section{Colloid Attachment Theory}

Attachment occurs as the result of interaction forces between charged colloidal particles and collectors. The net force, or net interaction energy, is described by the classic DLVO colloid stability theory, historically used to describe colloid-colloid interactions in aqueous solutions. The net force is the sum of the van der Waals attractive force and electric double layer force (attractive or repulsive) between charged particles $(28,34)$. The result is a net interaction energy profile that is a function of separation distance between colloid and collector. Figure 3a illustrates the net interaction energy profile of $1-\mu \mathrm{m}$ diameter spheres in a monovalent electrolyte as a function of separation distance.

(a)

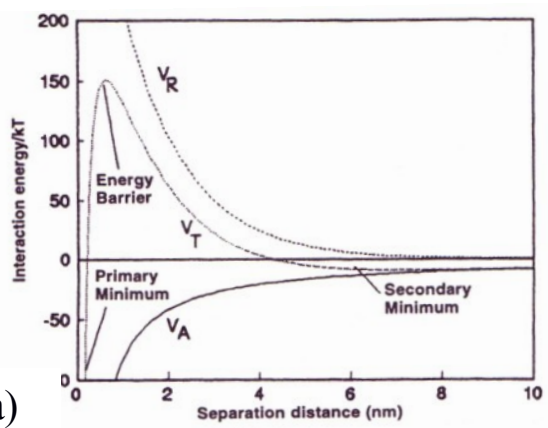

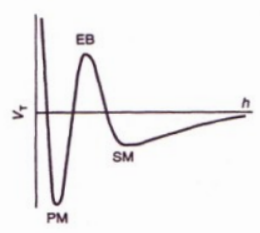

(b)

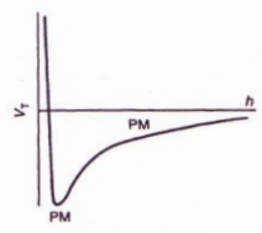

(c)

\section{Figure 3: DLVO theory of colloid stability}

Interaction energy profile. (a) Total interaction energy $\left(\mathrm{V}_{\mathrm{T}}\right)$ as the sum of electric double layer repulsion energy $\left(V_{R}\right)$ and van der Waals attraction energy $\left(V_{A}\right)$. (b) Energy profile of like-charged colloids. (c) Energy profile of oppositely charged particles.

(Source: Elimelech et al. (29)) 
Under natural environmental conditions in the subsurface, colloids and porous media typically carry an overall negative surface charge. As such, these negatively charged colloids will exhibit greater mobility than their positively charged counterparts due to electrostatic repulsion between these colloids and collectors $(35,36)$. When colloids are of like charge there is a large energy barrier (EB) to deposition in the primary minimum and a shallow secondary minimum (SM) energy well. Under these conditions electrostatic repulsion is the dominant force between colloids and porous media surfaces and attachment to those surfaces is deemed unfavorable. A typical interaction energy profile of colloids under these like-charged conditions is illustrated in Figure $3 b$. Attachment under these "unfavorable" conditions may occur in the deep primary energy well (PM) and/or in the shallow attractive secondary energy minimum (SM) where attachment is weaker than in the primary energy well and may be reversible. This shallow attractive energy well exists at an optimal separation distance where the net interaction energy is small and attractive; a direct result of the slower rate at which van der Waals attractive energy decreases with increasing separation distance relative to electrostatic repulsion $(37,38)$.

In contrast, when colloid and collector carry an opposite sign of surface charge the electrostatic interaction force is attractive and shows a net interaction energy profile as illustrated in Figure 3c. Coupled with attractive van der Waals forces there is no energy barrier to attachment. Under these favorable conditions attachment is described as irreversible and transport limited (29). 


\section{Colloid Deposition Kinetics}

Fundamental theories of deposition kinetics for colloidal particles are based on classic filtration theory. Originally developed to describe particle retention in packed bed filters employed in engineered water treatment systems, the theory describes particle removal at the initial stages of filtration under "clean bed conditions" when the filter bed is devoid of deposited particles (30). A one-dimensional advection dispersion equation with first-order kinetic deposition is typically used to describe colloid transport and fate through saturated porous media under these initial deposition conditions.

$$
\begin{gathered}
\frac{\partial C}{\partial t}+\frac{\rho_{b}}{\theta} \frac{\partial S}{\partial t}=D \frac{\partial^{2} C}{\partial x^{2}}-v \frac{\partial C}{\partial x} \\
\frac{\rho_{b}}{\theta} \frac{\partial S}{\partial t}=k_{d} C
\end{gathered}
$$

Here $C$ is aqueous concentration, $S$ is the deposited particle concentration, $\theta$ is volumetric water content, $\rho_{b}$ is bulk density, $D$ is the hydrodynamic dispersion coefficient, $v$ is porewater velocity, $x$ is column or bed length, $t$ is time, and $k_{d}$ is the particle deposition rate coefficient (39). Under steady state conditions of continuous particle injection and negligible hydrodynamic dispersion (typically assumed for laboratory column experiments) equations (1) and (2) can be simplified to a first-order deposition equation where $L$ is the bed or column length in equation (5).

$$
\begin{gathered}
k_{d} C=-v \frac{\partial C}{\partial x} \\
C(x)=C_{o} e^{-\frac{k_{d}}{v} x} \\
k_{d}=-\frac{v}{L} \ln \left(C / C_{o}\right)
\end{gathered}
$$


Colloid filtration theory assumes that during this initial deposition behavior, under "clean bed" conditions, the rate of deposition $\left(k_{d}\right)$ is constant. Results of aquifer tank experiments conducted by Loveland et al. (2003) illustrate the impact of "constant deposition rates" on colloidal transport behavior (see Figure 4). Specifically, an early low-concentration steady-state breakthrough is measured resulting from deposition under clean bed conditions followed by dynamic transport behavior wherein "blocking" occurs impacting subsequent particle deposition (e.g., 40). Additionally, colloid filtration

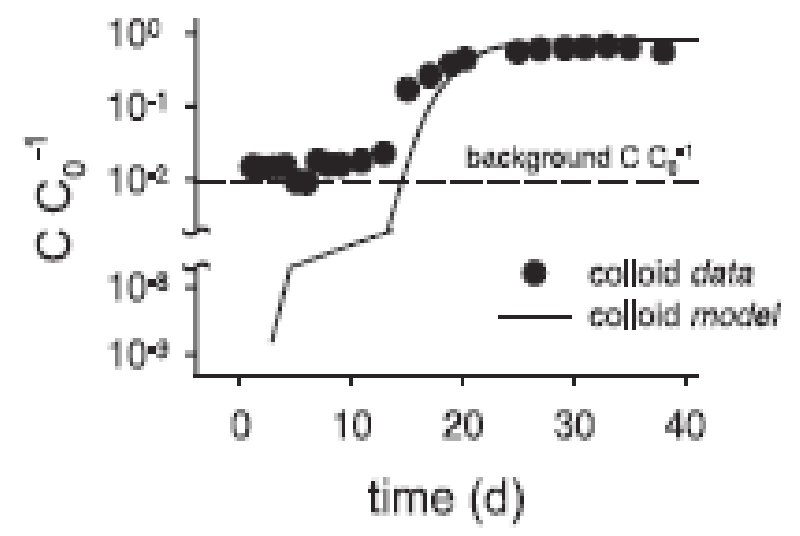

Figure 4: Breakthrough Curve of Silica Coated Zirconia - Favorable Attachment A low velocity $(v=2.2 \mathrm{~cm} / \mathrm{h})$ aquifer tank experiment conducted using negatively-charged $150 \mathrm{~nm}$ silicacoated zirconia colloids and positively-charged ferric oxyhydroxide coated sand.

(Source: Loveland et al. (41))

theory assumes that the rate of particle attachment to the collector surface is independent of particle concentration. For example, Liu et al. (1995) found that while the effluent concentration at any time-point was dependent on the influent concentration (as 
illustrated in Figure 5), the initial breakthrough relative concentration under clean bed conditions $\left(C / C_{o}=0.2\right)$ was independent of influent latex colloid aqueous-phase concentration (42).

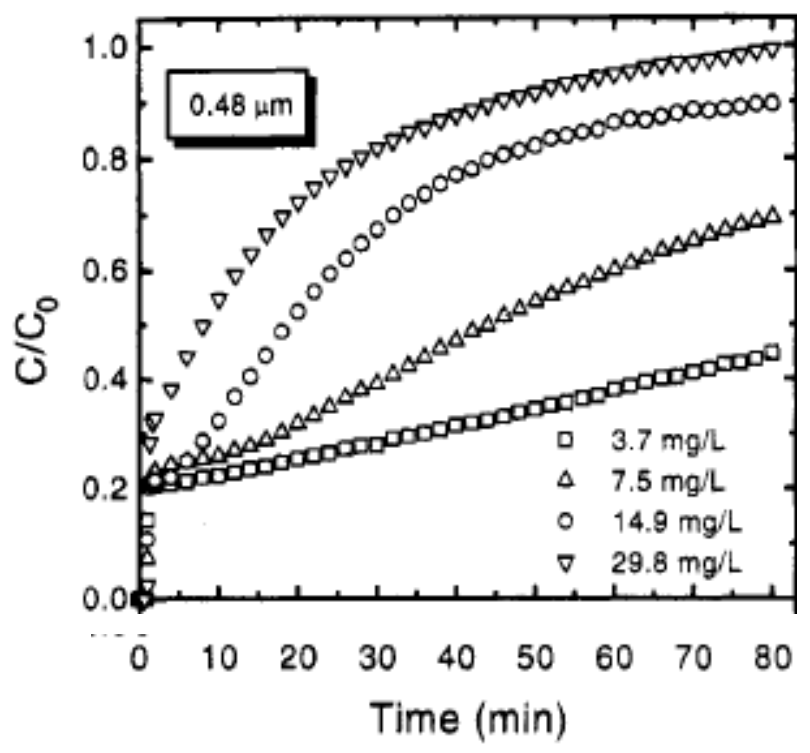

Figure 5: Breakthrough curves of $489 \mathrm{~nm}$ latex colloids as a function of aqueous-phase concentration and time - Favorable Attachment

(Source: Liu et al. (42))

\section{Modeling Colloid Deposition}

Several filtration models have been developed in an effort to predict colloid deposition rates in saturated porous media under "clean bed" conditions. These models are based on formulations of physical and chemical mechanisms that control colloid transport and attachment where the particle deposition rate coefficient $\left(k_{d}\right)$ is a function of the collector efficiency $(\eta)$ as illustrated in equation (6) wherein $d_{c}$ is the collector diameter and $f$ is porosity (32). Equation (6) describes the particle deposition rate onto a 
single-collector and as such $\eta$ is termed the single-collector efficiency by Yao et al. (1971) and Tufenkji and Elimelech (2004) (30, 32). The single-collector efficiency $(\eta)$ attempts to capture the rate of attachment of those colloids that have made contact

$$
k_{d}=\frac{3}{2} \frac{(1-f) v}{d_{c}} \eta
$$

with the collector surface via diffusion, interception, and/or gravitational sedimentation. Specifically, the single-collector efficiency $(\eta)$ is the ratio of particle attachment rate to rate of advective flow.

$$
\eta=\alpha \eta_{o}
$$

Equation (7) illustrates the proportional relationship between the single-collector efficiency $(\eta)$ and the single-collector contact efficiency $\left(\eta_{o}\right)$ where that contact efficiency is defined as the ratio of colloid-to-collector rate of contact to the rate of advective flow. The collision (or sticking) efficiency factor $(\alpha)$ describes the fraction of collisions resulting in attachment and is defined as the ratio of the colloid attachment rate to the colloid-to-collector rate of contact (32). When $\alpha$ is unity, all contacts with the collector result in attachment $\left(\eta=\eta_{o}\right)$, indicating there is no energy barrier to attachment; this is typically termed as favorable attachment conditions. When $\alpha$ is less than unity (i.e., unfavorable attachment conditions), not all contacts result in attachment such that an energy barrier exists wherein only a certain fraction of collisions will have enough energy to overcome the energy barrier. The extent of attachment is impacted by 
particle and collector surface chemistry (e.g., mineralogy and organic matter coatings and content) and solution chemistry (e.g., $\mathrm{pH}$ and ionic strength).

Yao et al. (1971) developed a theoretical expression for the single-collector contact efficiency $\left(\eta_{o}\right)$ wherein the contribution from diffusion, interception, and sedimentation on deposition $\left(\eta_{D}, \eta_{I}, \eta_{G}\right.$ respectively) are assumed additive as shown in equation (8) (30). While Yao et al. (1971) denotes the single-collector contact efficiency with $\eta$ (30), it is changed here in equation (8) for consistency with later research nomenclature using $\eta_{o}$. The contribution of particle diffusion, incorporated into Yao's

$$
\begin{aligned}
& \eta_{o}=\eta_{D}+\eta_{I}+\eta_{G} \\
& \eta_{D}=4.04 P e^{-2 / 3}=0.9\left(\frac{k T}{\mu d_{p} d_{c} U}\right)^{2 / 3} \\
& \eta_{I}=\frac{3}{2}\left(\frac{d_{p}}{d_{c}}\right)^{2} \\
& \eta_{G}=\frac{\left(\rho_{p}-\rho_{f}\right) g d_{p}^{2}}{18 \mu U}
\end{aligned}
$$

model with equation (9), to the single-collector contact efficiency is a function of the Peclet number $(\mathrm{Pe})$, a ratio of transport by advective fluid flow to transport by diffusion. Colloid contact via interception, incorporated into the model with equation (10), is a function of the aspect ratio (relative fraction of particle diameter to collector diameter), such that as particle size increases so does the probability that contact with the collector will occur. Gravitational sedimentation (equation 11) is the ratio of Stokes settling velocity to the fluid approach (darcy) velocity $(U)$. This parameter becomes important as 
particle diameter and/or particle density $\left(\rho_{p}\right)$ increases. All other parameters are as defined in the List of Symbols section of this thesis.

It is recognized that Yao's filtration model tends to underestimate experimental single-collector efficiencies in packed bed systems (Figure 6). For colloids in the $10 \mathrm{~nm}$ to $100 \mu \mathrm{m}$ size range, the theoretical model tends to under-predict the percent removal of colloids by the filter bed. It is presumed that this underestimation occurs as the model does not capture the impact van der Waals attraction forces and hydrodynamic interactions have on diffusion, interception, and sedimentation (30, 32). Accordingly, the single-collector contact efficiency $\left(\eta_{o}\right)$ equation has evolved over the years in an attempt
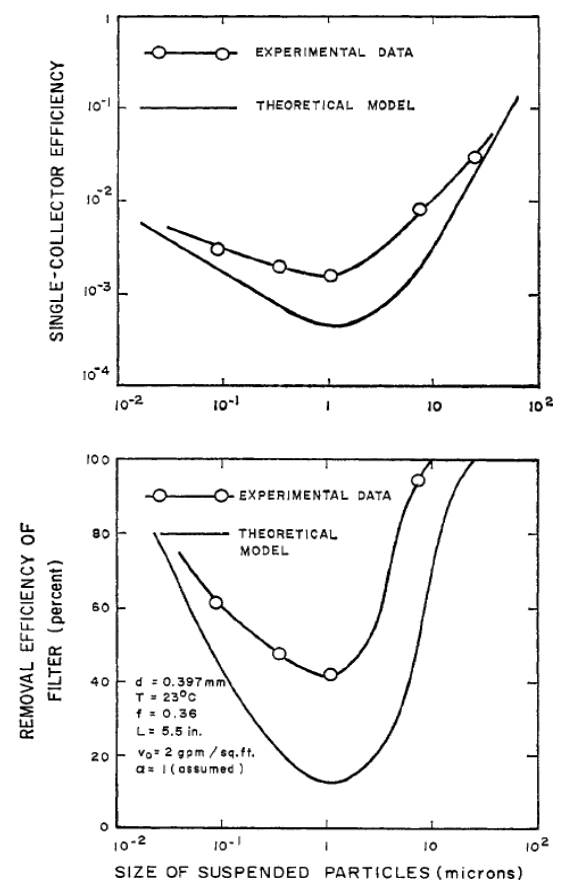

Figure 6: Single-collector efficiency model compared to experimental values (Source: Yao et al. (30)) 
to capture these processes. Tufenkji and Elimelech (2004) developed a correlation equation that accounts for the impact of van der Waals forces and hydrodynamic retardation (drag force and torque on particles), processes believed to be important in sub-micron particle transport (32). Specifically, those terms accounting for diffusion, interception, and sedimentation as they impact deposition are described as in equations (12), (13), and (14), respectively. As in the Yao et al. (1971) model, all three transport

$$
\begin{aligned}
& \eta_{D}=2.4 A_{s}^{1 / 3} N_{R}^{-0.081} N_{P e}^{-0.715} N_{v d W}^{0.052} \\
& \eta_{I}=0.55 A_{s} N_{R}^{1.675} N_{A}^{0.125} \\
& \eta_{G}=0.22 N_{R}^{-0.24} N_{G}^{1.11} N_{v d W}^{0.053}
\end{aligned}
$$

mechanisms (diffusion, interception, and gravitational sedimentation) are considered additive with dimensionless parameters defined as in Table 1 (parameters therein are as defined in the List of Symbols section of this thesis). The Tufenkji and Elimelech (2004) model incorporates a porosity dependent parameter $\left(A_{S}\right)$ that is meant to capture the impact of neighboring collectors on the velocity flow field where $\gamma=(1-f)^{1 / 3}$. The van der Waals number $\left(N_{v d W}\right)$, a ratio of van der Waals interaction energy to the colloid thermal energy $(k T)$, accounts for those van der Waals attraction forces between colloid and collector. Similarly, the attraction number $\left(N_{A}\right)$, is the combined influence of van der Waals attraction forces and fluid velocity on colloid attachment via interception. 


\section{Table 1: Tufenkji and Elimelech (2004) dimensionless parameters}

$$
\begin{array}{cc}
A_{s}=\frac{2\left(1-\gamma^{5}\right)}{2-3 \gamma+3 \gamma^{6}+2 \gamma^{6}} & \text { Porosity dependent parameter } \\
N_{R}=\frac{d_{p}}{d_{c}} & \text { Aspect ratio } \\
N_{P e}=\frac{U d_{c}}{D_{\infty}} & \text { Peclet number } \\
N_{v d W}=\frac{A}{k T} & \text { van der Waals number } \\
N_{A}=\frac{A}{12 \pi \mu a_{p}^{2} U} & \text { Attraction number } \\
N_{G}=\frac{2}{9} \frac{a_{p}^{2}\left(\rho_{p}-\rho_{f}\right) g}{\mu U} & \text { Gravity number }
\end{array}
$$

The Tufenkji and Elimelech single-collector efficiency model shows better agreement between predicted single-collector efficiencies $(\eta)$ and experimental singlecollector efficiencies $\left(\eta_{\text {exp }}\right)$ than the Yao model (equation 15). A side-by-side comparison is illustrated in Figure 7 where the dashed lines represent perfect agreement between the respective models and the experimental collector efficiency calculated from column experiments and the resulting breakthrough curves (equation 15).

$$
\eta_{\text {exp }}=-\frac{2}{3} \frac{d_{c}}{(1-f) L} \ln \left(C / C_{o}\right)
$$



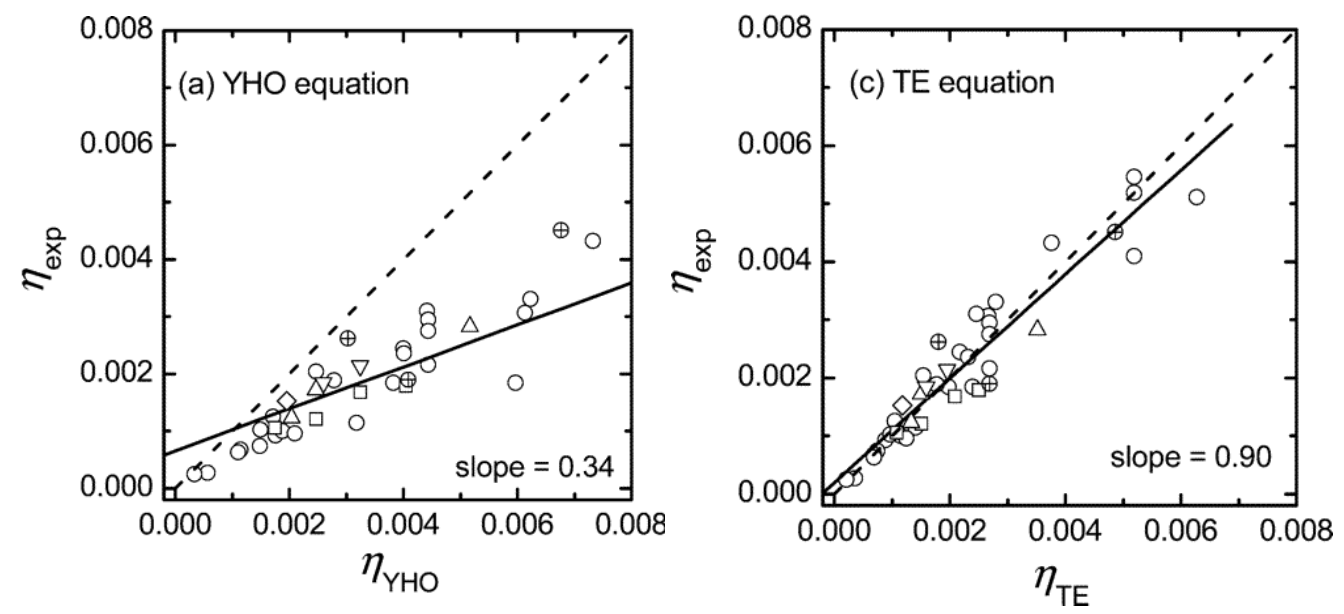

Figure 7: Tufenkji and Elimelech and Yao collector efficiency model performance

The dashed line represents perfect agreement between the single-collector efficiency model and the experimental single-collector efficiency $\left(\eta_{\text {exp }}\right)$. The Yao model is designated as YHO while the Tufenkji and Elimelech model is designated as TE.

(Source: Tufenkji and Elimelech (32))

The Yao model was again shown to under-predict single-collector efficiencies while the Tufenkji and Elimelech model appears to show near perfect agreement between theoretical and experimental values. The conditions under which this analysis was performed employed oppositely charged colloids and collectors such that no energy barrier exists to colloid attachment (favorable conditions) and all contacts are assumed to result in attachment $\left(\alpha \approx 1\right.$ and $\left.\eta \approx \eta_{o}\right)$.

While the Tufenkji and Elimelech model for predicting removal (collector) efficiency is based on the Eulerian approach that looks at the distribution of particle concentration over space and time around a single collector, a more recent model from Nelson and Ginn (2011) attempts to track a single particle's position over time (43). This Lagrangian approach considers the size of the filter bed whereas the Tufenkji and 
Elimelech model uses a single collector. As such, the Nelson and Ginn model (equation 16) calculates a collector efficiency using $\gamma^{2}$ to upscale their model from a single collector to a bed of collector surfaces where $\gamma=(1-f)^{1 / 3}$.

$$
\begin{gathered}
\eta \approx \gamma^{2}\left[2.4 A_{s}^{1 / 3}\left(\frac{N_{P E}}{N_{P E}+16}\right)^{0.75} N_{P E}^{-0.68} N_{L O}^{0.015} N_{G i}^{0.8}+A_{S} N_{L O}^{1 / 8} N_{R}^{15 / 8}\right. \\
\left.+0.7\left(\frac{N_{G i}}{N_{G i}+0.9}\right) N_{G} N_{R}^{-0.05}\right]
\end{gathered}
$$

Table 2: Nelson and Ginn (2011) dimensionless parameters

\begin{tabular}{cc|}
$N_{R}=\frac{d_{p}}{d_{c}}$ & Aspect ratio \\
$N_{P E}=\frac{U d_{c}}{D_{B M}}$ & Peclet number \\
$N_{L O}=\frac{A}{9 \pi \mu a_{p}^{2} U}$ & van der Waals number \\
$N_{G}=\frac{2}{9} \frac{a_{p}^{2}\left(\rho_{p}-\rho_{f}\right) g}{\mu U}$ & Gravity Number \\
$N_{G i}=\frac{1}{N_{G}+1}$ & \\
\hline
\end{tabular}

The first term of equation (16) accounts for transport via diffusion, the second term via interception and the last term via sedimentation with dimensionless parameters defined as in Table 2 (parameters therein are as defined in the List of Symbols section of this thesis). Furthermore, in developing their model, Nelson and Ginn (2011) have attempted to more fully capture the impacts of hydrodynamic retardation by considering drag forces and torques on translating and rotating colloids and is in contrast to the 
Tufenkji and Elimelech model that only considers hydrodynamic retardation on translating colloids. Finally, while the Yao and the Tufenkji and Elimelech models were developed using flow velocities typical of engineered water treatment systems, the Nelson and Ginn collector efficiency model was developed using groundwater velocities typical in the natural environment.

It should be noted that Nelson and Ginn (2011) have assumed all contacts result in attachment $(\alpha=1)$. They have denoted their equation just as a collector efficiency $(\eta)$, as their research focus was on conditions in which there is no energy barrier to particle attachment onto a bed of collectors $\left(\eta=\eta_{o}\right)$, those conditions where attachment is expected to be favorable. As in Yao et al. (1971) and Tufenkji and Elimelech (2004), the Nelson and Ginn (2011) particle deposition rate coefficient $\left(k_{d}\right)$ is a function of the collector efficiency $(\eta)$ (equation 17). It should be noted that Nelson and Ginn (2011) have designated their particle deposition rate coefficient as $k_{f}$ instead of $k_{d}$ in their research. To maintain a consistent nomenclature throughout this thesis the symbol $k_{d}$ is used here in equation (17).

$$
k_{d}=\frac{3(1-f)^{1 / 3} v}{2 d_{c}} \eta
$$

Similar to Tufenkji and Elimelech (2004), Nelson and Ginn (2011) compare their model in conjunction with several other models (including the Tufenkji and Elimelech model previously presented) to experimental results using breakthrough data from 112 transport experiments performed under favorable attachment conditions $(\alpha=1)$ (Figure 
8). The extent that the Tufenkji and Elimelech model (TE) and Nelson and Ginn model (NG) agree with experimental values is shown in Figure 8 as semi-log plot of the ratio of a theoretical deposition rate coefficient (equation 17) to the experimental deposition rate coefficient (equation 5) on the y-axis with increasing colloid diameter on the x-axis. For this analysis the Tufenkji and Elimelech model (equations $12-14$ ) was upscaled by a factor of $\gamma^{2}$ in order to make valid comparisons between models. Additionally, the experimental deposition rate coefficient $\left(k_{d}\right)$ for each experiment (equation 17) was calculated using an experimental collector efficiency values $\left(\eta_{\text {exp }}\right)$ from equation (18) below.

$$
\eta_{\text {exp }}=-\frac{2}{3} \frac{d_{c}}{(1-f)^{1 / 3} L} \ln \left(C / C_{o}\right)
$$




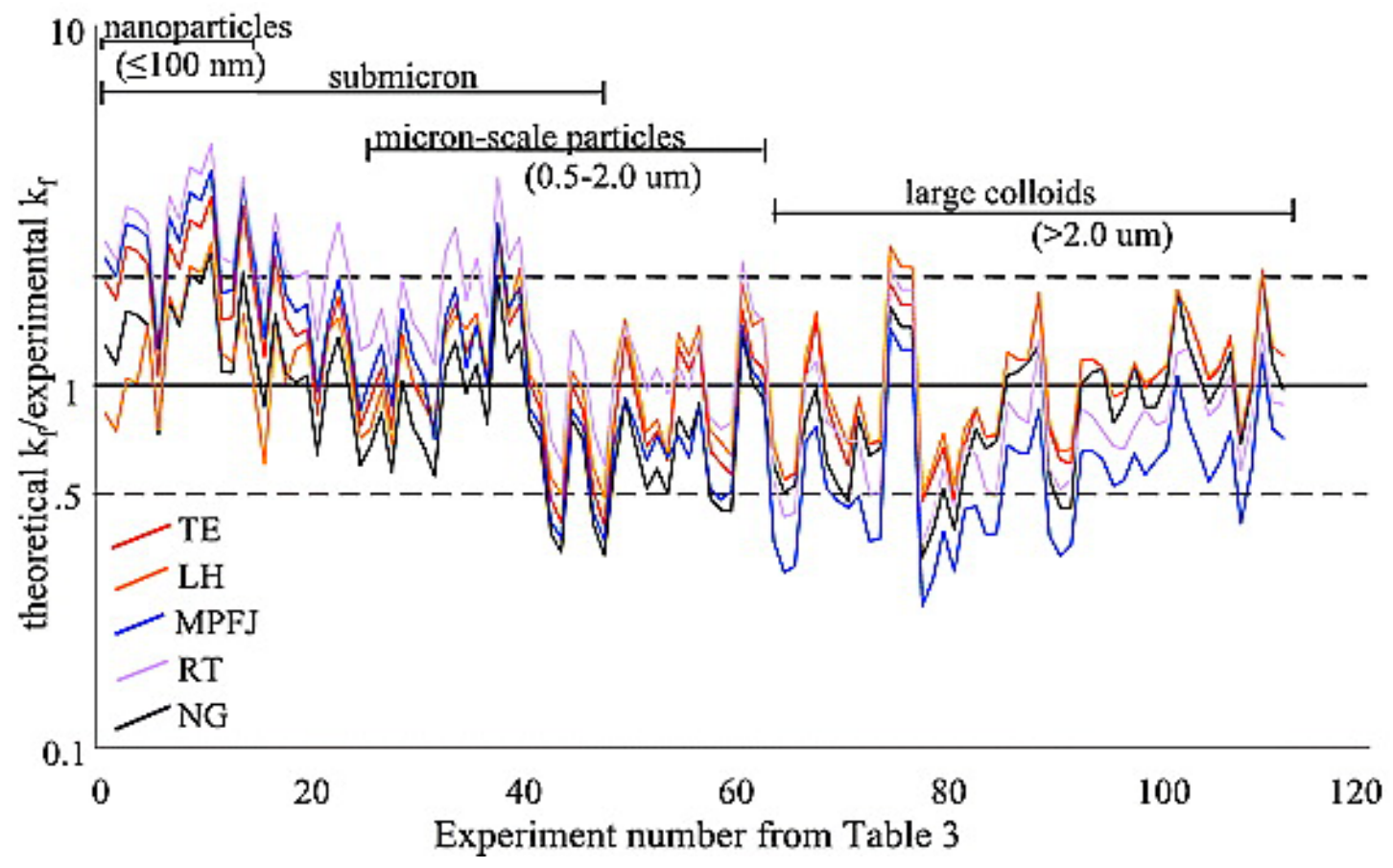

Figure 8: Nelson and Ginn and Tufenkji and Elimelech collector efficiency model performance

The Nelson and Ginn model (NG) results are represented by the solid black curve while the Tufenkji and Elimelech model (TE) is represented by the red curve. The solid horizontal line designates perfect agreement between the model and experimental values while the dashed lines indicate a 2 -fold under or over prediction of the deposition rate coefficient.

(Source: Nelson and Ginn (43))

For submicron colloids, both the Nelson and Ginn (NG) and the Tufenkji and Elimelech model (TE) generally over-predict the deposition rate coefficient with the NG model performing slightly better than the TE model in the nano-scale range (defined here as $d_{p} \leq 100 \mathrm{~nm}$ ) with the two models showing better agreement with each other and with experimental values in the $0.5 \mu \mathrm{m}$ size range (Figure 8). The TE model performs better than the NG model in the $1-2 \mu \mathrm{m}$ size range showing better agreement with 
experimental values. Both models showed better performance for large colloids with diameters greater than $2 \mu \mathrm{m}$.

\section{Colloid Deposition Research}

\section{$\underline{\text { Favorable Attachment }}$}

As discussed previously, when colloids and collectors carry opposite charges, there is no energy barrier to colloid attachment to the collector, as described in DLVO theory. All contacts with the collector via diffusion, interception, and/or gravitational sedimentation are assumed to result in attachment $(\alpha=1)$. Research has shown that particle size and ionic strength strongly control colloid deposition rates under initial "clean bed conditions" when attachment is believed to be favorable $(30-33,42,44)$. For example, Elimelech (1994) showed that under low ionic strength conditions (less than $\left.10^{-3} \mathrm{M}\right)$ the experimental single-collector efficiency $\left(\eta_{\exp }\right)$ increased as the diameter of positively-charged latex particles decreased below $1 \mu \mathrm{m}$ and increased above $1 \mu \mathrm{m}(44)$. This trend is believed to be the result of diffusion dominated transport to the collector surface for submicron colloids while for colloids greater than $1 \mu \mathrm{m}$ interception and gravitational sedimentation become increasingly dominant as illustrated previously in Figure 2. Additionally, as ionic strength decreased the experimental single-collector efficiency increased. As ionic strength decreases the electric diffuse double layer thickness around colloids and collectors increases (becomes less compressed) and is believed to result in an increasing magnitude and range of particle-collector attractive 
forces that results in increasing attachment $(42,44,45)$. Transport experiments conducted by Elimelech (1991) showed increased deposition of positively-charged latex colloids as ionic strength decreased (45). This deposition trend is illustrated in Figure 9 where the breakthrough relative concentration $\left(\mathrm{C} / \mathrm{C}_{\mathrm{o}}\right)$ decreased from $\sim 0.6$ to 0.4 (i.e., deposition increased) with a decreasing ionic strength from $10^{-1}$ to $10^{-5} \mathrm{M} \mathrm{KCl}$.

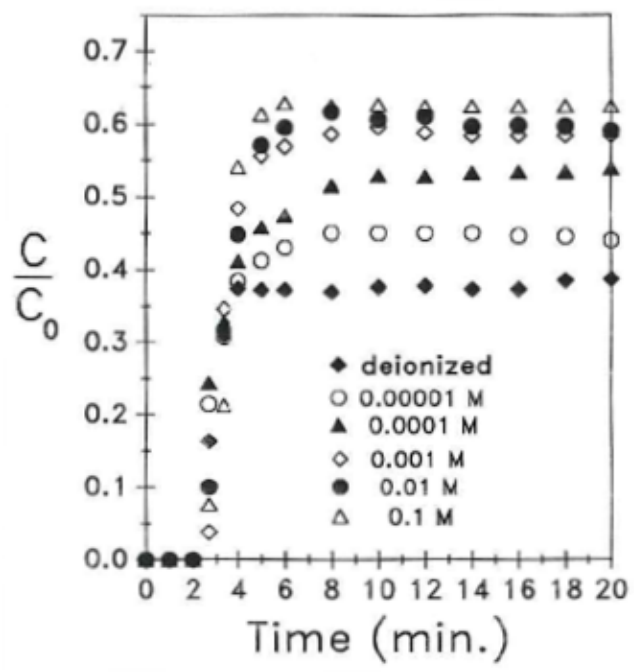

Figure 9: Latex colloid breakthrough curves with approach velocity of $8.2 \mathrm{~cm} / \mathrm{min}$ $(v=1224 \mathrm{~cm} / \mathrm{hr})$ - Favorable Attachment

Transport experiments used $477 \mathrm{~nm}$ positively latex colloids in deionized water and potassium chloride electrolyte solutions (ionic strength $10^{-5}$ to $10^{-1} \mathrm{M}$ ).

(Source: Elimelech (45))

\section{Unfavorable Attachment: Ionic Strength}

As discussed previously, there exists an energy barrier to attachment when colloids and collectors are of like charge and as such the attachment efficiency $(\alpha)$ is expected to be less than unity. DLVO theory predicts as ionic strength increases the energy barrier height to attachment in the primary energy minimum decreases, i.e., 
becomes less positive (46-48, Figure 10). Additionally, the depth of the secondary energy well, representing an attractive energy, increases (becomes more negative).
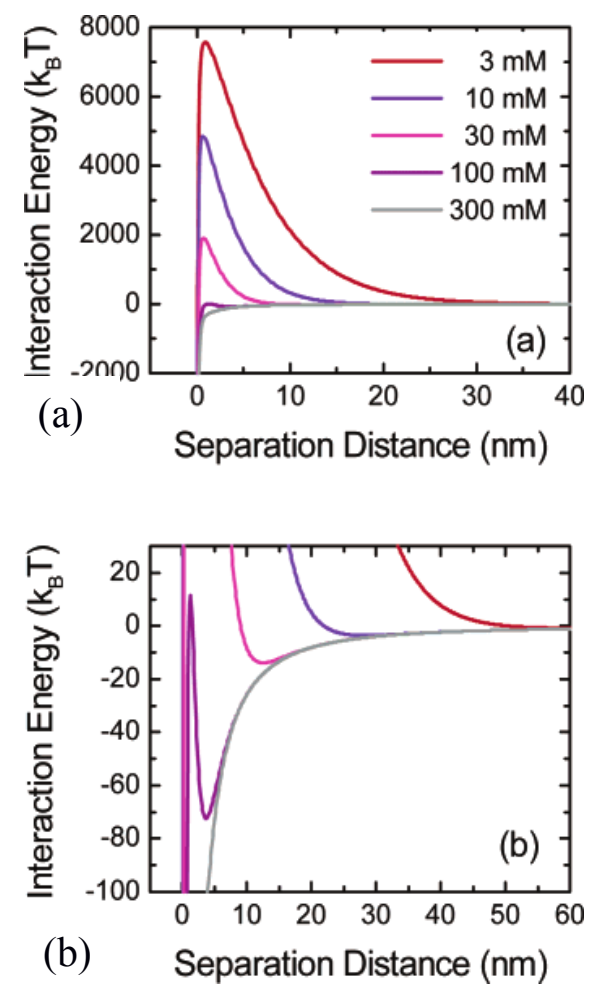

Figure 10: Colloid-collector interaction energy profiles for a representative negatively charged colloid-collector system

(a) Energy barrier to colloid deposition into primary energy minimum.(b) Energy well of the secondary energy minimum.

(Source: Tufenkji and Elimelech (47))

The increase in ion concentration results in compression of the diffuse double layer that translates into reduced electrostatic repulsion between colloids and collectors. As electrostatic repulsion decreases, the van der Waals attractive force, while independent of solution chemistry, becomes increasingly dominant. 
Column transport experiments, using negatively charged latex colloids, have shown increased deposition with increasing ionic strength as predicted from DLVO theory $(47-49)$. This deposition trend is illustrated in Figure 11 using $753 \mathrm{~nm}$ diameter latex colloids and shows that the breakthrough relative concentration

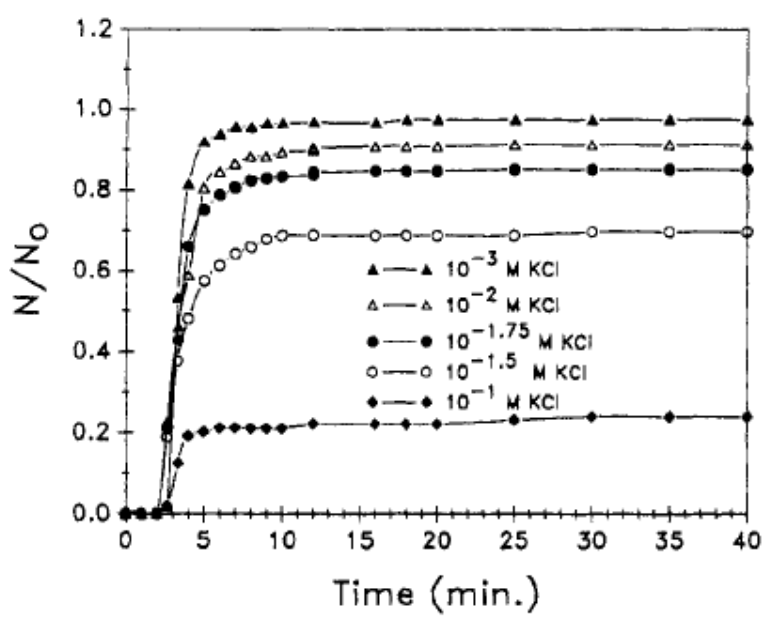

Figure 11: Particle breakthrough curves of $753 \mathrm{~nm}$ negatively charged latex colloids illustrating an increase in deposition with increasing ionic strength

(Source: Elimelech (49))

$\left(\mathrm{N} / \mathrm{N}_{\mathrm{o}}\right)$ significantly decreases from $\sim 0.9$ to 0.2 when ionic strength increases from $10^{-3}$ to $10^{-1} \mathrm{M} \mathrm{KCl}$, showing an increased retention of colloids onto collectors in the column. This research is further supported by Pelley and Tufenkji (2008) who showed increasing experimental attachment efficiencies $\left(\alpha_{\text {exp }}\right)$ with ionic strength, indicating a higher fraction of collisions are resulting in attachment to the collector surface (48). 


\section{$\underline{\text { Unfavorable Attachment: Colloid Size }}$}

Interaction energy profiles show an increasing energy barrier height to colloid deposition as diameter increases but concurrently show an increasing depth of the secondary energy well $(46,48,50)$. For example, Pelley and Tufenkji (2008) have reported a large increase in the height of the energy barrier as latex colloid diameter increased (see Figure 9) and suggested that the $1500 \mathrm{~nm}$ colloids would not attach in the primary energy minimum. Transport experiments showed increased attachment efficiency $\left(\alpha_{\text {exp }}\right)$ with increasing colloid diameter despite the presence of large primary energy barriers. These results suggest that attachment in the secondary energy well becomes increasingly dominant as colloid diameter increases.
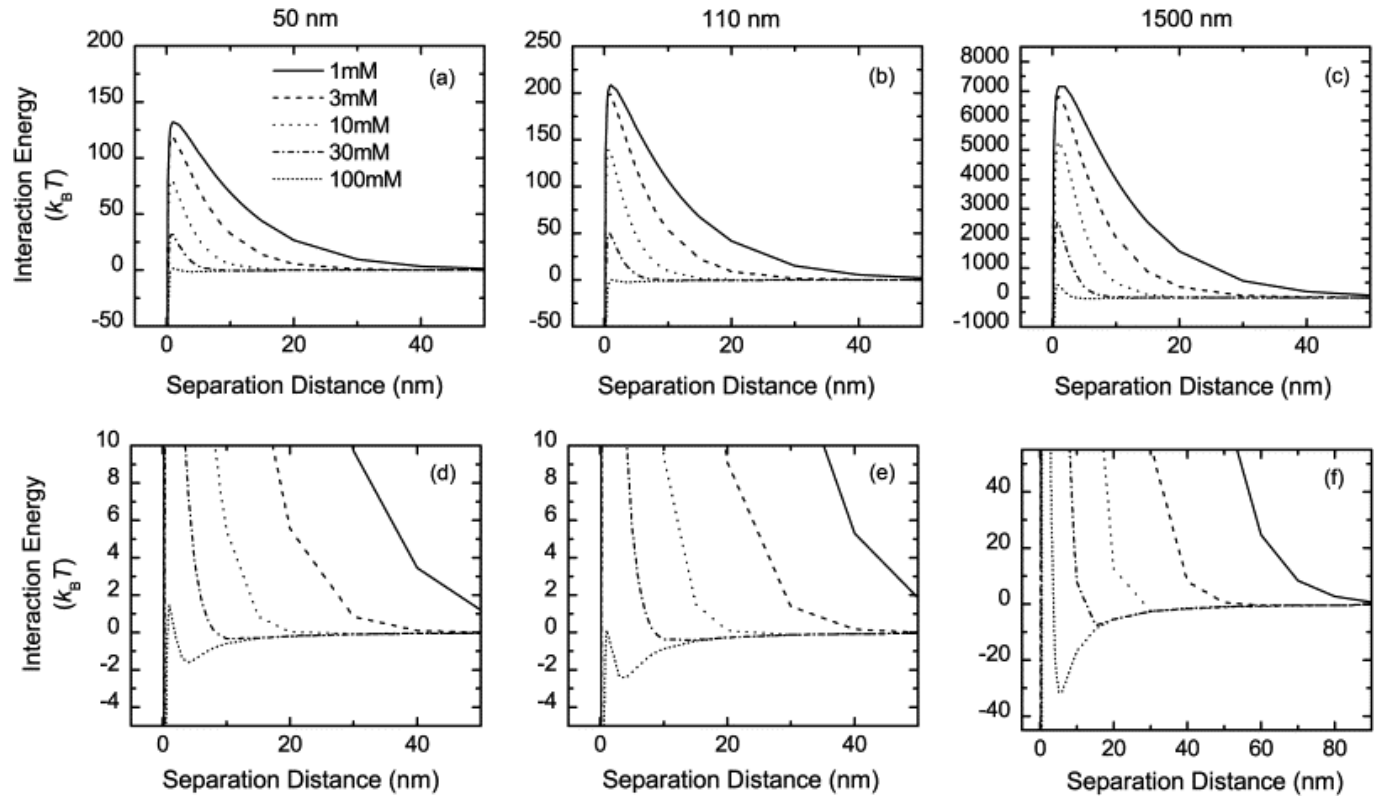

Figure 12: Interaction energy profiles for 50,110 , and $1500 \mathrm{~nm}$ negatively charged latex colloids in $0.001-0.1 \mathrm{M}$ electrolyte solutions

(Source: Pelley and Tufenkji (48)) 
Unfavorable Attachment: Discrepancies between $\alpha$ and $\alpha_{\text {exp }}$

Colloid filtration models incorporating colloid attachment theory have increasingly been developed to better predict colloid deposition under unfavorable attachment conditions, when $\alpha<1$. These models have been shown to significantly under-predict attachment efficiencies relative to experimentally determined values from column transport experiment breakthrough curves $(48-52)$. The discrepancies observed have been linked to deposition in the secondary minimum, particle straining, surface charge heterogeneity, and collector surface roughness $(49,50,52,53)$. For example, Elimelech and O'Melia (1990) showed (Figure 13) that experimental attachment efficiencies gradually decrease as ionic strength decreased and is in contrast to theoretical attachment efficiencies that exhibited a very sharp decrease as ionic strength decreased. This discrepancy between model predictions and experimental results

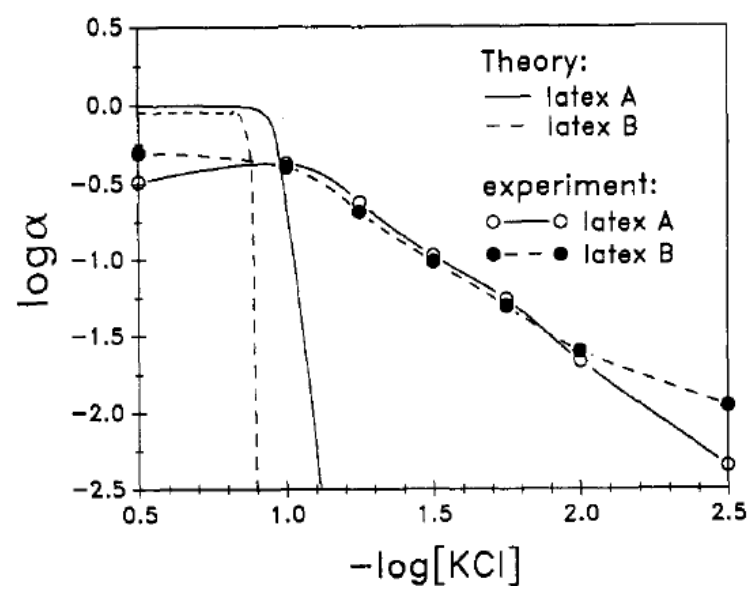

Figure 13: Discrepancies between theoretical and experimental attachment efficiencies with changes in ionic strength

(Source: Elimelech and O’Melia (49)) 
has been attributed by several researchers to the failure of the model in considering only attachment into the primary energy minimum without considering the contribution of the secondary energy minimum to deposition as was illustrated in Figure 10 and Figure 12 $(48-50,53)$. Litton and Olson (1996) showed that in the presence of large primary energy barriers, latex colloids exhibited an increasing experimental attachment efficiency that was strongly correlated with an increasing secondary energy well as diameter increased and ionic strength increased (50). When deposition in the secondary minimum is incorporated into these deposition models there is improved agreement between theoretical attachment efficiencies and experimental values $(50,53,54)$.

Straining, wherein particles become trapped in smaller pore throats, has been suggested as a filtration mechanism that may account for discrepancies observed between predicted and experimental attachment efficiency values. Evidence of straining was shown by Bradford et al. (2002) when $d_{p} / d_{c}>0.0017$ using negatively charged latex colloids (51). Likewise Tufenkji et al. (2004) found straining to be important when $d_{p} / d_{50}>0.05(55)$. As DLVO theory does not account for the occurrence of straining experimental attachment efficiencies may be larger than those theoretical values from colloid filtration models employing colloid attachment theory.

Classical DLVO theory assumes a uniform charge distribution on the collector surface while, in reality, imperfections in the crystal lattice structure either through ion arrangement or chemical impurities, such as iron and aluminum oxide substitutions, can 
result in a heterogeneously charged surface $(37,42,56)$. Additionally, while DLVO theory assumes colloids and collector surfaces are smooth and spherical, scanning electron microscopy has shown individual quartz grain surfaces with a substantial amount of surface roughness, with the surfaces appearing highly irregular, having sharp, angular terminations, jagged protrusions, and deep crevices $(55,57,58)$. Johnson et al. (1996) found that as charge heterogeneity decreased with the addition of minor fractions of iron oxyhydroxide coating quartz grain surfaces, deposition of silica colloids increased (Figure 14), and is believed due to the decrease in patchwise charge heterogeneity as the fraction of collector surface increased (59). As illustrated in Figure 14, the particle's breakthrough relative concentration $\left(n / n_{0}\right)$ decreases (deposition increases) as charge heterogeneity increases (specifically, as the fraction of quartz sand coated with iron oxyhydroxide increases from $0 \%$ to $16 \%$ ).

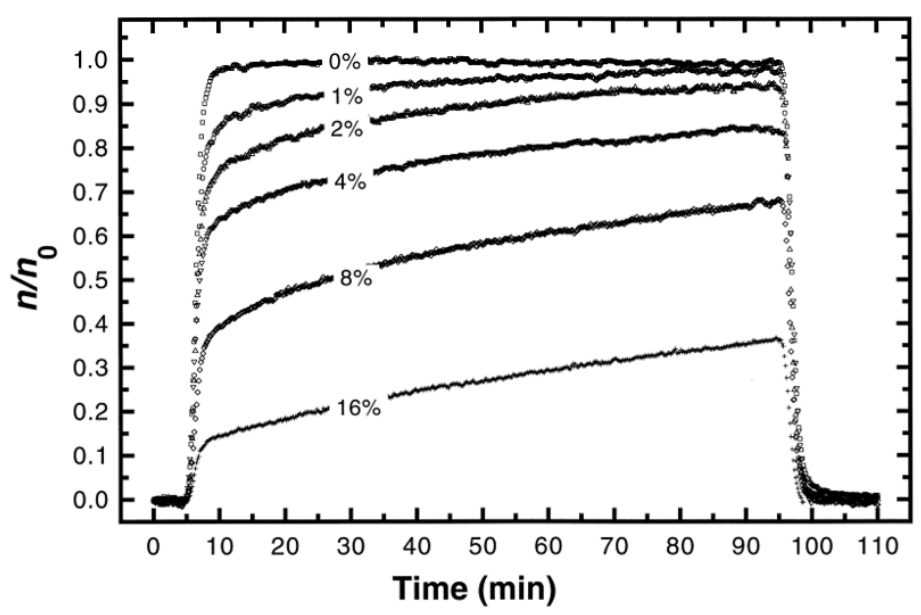

Figure 14: Increasing deposition of silica colloids due to collector patchwise charge heterogeneity and roughness

(Source: Johnson et al. (59)) 
Nano-scale Colloid Transport

Nano-scale colloids, or nanoparticles, are typically defined as particles with at least one dimension less than $100 \mathrm{~nm}$ and include organic and inorganic molecules (e.g., fulvic/humic acids, oxides, clays) and biocolloids (e.g., bacteria, viruses, algae) (60, Figure 15). Organic and inorganic nanoparticles can be naturally produced in the environment with biogenic, geogenic, pyrogenic, and atmospheric origins. These particles are also anthroprogenically produced as combustion by-products and as manufactured/engineered particles. (61).

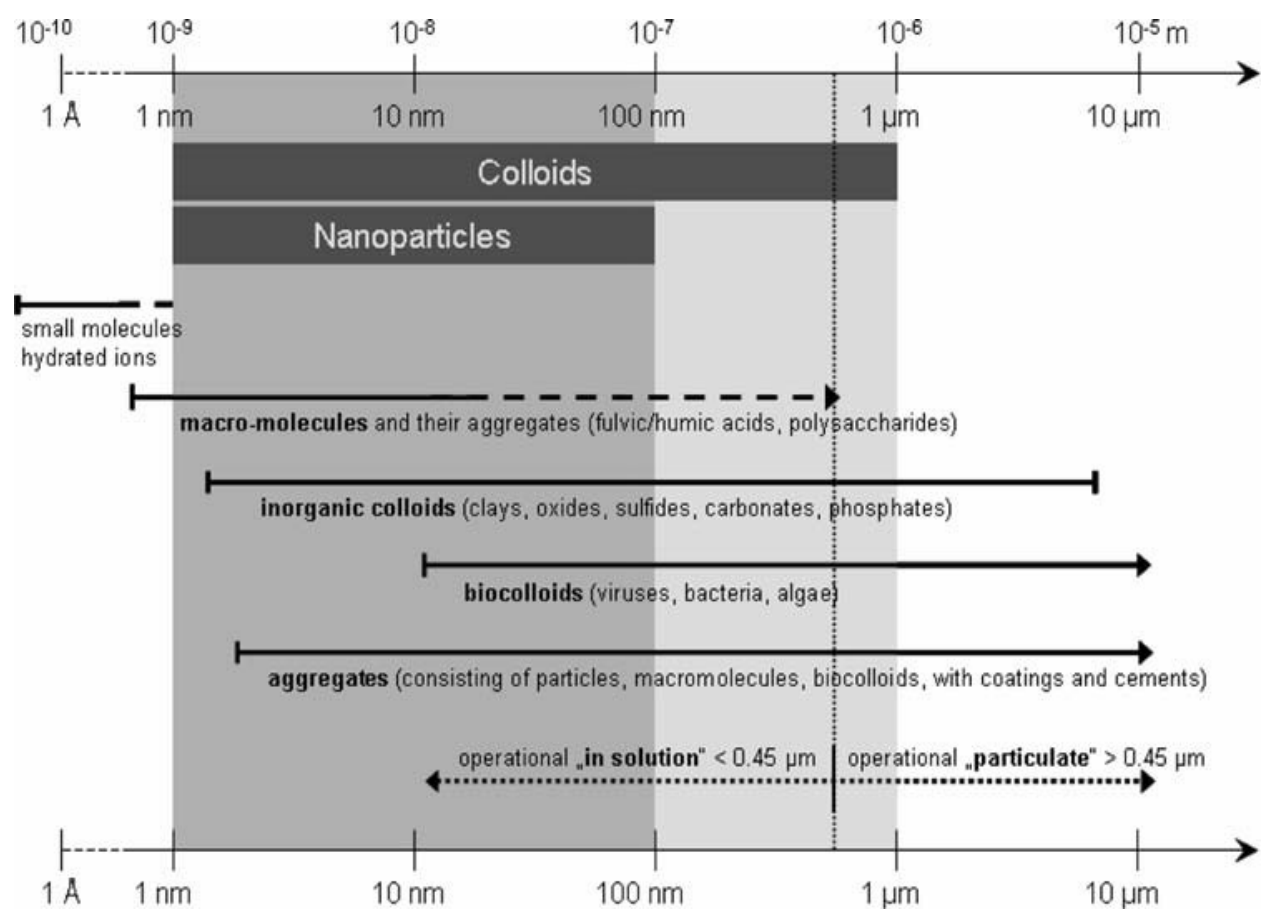

Figure 15: Nanoparticle classification: Size and representative natural colloids (Source: Christian et al. (62)) 
Engineered nanoparticles, sometimes designed to amplify surface reactivity, vary in shape and chemical composition including carbon nanotubes of varying complexity, metal oxides and light-emitting crystals called quantum dots. Release into the environment includes direct release from manufacturing processes and remediation efforts and indirect release as a result of consumer product usage and disposal of nanoparticle incorporated products. As particle size decreases the surface area to volume ratio increases, with the percentage of atoms at the particle surface increasing concurrently, resulting in a higher reactivity; a unique feature of nanoparticles $(62,63)$. For example, $5 \mathrm{~nm}$ gold particles have $31 \%$ of their atoms at the surface while $50 \mathrm{~nm}$ gold particles have only $3.4 \%$ at the surface, resulting in nano-scale gold of higher reactivity than its larger counterpart (62).

Transport behavior (mobility) of nano-scale colloids has been shown to be variable with that variability largely due to physicochemical interactions between colloids and collector surfaces. For example, Lecoanet et al. (2004) demonstrated (Figure 16) that mobility of negatively-charged engineered nanoparticles was highly variable in porous media (25). Monodisperse suspensions of spherical nanoparticles (1.2-nm fullerol and 57$\mathrm{nm}$ silica) showed similar transport behavior to the 21 -nm single-wall nanotubes with an approach to complete breakthrough occurring in less than 3 pore volumes. In contrast, monodisperse suspensions (135-nm silica and $168-\mathrm{nm} \mathrm{n}^{-\mathrm{C}_{60}}$ ) and polydisperse solutions (198-nm anatase titanium dioxide and 30- $\mathrm{nm}$ ferroxane) required more than 6 pore volumes of injection to reach complete breakthrough. These results suggest the import of nanoparticle characteristics (e.g., size, shape, composition, and aggregation kinetics) 
significantly impact mobility in porous media.

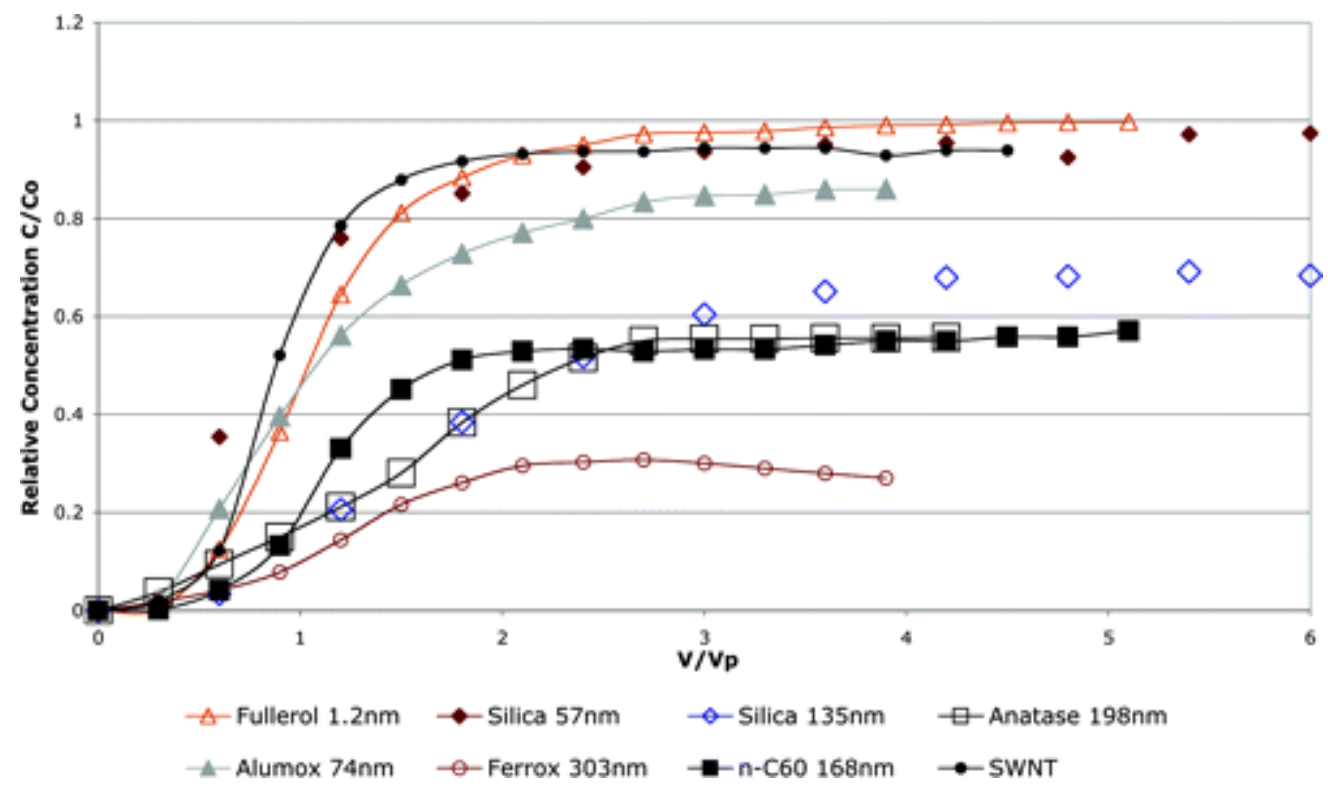

Figure 16: Engineered Nanoparticle Breakthrough Curves - Unfavorable Attachment Mondisperse and polydisperse (aggregated) nanoparticle suspensions injected through spherical glass beads at darcy velocity of $0.04 \mathrm{~cm} / \mathrm{s}(v=335 \mathrm{~cm} / \mathrm{h})$.

(Source: Lecoanet et al. (25))

Nanoparticles show a greater propensity to form aggregates as the energy barrier to attachment decreases with particle size, as has previously shown in Figure 12. The rate of aggregate formation (aggregation kinetics) and effective particle size are dependent on particle concentration and solution chemistry; namely ionic strength, $\mathrm{pH}$, and counterion valence (64 - 66). Environmental systems may be able to remove larger aggregates to prevent long range transport through water bodies and as such, interception and sedimentation may become important transport mechanisms with aggregate sizes larger than $1 \mu \mathrm{m}$ (62). Straining has been suggested as an additional colloid filtration mechanism for nano-scale particles and may occur with very small collector diameters, 
micron-sized nanoparticle aggregates, and those nanomaterials of irregular shapes such as ellipsoids and helices $(33,51,55,63,67)$. Subsequent disaggregation and transport of nanoparticles trapped in pore throats may occur with changes in solution chemistry $(\mathrm{pH}$, ionic strength, counterion valence) and flow rate (hydrodynamic shear) (35). Furthermore, changes in solution chemistry, flow rate, or the presence of natural organic matter may result in increased surface charge and stability in aqueous solution subsequently resulting in increased mobility into surface and subsurface drinking water supplies $(33,48,63,64,68-70)$. Additionally, humic acid has been shown to induce disaggregation of iron oxide nanoparticles, resulting in decreasing hydrodynamic diameter and an increase in electrophoretic mobility over a 28 day period (69). A reduction in groundwater ionic strength and shifts in counterion valence, for example from $\mathrm{Ca}^{2+}$ to $\mathrm{Na}^{+}$, could also increase mobility through disaggregation and/or release of colloidal material (35).

While research has focused on potential organism uptake or adsorption, transport and fate of manufactured nanoparticles is in its infancy $(61,71,72)$. Colloid filtration theory and DLVO theory are typically applied to the transport and attachment of nanoparticles to a collector surface. Diffusion is the dominant transport mechanism to the collector while the total particle-particle and particle-collector interaction energies are used as a predictor of nanoparticle stability, aggregation, and deposition onto a collector surface $(30,31,44,49,63)$. Additionally, non-DLVO or extended DLVO interactions, while not unique to nanoparticles, are amplified and believed to influence nanoparticle 
stability and potential transport. These non-DLVO (or extended) interactions include steric repulsive forces due to adsorbed layers of particles such as surfactants or natural organic matter, magnetic forces due to dipole moment(s), and hydration forces resulting from hydrophilic surface functional groups $(33,63)$.

Under favorable deposition conditions, the deposition rate approaches rate-limited mass transfer and the attachment efficiency approaches unity. When an energy barrier exists, typically under unfavorable attachment conditions, nanoparticles exhibit a lower energy barrier to deposition and aggregation in the primary energy minimum than microscale colloids $(29,48-50)$. Furthermore, secondary minimum energies at typical environmental ionic strengths are small so that deposition in the secondary energy well is expected to be minimal. Geochemical heterogeneities and surface roughness are expected to play a larger role in nanoparticle deposition when an energy barrier exists. This is due to the smaller particle size relative to patch-wise charge heterogeneities and areas of surface roughness (33).

\section{Nano-scale Metal Oxide Transport}

Metal oxides, while naturally occurring, are increasingly being engineered or manufactured at the nano-scale for a variety of functions. From use as whitening agents and ultraviolet light absorbers to application in environmental remediation and wastewater treatment, there is a concern regarding the potential toxicity of these metal oxide nanoparticles in the environment $(73-76)$. 
While nano-colloid metal oxide transport is expected to be dominated by Brownian diffusion, gravitational sedimentation may become important in transport to collector surface given their relatively large particle densities $(33,52)$. Metal oxides are, for the most part, amphoteric; their surface charge is strongly $\mathrm{pH}$ dependent (77). As such, solution $\mathrm{pH}$, in addition to ionic strength and counterion valence, heavily impacts particle stability in an aqueous solution and, subsequently, transport and deposition in saturated porous media.

Isoelectric points vary among metal oxide nanoparticles and are typically lower than their bulk counterpart. Consequently, these particles may have a positive or negative surface charge under environmentally relevant conditions $(33,50,66,78-82)$. For example, silicon dioxide $\left(\mathrm{SiO}_{2}\right)$, an electrical insulator, has an isoelectric point around $\mathrm{pH}$ 2.0 while cerium dioxide's $\left(\mathrm{CeO}_{2}\right)$ isoelectric point is between $\mathrm{pH} 7$ and 8 while zinc oxide $(\mathrm{ZnO})$, an effective UV absorber, has a high isoelectric point at around $\mathrm{pH} 9(81)$. As "most groundwater matrices carry a net negative charge", at environmentally relevant $\mathrm{pH}$ conditions, negatively charged $\mathrm{SiO}_{2}$ would be more mobile than the positively charged $\mathrm{ZnO}(31)$.

As solution $\mathrm{pH}$ moves toward the isoelectric point, particle stability decreases (aggregation rate increases) and the hydrodynamic diameter increases $(80,83)$. For example, He et al. (2008) showed (Figure 17) as the solution $\mathrm{pH}$ of $32 \mathrm{~nm}$ hematite ( $\alpha$ $\mathrm{Fe}_{2} \mathrm{O}_{3}$ ) nanoparticles decreases from the point of zero charge ( $\left.\mathrm{pH} 8.2\right)$, the 


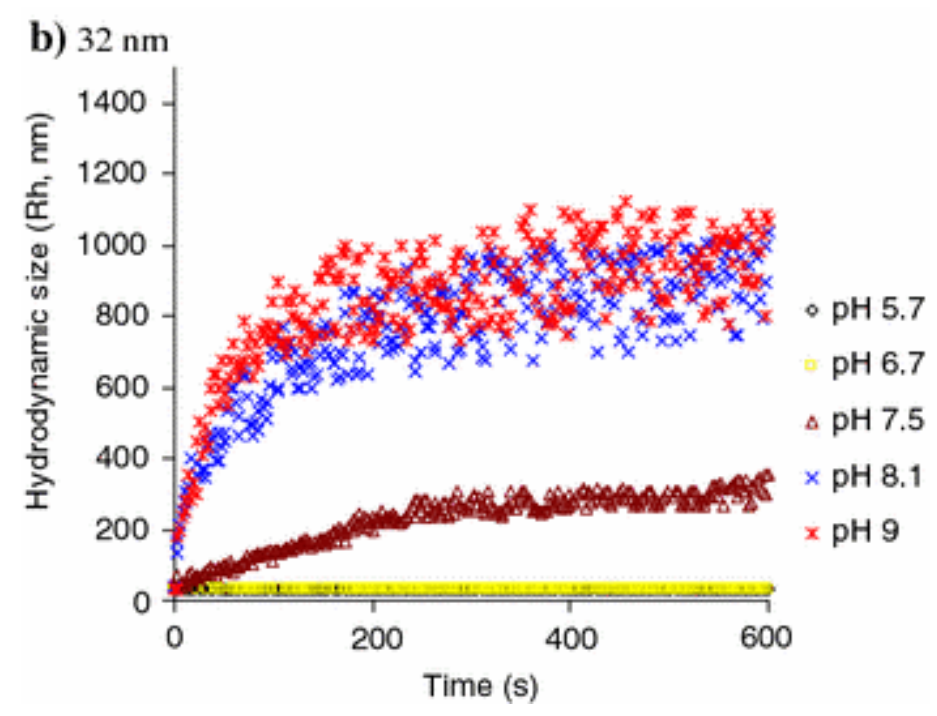

Figure 17: Impact of solution $\mathrm{pH}$ on hematite $\left(\alpha-\mathrm{Fe}_{2} \mathrm{O}_{3}\right)$ nanoparticle aggregation rate and hydrodynamic diameter

(Source: He et al. (83))

aggregation rate increases and the hydrodynamic diameter increases (83). Additionally, despite the propensity for aggregation, polydisperse solutions of nanoparticles have been shown to be mobile. For example, as shown in Figure 18, despite the measured tendency for fast aggregation behavior (78), nanoparticles of $\mathrm{Fe}_{2} \mathrm{O}_{3}$ are mobile in aquifer material with complete breakthrough within $\sim 2$ pore volumes. Furthermore, Guzman et al. (2006) showed that while only $3 \%$ of $\mathrm{TiO}_{2}$ nanoparticles were mobile through a micromodel at the point of zero charge $(\mathrm{pH} 7)$, over $80 \%$ were mobile at all other solution $\mathrm{pHs}$. 

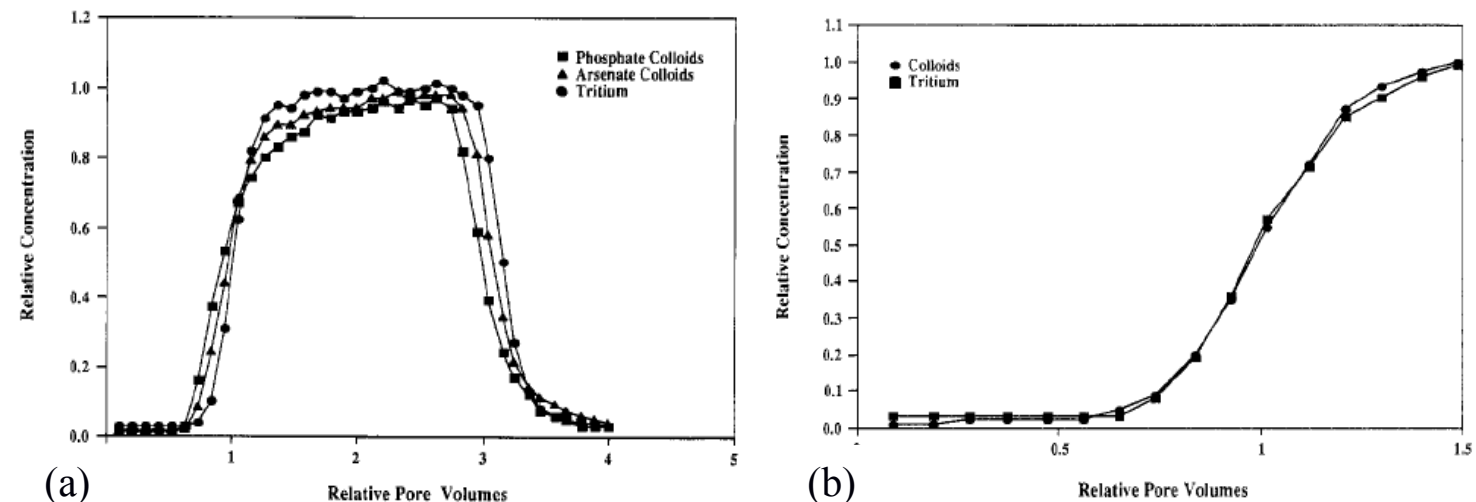

Figure 18: Breakthrough Curves of $100 \mathrm{~nm} \mathrm{Fe}_{2} \mathrm{O}_{3}$ Particles - Unfavorable Attachment Transport experiments using natural aquifer material and approach (darcy) velocity $0.236 \mathrm{~cm} / \mathrm{min}$. (a) Full breakthrough curves of $100-\mathrm{nm} \mathrm{Fe}_{2} \mathrm{O}_{3}$ nanoparticles in $0.01 \mathrm{M} \mathrm{NaH}_{2} \mathrm{PO}_{4}$ (phosphate colloids) and $0.01 \mathrm{M}$ $\mathrm{Na}_{2} \mathrm{HAsO}_{4}$ (arsenate colloids) electrolyte solutions. (b) Arrival wave of the $100-\mathrm{nm} \mathrm{Fe}{ }_{2} \mathrm{O}_{3}$ nanoparticles in $0.005 \mathrm{M} \mathrm{NaCl}$.

(Source: Puls and Powell (78))

As with other nanoparticles, metal oxide nanoparticles show increased aggregation and deposition with increases in ionic strength $(70,83)$. Domingos et al. (2009) demonstrated the average hydrodynamic diameter of anatase $\mathrm{TiO}_{2}$ increased with increases in electrolyte ionic strength (70). Ben-Moshe et al. (2010) showed increased retention in glass bead column transport experiments of rutile $\mathrm{TiO}_{2}, \mathrm{ZnO}$, and $\mathrm{CuO}$ with a 10-fold increase in ionic strength from 0.01 to $0.1 \mathrm{M} \mathrm{NaCl}(81)$.

The presence of natural organic matter would likely confer an enhanced stability through steric stabilization and negative surface charge (31). For example, addition of fulvic acid to a titanium dioxide nanoparticle (isoelectric point at $\mathrm{pH}$ 6) solution resulted in a stable nanoparticle dispersion at environmentally relevant conditions of fulvic acid, $\mathrm{pH}$, and ionic strength (70). Furthermore, disaggregation has been shown to occur in the presence of humic and fulvic acid with iron oxide and titanium dioxide nanoparticles, 
respectively $(69,70)$. Fulvic acid addition to solutions of negatively charged magnetite $\left(\mathrm{Fe}_{3} \mathrm{O}_{4}\right)$ and rutile titanium dioxide $\left(\mathrm{TiO}_{2}\right)$, and positively charged zinc oxide $(\mathrm{ZnO})$ and copper oxide $(\mathrm{CuO})$ resulted in increased elution (or decreased retention) through a packed bed of negatively charged glass beads (81). These results suggest that long-range transport of metal oxide nanoparticles may be possible and that, while some metal oxides may be unstable in aqueous solution at environmentally relevant ionic strength and $\mathrm{pH}$, stabilizing agents like natural organic matter may enhance mobility through porous media.

\section{$\mathrm{Al}_{2} \mathrm{O}_{3}$ Nanoparticle Transport}

Aluminum oxide, also referred to as alumina, can be found naturally in mineral form and is increasingly manufactured for use as an abrasive and an insulator $(27,84)$. Activated alumina, a highly porous material with a surface area $>200 \mathrm{~m}^{2} / \mathrm{g}$, is used in wastewater treatment as an absorbent for contaminant filtration (9). Nanoparticles of aluminum oxide exhibit amphoteric behavior with an isoelectric point that varies from 8.2 to 10.4 depending upon mineral type (crystalline structure) and method of measurement (85). Ghosh et al. (2008) found the point of zero charge for $\mathrm{Al}_{2} \mathrm{O}_{3}$ nanoparticles in a $\mathrm{KNO}_{3}$ solution to be 7.9 , lower than the 8.7 found by Tombácz et al. (2008) for bulk $\mathrm{Al}_{2} \mathrm{O}_{3}$ using the same electrolyte, suggesting that, in general, isoelectric point decreases as size decreases $(86,87)$. 
Ghosh et al. (2008) has shown that while $\mathrm{Al}_{2} \mathrm{O}_{3}$ nanoparticle suspensions were stable at $\mathrm{pH}$ values far from the $\mathrm{ZPC}$, the largest enhancement in particle stability was observed at $\mathrm{pH}$ values at or above the $\mathrm{ZPC}$ where the zeta potential of the $\mathrm{HA}-\mathrm{Al}_{2} \mathrm{O}_{3}$ particles is increasing (86). Additionally, enhanced aggregation has been shown to occur with the humic acid fraction comprised of small polar fractions and hydrophobic long chains (88). These long chains may act as bridging ligands in the formation of large aggregates. This behavior suggests that natural organic matter may either enhance or reduce $\mathrm{Al}_{2} \mathrm{O}_{3}$ nanoparticle stability in aqueous solution and therefore their potential for transport through saturated porous media.

Little research has been performed regarding the transport and fate of these nanoparticles in the environment. Zeta potential (a surface potential proxy) of $\gamma-\mathrm{Al}_{2} \mathrm{O}_{3}$ was shown to decrease with increasing ionic strength and as solution $\mathrm{pH}$ moved toward the point of zero charge $(86,89)$. These results indicate, similar to other metal oxide nanoparticle research, a decrease in energy of repulsion between particles and hence a reduction of particle stability in solution and increased aggregation (80). Transport experiments using $0.123 \mathrm{~nm}$ positively-charged $\mathrm{Al}_{2} \mathrm{O}_{3}$ in $\mathrm{KCl}$ under high velocity conditions show increased mobility as ionic strength decreased (Figure 19). 


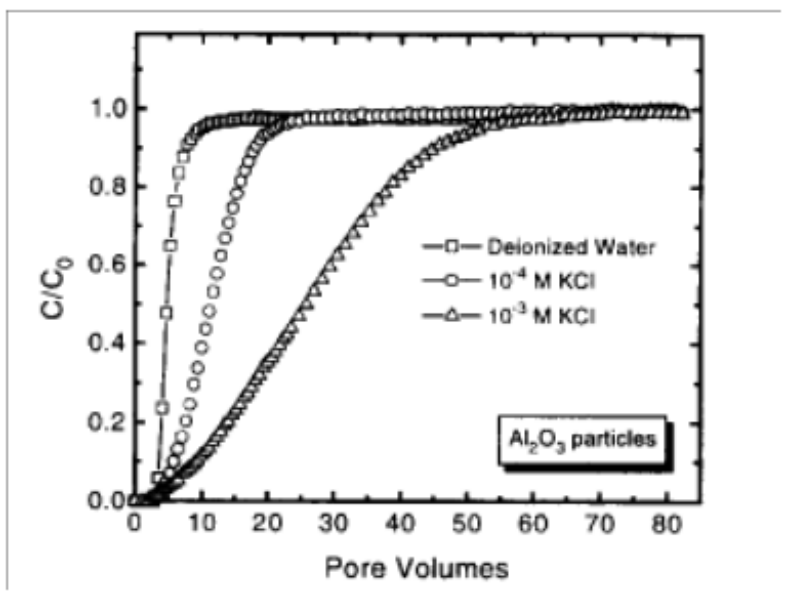

Figure 19: Alumina $\left(\mathrm{Al}_{2} \mathrm{O}_{3}\right)$ breakthrough curves with approach velocity Transport Experiments - Favorable Attachment

Breakthrough curves using $123 \mathrm{~nm} \mathrm{Al}{ }_{2} \mathrm{O}_{3}$ in $\mathrm{pH} 5.6 \mathrm{KCl}$ electrolyte solutions and silica sand as porous media.

(Source: Liu (90); Graphic taken from Ryan and Elimelech (37))

These transport studies, while indicating $\mathrm{Al}_{2} \mathrm{O}_{3}$ is mobile under flow conditions typical of engineered systems (for example, darcy velocity of $6.0 \mathrm{~cm} / \mathrm{min}$ ), may not represent flow conditions expected under natural subsurface conditions. Similar to $\mathrm{TiO}_{2}$, these polydisperse solutions of $\mathrm{Al}_{2} \mathrm{O}_{3}$ would likely be mobile in saturated porous media when experimental parameters are more representative of the natural subsurface environment. Transport under favorable and unfavorable conditions is likely to be similar to results obtained in other metal oxide nanoparticle studies with transport influenced by solution $\mathrm{pH}$, ionic strength, counterion valence, and presence of natural organic matter $(64,80)$.

The purpose of this current thesis research is to investigate the transport behavior of aluminum oxide nanoparticles through saturated porous media under environmentally relevant conditions. Research performed at the benchtop scale employed miscible 
displacement experiments to delineate the impact of $\mathrm{pH}$, aqueous-phase concentration, linear pore-water velocity, and electrolyte cation valence on the transport of aluminum oxide nanoparticles. Additionally, experimental particle deposition rates under clean bed conditions were determined and compared to models developed by Yao et al (1971), Tufenkji and Elimelech (2004) and Nelson and Ginn (2011). 


\section{MATERIALS AND METHODS}

Apparatus

Miscible displacement experiments were conducted using acrylic flow cells $5 \mathrm{~cm}$ in length with $2.54 \mathrm{~cm}$ diameter (Soil Measurement Systems, Tucson, AZ). Column endplates were fitted with porous polyethylene frits with a 15 to $45-\mu \mathrm{m}$ pore size from Interstate Specialty Products. Washers were added to the influent and effluent stainless steel compression tube fittings to produce a more uniform wetting front through the column. Flow cell saturation and non-reactive tracer injections were performed using a Hitachi L-6000 HPLC pump, a FMI Q pump or a Sage Instruments 341 Syringe pump. Aluminum oxide injection experiments were performed using a Sage Instruments 341 syringe pump for high and low velocity injections while a FMI Q pump was used for all $0.5 \mathrm{ml} / \mathrm{min}$ injections. Parker Paraflex $1 / 8$-inch polyethylene tubing was used as influent and effluent tubing on the Hitachi L-6000 HPLC pump and the FMI Q pump while Tygon $1 / 8$-inch soft tubing was used for the Sage Instruments syringe pump in conjunction with a 50-ml polyethylene syringe.

\section{Porous Media}

Flow cells were packed with 20/30 Accusand $\left(\mathrm{d}_{50}=0.713 \mathrm{~mm}\right)$ from Unimin Corporation, a highly uniform, low organic matter content sand containing trace levels of metals and a small cation exchange capacity (58). Prior to packing, the porous media was cleaned using sonication and nanopure water from a Barnstead Nanopure System. 
The sand was sonicated for sixty minutes with stirring every five minutes and then rinsed with approximately $10 \mathrm{~L}$ of nanopure water and air-dried for 48 hours.

Columns were saturated with electrolyte solution at $0.25 \mathrm{ml} / \mathrm{min}$ for 24 hours, followed by $0.35 \mathrm{ml} / \mathrm{min}$ for an additional 24 hours. Finally, saturation at $0.5 \mathrm{ml} / \mathrm{min}$ was performed for 48 - 72 hours or until no mass change occurred day to day. Saturated pore volume was determined using column volume and porosity. Column porosity was determined using a calculated bulk density and a uniform sand particle density of 2.65 $\mathrm{g} / \mathrm{cm}^{3}$. Experimental parameters are included in Table 3.

\section{Table 3: Experimental Parameters}

\begin{tabular}{|cccc|}
\hline & $\begin{array}{c}\text { Bulk } \\
\text { Density } \\
\text { Study Number }\end{array}$ & $\begin{array}{c}\text { Pore } \\
\left(\mathrm{g} / \mathrm{cm}^{3}\right)\end{array}$ & $\begin{array}{c}\text { Porosity } \\
\text { Volume } \\
(\mathrm{mL})\end{array}$ \\
\hline Study \#1_pH6 & 1.87 & 0.296 & 7.62 \\
Study \#2_pH6 & 1.83 & 0.308 & 7.92 \\
Study \#3_pH6 & 1.78 & 0.329 & 8.48 \\
Study \#4_pH9 & 1.80 & 0.320 & 8.13 \\
Study \#5_pH9 & 1.73 & 0.348 & 8.85 \\
Study \#6_pH9 & 1.79 & 0.324 & 8.23 \\
Study \#7_pH9 & 1.79 & 0.324 & 8.24 \\
Study \#8_pH9 & 1.80 & 0.320 & 8.14 \\
Study \#9_pH9 & 1.75 & 0.338 & 8.61 \\
\hline
\end{tabular}




\section{Aluminum Oxide Nanoparticles}

Aluminum oxide nanopowder $\left(\gamma-\mathrm{Al}_{2} \mathrm{O}_{3}\right)$, particle diameter $<50 \mathrm{~nm}$ (SigmaAldrich), was suspended in electrolyte solutions with an ionic strength of $0.015 \mathrm{M}$ or $0.030 \mathrm{M}$. All aluminum oxide handling was performed in polypropylene containers to prevent particle adhesion to container walls. Particle suspensions, 25 and $200 \mathrm{mg} / \mathrm{L}$ in calcium chloride dehydrate $\left(\mathrm{CaCl}_{2} \cdot 2 \mathrm{H}_{2} \mathrm{O}\right)$ solutions and $100 \mathrm{mg} / \mathrm{L}$ in a potassium chloride $(\mathrm{KCl})$ solution were $\mathrm{pH}$ adjusted to $6.0 \pm 0.1 \mathrm{using}$ a sodium hydroxide solution. Additionally, $\gamma$-A12O3 nanoparticles $(100 \mathrm{mg} / \mathrm{L})$ were suspended in a potassium phosphate buffer solution $\left(\mathrm{K}_{2} \mathrm{HPO}_{4} / \mathrm{K}_{3} \mathrm{PO}_{4}\right.$, Fisher Scientific and J.T. Baker) to achieve a stable solution $\mathrm{pH}$ between 9 and 10. All electrolyte solutions were made using nanopure water.

Aluminum oxide hydrodynamic diameter in calcium chloride electrolyte solution (pH 6) was obtained from research performed in conjunction with the University of Arizona using a Malvern Zetasizer Nano ZS. Aluminum oxide nanoparticle absorbance values were measured at an optimum wavelength of $204 \mathrm{~nm}$ with a UV-Visible Spectrophotometer (Hitachi U-1800) standardized to a ten point calibration curve with a lower detection limit of $\sim 1 \mathrm{mg} / \mathrm{L}$.

\section{Column Experiments}

Conservative tracer experiments were performed to delineate hydrodynamic characteristics of each packed column using pentafluorobenzoic acid (PFBA) from Acros 
Organics and Alfa Aesar in either a pH $6 \mathrm{CaCl}_{2}$, a pH $6 \mathrm{KCl}$, or a pH $9.2 \mathrm{~K}_{2} \mathrm{HPO}_{4} / \mathrm{K}_{3} \mathrm{PO}_{4}$ electrolyte solution. PFBA effluent samples were collected in glass scintillation vials and absorbance values measured using the UV-Visible spectrophotometer (Hitachi U-1800) at an optimum absorbance wavelength of $226 \mathrm{~nm}$. PFBA concentration was determined using a ten-point standard calibration curve with a lower detection limit of $\sim 1 \mathrm{mg} / \mathrm{L}$. Each calibration curve was performed through serial dilution of a $525 \mathrm{mg} / \mathrm{L}$ PFBA stock standard solution prepared on the day of the tracer experiment. Samples whose absorbance was expected to exceed the upper limit of detection were diluted before absorbance measurement.

As part of the analysis to ensure reproducibility between column packings and between the column apparati a standard moment analysis was performed for all PFBA breakthrough curves. The zeroth moment was calculated, representing the total PFBA mass recovered in the column effluent, and compared to the total mass injected. The percent mass recovery was used as part of the reproducibility analysis. Additionally, the non-reactive tracer breakthrough curves were analyzed using the nonlinear least-squared optimization program CFITIM3 (91) to determine the extent of physical heterogeneity in each packed core.

Large injection pulses of $\gamma-\mathrm{Al}_{2} \mathrm{O}_{3}$ nanoparticle suspensions were performed for all experiments to fully capture the impact of long-term retention and the multiple ongoing transport processes that may be occurring. The absorbance value of each effluent sample was immediately measured upon collection using the UV- Vis spectrophotometer at 204 
$\mathrm{nm}$ and quantified using the calibration curve made using an $\mathrm{Al}_{2} \mathrm{O}_{3}$ stock solution prepared on the day of the experiment.

Experiments under favorable attachment conditions, $\mathrm{pH}<\mathrm{ZPC}$, were performed using 25 and $200 \mathrm{mg} / \mathrm{L}$ of $\gamma-\mathrm{Al}_{2} \mathrm{O}_{3}$ in a $\mathrm{CaCl}_{2}$ electrolyte solution (IS $=0.015 \mathrm{M}$ ) adjusted to $\mathrm{pH} 6$ with a sodium hydroxide solution. Additionally, a $\mathrm{pH} 6$ experiment was conducted using a $\mathrm{KCl}$ electrolyte solution $(\mathrm{IS}=0.015 \mathrm{M}$ ) to ascertain the potential impact a monovalent cation has on $\mathrm{Al}_{2} \mathrm{O}_{3}$ nanoparticle transport relative to the divalent calcium cation of the $\mathrm{CaCl}_{2}$ electrolyte. At a $\mathrm{pH}<\mathrm{ZPC}$ the $\mathrm{Al}_{2} \mathrm{O}_{3}$ nanoparticles are expected to carry a net positive surface charge while the porous media (i.e. collectors) carries an overall net negative surface charge.

Experiments under unfavorable attachment conditions, $\mathrm{pH}>\mathrm{ZPC}$, were performed using $100 \mathrm{mg} / \mathrm{L} \mathrm{Al}_{2} \mathrm{O}_{3}$ in a potassium phosphate buffer $\left(\mathrm{K}_{2} \mathrm{HPO}_{4} / \mathrm{K}_{3} \mathrm{PO}_{4}\right)$ at an average $\mathrm{pH}$ of 9.2 and ionic strength of $0.015 \mathrm{M}$. At a $\mathrm{pH}>\mathrm{ZPC}$ the $\mathrm{Al}_{2} \mathrm{O}_{3}$ nanoparticles are expected to carry an overall negative charge with the porous media maintaining a net negative surface charge. Under these experimental conditions attachment is deemed unfavorable.

Elution of $\mathrm{Al}_{2} \mathrm{O}_{3}$ from flow cells was performed using a nanoparticle-free electrolyte solution once a gently sloping high concentration, nearly linear, pseudosteady state condition was measured in the flowcell effluent. The three experiments conducted at $\mathrm{pH} 6$ under favorable attachment conditions were performed using a darcy 
velocity (q) of $0.10 \mathrm{~cm} / \mathrm{min}$ or average pore-water velocity $(v)$ of $18.7 \mathrm{~cm} / \mathrm{h}$.

Experiments conducted at $\mathrm{pH} 9-10$ under unfavorable attachment conditions were performed at three darcy velocities; $0.03,0.10,1.8 \mathrm{~cm} / \mathrm{min}(v=4.5,17.5,338 \mathrm{~cm} / \mathrm{h}$, respectively).

\section{Collector Efficiency and Deposition Rate Coefficients}

Predicted collector efficiencies $(\eta)$ and predicted deposition rate coefficients $\left(k_{d}\right)$ were calculated for all favorable attachment transport studies conducted in our research group at $\mathrm{pH}$ 6; conditions under which no energy barrier is assumed to exist for particle attachment to the porous media.

A theoretical single-collector efficiency $\left(\eta_{o}\right)$ was calculated using both the Yao et al. (1971) and Tufenkji and Elimelech (2004) model for all pH 6 transport experiments (equations 7-14). A theoretical collector efficiency $(\eta)$ was also calculated using the Nelson and Ginn (2011) model, an upscaled model with the potential for large-scale field applications (equation 16). Each theoretical value was compared to an experimentally derived collector efficiency $\left(\eta_{\text {exp }}\right)$ calculated using equations (15) and (18). A Hamaker constant $(A)$ for alumina and silica in water $\left(1.83 \times 10^{-20} \mathrm{~J}\right)$ was used in calculating the van der Waals number and the attraction number ( $N_{v d W}$ and $N_{A}$, respectively) in the Tufenkji and Elimelech model and the van der Waals number $\left(N_{L O}\right)$ in the Nelson and Ginn model (92). Additionally, the theoretical and experimental collector efficiencies 
were used to calculated deposition rate coefficients $\left(k_{d}\right)$ (equations 6 and 17) using the theoretical and experimental collector efficiencies from each respective model. 


\section{RESULTS AND DISCUSSION}

Physical Heterogeneity - Non-reactive Tracer

Non-reactive tracer (NRT) experimental results (Figure 20) show reproducible and nearly ideal transport behavior for all experimental conditions (e.g., $\mathrm{pH}$, electrolyte, and pore water velocity). Additionally, a comparison of measured NRT breakthrough curves to a simulated, ideal NRT breakthrough curve shows a small degree of non-ideal transport behavior. That nonideality is evidenced by the slightly earlier measured

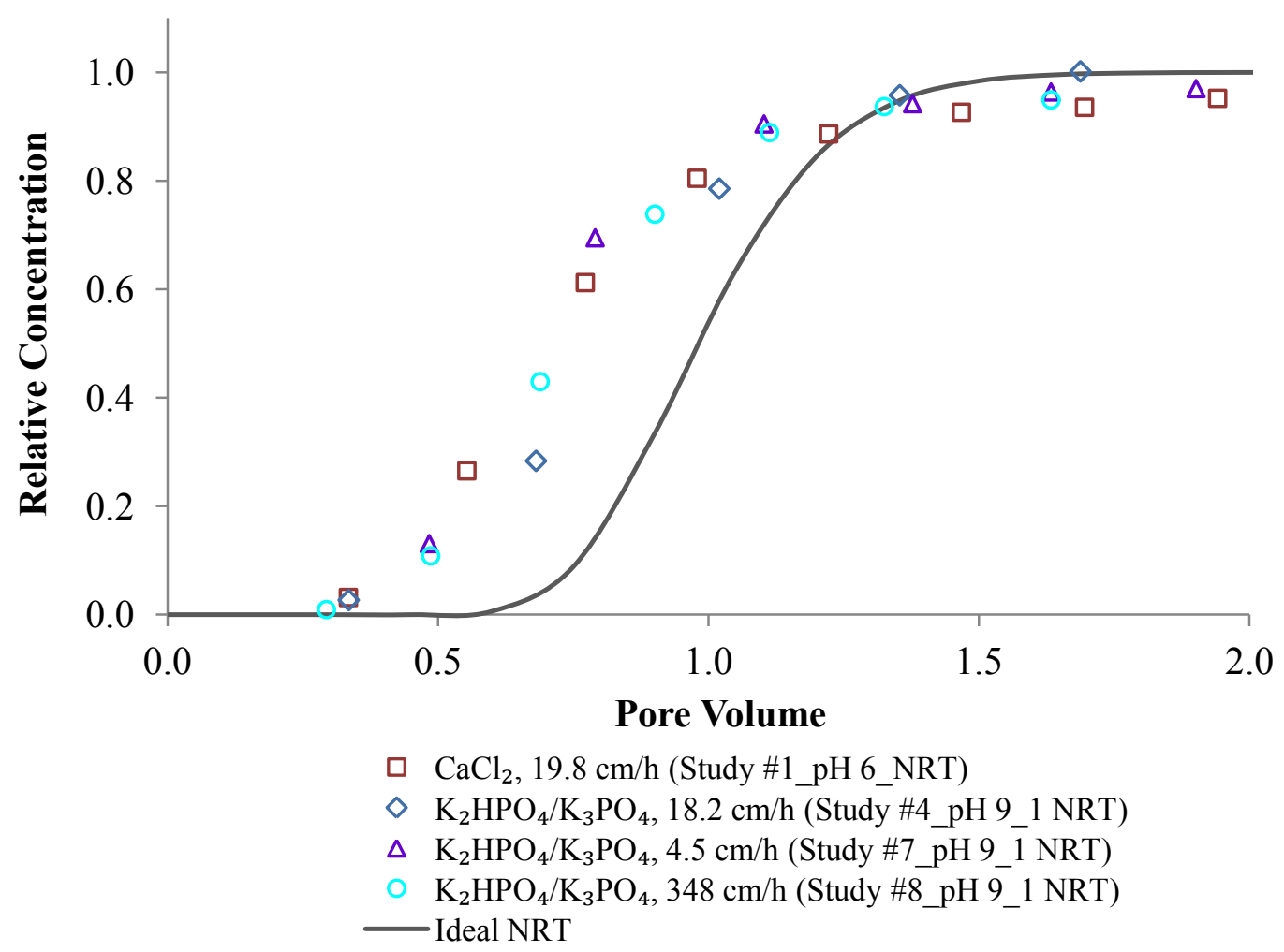

Figure 20: Representative Non-reactive Tracer Studies Illustrating Physical Heterogeneity Representative non-reactive tracer arrival waves for experiments conducted at $\mathrm{pH} 6$ and $\mathrm{pH} 9$, pore water velocity $(4.5, \sim 19,348 \mathrm{~cm} / \mathrm{h})$, and electrolyte type $\left(\mathrm{CaCl}_{2}, \mathrm{~K}_{2} \mathrm{HPO}_{4} / \mathrm{K}_{3} \mathrm{PO}_{4}\right)$. All experiments conducted at $0.015 \mathrm{M}$ ionic strength. The ideal NRT assumes dispersive fluxes are negligible $(\mathrm{Pe}=50, \beta=1)$. 
breakthrough of the tracer relative to an ideal NRT arrival wave (simulated herein for comparison). Specifically, that simulated breakthrough curve illustrates transport behavior under "idealized" conditions such that the impact of physical heterogeneity in the system on overall transport behavior is negligible. Modeling of measured NRT transport results indicates the degree of non-ideality measured is small, such that the fraction of flow in the mobile domain (83\%) dominates transport through this porous media (i.e. $\beta=0.83$ ). The nonideality observed in these tracer studies is a direct result of physical heterogeneities present in the system and is likely due to some preferential flow pathways, velocity variability, and solution movement between the mobile and immobile domain of the porous media. A non-uniform flow front in the influent end of the apparatus employed in these experiments may have resulted in the measured non-ideal transport behavior. While these results show a relatively small degree of nonideality (with $83 \%$ of the flow occurring in the mobile domain), a comparison of transport behavior under the various experimental conditions show reproducibility. These results suggest the impacts of physical heterogeneity on solute transport behavior are independent of $\mathrm{pH}$, pore water velocity, and the electrolytes employed in these transport experiments.

Physical and Chemical Heterogeneity

A comparison of $\mathrm{Al}_{2} \mathrm{O}_{3}$ nanoparticle transport curves to those measured for the non-reactive tracer is shown in Figure 21. These results indicate both physical and 
chemical heterogeneity is contributing to the overall transport behavior of $\mathrm{Al}_{2} \mathrm{O}_{3}$ nanoparticles through this porous media. One additional physical transport phenomena $\mathrm{Al}_{2} \mathrm{O}_{3}$ may experience (not evidenced by PFBA as a NRT) is associated

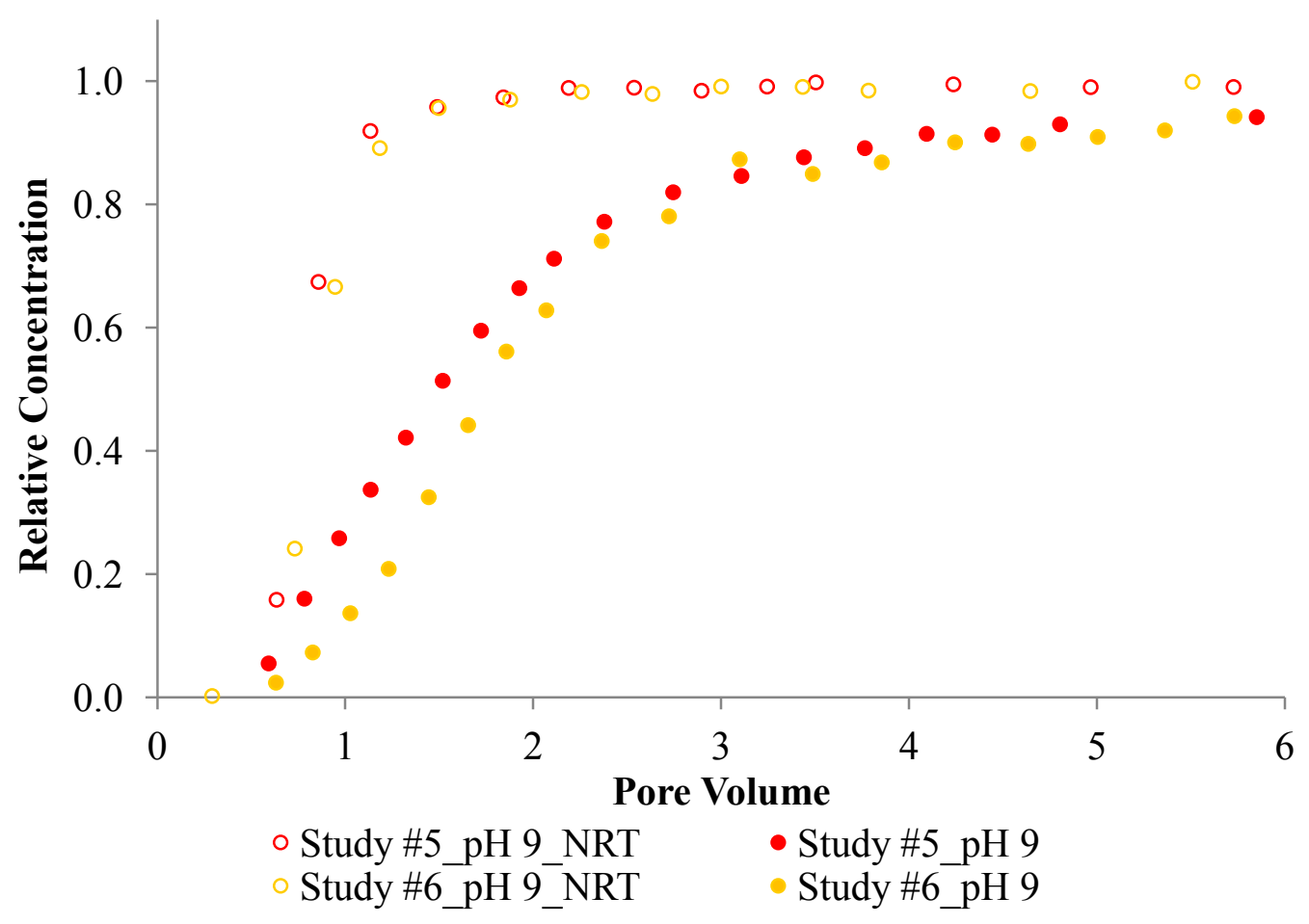

Figure 21: $\mathrm{Al}_{2} \mathrm{O}_{3}$ Arrival Waves Illustrating Physical and Chemical Heterogeneity Relative to NRT Physical Heterogeneity

Representative non-reactive tracer arrival waves compared to representative $\mathrm{Al}_{2} \mathrm{O}_{3}$ arrival waves illustrating the impact of physical and chemical heterogeneity on overall transport behavior.

physical straining. While straining has been shown to occur when $\mathrm{d}_{\mathrm{p}} / \mathrm{d}_{50}>0.0017$, it is not expected to occur in these systems as the $\mathrm{d}_{\mathrm{p}} / \mathrm{d}_{50}<0.0004$, an order of magnitude smaller than what has been observed in the literature (51).The impact of physical heterogeneities (illustrated by the NRT) is likely to be similar across both $\mathrm{pH} 6$ and $\mathrm{pH} 9$ 
experiments such that the observed nanoparticle transport behavior is likely due to the presence of on-going chemical phenomena (e.g., attachment, blocking).

Favorable and Unfavorable Attachment Conditions (pH 6 and $\mathrm{pH}$ 9)

A comparison of aluminum oxide $\left(\gamma-\mathrm{Al}_{2} \mathrm{O}_{3}\right)$ nanoparticle transport measured at pH 6 and pH 9 shows markedly different colloid transport behavior in porous media under favorable versus unfavorable attachment conditions as illustrated in Figure 22. As with other metal oxides, $\gamma-\mathrm{Al}_{2} \mathrm{O}_{3}$ exhibits amphoteric behavior with a zero point of charge occurring at $\mathrm{pH} 8$ such that at $\mathrm{pH} 9$ conditions are unfavorable for nanoparticle attachment to the porous media as the nanoparticles and porous media carry an overall negative surface charge. Miscible displacement experiments performed at $\mathrm{pH} 9$ (unfavorable attachment) showed a gently sloping, nearly linear, pseudo-steady state $\left(C / C_{o}=0.95-0.98\right)$ occurring within approximately 5 pore volumes of injection. 


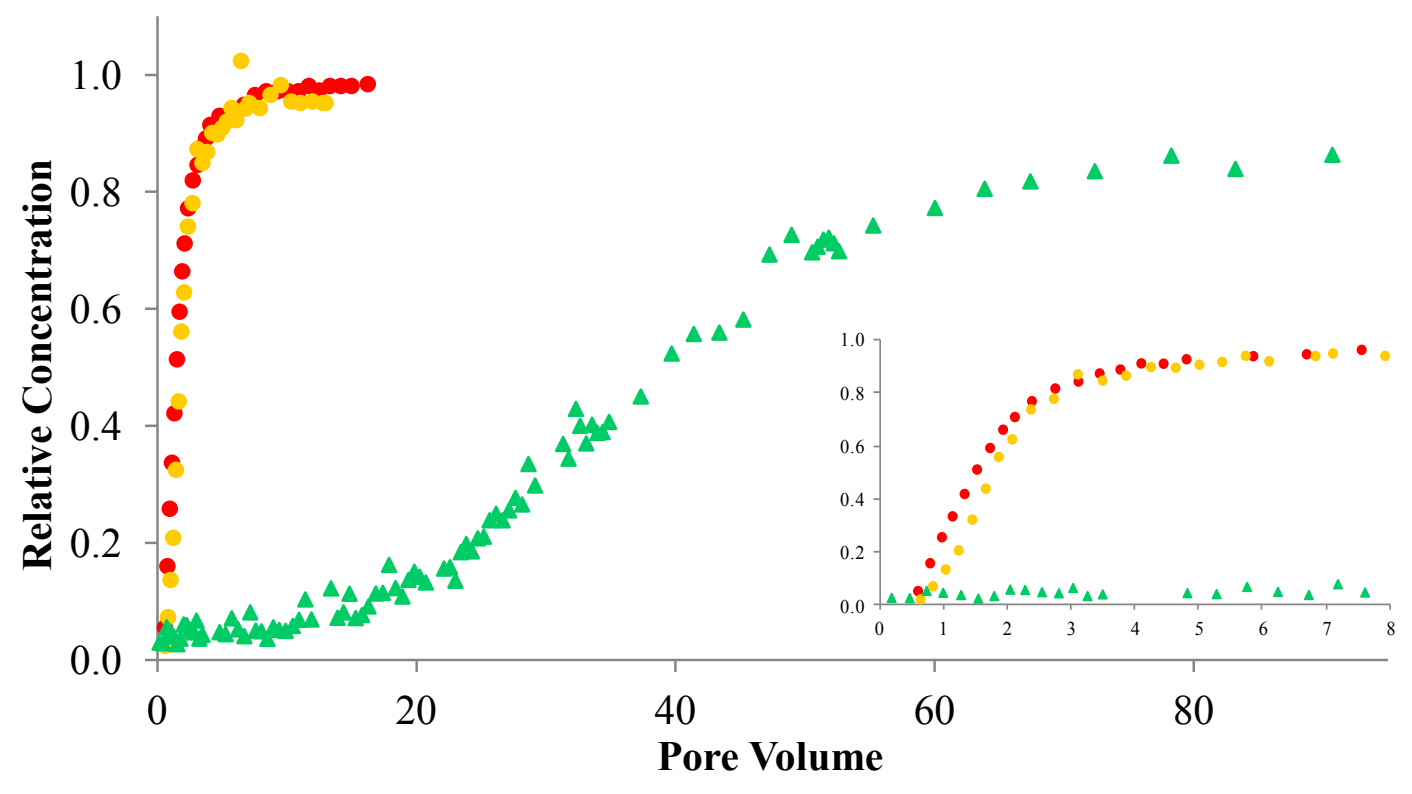

- Study \#2_pH 9 • Study \#3_pH $9 \quad$ × pH 6

Figure 22: $\mathrm{Al}_{2} \mathrm{O}_{3}$ Arrival Waves- Favorable (pH 6) and Unfavorable Attachment (pH 9) Aluminum oxide solutions at $\mathrm{pH} 9$ were $100 \mathrm{mg} / \mathrm{L}$ in a $\mathrm{K}_{2} \mathrm{HPO}_{4} / \mathrm{K}_{3} \mathrm{PO}_{4}(\mathrm{IS}=0.015 \mathrm{M})$ solution. The $\mathrm{pH} 6$ experiment, conducted previously in our research group, used a $125 \mathrm{mg} / \mathrm{L}$ aluminum oxide solution in $\mathrm{CaCl}_{2}(\mathrm{IS}=0.015 \mathrm{M})$. Experimental flow rate was $0.5 \mathrm{~mL} / \mathrm{min}(\mathrm{pH} 9 v \approx 17.5 \mathrm{~cm} / \mathrm{h} ; \mathrm{pH} 6 v=18.4 \mathrm{~cm} / \mathrm{h})$ for all three experiments.

In contrast, column experiments previously performed by researchers in our group under favorable attachment conditions ( $\mathrm{pH}$ 6), where $\gamma-\mathrm{Al}_{2} \mathrm{O}_{3}$ is positively charged and the porous media is negatively charged, showed that a significantly larger injection pulse (greater than 70 pore volumes) was required to reach a gently sloping approach towards complete breakthrough.

Moment analysis performed on the arrival wave, under unfavorable attachment (pH 9), shows that $10 \%$ of $\mathrm{Al}_{2} \mathrm{O}_{3}$ nanoparticles are retained in the system. In contrast, $52 \%$ of the nanoparticle mass injected is held up in the system under favorable attachment conditions ( $\mathrm{pH}$ 6). Retardation is significantly less under unfavorable 
attachment conditions and likely due to the electrostatic repulsion between $\mathrm{Al}_{2} \mathrm{O}_{3}$ nanoparticles and the porous media. Those particles retained under unfavorable conditions are likely the result of multiple retention mechanisms including porous media geophysical heterogeneities and nanoparticle attachment in the secondary energy minimum. Surface charge heterogeneity is believed to play a part in attachment observed under unfavorable conditions wherein areas of positive surface charge, or favorable attachment sites located on the overall negatively-charged surface of the collector, may result in a larger retention of particles than predicted (i.e. negatively charged $\mathrm{Al}_{2} \mathrm{O}_{3}$ nanoparticles may attach) $(41,52,59)$. Additionally, when surface charge heterogeneity is masked, deposition still occurs and is believed the result of deposition in the secondary energy well $(50,52)$.

Many researchers have focused on the initial stage of deposition under "clean bed" conditions, when processes contributing to colloid deposition are "simplest", using short input pulses and high approach velocities not typically observed in groundwater flow. In contrast, the large injection volumes or input pulses employed in these nanoparticle transport experiments aimed to fully characterize long-term transport behavior at approach velocities typical of groundwater flow.

As described above, breakthrough curves of $\mathrm{Al}_{2} \mathrm{O}_{3}$ under unfavorable attachment conditions (pH 9) show a nearly linear approach to a pseudo-steady state relative concentration of $\sim 0.95$ within $\sim 5$ pore volumes of injection. These results are congruent to those presented in nanocolloid transport research conducted at similar darcy velocities, 
employing nanocolloids of like size and shape, and electrolyte ionic strength $(25,49,52$, $78,79,93)$. For example, breakthrough curves (previously shown in Figure 18) of negatively charged $100 \mathrm{~nm} \mathrm{Fe}_{2} \mathrm{O}_{3}$ (IS $=0.03 \mathrm{M}$ ) demonstrated a gently sloping, nearly linear approach to complete breakthrough within approximately 3 pore volumes of injection.

The nanoparticle transport curves under favorable attachment conditions ( $\mathrm{pH}$ 6) as presented herein are markedly different from those typically reported in the literature. Specifically, our breakthrough curves show an early, low-concentration steady-state plateau followed by a gently-sloping rising limb with greater than 70 pore volumes required to reach complete breakthrough. In contrast, for example, breakthrough curves of positively-charged colloids, such as those of model latex colloids shown previously in Figure 9, exhibit a very sharp rising limb in the arrival wave with a fast approach to a steady-state relative concentration. Additionally, breakthrough curves from nanoparticle transport experiments (Figure 19) using positively-charged 123-nm $\mathrm{Al}_{2} \mathrm{O}_{3}$ displayed complete breakthrough $\left(\mathrm{C} / \mathrm{C}_{\mathrm{o}}=1\right)$ but not the early low-concentration steady-state behavior as observed in our $\mathrm{Al}_{2} \mathrm{O}_{3}$ transport experiments (see Figure 22). The approach velocities employed in these transport studies are $\sim 80$-fold higher $(\mathrm{U}=8.2 \mathrm{~cm} / \mathrm{min}$ and $6.0 \mathrm{~cm} / \mathrm{min}$, respectively) than in our transport studies $(\mathrm{U}=0.10 \mathrm{~cm} / \mathrm{min})$ and employ markedly smaller input pulses such that they may not be able to fully characterize transport behavior associated with long-term transport at natural groundwater velocities. Interestingly, transport studies conducted previously in our research group using 100 
$\mathrm{mg} / \mathrm{L} \mathrm{Al} \mathrm{O}_{3}$ in nanopure water at $\mathrm{pH} 6$ showed that as pore-water velocity increased from 18 to $217 \mathrm{~cm} / \mathrm{h}$ the resulting breakthrough curves become increasingly similar to that found in the literature (Figure 23). Finally, transport experiments using large injection pulses, while still employing large approach velocities, have the ability to characterize long-term transport behavior, but at approach velocities typical of engineered systems, not natural groundwater systems.

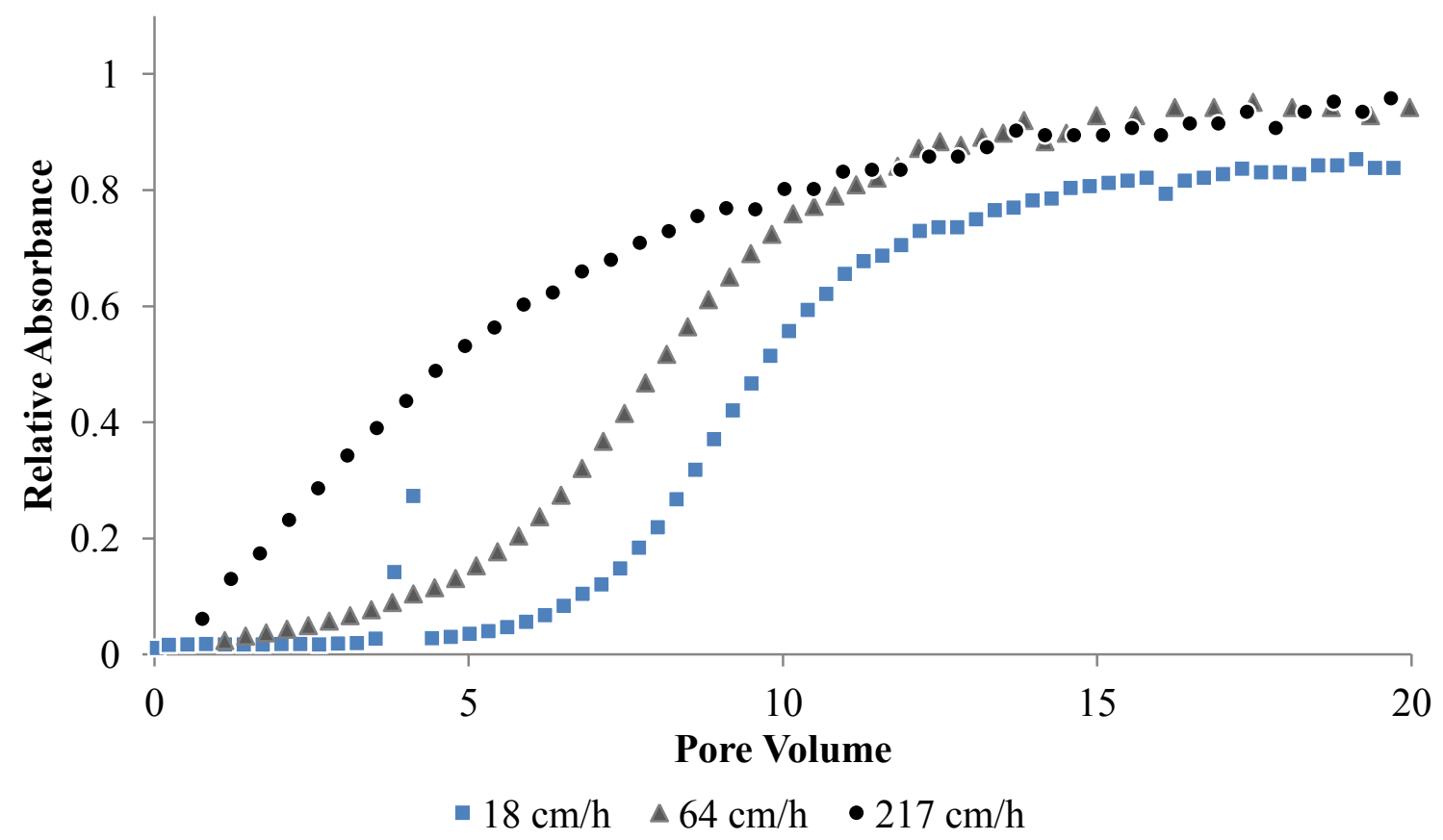

Figure 23: High velocity $\mathrm{Al}_{2} \mathrm{O}_{3}$ Nanoparticle Breakthrough Curve $(v=217 \mathrm{~cm} / \mathrm{h})-$ Favorable Attachment

Experiments conducted using $100 \mathrm{mg} / \mathrm{L} \mathrm{Al}_{2} \mathrm{O}_{3}$ in $\mathrm{pH} 6$ nanopure water at three different pore water velocities: 18, 64, and $217 \mathrm{~cm} / \mathrm{h}$.

A 2003 aquifer tank experiment using 150-nm silica-coated zirconia, employing large injection pulses and approach velocities similar to this current research, is, at the 
time of this thesis, the only nanoparticle transport study to present breakthrough curves similar to this current research (41). The silica-coated zirconia breakthrough curves (Figure 4) demonstrate the same low-concentration steady-state transport behavior and gently sloping approach to complete breakthrough as observed in the $\mathrm{pH} 6 \mathrm{Al}_{2} \mathrm{O}_{3}$ breakthrough curve shown in Figure 22.

Linear Pore Water Velocity

Transport experiments conducted under unfavorable attachment conditions ( $\mathrm{pH}$ 9) at three average linear pore water velocities $(4.5,17.5$, and $338 \mathrm{~cm} / \mathrm{h})$ show initial breakthrough within one pore volume and an approach to complete breakthrough within 5 pore volumes of injection (Figure 24). The mass retained within each system is small 


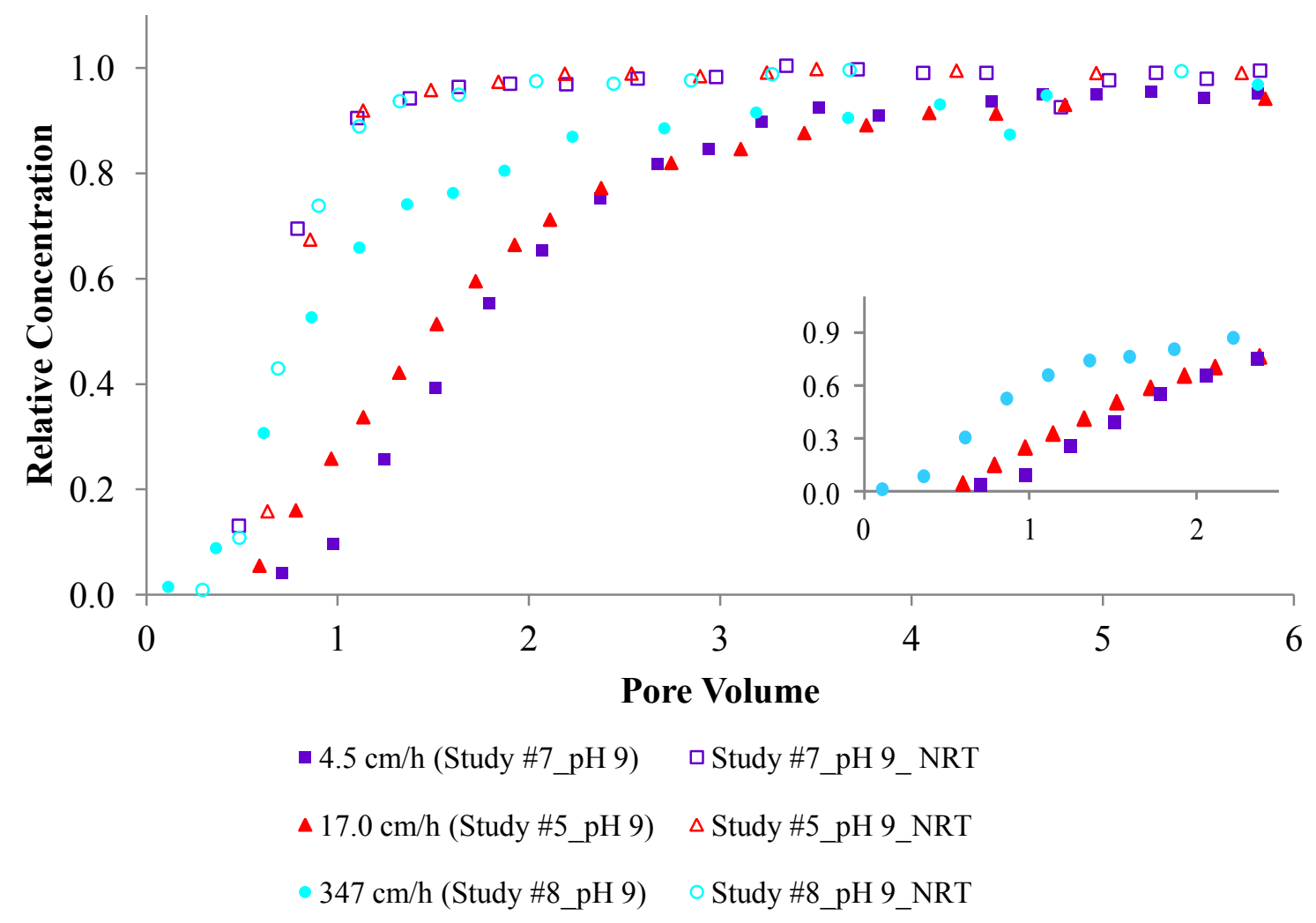

Figure 24: Characterization of Velocity Effects on Transport Behavior of $\mathrm{Al}_{2} \mathrm{O}_{3}-$ Unfavorable Conditions (pH 9)

These unfavorable attachment transport experiments were performed using $100 \mathrm{mg} / \mathrm{L} \mathrm{Al} \mathrm{O}_{3}$ in $\mathrm{K}_{2} \mathrm{HPO}_{4} / \mathrm{K}_{3} \mathrm{PO}_{4}(\mathrm{IS}=0.015 \mathrm{M})$ buffer solution at a darcy velocity of approximately $0.03,0.10$, and 1.8 $\mathrm{cm} / \min (v=4.5,17.5,338 \mathrm{~cm} / \mathrm{h})$.

(5-13\%) under these unfavorable attachment conditions and is likely associated with deposition in the shallow secondary energy minimum and/or surface charge heterogeneity on the sand grain surfaces. All variable flow experiments exhibit some degree of tailing on the nanoparticle transport arrival wave as evidenced on comparing that transport arrival wave to that observed for the non-reactive tracer. The higher flow $(338 \mathrm{~cm} / \mathrm{h})$ breakthrough curve showed slightly earlier breakthrough than the lower flow $(4.5,17.5$ 
$\mathrm{cm} / \mathrm{h}$ ) breakthrough curves, suggesting deposition is kinetically controlled (see inset Figure 24). This proposed kinetically-controlled deposition behavior is supported by concentration effects observed on the arrival wave following minor stop flow (5 - 10 minute) experiments during the high flow $(329 \mathrm{~cm} / \mathrm{h})$ transport study (Figure $25 \mathrm{a}$ ). Furthermore, a six-day stop flow experiment conducted during the low flow $(4.5 \mathrm{~cm} / \mathrm{h})$ transport study exhibits a significant effect on measured column effluent concentrations (Figure 25b). Variable flow experiments (discussed previously) conducted within our research group under favorable attachment conditions ( $\mathrm{pH} 6$ ) also exhibit slightly earlier breakthrough at higher flow (see Figure 23) and concentration effects during stop flows (Figure 26). These results indicate $\mathrm{Al}_{2} \mathrm{O}_{3}$ nanoparticle deposition may be kinetically controlled irrespective of $\mathrm{pH}$. 


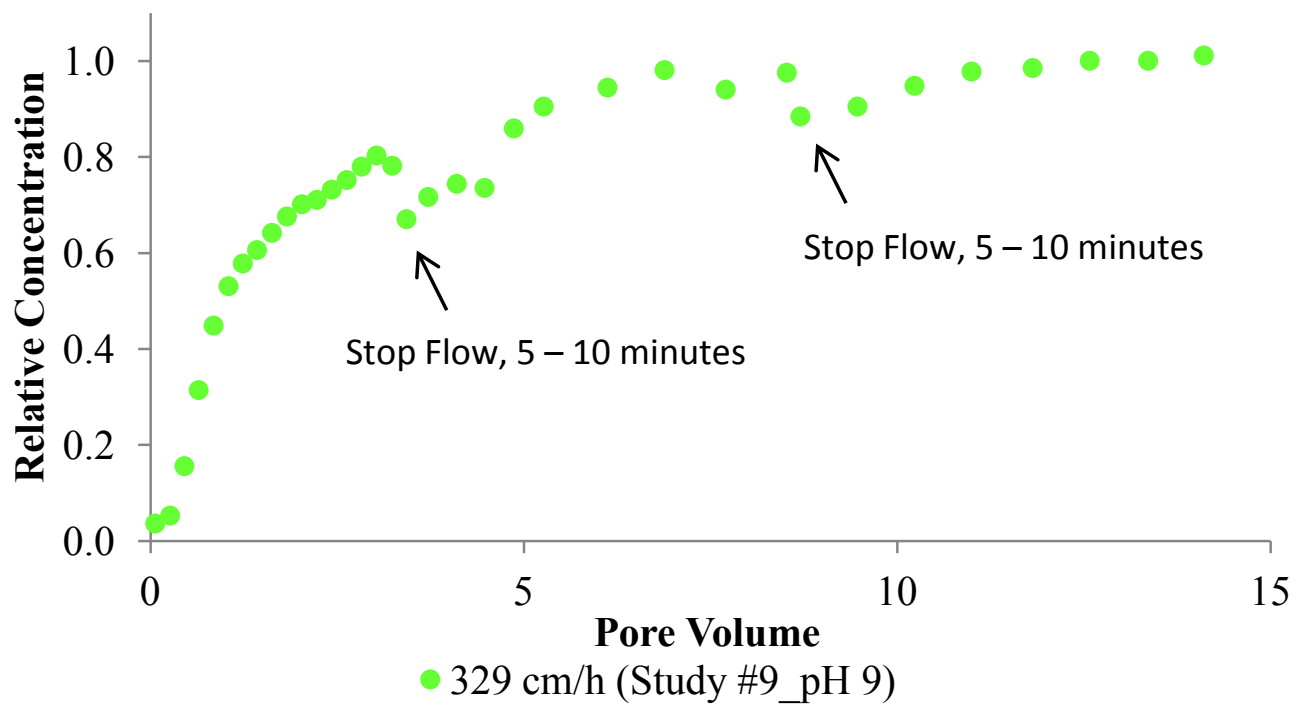

a)

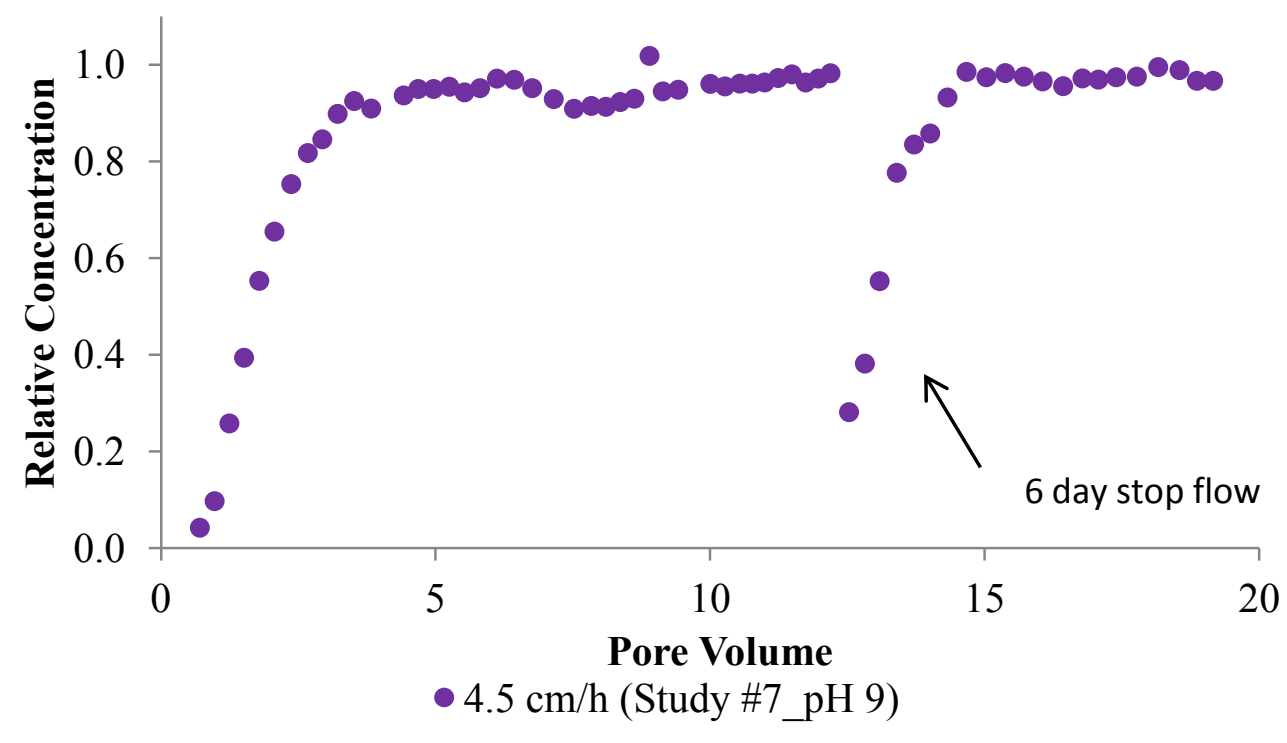

Figure 25: Concentration effects upon stop flow events - Unfavorable Attachment Stop flow events ranged from $5-10$ minutes to approximately 1 week using $100 \mathrm{mg} / \mathrm{L} \mathrm{Al}_{2} \mathrm{O}_{3}$ in $\mathrm{K}_{2} \mathrm{HPO}_{4} / \mathrm{K}_{3} \mathrm{PO}_{4}(\mathrm{IS}=0.015 \mathrm{M})$ buffer solution. (a) Two small stop flows conducted during a high velocity $(v=329 \mathrm{~cm} / \mathrm{h})$ transport experiment $(\mathrm{pH} 9.4)$. (b) Six day stop flow conducted during a low velocity $(v=$ $4.5 \mathrm{~cm} / \mathrm{h}$ ) transport experiment ( $\mathrm{pH} 9.1)$. 


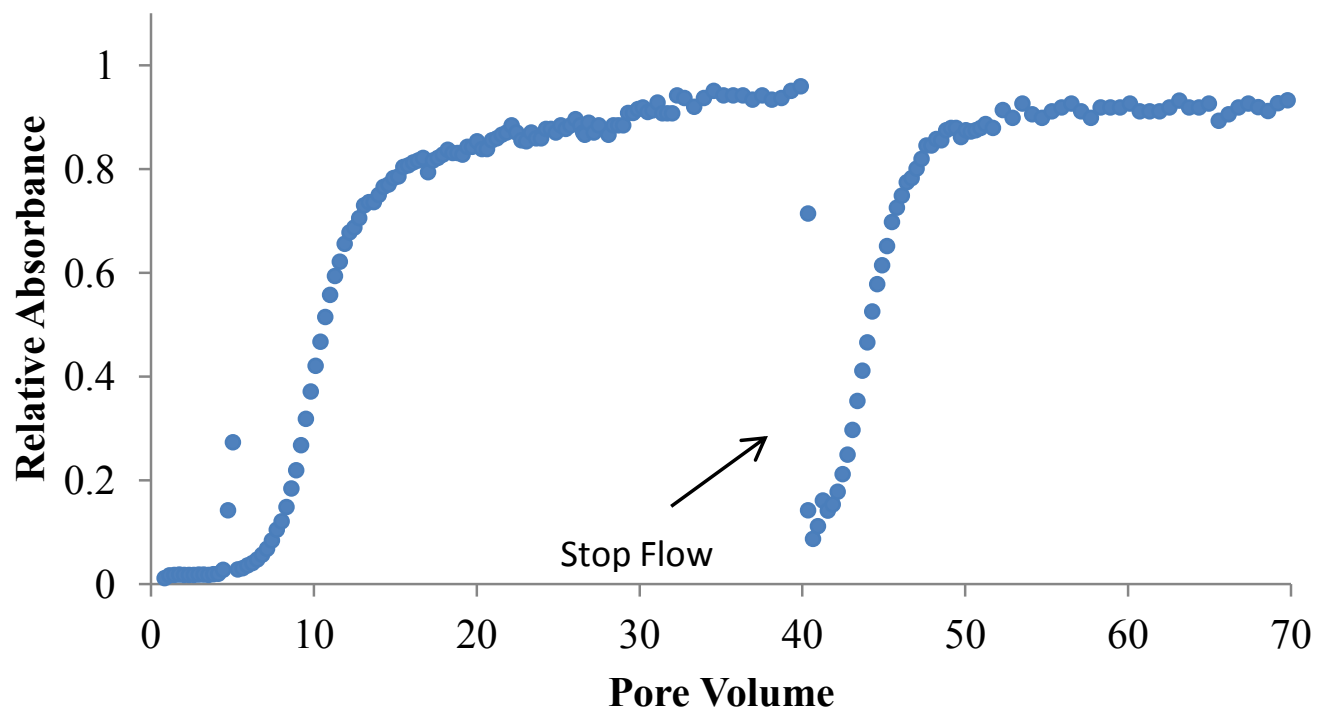

Figure 26: Stop Flow, Favorable Attachment Conditions (pH 6)

Stop flow experiment conducted at $\mathrm{pH} 6$ illustrating rate-limited $\mathrm{Al}_{2} \mathrm{O}_{3}$ nanoparticle deposition. Experiment conducted using $100 \mathrm{mg} / \mathrm{L} \mathrm{Al}_{2} \mathrm{O}_{3}$ in deionized water and a linear pore-water velocity of $18 \mathrm{~cm} / \mathrm{h}$.

Aqueous-Phase Concentration

The results of nanoparticle transport experiments under favorable attachment conditions ( $\mathrm{pH} \mathrm{6)}$ and three different aqueous-phase concentrations are shown in Figure 27. As $\mathrm{Al}_{2} \mathrm{O}_{3}$ aqueous concentration decreased breakthrough times increased, with the low concentration experiment $(25 \mathrm{mg} / \mathrm{L})$ requiring greater than 500 pore volumes to reach a gently sloping approach to complete breakthrough at $\mathrm{pH} 6$. Higher aqueous concentration resulted in a faster approach to dynamic deposition conditions with a gently sloping approach to complete breakthrough occurring within approximately 40 pore volumes (see inset in Figure 27). 


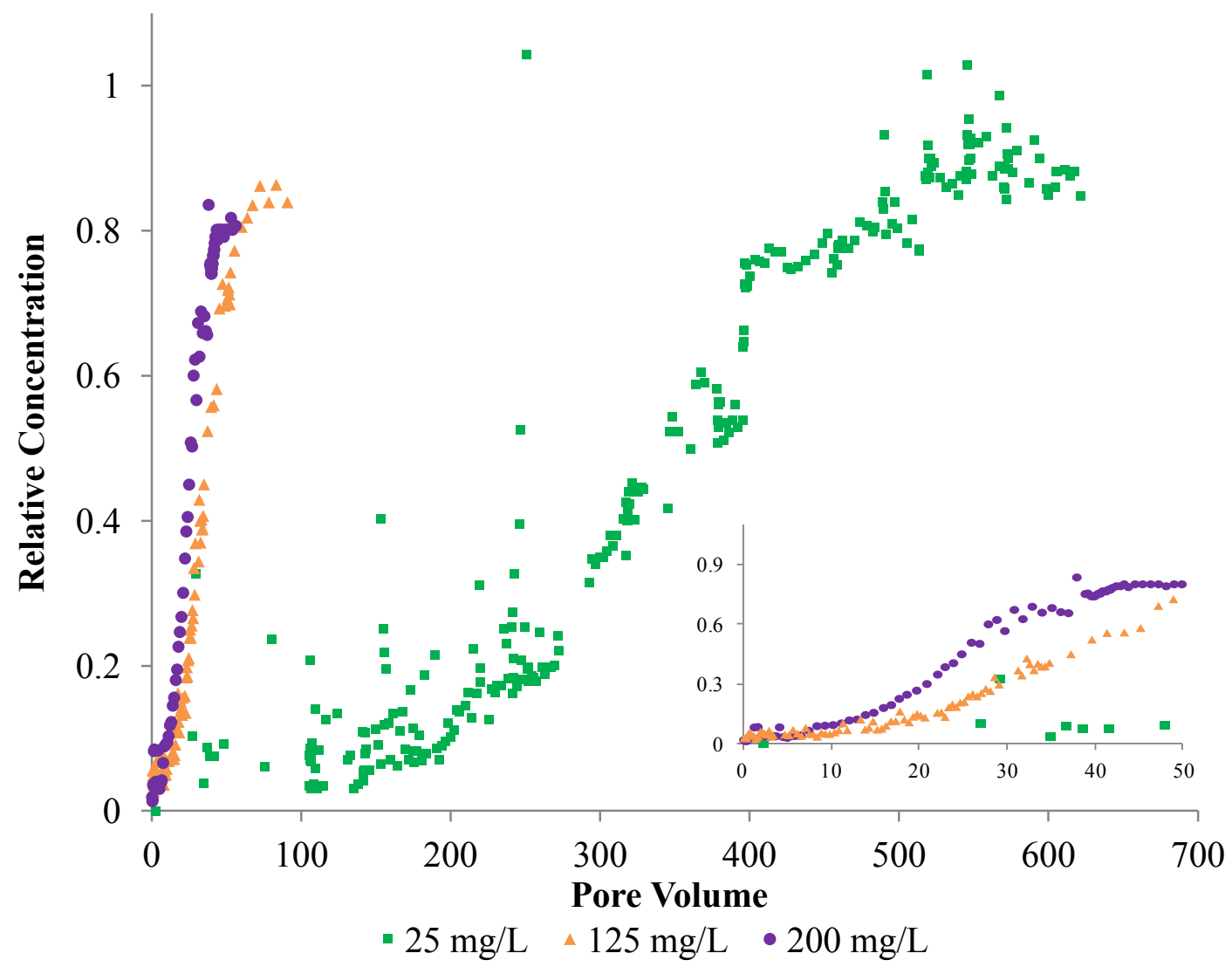

Figure 27: $\mathrm{Al}_{2} \mathrm{O}_{3}$ aqueous-phase concentration transport studies

Transport studies conducted at $\mathrm{pH} 6$ using $25 \mathrm{mg} / \mathrm{L} \mathrm{Al}_{2} \mathrm{O}_{3}$ (Study \#2_ pH 6), $125 \mathrm{mg} / \mathrm{L} \mathrm{Al}_{2} \mathrm{O}_{3}$ (conducted previously in our research group), and $200 \mathrm{mg} / \mathrm{L} \mathrm{Al}_{2} \mathrm{O}_{3}$ (Study \#1_pH 6) in a $\mathrm{CaCl}_{2}$ electrolyte (IS $=0.015$ $\mathrm{M})$; darcy velocity approximately $0.1 \mathrm{~cm} / \mathrm{min}(v=18.4-19.8 \mathrm{~cm} / \mathrm{h})$.

The onset of blocking wherein the transport of nanoparticles transitions from an early, low-concentration, steady-state plateau to "dynamic" transport conditions occurs within 10 pore volumes of injection in the 125 and $200 \mathrm{mg} / \mathrm{L} \mathrm{Al}_{2} \mathrm{O}_{3}$ experiment, while the $25 \mathrm{mg} / \mathrm{L}$ experiment requires $\sim 100$ pore volumes of injection. Similar to our $\mathrm{Al}_{2} \mathrm{O}_{3}$ transport curves, Liu et al. (1995) found the approach to a long-term, high relative concentration of $0.48-\mu \mathrm{m}$ latex particles occurred faster as colloid concentration 
increased (42) as shown previously (Figure 5). This behavior was attributed to the limited availability of attachment sites on the collectors such that the onset of blocking, where deposited particles impact attachment of subsequent particles (40), occurs more quickly as concentration increases. Our $\mathrm{Al}_{2} \mathrm{O}_{3}$ results are likely due to the limited availability of attachment sites on the porous media such that increasing the nanoparticle concentration results in filling those attachment sites over a smaller input pulse.

Colloid filtration theory assumes that the rate of particle attachment to the collector surface is independent of particle concentration. That theory is supported by results herein. Specifically, while the time to achieve the long-term, steady state high concentration increases with decreasing aqueous-phase concentration, the total mass retained in the system is independent of concentration as shown in Figure 28. The fraction of mass retained shows a similar linear relationship to the mass injected across all three aqueous-phase concentrations and is followed by decreasing retention (gently sloping curve) as the system approaches complete breakthrough. While the input pulse increases with decreasing nanoparticle concentration the total mass retained in the system upon reaching complete breakthrough is similar. 


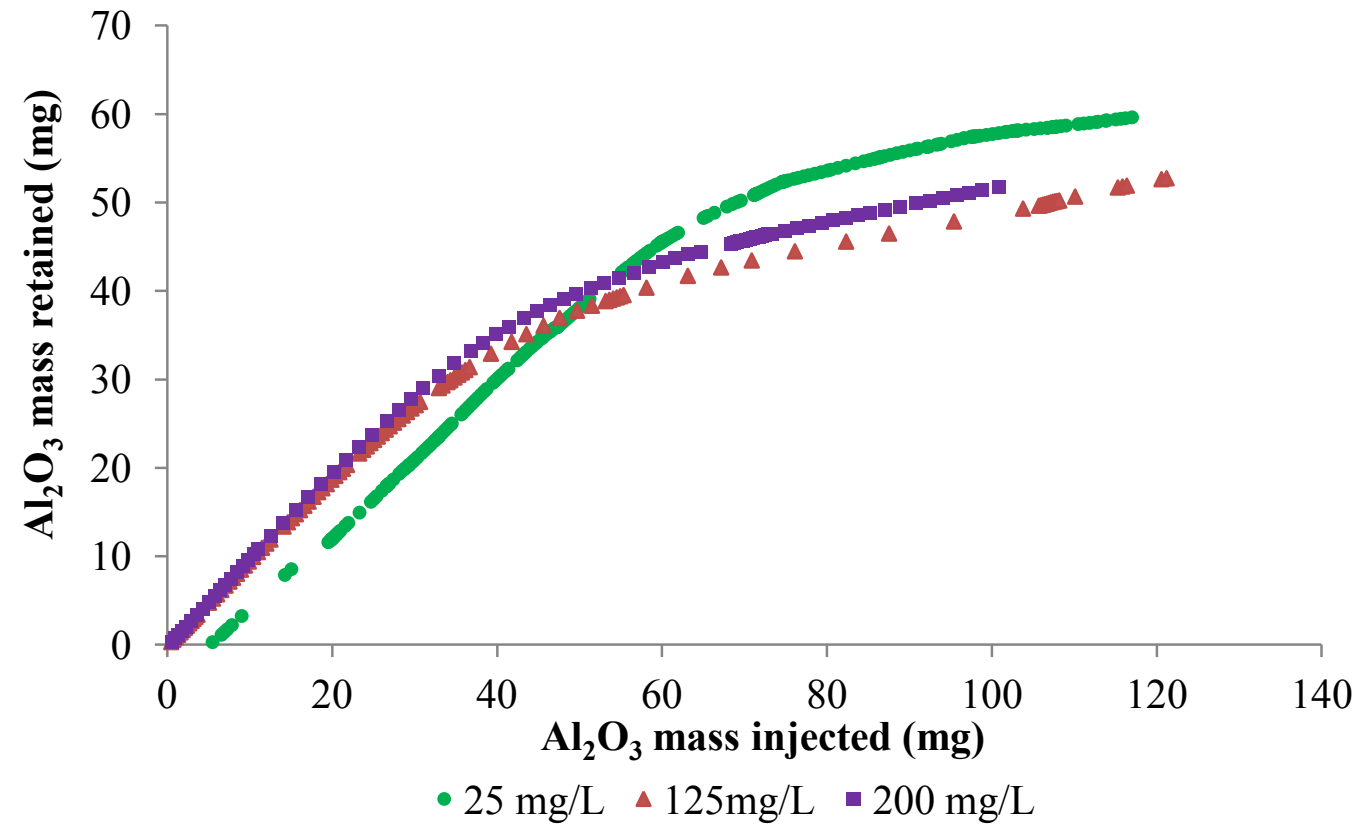

Figure 28: Total mass $\mathrm{Al}_{2} \mathrm{O}_{3}$ nanoparticles retained relative to the total mass injected at three different aqueous phase concentrations

Electrolyte - Monovalent Versus Divalent Cation

A $100 \mathrm{mg} / \mathrm{L} \mathrm{Al} \mathrm{O}_{3}$ nanoparticle transport study at $\mathrm{pH} 6$ in a $0.015 \mathrm{M}$ electrolyte solution of $\mathrm{KCl}$ was conducted and compared to that measured under similar experimental conditions using a $0.015 \mathrm{M}$ electrolyte solution of $\mathrm{CaCl}_{2}$. Initial breakthrough of nanoparticles using the monovalent electrolyte $(\mathrm{KCl})$ occurred within one pore volume of injection similar to that initial breakthrough observed using the divalent electrolyte $\left(\mathrm{CaCl}_{2}\right)$. With the onset of the dynamic transport phase (i.e., the onset of blocking), the $\mathrm{Al}_{2} \mathrm{O}_{3}$ transport measured using the $\mathrm{KCl}$ electrolyte solution diverged from that measured for using $\mathrm{CaCl}_{2}$. Specifically, the transition from the low- 
concentration, steady-state behavior to dynamic transport conditions in the $\mathrm{KCl}$

experiment is not as sharp/steep as that observed for the $\mathrm{CaCl}_{2}$ experiment (Figure 29).

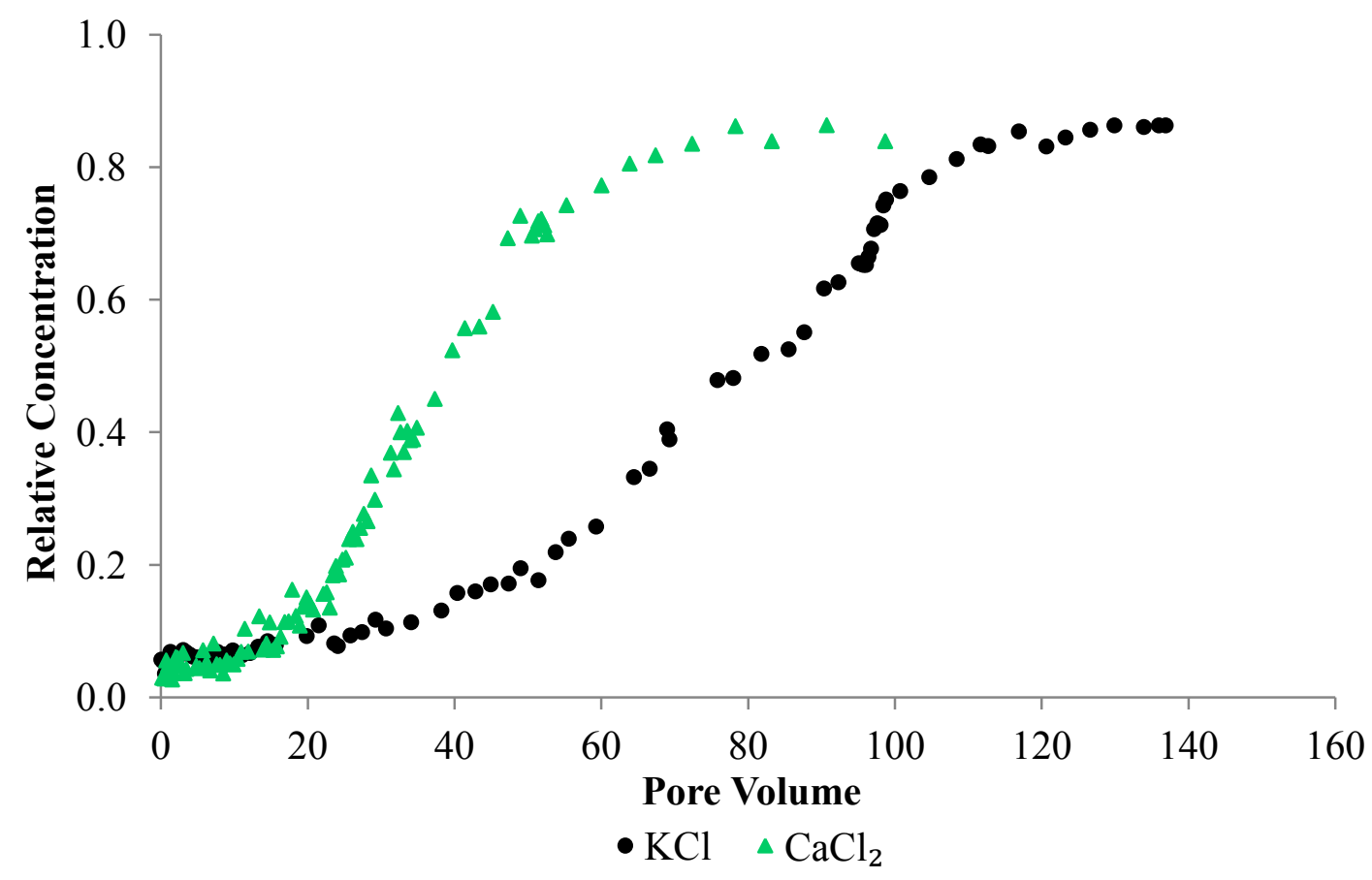

Figure 29: Comparison of $\mathrm{Al}_{2} \mathrm{O}_{3}$ transport using a monovalent $(\mathrm{KCl})$ and divalent $\left(\mathrm{CaCl}_{2}\right)$ electrolyte solution

Both transport studies conducted at $\mathrm{pH} 6$ using $100 \mathrm{mg} / \mathrm{L} \mathrm{Al}_{2} \mathrm{O}_{3}$ in either $\mathrm{KCl}$ or $\mathrm{CaCl}_{2}$ electrolyte solutions (IS $=0.015 \mathrm{M}$ ) and at an average linear pore water velocity of $19 \mathrm{~cm} / \mathrm{h}$. The $\mathrm{KCl}$ transport study

corresponds to Study \#3_pH 6 in this thesis while $\mathrm{CaCl}_{2}$ transport study was conducted previously within our research group.

A sharp transition occurs within approximately 20 pore volumes in the $\mathrm{CaCl}_{2}$ study with a steep slope and approach to a long-term, steady-state plateau approaching complete breakthrough. Conversely, the observed transition in the $\mathrm{KCl}$ study is less sharp requiring nearly twice the number of injection-solution pore volumes to begin a high-concentration plateau condition. The two studies reach a similar long-term high concentration state at $\mathrm{C} / \mathrm{C}_{\mathrm{o}}=0.83-0.86$ but the $\mathrm{KCl}$ study required approximately 150 pore volumes of 
solution injection whereas the $\mathrm{CaCl}_{2}$ study required only 80 pore volumes to reach the same relative concentration.

Experimental conditions were similar for these two transport studies (e.g., ionic strength, flow velocity, aqueous-phase concentration) apart from the presence of monoversus divalent cations in solution and the differences in ion species concentrations.

Although ionic strength was the same, the $\mathrm{K}^{+}$molar concentration $(0.015 \mathrm{M})$ was three times higher than the $\mathrm{Ca}^{2+}$ molar concentration $(0.005 \mathrm{M})$ while the anion concentrations were similar $\left(\mathrm{Cl}^{-} \mathrm{CaCl}_{2}=0.01 \mathrm{M}\right.$ and $\left.\mathrm{Cl}_{\mathrm{KCl}}^{-}=0.015 \mathrm{M}\right)$. A comparison of transport behavior for these two cations in solution at more similar concentrations is shown in Figure 30. The $\mathrm{KCl}$ transport study demonstrates similar behavior to a higher ionic strength (IS = $0.030 \mathrm{M}) \mathrm{CaCl}_{2}$ transport study conducted within our research group. Again, the $\mathrm{Cl}^{-}$

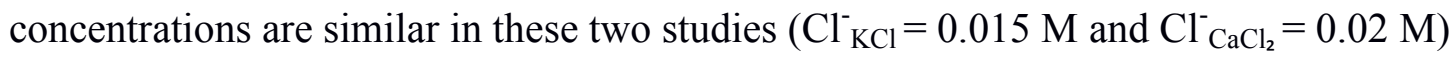
and are not believed to be impacting transport behavior. Overall these results suggest it is the cation (irrespective of valence) dominantly affecting/contributing to nanoparticle deposition to this porous media. As that cation concentration increases, from $0.005 \mathrm{M}$ to $0.015 \mathrm{M}$, deposition of $\mathrm{Al}_{2} \mathrm{O}_{3}$ nanoparticles increases, resulting in greater retardation on transport through the porous media. 


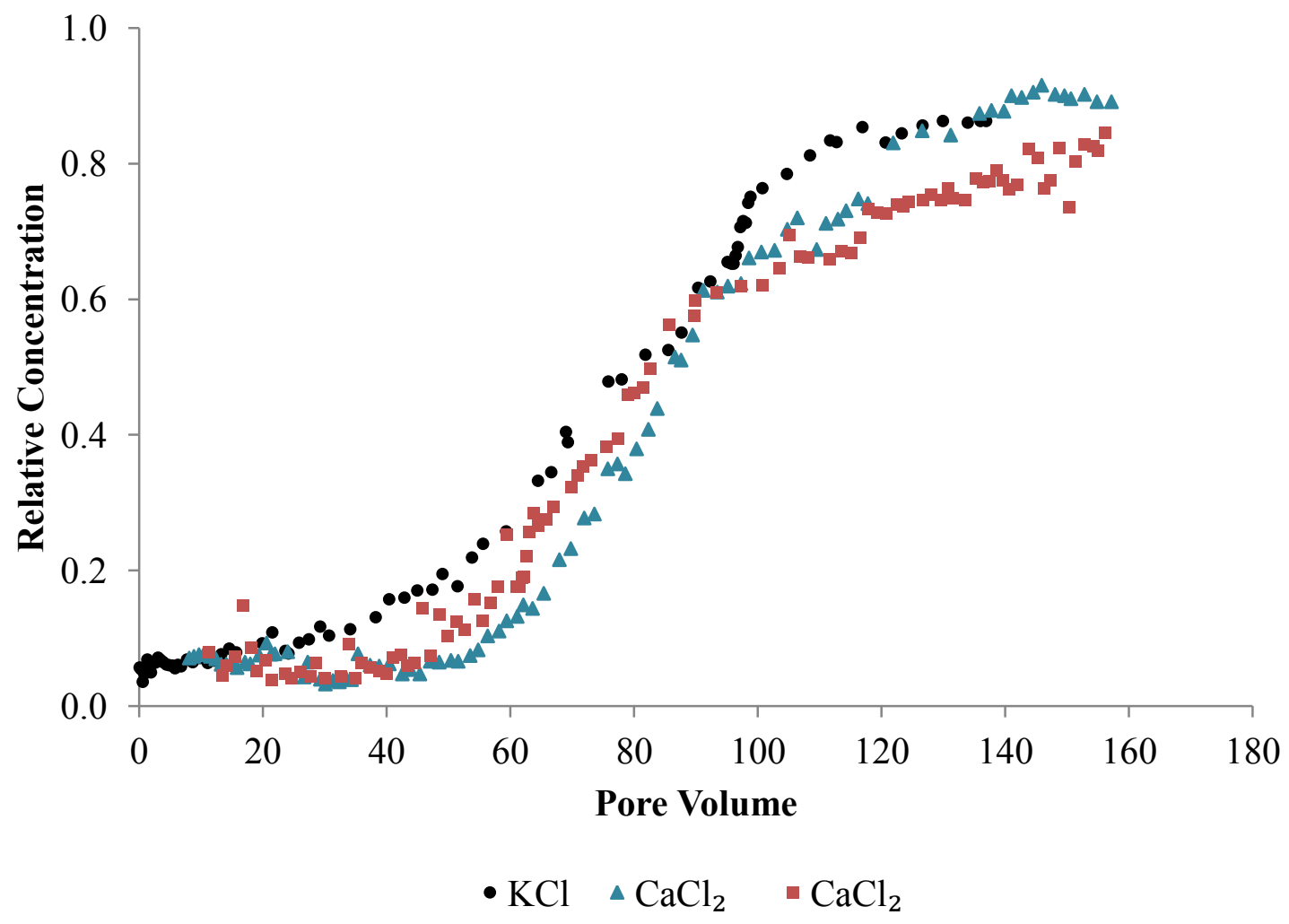

Figure 30: Comparison of $\mathrm{Al}_{2} \mathrm{O}_{3}$ Transport Study in $\mathrm{KCl}$ to a Higher Ionic Strength Study using $\mathrm{CaCl}_{2}$

All three transport studies conducted at $\mathrm{pH} 6$ using $100 \mathrm{mg} / \mathrm{L} \mathrm{Al}_{2} \mathrm{O}_{3}$ in either $\mathrm{KCl}(\mathrm{IS}=0.015 \mathrm{M})$ or $\mathrm{CaCl}_{2}$ (IS $=0.030 \mathrm{M}$ ) electrolyte solutions and at an average linear pore water velocity of $19 \mathrm{~cm} / \mathrm{h}$. The $\mathrm{KCl}$ transport study corresponds to Study \#3_pH 6 in this thesis while the $\mathrm{CaCl}_{2}$ transport studies were conducted previously within our research group.

\section{Collector Efficiency/First-order Reaction Rate Coefficient}

Classic colloid filtration theory speaks to the early deposition behavior at the initial stages of deposition with the assumption that the deposition rate coefficient $\left(k_{d}\right)$ is constant. This assumption points to a period, at this initial stage of deposition, where the relative effluent concentration is constant, occurring before the onset of blocking and the 
transition to "dynamic" transport conditions. The early low-concentration, steady-state transport behavior observed in the $\mathrm{pH} 6 \mathrm{Al}_{2} \mathrm{O}_{3}$ nanoparticle breakthrough curves, as highlighted in Figure 31, are in accordance with conditions under which deposition is deemed constant. Theoretical collector efficiencies predicted using various colloid

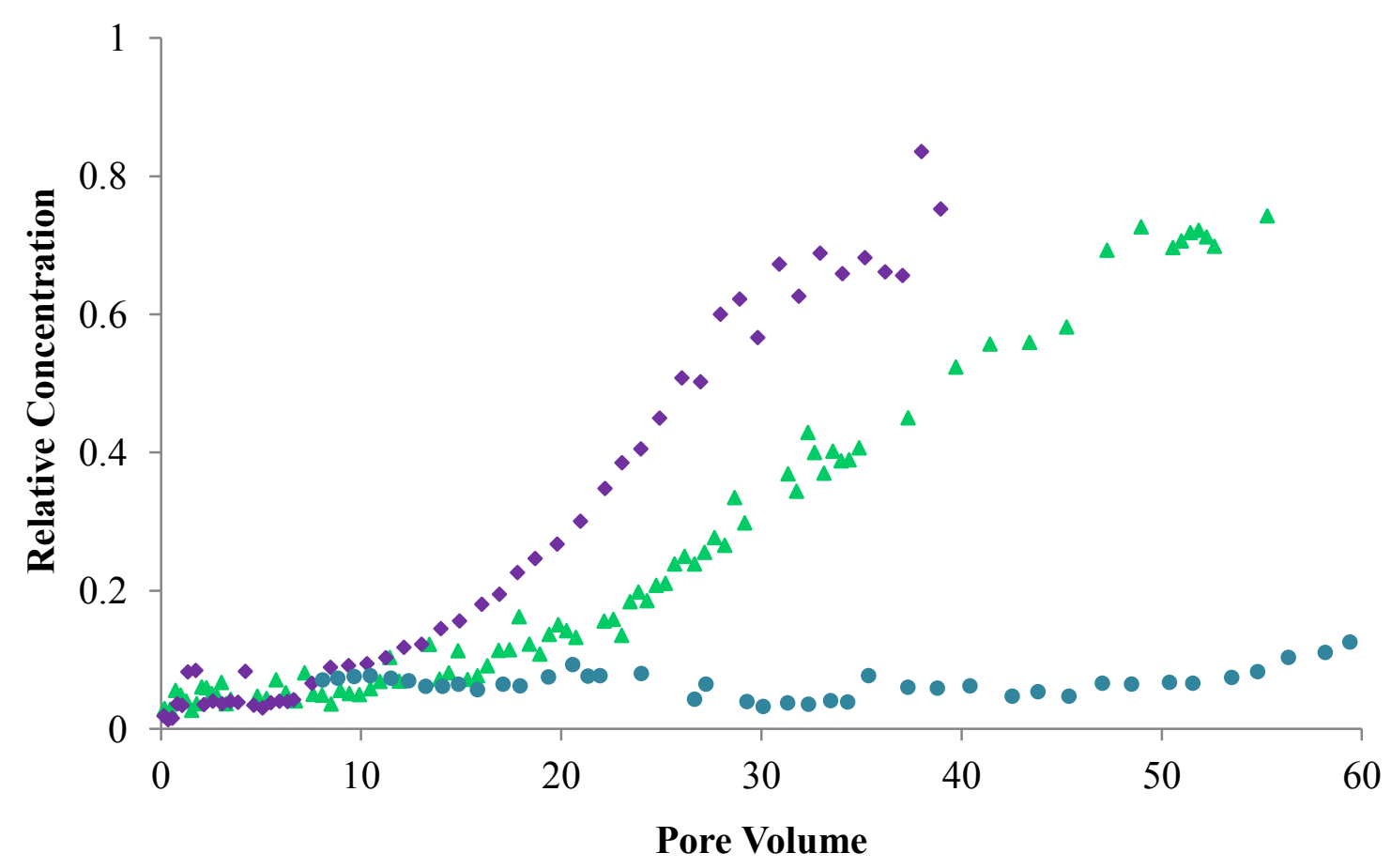

$$
\begin{aligned}
& \triangle 125 \mathrm{mg} / \mathrm{L} \mathrm{Al}_{2} \mathrm{O}_{3}(\mathrm{IS}=0.015 \mathrm{M}) \\
& -200 \mathrm{mg} / \mathrm{L} \mathrm{Al}_{2} \mathrm{O}_{3}(\mathrm{IS}=0.015 \mathrm{M}) \\
& -100 \mathrm{mg} / \mathrm{L} \mathrm{Al}_{2} \mathrm{O}_{3}(\mathrm{IS}=0.030 \mathrm{M})
\end{aligned}
$$

Figure 31: $\mathrm{Al}_{2} \mathrm{O}_{3}$ Early Transport Behavior - Favorable Attachment Conditions The $200 \mathrm{mg} / \mathrm{L} \mathrm{Al}{ }_{2} \mathrm{O}_{3}$ transport experiment is Study pH 6_1 with the remaining experiments previously conducted within our research group. All experiments conducted at $\mathrm{pH} 6$ and a darcy velocity of 0.10 $\mathrm{cm} / \min (v=18.4-20.2 \mathrm{~cm} / \mathrm{h})$. 
deposition models and compared to those determined experimentally are shown in Table 4 and Table 5. The Yao model (30) consistently under-predicted our experimental results while the Tufenkji and Elimelech model (32) over-predicted $\mathrm{Al}_{2} \mathrm{O}_{3}$ deposition relative to our experimentally determined single-collector efficiencies across all aqueous-phase concentrations $(25-200 \mathrm{mg} / \mathrm{L})$ and ionic strength $(0.015-0.030 \mathrm{M})$ conditions (Table 4).

Table 4: Theoretical single-collector efficiencies $(\eta)$ compared to experimental singlecollector efficiencies $\left(\eta_{\text {exp }}\right)$ from $\mathrm{Al}_{2} \mathrm{O}_{3} \mathrm{pH} 6$ nanoparticle transport experiments

\begin{tabular}{|c|c|c|c|c|}
\hline $\begin{array}{c}\mathrm{Al}_{2} \mathrm{O}_{3} \\
\text { Concentration } \\
(\mathrm{mg} / \mathrm{L})\end{array}$ & $\begin{array}{c}\text { Ionic } \\
\text { Strength } \\
(\mathrm{M})\end{array}$ & $\begin{array}{c}\text { Yao et al. } \\
(30) \\
\eta\end{array}$ & $\begin{array}{c}\text { Tufenkji and } \\
\text { Elimelech } \\
(32) \\
\eta\end{array}$ & $\eta_{\exp }$ \\
\hline 25 & 0.015 & 0.017 & 0.050 & 0.044 \\
125 & 0.015 & 0.017 & 0.050 & 0.048 \\
125 & 0.015 & 0.017 & 0.051 & 0.042 \\
200 & 0.015 & 0.017 & 0.052 & 0.044 \\
100 & 0.030 & 0.018 & 0.037 & 0.031 \\
100 & 0.030 & 0.019 & 0.038 & 0.033 \\
\hline
\end{tabular}

Conversely, the Nelson and Ginn model (43) consistently under-predicted collector efficiencies relative to those experimentally-determined values across the same experimental conditions (Table 5). The discrepancy between these models as a predicting tool for deposition under clean bed conditions as compared to experimentally-determined deposition results are similar to those previously reported. 
Table 5: Theoretical collector efficiencies $(\eta)$ compared to experimental collector efficiencies $\left(\eta_{\text {exp }}\right)$ from $\mathrm{Al}_{2} \mathrm{O}_{3}$ pH 6 nanoparticle transport experiments

\begin{tabular}{|c|c|c|c|}
\hline $\begin{array}{c}\text { Concentration } \\
(\mathrm{mg} / \mathrm{L})\end{array}$ & Ionic Strength $(\mathrm{M})$ & $\begin{array}{c}\text { Nelson and Ginn (43) } \\
\eta\end{array}$ & $\eta_{\exp }$ \\
\hline 25 & 0.015 & 0.025 & 0.034 \\
125 & 0.015 & 0.026 & 0.038 \\
125 & 0.015 & 0.025 & 0.033 \\
200 & 0.015 & 0.027 & 0.035 \\
100 & 0.030 & 0.019 & 0.024 \\
100 & 0.030 & 0.020 & 0.026 \\
\hline
\end{tabular}

Across all pH6 $\mathrm{Al}_{2} \mathrm{O}_{3}$ nanoparticle transport experiments conducted within our research group, the Yao model under-predicts the reaction rate coefficient by $69-189 \%$, the Tufenkji and Elimelech model over-predicts by $4-17 \%$, and the Nelson and Ginn model under-predicts by $26-49 \%$ (Table 6). These results are in relative agreement to what Nelson and Ginn (2011) found when comparing the Tufenkji and Elimelech (2004) model and their own model with experimental data wherein the TE model over-predicted reaction rate coefficients, particularly for nanoscale particles, while the NG model was found to under-predict primarily in the sub-micron size region. 
Table 6: Experimental and Theoretical Reaction Rate Coefficients- Favorable Attachment Condition Experiments (pH 6)

\begin{tabular}{|c|c|c|c|c|c|c|c|c|}
\hline \multirow[b]{2}{*}{$\begin{array}{c}\mathrm{Al}_{2} \mathrm{O}_{3} \\
\text { Concentration } \\
(\mathrm{mg} / \mathrm{L})\end{array}$} & \multirow[b]{2}{*}{$\begin{array}{l}\text { Ionic } \\
\text { Strength } \\
\text { (M) }\end{array}$} & \multirow[b]{2}{*}{$\begin{array}{c}k_{\mathrm{d}} \\
\text { experimental } \\
\left(\mathrm{s}^{-1}\right)\end{array}$} & \multicolumn{2}{|c|}{ Yao et al. (30) } & \multicolumn{2}{|c|}{$\begin{array}{c}\text { Tufenkji \& } \\
\text { Elimelech (32) }\end{array}$} & \multicolumn{2}{|c|}{$\begin{array}{c}\text { Nelson \& Ginn } \\
\text { (43) }\end{array}$} \\
\hline & & & $\begin{array}{c}k_{\mathrm{d}} \\
\text { predicted } \\
\left(\mathrm{s}^{-1}\right)\end{array}$ & $\begin{array}{c}\% \\
\text { Difference }\end{array}$ & $\begin{array}{c}k_{\mathrm{d}} \\
\text { predicted } \\
\left(\mathrm{s}^{-1}\right)\end{array}$ & $\begin{array}{c}\% \\
\text { Difference }\end{array}$ & $\begin{array}{c}k_{\mathrm{d}} \\
\text { predicted } \\
\left(\mathrm{s}^{-1}\right)\end{array}$ & $\begin{array}{c}\% \\
\text { Difference }\end{array}$ \\
\hline 25 & 0.015 & 0.0033 & 0.0013 & -155 & 0.0038 & 12 & 0.0025 & -36 \\
\hline 125 & 0.015 & 0.0040 & 0.0014 & -189 & 0.0041 & 4 & 0.0027 & -49 \\
\hline 125 & 0.015 & 0.0031 & 0.0013 & -142 & 0.0037 & 17 & 0.0024 & -28 \\
\hline 200 & 0.015 & 0.0036 & 0.0014 & -158 & 0.0043 & 15 & 0.0028 & -31 \\
\hline 100 & 0.03 & 0.0025 & 0.0015 & -69 & 0.0030 & 17 & 0.0020 & -26 \\
\hline 100 & 0.03 & 0.0027 & 0.0015 & -77 & 0.0031 & 14 & 0.0020 & -31 \\
\hline
\end{tabular}




\section{CONCLUDING REMARKS}

Colloid filtration theory (typically) describes the initial stages of deposition under "clean bed" conditions while assuming a monodisperse colloid in a monovalent electrolyte solution. Additionally, the theory assumes spherical colloids and collectors of uniform surface charge. In contrast, the $\mathrm{Al}_{2} \mathrm{O}_{3}$ in this research is a polydisperse nanocolloid. Furthermore, the porous media employed here is a natural porous media, and while a fairly uniform quartz sand, does contain a small amount of metal oxide impurities within the crystalline structure and likely does not have a uniform surface charge. For example, scanning electron microscopy (SEM) analysis of the Accusand employed in these transport experiments showed quartz sand grains with rough heterogeneous surfaces and metal impurities (e.g., iron and aluminum oxide). While our experimental conditions are not ideal with regard to what is typically assumed under colloid filtration theory, the transport behavior observed, for the most part, supports colloid filtration theory. More importantly, the large input pulses and smaller approach velocities employed in our transport studies serve to illustrate that $\mathrm{Al}_{2} \mathrm{O}_{3}$ nanoparticles are mobile across the range of chemical conditions employed in these experiments. Future research will further examine the impact of counterion valence on transport of positively charged $\mathrm{Al}_{2} \mathrm{O}_{3}$ nanoparticles using a $\mathrm{CaSO}_{4}$ electrolyte solution under the same experimental conditions as our $\mathrm{pH} 6$ experiments using $\mathrm{CaCl}_{2}$. Additionally, transport experiments will be performed using, again under favorable attachment conditions, to ascertain what impact, if any, a multi-valent counter anion has on $\mathrm{Al}_{2} \mathrm{O}_{3}$ nanoparticle 
transport. Measurement of the impact of natural organic matter, in the form of humic acid, and the subsequent effect on the overall transport behavior of these $\mathrm{Al}_{2} \mathrm{O}_{3}$ nanoparticles will also be assessed.

This current research has shown that, under environmentally relevant groundwater conditions, nanocolloids associated with biosolids, specifically $\mathrm{Al}_{2} \mathrm{O}_{3}$, are mobile through saturated porous media. Mobility increased under conditions in which the nanoparticles and porous media were of like charge; observed under high $\mathrm{pH}$ conditions such as those occurring with the land-application of lime-stabilized biosolids. The use of calcium chloride electrolyte solution in transport studies resulted in enhanced mobility relative to potassium chloride suggesting that changes in groundwater solution chemistry could impact mobility of contaminants associated with biosolids. Given the ubiquity of nanoscale materials, in particular nano-particles, in the environment coupled with the expected increases in biosolid generation and land-application, a clear understanding of their transport and fate is necessary to assess the potential for contaminant transport and the facilitated transport of toxins through the subsurface and into our surface and groundwater bodies. 


\section{REFERENCES}

1. Daughton, C. G.; Ternes, T. A. Pharmaceuticals and Personal Care Products in the Environment: Agents of Subtle Change? Environmental Health Perspectives 1999, 107, 907-938.

2. Kolpin, D. W.; Furlong, E. T.; Meyer, M. T.; Thurman, E. M.; Zaugg, S. D.; Barber, L. B.; Buxton, H. T. Pharmaceuticals, Hormones, and Other Organic Wastewater Contaminants in U.S. Streams, 1999-2000: A National Reconnaissance.

Environmental Science and Technology 2002, 36, 1202-1211.

3. Ellis, J. B. Pharmaceutical and personal care products (PPCPs) in urban receiving waters. Environmental Pollution 2006, 144, 184-189.

4. Yu, C.-P.; Chu, K.-H. Occurence of pharmaceuticals and personal care products along the West Prong Little Pigeon River in east Tennessee, USA. Chemosphere 2009, 75, 1281-1286.

5. Dougherty, J. A.; Swarzenski, P. W.; Dinicola, R. S.; Reinhard, M. Occurence of Herbicides and Pharmaceutical and Personal Care Products in Surface Water and Groundwater around Liberty Bay, Puget Sound, Washington. Journal of Environmental Quality 2010, 39 (4), 1173-1180.

6. Schultz, M. M.; Furlong, E. T.; Kolpin, D. W.; Werner, S. L.; Schoenfuss, H. L.; Barber, L. B.; Blazer, V. S.; Norris, D. O.; Vaida, A. M. Antidepressant pharmaceuticals in two U.S. effluent-impacted streams: occurence and fate in water and sediment, and selective uptake in fish neural tissue. Environmental Science and Technology 2010, 44 (6), 1918-1925.

7. Morace, J. L. Reconnaissance of Contaminants in Selected Wastewater-TreatmentPlant Effluent and Stormwater Runoff Entering the Columbia River, Columbia River Basin, Washington and Oregon, 2008-10; U.S. Geological Survey Scientific Investigations Report 2012-5068, 2012.

8. Cientifica Ltd. Half Way to the Trillion Dollar Market? A Critical Review of the Diffusion of Nanotechnologies; London, 2007.

9. Zhang, T. C.; Surampalli, R. Y.; Lai, K. C. K.; Hu, Z.; Tyagi, R. D.; Lo, I. M. C. Nanotechnologies for Water Environment Applications ; American Society of Civil Engineers: Reston, 2009. 
10. U.S. Environmental Protection Agency. Biosolids Generation, Use, and Disposal in The United States; U.S. EPA Municipal and Industrial Solid Waste Divison: EPA 530R-99-009, 1999.

11. North East Biosolids and Residuals Association (NEBRA). A National Biosolids Regulation, Quality, End Use \& Disposal Survey Final Report;, 2007.

12. Xia, K.; Bhandari, A.; Das, K.; Pillar, G. Occurence and Fate of Pharmaceuticals and Personal Care Products (PPCPs) in Biosolids. Journal of Environmental Quality 2005, 34, 91-104.

13. Kinney, C. A.; Furlong, E. T.; Burkhardt, M. R.; Werner, S. L.; Cahill, J. D.; Jorgensen, G. R. Survey of Organic Wastewater Contaminants in Biosolids Destined for Land Application. Environmental Science and Technology 2006, 40, 7207-7215.

14. U.S. Environmental Protection Agency. Targeted National Sewage Sludge Survey: Sampling and Analysis Technical Report; U.S. Environmental Protection Agency Office of Water: EPA 822-R-08-016, 2009.

15. Chari, B. P.; Halden, R. U. Validation of mega composite sampling and nationwide mass inventories for 26 previously unmonitored contaminants in archived biosolids from the U.S. National Biosolids Repository. Water Research 2012, 46, 4814-4824.

16. Jaynes, W. F.; Zartman, R. E. Origin of Talc, Iron Phosphates, and Other Minerals in Biosolids. Soil Science Society of America Journal 2005, 69, 1047-1056.

17. Karathanasis, A. D.; Johnson, D. M. C.; Matocha, C. J. Biosolid Colloid-Mediated Transport of Copper, Zinc, and Lead in Waste-Amended Soils. Journal of Environmental Quality 2005, 34, 1153-1164.

18. Lapen, D. R.; Topp, E.; Metcalfe, C. D.; Li, H.; Edwards, M.; Gottschall, N.; Bolton, P.; Curnoe, W.; Payne, M.; Beck, A. Pharmaceutical and personal care products in tile drainage following land application of municipal biosolids. Science of the Total Environment 2008, 399, 50-65.

19. Edwards, M.; Topp, E.; Metcalfe, C. D.; Li, H.; Gottschall, N.; Bolton, P.; Curnoe, W.; Payne, M.; Beck, A.; Kleywegt, S.; Lapen, D. R. Pharmaceutical and personal care products in tile drainage following surface spreading and injection of dewatered municipal biosolids to an agricultural field. Science of the Total Environment 2009, 407, 4220-4230. 
20. Gottschall, N.; Topp, E.; Metcalfe, C.; Edwards, M.; Payne, M.; Kleywegt, S.; Russell, P.; Lapen, D. R. Pharmaceutical and personal care products in groundwater, subsurface drainage, soil, and wheat grain, following a high single application of municipal biosolids to a field. Chemosphere 2012, 87, 194-203.

21. Grolimund, D.; Borkovec, M.; Barmettler, K.; Sticher, H. Colloid -Facilitated Transport of Strongly Sorbing Contaminants in Natural Porous Media: A Laboratory Column Study. Environmental Science and Technology 1996, 30, 3118-3123.

22. Roy, S. B.; Dzombak, D. A. Chemical Factors Influencing Colloid-Facilitated Transport of Contaminants in Porous Media. Environmental Science and Technology 1997, 31, 656-664.

23. Karathanasis, A. D.; Ming, D. W. Colloid-Mediated Transport of Metals Associated with Lime-Stabilized Biosolids. Developments in Soil Science 2002, 28A, 49-62.

24. de Jong, L. W.; Kjaergaard, C.; Moldrup, P. Colloids and Colloid-Facilitated Transport of Contaminants in Soils: An Introduction. Vadose Zone Journal 2004, 3, 321-325.

25. Lecoanet, H. F.; Bottero, J. Y.; Wiesner, M. R. Laboratory Assessment of the Mobility of Nanomaterials in Porous Media. Environmental Science and Technology 2004, 38 (19), 5164-5169.

26. Doshi, R.; Braida, W.; Christodoulatos, C.; Wazne, M.; O'Conner, G. NanoAluminum: Transport Through Sand Columns and Environmental Effects on Plants and Soil Communities. Environmental Research 2008, 106, 296-303.

27. Wang, H.; Wick, R. L.; Xing, B. Toxicity of Nanoparticle and Bulk ZnO, Al2O3 and TiO2 to the Nematode Caenorhabditis elegans. Environmental Pollution 2009, 157, 1171-1177.

28. Hiemenz, P. C. Principles of Colloid and Surface Chemistry, 2nd ed.; Marcel Dekker: New York, 1986.

29. Elimelech, M.; Gregory, J.; Jia, X.; Williams, R. A. Particle Aggregation and Deposition: Measurement, Modeling, and Simulation, 1st ed.; ButterworthHeinemann: Oxford, 1995.

30. Yao, K.; Habibian, M. T.; O'Melia, C. R. Water and Waste Water Filtration: Concepts and Applications. Environmental Science and Technology 1971, 5 (11), 1105-1112. 
31. O'Melia, C. R. Aquasols: The Behavior of Small Particles in Aquatic Systems. Environmental Science and Technology 1980, 14 (9), 1052-1060.

32. Tufenkji, N.; Elimelech, M. Correlation Equation for Predicting Single-Collector Efficiency in Physicochemical Filtration in Saturated Porous Media. Environmental Science and Technology 2004, 38 (2), 529-536.

33. Petosa, A.; Jaisi, D. P.; Quevedo, I. R.; Elimelech, M.; Tufenkji, N. Aggregation and Deposition of Engineered Nanoparticles in Aquatic Environments: Role of Physicochemical Filtration. Environmental Science and Technology 2010, 44, 65326549.

34. Verway, E. J. W.; Overbeek, J. T. G. Theory of the Stability of Lyophobic Colloids; Elsevier Publishing: New York, 1948.

35. McCarthy, J. F.; Zachara, J. M. Subsurface Transport of Contaminants. Environmental Science and Technology 1989, 23 (5), 496-502.

36. McCarthy, J. F.; McKay, L. D. Colloid Transport in the Subsurface: Past, Present, and Future Challenges. Vadose Zone Journal 2004, 3, 326-337.

37. Ryan, J. N.; Elimelech, M. Review: Colloid Mobilization and Transport in Groundwater. Colloids and Surfaces A: Physicochemical and Engineering Aspects 1996, 107, 1-56.

38. Hahn, M. W. Aquasols: On the Role of Secondary Minima. Environmental Science and Technology 2004, 38 (22), 5915-5924.

39. N, T.; Redman, J. A.; Elimelech, M. Interpreting Deposition Patterns of Microbial Particles in Laboratory-Scale Column Experiments. Environmental Science and Technology 2003, 37 (3), 616-623.

40. Ko, C.; Elimelech, M. The "Shadow Effect" in Colloid Transport and Deposition Dynamics in Granular Porous Media: Measurements and Mechanisms. Environmental Science and Technology 2000, 34 (17), 3681-3689.

41. Loveland, J. P.; Bhattacharjee, S.; Ryan, J. N.; Elimelech, M. Colloid Transport in Geochemically Heterogeneous Porous Media: Aquifer Tank Experiment and Modeling. Journal of Contaminant Hydrology 2003, 65, 161-182.

42. Liu, D.; Johnson, P. R.; Elimelech, M. Colloid Deposition in Flow Through Porous Media: Role of Electrolyte Concentration. Environmental Science and Technology 1995, 29 (12), 2963-2973. 
43. Nelson, K. E.; Ginn, T. R. New Collector Efficiency Equation for Colloid Filtration in Both Natural and Engineered Flow Conditions. Water Resources Research 2011, 47, $1-17$.

44. Elimelch, M. Effect of Particle Size on the Kinetics of Particle Deposition Under Attractive Double Layer Interactions. Journal of Colloid and Interface Science 1994, 164, 190-199.

45. Elimelech, M. Kinetics of Capture of Colloidal Particles in Packed Beds Under Attractive Double Layer Interactions. Journal of Colloid and Interface Science 1991, $146(2), 337-351$.

46. Reerink, H.; Overbeek, J. T. G. The Rate of Coagulation as a Measure of the Stability of Silver Iodide Sols. Discussions of the Faraday Society 1954, 18, 74-84.

47. Tufenkji, N.; Elimelech, M. Deviation from the Classical Colloid Filtration Theory in the Presence of Repulsive DLVO Interactions. Langmuir 2004, 20, 10818-10828.

48. Pelley, A. J.; Tufenkji, N. Effect of Particle Size and Natural Organic Matter on the Migration of Nano- and Microscale Latex Particles in Saturated Porous Media. Journal of Colloid and Interface Science 2008, 321, 74-83.

49. Elimelech, M.; O'Melia, C. R. Effect of Particle Size on Collision Efficiency in the Deposition of Brownian Particles with Electrostatic Energy Barriers. Langmuir 1990, 6, 1153-1163.

50. Litton, G. M.; Olson, T. M. Particle Size Effects on Colloid Deposition Kinetics: Evidence of Secondary Minimum Deposition. Colloids and Surfaces A:Physicochemical and Engineering Aspects 1996, 107, 273-283.

51. Bradford, S. A.; Yates, S. R.; Bettahar, M.; Simunek, J. Physical Factors Affecting the Transport and Fate of Colloids in Saturated Porous Media. Water Resources Research 2002, 38 (12), 63-1 - 63-12.

52. Tufenkji, N.; Elimelech, M. Breakdown of Colloid Filtration Theory: Role of the Secondary Minimum and Surface Charge Heterogeneity. Langmuir 2005, 21, 841852.

53. Hahn, M. W.; O'Melia, C. R. Deposition and Reentrainment of Brownian Particles in Porous Media under Unfavorable Chemical Conditions: Some Concepts and Applications. Environmental Science and Technology 2004, 38 (1), 210-220. 
54. Elimelech, M.; O'Melia, C. R. Kinetics of Deposition of Colloidal Particles in Porous Media. Environmental Science and Technology 1990, 24, 1528-1536.

55. Tufenkji, N.; Miller, G. F.; Ryan, J. N.; Harvey, R. W.; Elimelech, M. Transport of Cryptosporidium Oocysts in Porous Media: Role of Straining and Physcicochemical Filtration. Environmental Science and Technology 2004, 38, 5932-5938.

56. Song, L.; Johnson, P. R.; Elimelech, M. Kinetics of Colloid Deposition onto Heterogeneously Charged Surfaces in Porous Media. Environmental Science and Technology 1994, 28, 1164-1171.

57. Ryan, J. N.; Gschwend, P. M. Effects of Ionic Strength and Flow Rate on Colloid Release: Relating Kinetics to Intersurface Potential Energy. Journal of Colloid and Interface Science 1994, 164, 21-34.

58. Schroth, M. H.; Ahearn, S. J.; Selker, J. S.; Istok, J. D. Characterization of MillerSimilar Silica Sands for Laboratory Hydrologic Studies. Soil Science Society of America Journal 1996, 60, 1331-1339.

59. Johnson, P. R.; Sun, N.; Elimelech, M. Colloid Transport in Geochemically Heterogenous Porous Media: Modeling and Measurements. Environmental Science and Technology 1996, 30, 3284-3293.

60. U.S. Environmental Protection Agency. Nanotechnology White Paper; Office of the Science Advisor, 2007.

61. Nowack, B.; Bucheli, T. D. Occurence, Behavior, and Effects of Nanoparticles in the Environment. Environmental Pollution 2007, 150, 5-22.

62. Christian, P.; Von der Kammer, F.; Baalousha, M.; Hofmann, T. Nanoparticles: Structure, Properties, Preparation, and Behaviour in Environmental Media. Ecotoxicology 2008, 17, 326-343.

63. Hotze, E. M.; Phenrat, T.; Lowry, G. V. Nanoparticle Aggregation: Challenges to Understanding Transport and Reactivity in the Environment. Journal of Environmental Quality 2010, 39, 1909-1924.

64. Chen, K. L.; Elimelech, M. Aggregation and Deposition Kinetics of Fullerene (C60) Nanoparticles. Langmuir 2006, 22, 10994-11001.

65. Chowdury, I.; Hong, Y.; Walker, S. L. Container to Characterization: Impacts of Metal Oxide Handling, Preparation, and Solution Chemistry on Particle Stability. Colloids and Surfaces A: Physicochemical and Engineering Aspects 2010, 368, 91-95. 
66. Keller, A. A.; Wang, H.; Zhou, D.; Lenihan, H. S.; Cherr, G.; Cardinale, B. J.; Miller, R.; Ji, Z. Stability and Aggregation of Metal Oxide Nanoparticles in Natural Aqueous Matrices. Environmental Science and Technology 2010, 44 (6), 1962-1967.

67. Shen, C.; Huang, Y.; Li, B.; Jin, Y. Predicting Attachment Efficiency of Colloid Deposition Under Unfavorable Attachment Conditions. Water Resources Research 2010, 46, 1-12.

68. Franchi, A.; O'Melia, C. R. Effects of Natural Organic Matter and Solution Chemistry on th Deposition and Reentrainment of Colloids in Porous Media. Environmental Science and Technology 2003, 37 (6), 1122-1129.

69. Baalousha, M. Aggregation and Disaggregation of Iron Oxide Nanoparticles: Influence of Particle Concentration, $\mathrm{pH}$, and Natural Organic Matter. Science of the Total Environment 2009, 407, 2093-2101.

70. Domingos, R. F.; Tufenkji, N.; Wilkinson, K. J. Aggregation of Titanium Dioxide Nanoparticles Role of Fulvic Acid. Environmental Science and Technology 2009, 43 (5), 1282-1286.

71. Wiesner, M. R.; Lowry, G. V.; Alvarez, P.; Dionysiou, D.; Biswas, P. Assessing the Risks of Manufactured Nanomaterials. Environmental Science and Technology 2006, 40, 4336-4345.

72. Strigual, N.; Vaccari, L.; Galdun, C.; Wazne, M.; Liu, X.; Christodoulatos, C.; Jasinkiewicz, K. Acute Toxicity of Boron, Titanium Dioxide, and Aluminum Nanoparticles to Daphnia magna and Vibrio fischeri. Desalination 2009, 248, 771782.

73. Chen, J.; Liu, M.; Zhang, J.; Ying, X.; Jin, L. Photocatalytic Degradation of Organic Wastes by Electrochemically Assisted TiO2 Photocatalytic System. Journal of Environmental Management 2004, 70, 43-47.

74. Aitken, R. J.; Chaudhry, M. Q.; Boxall, A. B. A.; Hull, M. Manufacture and Use of Nanomaterials" Current Status in the UK and Global Trends. Occupational Medicine 2006, 56, 300-306.

75. Kansal, S. K.; Singh, M.; Sud, D. Effluent Quality at Kraft/Soda Agro-based Paper Mills and its Treatment Using a Heterogeneous Photocatalytic System. Desalination 2008, 228, 183-190. 
76. Xiong, D.; Fang, T.; Yu, L.; Sima, X.; Zhu, W. Effects of Nano-Scale TiO2, ZnO and Their Bulk Counterparts on Zebrafish: Acute Toxicity, Oxidative Stress and Oxidative Damage. Science of the Total Environment 2011, 409, 1444-1452.

77. Stumm, W.; Sigg, L.; Sulzberger, B. Chemistry of the Solid-Water Interface: Processes at the Mineral-Water and Particle-Water Interface in Natural Systems; Wiley: New York, 1992.

78. Puls, R. W.; Powell, R. M. Transport of Inorganic Colloids Through natural Aquifer Material Implications for Contaminant Transport. Environmental Science and Technology 1992, 26, 614-621.

79. Lecoanet, H. F.; Wiesner, M. R. Velocity Effects on Fullerene and Oxide Nanoparticle Deposition in Porous Media. Environmental Science and Technology 2004, 38, 4377 4382.

80. Guzman, K. A. D.; Finnegan, M. P.; Banfield, J. F. Influence of Surface Potential on Aggregation and Transport of Titania Nanoparticles. Environmental Science and Technology 2006, 40, 7688-7693.

81. Ben-Moshe, T.; Dror, I.; Berkowitz, B. Transport of Metal Oxide Nanoparticles in Saturated Porous Media. Chemosphere 2010, 81, 387-393.

82. Chowdhury, I.; Hong, Y.; Honda, R. J.; Walker, S. L. Mechanisms of TiO2 nanoparticle Transport in Porous Media: Role of Solution Chemistry, nanoparticle Concentration, and Flowrate. Journal of Colloid and Interface Science 2011, 360, 548-555.

83. He, Y. T.; Wan, J. W.; Tokunaga, T. Kinetic stability of hematite nanoparticles: the effect of particle sizes. Journal of Nanoparticle Research 2008, 10 (2), 321-332.

84. Sposito, G. The Surface Chemistry of Soils; Oxford University Press: New York, 1984.

85. Sposito, G. The Environmental Chemistry of Aluminum, 2nd ed.; CRC Press: Berkeley, 1995.

86. Ghosh, S.; Mashayekhi, H.; Pan, B.; Bowmilk, P.; Xing, B. Colloidal Behavior of Aluminum Oxide Nanoparticles as Affected by $\mathrm{pH}$ and natural Organic matter. Langmuir 2008, 24, 12385-12391. 
87. Tombacz, E.; Dobos, A.; Szekeres, M.; Narres, H. D.; Klumpp, E.; Dekany, I. Effect of $\mathrm{pH}$ and Ionic Strength on the Interaction of Humic Acid with Aluminum Oxide. Colloid Polymer Science 2000, 278, 337-345.

88. Ghosh, S.; Mashayekhi, H.; Bhowmik, P.; Xing, B. Colloidal Stability of A12O3 Nanoparticles as Affected by Coating of Structurally Different Humic Acids. Langmuir 2009, 26 (2), 873-879.

89. Sprycha, R. Electrical Double Layer at Alumina/Electrolyte Interface 1. Surface Charge and Zeta Potential. Journal of Colloid and Interface Science 1989, 127 (1), 111 .

90. Liu, D. Chemical Aspects in the Dynamics of Particle Deposition in Porous Media; $\mathrm{PhD}$ Dissertation; University of California, Los Angeles, 1994.

91. van Genuchten. Non-equilibrium transport parameters from miscible displacement experiments; M.Th.; USDA Salinity Laboratory: Riverside, 1971.

92. Bergstrom, L. Hamaker constants of inorganic materials. Advances in Colloid and Interface Science 1997, 70, 125-169.

93. Tian, Y.; Gao, B.; Silvera-Batista, C.; Ziegler, K. J. Transport of Engineered Nanoparticles in Saturated Porous Media. Journal of Nanoparticle Research 2010, $12,2371-2380$. 


\section{APPENDIX - EXPERIMENTAL DATA}

Table 7: Non-Reactive Tracer Study Data - Study \#1_pH 6_NRT

Performed for $\mathrm{Al}_{2} \mathrm{O}_{3}$ Study \#1_pH 6

Column: C

Darcy Velocity: 0.098/min

Electrolyte: $\mathrm{CaCl}_{2}$

Ionic Strength: $0.015 \mathrm{M}$

Data results for pentafluorobenzoic acid transport Study \#1_pH 6_NRT; Samples 1 - 27.

\begin{tabular}{|c|c|c|c|c|c|}
\hline Sample & $\begin{array}{c}\text { Pore } \\
\text { Volume } \\
(\mathrm{mL})\end{array}$ & $\begin{array}{c}\text { UV-Vis } \\
\text { Abs }\end{array}$ & Dilution & $\mathrm{C} / \mathrm{C}_{\mathrm{o}}$ & \\
\hline 1 & -0.507 & 0.003 & 1 & -0.004 & LDL \\
\hline 2 & -0.299 & 0.000 & 1 & -0.005 & LDL \\
\hline 3 & -0.093 & -0.002 & 1 & -0.006 & LDL \\
\hline 4 & 0.122 & 0.004 & 1 & -0.004 & LDL \\
\hline 5 & 0.334 & 0.256 & 1 & 0.032 & \\
\hline 6 & 0.553 & 2.057 & 1 & 0.265 & \\
\hline 7 & 0.772 & 1.571 & 3.0 & 0.612 & \\
\hline 8 & 0.979 & 2.063 & 3.0 & 0.805 & \\
\hline 9 & 1.222 & 2.273 & 3.0 & 0.886 & \\
\hline 10 & 1.467 & 2.374 & 3.0 & 0.926 & \\
\hline 11 & 1.695 & 2.395 & 3.0 & 0.935 & \\
\hline 12 & 1.941 & 2.441 & 3.0 & 0.952 & \\
\hline 13 & 2.191 & 2.453 & 3.0 & 0.957 & \\
\hline 14 & 2.413 & 2.465 & 3.0 & 0.961 & \\
\hline 15 & 2.708 & 2.506 & 3.0 & 0.978 & \\
\hline 16 & 3.101 & 2.506 & 3.0 & 0.976 & \\
\hline 17 & 3.537 & 2.520 & 3.0 & 0.981 & \\
\hline 18 & 3.946 & 2.534 & 3.0 & 0.987 & \\
\hline 19 & 5.356 & 2.550 & 3.0 & 0.994 & \\
\hline 20 & 6.232 & 2.534 & 3.0 & 0.993 & \\
\hline 21 & 7.122 & 2.565 & 3.0 & 1.003 & \\
\hline 22 & 8.077 & 2.565 & 3.0 & 1.000 & \\
\hline 23 & 9.006 & 2.565 & 3.0 & 1.000 & \\
\hline 24 & 9.901 & 2.550 & 3.0 & 0.995 & \\
\hline 25 & 10.796 & 2.550 & 3.0 & 0.997 & \\
\hline 26 & 11.789 & 2.550 & 3.0 & 0.994 & \\
\hline 27 & 12.761 & 2.550 & 3.0 & 0.997 & \\
\hline
\end{tabular}


Table 7 (Continued): Non-Reactive Tracer Study Data - Study \#1_pH 6_NRT

Data results for pentafluorobenzoic acid transport Study \#1_pH 6_NRT; Samples 28 - 53.

\begin{tabular}{|c|c|c|c|c|c|}
\hline Sample & $\begin{array}{c}\text { Pore } \\
\text { Volume } \\
(\mathrm{mL})\end{array}$ & $\begin{array}{c}\text { UV-Vis } \\
\text { Abs }\end{array}$ & Dilution & $\mathrm{C} / \mathrm{C}_{\mathrm{o}}$ & \\
\hline 28 & 13.099 & 2.550 & 3.0 & 0.993 & Elution \\
\hline 29 & 13.399 & 2.550 & 3.0 & 0.992 & \\
\hline 30 & 13.632 & 2.534 & 3.0 & 0.989 & \\
\hline 31 & 13.854 & 2.479 & 3.0 & 0.966 & \\
\hline 32 & 14.102 & 1.845 & 3.0 & 0.718 & \\
\hline 33 & 14.355 & 2.675 & 1 & 0.346 & \\
\hline 34 & 14.606 & 1.217 & 1 & 0.155 & \\
\hline 35 & 14.842 & 0.712 & 1 & 0.091 & \\
\hline 36 & 15.085 & 0.506 & 1 & 0.064 & \\
\hline 37 & 15.408 & 0.373 & 1 & 0.046 & \\
\hline 38 & 15.811 & 0.271 & 1 & 0.033 & \\
\hline 39 & 16.215 & 0.198 & 1 & 0.024 & \\
\hline 40 & 16.599 & 0.152 & 1 & 0.018 & \\
\hline 41 & 17.017 & 0.118 & 1 & 0.032 & \\
\hline 42 & 17.483 & 0.097 & 1 & 0.026 & \\
\hline 43 & 18.586 & 0.053 & 1 & 0.012 & \\
\hline 44 & 19.553 & 0.045 & 1 & 0.009 & \\
\hline 45 & 20.485 & 0.045 & 1 & 0.009 & \\
\hline 46 & 21.356 & 0.032 & 1 & 0.005 & \\
\hline 47 & 22.304 & 0.030 & 1 & 0.004 & \\
\hline 48 & 23.226 & 0.027 & 1 & 0.003 & \\
\hline 49 & 24.141 & 0.029 & 1 & 0.004 & \\
\hline 50 & 24.988 & 0.025 & 1 & 0.003 & \\
\hline 51 & 25.885 & 0.023 & 1 & 0.002 & \\
\hline 52 & 26.783 & 0.024 & 1 & 0.002 & \\
\hline 53 & 27.664 & 0.018 & 1 & 0.000 & LDL \\
\hline
\end{tabular}


Table 8: Aluminum Oxide Transport Data - Study \#1_pH 6

Concentration: $200 \mathrm{mg} / \mathrm{L}$

Column: C

Darcy Velocity: $0.098 \mathrm{~cm} / \mathrm{min}$

Electrolyte: $\mathrm{CaCl}_{2}$

Ionic Strength: $0.15 \mathrm{M}$

Data results for aluminum oxide nanoparticle transport Study \#1_pH 6; samples 1 - 27.

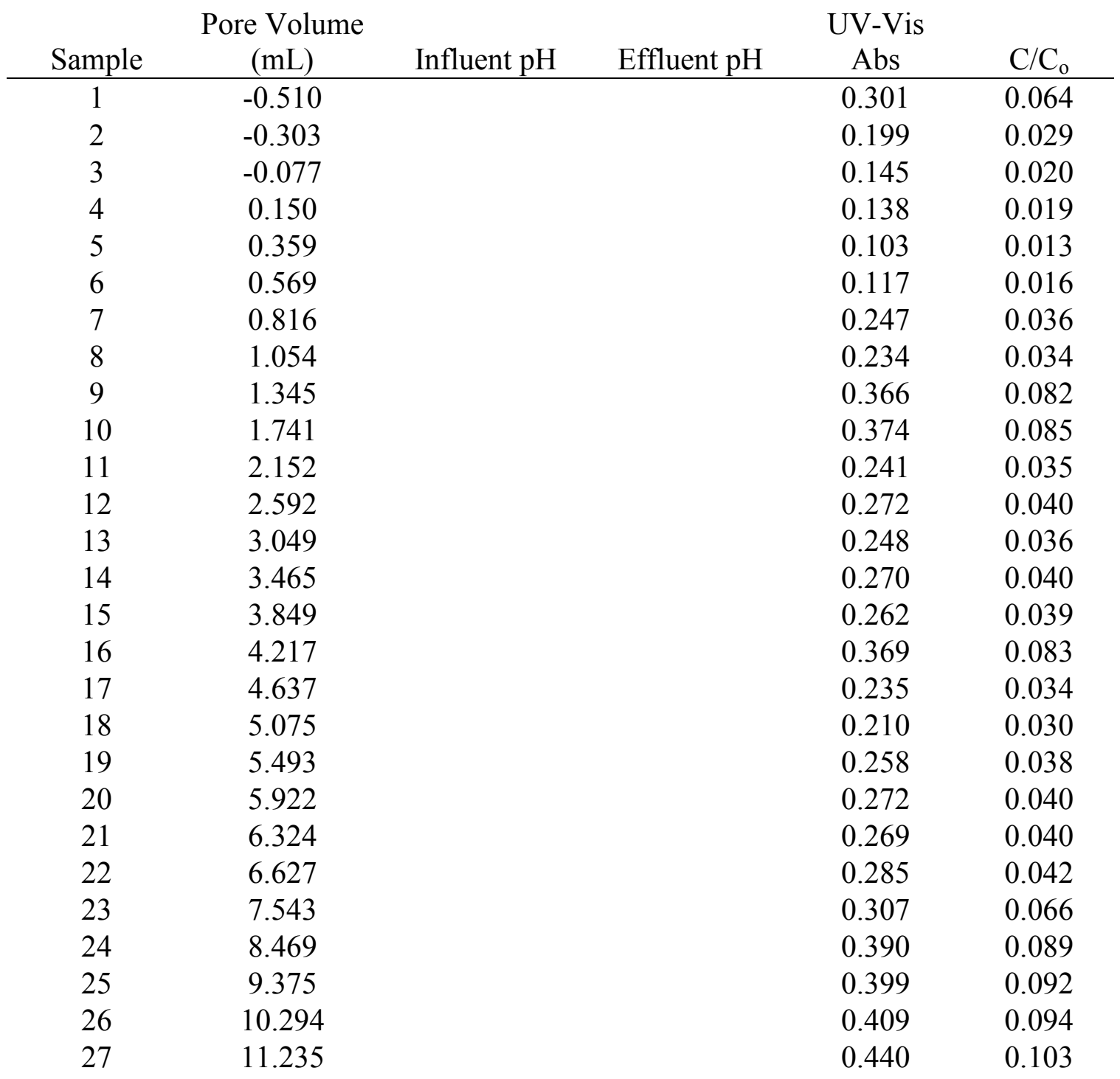


Table 8 (Continued): Aluminum Oxide Transport Data - Study \#1_pH 6

Data results for aluminum oxide nanoparticle transport Study \#1_pH 6; samples 28 - 61.

\begin{tabular}{|c|c|c|c|c|c|}
\hline Sample & $\begin{array}{l}\text { Pore Volume } \\
\quad(\mathrm{mL})\end{array}$ & Influent $\mathrm{pH}$ & Effluent $\mathrm{pH}$ & $\begin{array}{c}\mathrm{UV}-\mathrm{Vis} \\
\mathrm{Abs}\end{array}$ & $\mathrm{C} / \mathrm{C}_{\mathrm{o}}$ \\
\hline 28 & 12.141 & & & 0.494 & 0.118 \\
\hline 29 & 13.023 & & & 0.510 & 0.122 \\
\hline 30 & 13.986 & & & 0.591 & 0.145 \\
\hline 31 & 14.918 & & & 0.631 & 0.156 \\
\hline 32 & 15.473 & & & & \\
\hline 33 & 16.030 & 5.98 & & 0.718 & 0.180 \\
\hline 34 & 16.470 & 5.77 & 5.86 & & \\
\hline 35 & 16.911 & & & 0.770 & 0.195 \\
\hline 36 & 17.365 & & & & \\
\hline 37 & 17.811 & & & 0.883 & 0.226 \\
\hline 38 & 18.245 & & 5.86 & & \\
\hline 39 & 18.695 & & & 0.956 & 0.247 \\
\hline 40 & 19.223 & & & & \\
\hline 41 & 19.797 & & & 1.031 & 0.267 \\
\hline 42 & 20.303 & & 5.86 & & \\
\hline 43 & 20.959 & & & 1.150 & 0.301 \\
\hline 44 & 21.676 & & & & \\
\hline 45 & 22.186 & & & 1.255 & 0.348 \\
\hline 46 & 22.602 & 5.89 & 5.86 & & \\
\hline 47 & 23.033 & & & 1.382 & 0.385 \\
\hline 48 & 23.503 & & & & \\
\hline 49 & 23.976 & & & 1.450 & 0.405 \\
\hline 50 & 24.447 & & 5.8 & & \\
\hline 51 & 24.915 & & & 1.602 & 0.450 \\
\hline 52 & 25.475 & & & & \\
\hline 53 & 26.027 & & & 1.800 & 0.508 \\
\hline 54 & 26.471 & & 5.79 & & \\
\hline 55 & 26.958 & & & 1.781 & 0.502 \\
\hline 56 & 27.473 & & & & \\
\hline 57 & 27.951 & & & 2.114 & 0.600 \\
\hline 58 & 28.426 & & 5.8 & & \\
\hline 59 & 28.913 & & & 2.189 & 0.622 \\
\hline 60 & 29.371 & & & & \\
\hline 61 & 29.815 & & & 1.999 & 0.566 \\
\hline
\end{tabular}


Table 8 (Continued): Aluminum Oxide Transport Data - Study \#1_pH 6

Data results for aluminum oxide nanoparticle transport Study \#1_pH 6; samples 62 - 93.

\begin{tabular}{|c|c|c|c|c|c|c|}
\hline Sample & $\begin{array}{c}\text { Pore } \\
\text { Volume } \\
(\mathrm{mL})\end{array}$ & Influent $\mathrm{pH}$ & $\begin{array}{c}\text { Effluent } \\
\mathrm{pH}\end{array}$ & $\begin{array}{c}\text { UV-Vis } \\
\text { Abs }\end{array}$ & $\mathrm{C} / \mathrm{C}_{\mathrm{o}}$ & \\
\hline 62 & 30.338 & & 5.76 & & & \\
\hline 63 & 30.893 & & & 2.361 & 0.673 & \\
\hline 64 & 31.380 & & & & & \\
\hline 65 & 31.871 & & & 2.203 & 0.626 & \\
\hline 66 & 32.416 & & 5.83 & & & \\
\hline 67 & 32.934 & & & 2.415 & 0.688 & \\
\hline 68 & 33.458 & & & & & \\
\hline 69 & 34.047 & & & 2.314 & 0.659 & \\
\hline 70 & 34.612 & & 5.96 & & & \\
\hline 71 & 35.173 & & & 2.393 & 0.682 & \\
\hline 72 & 35.723 & & & & & \\
\hline 73 & 36.183 & & & 2.323 & 0.661 & \\
\hline 74 & 36.636 & & 5.82 & & & \\
\hline 75 & 37.051 & & & 2.305 & 0.656 & \\
\hline 76 & 37.537 & & & & & \\
\hline 77 & 37.999 & & & 2.916 & 0.836 & \\
\hline 78 & 38.472 & & & & & \\
\hline 79 & 38.957 & 5.93 & & 2.633 & 0.752 & \\
\hline 80 & 39.244 & & & 0.173 & 0.046 & $\begin{array}{c}7 \text { day Stop } \\
\text { Flow }\end{array}$ \\
\hline 81 & 39.450 & & & 0.133 & 0.034 & \\
\hline 82 & 39.647 & & & 0.122 & 0.031 & \\
\hline 83 & 39.834 & & & 0.141 & 0.036 & \\
\hline 84 & 40.029 & & & 0.337 & 0.097 & \\
\hline 85 & 40.239 & & & 1.023 & 0.315 & \\
\hline 86 & 40.456 & & & 1.759 & 0.548 & \\
\hline 87 & 40.679 & & & 2.141 & 0.669 & \\
\hline 88 & 40.913 & & 6.23 & 2.293 & 0.717 & \\
\hline 89 & 41.128 & & & 2.415 & 0.755 & \\
\hline 90 & 41.356 & & & 2.390 & 0.748 & \\
\hline 91 & 41.586 & & & 2.369 & 0.741 & \\
\hline 92 & 41.806 & & & 2.369 & 0.741 & \\
\hline 93 & 42.019 & & & 2.369 & 0.741 & \\
\hline
\end{tabular}


Table 8 (Continued): Aluminum Oxide Transport Data - Study \#1_pH 6

Data results for aluminum oxide nanoparticle transport Study \#1_pH 6; samples 94 - 127.

\begin{tabular}{|c|c|c|c|c|c|}
\hline Sample & $\begin{array}{l}\text { Pore Volume } \\
\qquad(\mathrm{mL})\end{array}$ & Influent $\mathrm{pH}$ & Effluent $\mathrm{pH}$ & $\begin{array}{c}\mathrm{UV}-\mathrm{Vis} \\
\mathrm{Abs}\end{array}$ & $\mathrm{C} / \mathrm{C}_{\mathrm{o}}$ \\
\hline 94 & 42.240 & & & 2.390 & 0.747 \\
\hline 95 & 42.488 & & & 2.412 & 0.754 \\
\hline 96 & 42.730 & & & 2.412 & 0.754 \\
\hline 97 & 42.940 & & 6.02 & 2.448 & 0.766 \\
\hline 98 & 43.142 & & & 2.448 & 0.766 \\
\hline 99 & 43.379 & & & 2.448 & 0.766 \\
\hline 100 & 43.612 & 5.95 & & 2.474 & 0.774 \\
\hline 101 & 43.855 & & & 2.474 & 0.774 \\
\hline 102 & 44.138 & & 5.91 & 2.501 & 0.783 \\
\hline 103 & 44.617 & & 6.76 & & \\
\hline 104 & 45.039 & & & 2.529 & 0.791 \\
\hline 105 & 45.477 & & 6.04 & & \\
\hline 106 & 45.929 & & & 2.529 & 0.791 \\
\hline 107 & 46.387 & & 5.95 & & \\
\hline 108 & 46.832 & 6.12 & & 2.560 & 0.801 \\
\hline 109 & 47.289 & & 5.96 & & \\
\hline 110 & 47.750 & & & 2.515 & 0.787 \\
\hline 111 & 48.155 & & 5.84 & & \\
\hline 112 & 48.597 & & & 2.560 & 0.801 \\
\hline 113 & 49.059 & & 5.88 & & \\
\hline 114 & 49.504 & & & 2.560 & 0.801 \\
\hline 115 & 49.947 & & 5.84 & & \\
\hline 116 & 50.390 & & & 2.560 & 0.801 \\
\hline 117 & 50.813 & 5.86 & 5.84 & & \\
\hline 118 & 51.241 & & & 2.560 & 0.801 \\
\hline 119 & 51.734 & & 5.81 & & \\
\hline 120 & 52.358 & & & 2.529 & 0.791 \\
\hline 121 & 52.983 & 5.91 & 5.84 & & \\
\hline 122 & 53.489 & & & 2.560 & 0.801 \\
\hline 123 & 53.973 & & 5.86 & & \\
\hline 124 & 54.620 & & & 2.560 & 0.801 \\
\hline 125 & 55.221 & & 5.87 & & \\
\hline 126 & 55.642 & & & 2.560 & 0.801 \\
\hline 127 & 56.102 & & 5.87 & & \\
\hline
\end{tabular}


Table 8 (Continued): Aluminum Oxide Transport Data - Study \#1_pH 6

Data results for aluminum oxide nanoparticle transport Study \#1_pH 6; samples 128-161.

\begin{tabular}{|c|c|c|c|c|c|c|}
\hline Sample & $\begin{array}{l}\text { Pore } \\
\text { Volume } \\
\text { (mL) }\end{array}$ & Influent $\mathrm{pH}$ & $\begin{array}{l}\text { Effluent } \\
\mathrm{pH}\end{array}$ & $\begin{array}{c}\text { UV-Vis } \\
\text { Abs }\end{array}$ & $\mathrm{C} / \mathrm{C}_{\mathrm{o}}$ & \\
\hline 128 & 56.608 & & & 2.560 & 0.801 & \\
\hline 129 & 57.153 & 5.85 & 5.84 & & & \\
\hline 130 & 57.630 & & & 2.612 & 0.818 & \\
\hline 131 & 58.063 & & 5.82 & & & \\
\hline 132 & 58.518 & & & 2.560 & 0.801 & \\
\hline 133 & 58.992 & & 5.86 & & & \\
\hline 134 & 59.480 & & & 2.577 & 0.807 & \\
\hline 135 & 60.081 & & 5.88 & & & \\
\hline 136 & 60.656 & 5.84 & & 2.577 & 0.807 & \\
\hline 137 & 60.935 & & & 2.401 & 0.751 & Elution \\
\hline 138 & 61.154 & & & 2.460 & 0.770 & \\
\hline 139 & 61.355 & & & 2.501 & 0.783 & \\
\hline 140 & 61.570 & & & 2.501 & 0.783 & \\
\hline 141 & 61.839 & & & 2.179 & 0.681 & \\
\hline 142 & 62.078 & & 5.95 & 1.336 & 0.414 & \\
\hline 143 & 62.269 & & & 0.687 & 0.208 & \\
\hline 144 & 62.489 & & & 0.298 & 0.085 & \\
\hline 145 & 62.721 & & 5.9 & 0.131 & 0.034 & \\
\hline 146 & 63.101 & & & 0.072 & 0.017 & \\
\hline 147 & 63.475 & 6.09 & & 0.035 & 0.006 & \\
\hline 148 & 63.773 & & & 0.017 & 0.001 & \\
\hline 149 & 64.127 & & & 0.011 & -0.001 & LDL \\
\hline 150 & 64.496 & & 5.91 & 0.010 & -0.001 & LDL \\
\hline 151 & 64.894 & & & 0.017 & 0.001 & \\
\hline 152 & 65.224 & & & 0.013 & 0.000 & LDL \\
\hline 153 & 65.663 & & 5.88 & & & \\
\hline 154 & 66.090 & & & 0.004 & -0.003 & LDL \\
\hline 155 & 66.560 & 6.08 & 5.83 & & & \\
\hline 156 & 67.248 & & 5.86 & 0.008 & -0.002 & LDL \\
\hline 157 & 67.869 & & 5.84 & & & \\
\hline 158 & 68.262 & & & -0.005 & -0.006 & LDL \\
\hline 159 & 68.365 & & 5.84 & & & \\
\hline 160 & 68.715 & & & -0.002 & -0.005 & LDL \\
\hline 161 & 68.883 & 6.07 & & -0.001 & -0.004 & LDL \\
\hline
\end{tabular}


Table 9: Non-Reactive Tracer Study Data - Study \#2_pH 6_NRT

Performed for $\mathrm{Al}_{2} \mathrm{O}_{3}$ Study \#2_pH 6

Column: C

Darcy Velocity: $0.092 \mathrm{~cm} / \mathrm{min}$

Electrolyte: $\mathrm{CaCl}_{2}$

Ionic Strength: $0.015 \mathrm{M}$

Data results for pentafluorobenzoic acid transport Study \#2_pH 6_NRT; Samples 1 - 28.

\begin{tabular}{|c|c|c|c|c|c|}
\hline Sample & $\begin{array}{l}\text { Pore Volume } \\
\quad(\mathrm{mL})\end{array}$ & UV-Vis Abs & Dilution & $\mathrm{C} / \mathrm{C}_{\mathrm{o}}$ & \\
\hline 1 & -0.795 & 0.030 & 1 & 0.002 & \\
\hline 2 & -0.607 & 0.013 & 1 & -0.001 & LDL \\
\hline 3 & -0.438 & 0.011 & 1 & -0.001 & LDL \\
\hline 4 & -0.270 & 0.011 & 1 & -0.001 & LDL \\
\hline 5 & -0.063 & 0.010 & 1 & -0.001 & LDL \\
\hline 6 & 0.183 & 0.114 & 1 & 0.013 & \\
\hline 7 & 0.429 & 1.496 & 1 & 0.199 & \\
\hline 8 & 0.644 & 1.563 & 2.9 & 0.598 & \\
\hline 9 & 0.927 & 2.115 & 3.1 & 0.870 & \\
\hline 10 & 1.299 & 2.202 & 3.2 & 0.930 & \\
\hline 11 & 1.616 & 2.510 & 2.9 & 0.964 & \\
\hline 12 & 1.928 & 2.311 & 3.1 & 0.967 & \\
\hline 13 & 2.281 & 2.421 & 3.0 & 0.960 & \\
\hline 14 & 2.651 & 2.269 & 3.2 & 0.975 & \\
\hline 15 & 3.057 & 2.057 & 3.6 & 0.981 & \\
\hline 16 & 3.366 & 2.082 & 3.5 & 0.975 & \\
\hline 17 & 4.535 & 2.510 & 2.9 & 0.985 & \\
\hline 18 & 5.507 & 2.175 & 3.4 & 0.980 & \\
\hline 19 & 6.323 & 2.586 & 2.9 & 0.987 & \\
\hline 20 & 7.120 & 2.294 & 3.2 & 0.981 & \\
\hline 21 & 8.053 & 2.277 & 3.2 & 0.980 & \\
\hline 22 & 8.673 & 2.554 & 2.8 & 0.957 & \\
\hline 23 & 8.894 & 2.445 & 3.0 & 0.982 & \\
\hline 24 & 9.118 & 2.399 & 3.1 & 0.982 & \\
\hline 25 & 9.360 & 2.679 & 2.7 & 0.978 & \\
\hline 26 & 9.596 & 2.445 & 3.0 & 0.989 & \\
\hline 27 & 9.833 & 2.510 & 2.9 & 0.984 & \\
\hline 28 & 10.087 & 2.679 & 2.7 & 0.972 & \\
\hline
\end{tabular}


Table 9 (Continued): Non-Reactive Tracer Study Data - Study \#2_pH 6_NRT

Data results for pentafluorobenzoic acid transport Study \#2_pH 6_NRT; Samples 29 - 57.

\begin{tabular}{|c|c|c|c|c|c|}
\hline Sample & $\begin{array}{l}\text { Pore Volume } \\
(\mathrm{mL})\end{array}$ & $\mathrm{UV}-\mathrm{V}$ is $\mathrm{Abs}$ & Dilution & $\mathrm{C} / \mathrm{C}_{\mathrm{o}}$ & \\
\hline 29 & 10.428 & 2.722 & 2.7 & 0.984 & \\
\hline 30 & 10.879 & 2.399 & 2.8 & 0.910 & \\
\hline 31 & 11.843 & 2.410 & 3.1 & 0.990 & \\
\hline 32 & 12.197 & 2.509 & 2.9 & 0.986 & Elution \\
\hline 33 & 12.402 & 2.509 & 3.0 & 0.997 & \\
\hline 34 & 12.666 & 2.585 & 2.9 & 0.990 & \\
\hline 35 & 12.923 & 2.252 & 3.3 & 1.001 & \\
\hline 36 & 13.127 & 2.585 & 2.8 & 0.984 & \\
\hline 37 & 13.351 & 2.482 & 2.6 & 0.869 & \\
\hline 38 & 13.598 & 1.120 & 2.9 & 0.441 & \\
\hline 39 & 13.806 & 0.414 & 3.0 & 0.164 & \\
\hline 40 & 14.123 & 0.537 & 1 & 0.071 & \\
\hline 41 & 14.545 & 0.325 & 1 & 0.043 & \\
\hline 42 & 15.026 & 0.257 & 1 & 0.033 & \\
\hline 43 & 15.529 & 0.220 & 1 & 0.028 & \\
\hline 44 & 15.965 & 0.203 & 1 & 0.025 & \\
\hline 45 & 16.404 & 0.192 & 1 & 0.024 & \\
\hline 46 & 16.743 & 0.178 & 1 & 0.022 & \\
\hline 47 & 17.624 & 0.147 & 1 & 0.018 & \\
\hline 48 & 18.575 & 0.121 & 1 & 0.014 & \\
\hline 49 & 19.465 & 0.096 & 1 & 0.011 & \\
\hline 50 & 20.446 & 0.080 & 1 & 0.009 & \\
\hline 51 & 21.404 & 0.068 & 1 & 0.007 & \\
\hline 52 & 22.336 & 0.072 & 1 & 0.008 & \\
\hline 53 & 23.318 & 0.053 & 1 & 0.005 & \\
\hline 54 & 24.235 & 0.049 & 1 & 0.004 & \\
\hline 55 & 25.151 & 0.051 & 1 & 0.005 & \\
\hline 56 & 26.020 & 0.047 & 1 & 0.004 & \\
\hline 57 & 27.114 & 0.032 & 1 & 0.002 & \\
\hline
\end{tabular}


Table 10: Aluminum Oxide Transport Data - Study \#2_pH 6

Concentration: $25 \mathrm{mg} / \mathrm{L}$

Column: C

Darcy Velocity: $0.096 \mathrm{~cm} / \mathrm{min}$

Electrolyte: $\mathrm{CaCl}_{2}$

Ionic Strength: $0.015 \mathrm{M}$

Data results for aluminum oxide nanoparticle transport Study \#2_pH 6; samples 1 - 27.

\begin{tabular}{|c|c|c|c|c|c|c|}
\hline Sample & $\begin{array}{l}\text { Pore } \\
\text { Volume } \\
\text { (mL) }\end{array}$ & $\begin{array}{c}\text { Influent } \\
\text { pH }\end{array}$ & $\begin{array}{c}\text { Effluent } \\
\text { pH }\end{array}$ & $\begin{array}{c}\text { UV-Vis } \\
\text { Abs }\end{array}$ & $\mathrm{C} / \mathrm{C}_{\mathrm{o}}$ & \\
\hline 1 & -0.818 & & & 0.001 & & LDL \\
\hline 2 & -0.563 & & & 0.001 & & LDL \\
\hline 3 & -0.284 & & & 0.018 & & LDL \\
\hline 4 & -0.036 & & & 0.001 & & LDL \\
\hline 5 & 0.235 & & & 0.001 & & LDL \\
\hline 6 & 0.542 & & 5.95 & 0.004 & & LDL \\
\hline 7 & 0.882 & 6.07 & & 0.006 & & LDL \\
\hline 8 & 1.185 & & & 0.011 & & LDL \\
\hline 9 & 1.420 & & & 0.001 & & LDL \\
\hline 10 & 1.688 & & & 0.004 & & LDL \\
\hline 11 & 2.008 & & 5.75 & 0.000 & & LDL \\
\hline 12 & 2.424 & & & 0.001 & & LDL \\
\hline 13 & 2.959 & & & 0.011 & & LDL \\
\hline 14 & 3.415 & & 5.82 & -0.002 & & LDL \\
\hline 15 & 3.741 & & & 0.018 & & LDL \\
\hline 16 & 4.231 & & 5.84 & & & \\
\hline 17 & 4.663 & & & 0.014 & & LDL \\
\hline 18 & 5.091 & 5.98 & 5.89 & & & \\
\hline 19 & 5.524 & & & 0.015 & & LDL \\
\hline 20 & 5.960 & & 5.88 & & & \\
\hline 21 & 6.386 & & & 0.020 & & LDL \\
\hline 22 & 6.827 & & 5.88 & & & \\
\hline 23 & 7.276 & & & 0.016 & & LDL \\
\hline 24 & 7.688 & & 5.85 & & & \\
\hline 25 & 8.101 & & & 0.015 & & LDL \\
\hline 26 & 8.861 & & 5.94 & & & \\
\hline 27 & 9.663 & & & 0.014 & & LDL \\
\hline
\end{tabular}


Table 10 (Continued): Aluminum Oxide Transport Data - Study \#2_pH 6

Data results for aluminum oxide nanoparticle transport Study \#2_pH 6; samples 28 - 60.

\begin{tabular}{|c|c|c|c|c|c|c|}
\hline Sample & $\begin{array}{c}\text { Pore } \\
\text { Volume } \\
(\mathrm{mL})\end{array}$ & $\begin{array}{c}\text { Influent } \\
\mathrm{pH}\end{array}$ & $\begin{array}{c}\text { Effluent } \\
\mathrm{pH}\end{array}$ & $\begin{array}{c}\text { UV-Vis } \\
\text { Abs }\end{array}$ & $\mathrm{C} / \mathrm{C}_{\mathrm{o}}$ & \\
\hline 28 & 10.420 & 5.96 & 5.92 & & & \\
\hline 29 & 11.187 & & & 0.015 & & LDL \\
\hline 30 & 12.017 & & 5.98 & & & \\
\hline 31 & 12.825 & & & 0.019 & & LDL \\
\hline 32 & 13.585 & & 5.95 & & & \\
\hline 33 & 14.344 & & & 0.022 & & LDL \\
\hline 34 & 15.177 & 5.95 & 5.99 & & & \\
\hline 35 & 15.988 & & & 0.022 & & LDL \\
\hline 36 & 16.753 & & 5.98 & & & \\
\hline 37 & 17.533 & & & 0.013 & & LDL \\
\hline 38 & 18.333 & & 5.96 & & & \\
\hline 39 & 19.146 & & & 0.023 & & LDL \\
\hline 40 & 19.910 & 5.94 & 5.96 & & & \\
\hline 41 & 20.653 & & & 0.013 & & LDL \\
\hline 42 & 21.406 & & 5.98 & & & \\
\hline 43 & 22.201 & & & 0.013 & & LDL \\
\hline 44 & 23.010 & & 5.98 & & & \\
\hline 45 & 23.797 & & & 0.021 & & LDL \\
\hline 46 & 24.649 & & 5.95 & & & \\
\hline 47 & 25.489 & & & 0.013 & & LDL \\
\hline 48 & 26.270 & & 5.98 & & & \\
\hline 49 & 27.058 & & & 0.082 & 0.103 & \\
\hline 50 & 27.245 & & & & & \\
\hline 51 & 27.416 & & & 0.027 & & LDL \\
\hline 52 & 27.618 & & & 0.020 & & LDL \\
\hline 53 & 27.826 & & & 0.019 & & LDL \\
\hline 54 & 28.069 & & & 0.046 & 0.066 & Stop Flow \\
\hline 55 & 28.268 & & & 0.019 & & LDL \\
\hline 56 & 28.468 & & & 0.009 & & LDL \\
\hline 57 & 28.697 & & & 0.008 & & LDL \\
\hline 58 & 28.966 & & & 0.017 & & LDL \\
\hline 59 & 29.202 & & & 0.146 & 0.327 & \\
\hline 60 & 29.417 & & & 0.027 & & LDL \\
\hline
\end{tabular}


Table 10 (Continued): Aluminum Oxide Transport Data - Study \#2_pH 6

Data results for aluminum oxide nanoparticle transport Study \#2_pH 6; samples 61 - 93.

\begin{tabular}{|c|c|c|c|c|c|}
\hline Sample & $\begin{array}{c}\text { Pore } \\
\text { Volume } \\
(\mathrm{mL})\end{array}$ & $\begin{array}{c}\text { Influent } \\
\mathrm{pH}\end{array}$ & $\begin{array}{c}\text { Effluent } \\
\mathrm{pH}\end{array}$ & $\begin{array}{c}\text { UV-Vis } \\
\mathrm{Abs}\end{array}$ & $\mathrm{C} / \mathrm{C}_{\mathrm{o}}$ \\
\hline 61 & 29.673 & & 5.91 & 0.031 & \\
\hline 62 & 30.015 & & & 0.019 & \\
\hline 63 & 30.460 & & & 0.018 & \\
\hline 64 & 30.930 & & 5.84 & 0.025 & \\
\hline 65 & 31.275 & & & 0.020 & \\
\hline 66 & 31.700 & 5.91 & 5.72 & & \\
\hline 67 & 32.105 & & & 0.013 & \\
\hline 68 & 32.561 & & 5.73 & & \\
\hline 69 & 33.090 & & & 0.016 & \\
\hline 70 & 33.586 & & 5.76 & & \\
\hline 71 & 34.009 & & & 0.009 & \\
\hline 72 & 34.484 & & 5.75 & & \\
\hline 73 & 34.985 & & & 0.032 & 0.038 \\
\hline 74 & 35.469 & & 5.76 & & \\
\hline 75 & 35.924 & & & 0.026 & \\
\hline 76 & 36.341 & & 5.77 & & \\
\hline 77 & 36.776 & & & 0.057 & 0.087 \\
\hline 78 & 37.224 & & 5.73 & & \\
\hline 79 & 37.673 & & & 0.016 & \\
\hline 80 & 38.192 & 5.86 & 5.75 & & \\
\hline 81 & 38.716 & 5.95 & & 0.051 & 0.075 \\
\hline 82 & 39.489 & & 5.83 & & \\
\hline 83 & 40.234 & & & 0.023 & \\
\hline 84 & 40.958 & & 5.85 & & \\
\hline 85 & 41.692 & & & 0.051 & 0.075 \\
\hline 86 & 42.454 & & 5.86 & & \\
\hline 87 & 43.214 & & & 0.007 & \\
\hline 88 & 44.111 & & 5.88 & & \\
\hline 89 & 44.995 & & & 0.014 & \\
\hline 90 & 45.741 & & 5.93 & & \\
\hline 91 & 46.496 & & & 0.014 & \\
\hline 92 & 47.239 & 5.95 & 5.95 & & \\
\hline 93 & 48.003 & & & 0.091 & 0.092 \\
\hline
\end{tabular}


Table 10 (Continued): Aluminum Oxide Transport Data - Study \#2_pH 6

Data results for aluminum oxide nanoparticle transport Study \#2_pH 6; samples 94 - 126.

\begin{tabular}{|c|c|c|c|c|c|c|}
\hline Sample & $\begin{array}{c}\text { Pore } \\
\text { Volume } \\
(\mathrm{mL})\end{array}$ & $\begin{array}{c}\text { Influent } \\
\mathrm{pH}\end{array}$ & $\begin{array}{c}\text { Effluent } \\
\text { pH }\end{array}$ & $\begin{array}{c}\text { UV-Vis } \\
\text { Abs }\end{array}$ & $\mathrm{C} / \mathrm{C}_{\mathrm{o}}$ & \\
\hline 94 & 48.393 & & & 0.012 & & LDL \\
\hline 95 & 49.139 & & 5.96 & & & \\
\hline 96 & 49.886 & & & 0.014 & & LDL \\
\hline 97 & 50.638 & & 5.94 & & & \\
\hline 98 & 51.382 & & & 0.011 & & LDL \\
\hline 99 & 52.108 & 5.89 & 5.89 & & & \\
\hline 100 & 52.866 & & & 0.014 & & LDL \\
\hline 101 & 53.620 & & 5.93 & & & \\
\hline 102 & 54.340 & & & 0.011 & & LDL \\
\hline 103 & 55.166 & & 5.95 & & & \\
\hline 104 & 56.002 & 5.88 & & 0.026 & & LDL \\
\hline 105 & 57.054 & 6.10 & 5.98 & & & \\
\hline 106 & 58.130 & & & 0.015 & & LDL \\
\hline 107 & 59.084 & & 5.98 & & & \\
\hline 108 & 60.044 & & & 0.013 & & LDL \\
\hline 109 & 60.907 & 6.07 & 5.97 & & & \\
\hline 110 & 61.743 & & & 0.015 & & LDL \\
\hline 111 & 62.510 & & 6.03 & & & \\
\hline 112 & 63.287 & & & 0.014 & & LDL \\
\hline 113 & 64.056 & & 6.06 & & & \\
\hline 114 & 64.835 & & & 0.018 & & LDL \\
\hline 115 & 65.635 & 5.98 & 6.01 & & & \\
\hline 116 & 66.432 & & & 0.016 & & LDL \\
\hline 117 & 66.704 & & & 0.028 & & Stop Flow,LDL \\
\hline 118 & 66.907 & & & 0.013 & & LDL \\
\hline 119 & 67.135 & & & 0.008 & & LDL \\
\hline 120 & 67.384 & & & 0.004 & & LDL \\
\hline 121 & 67.624 & & & 0.007 & & LDL \\
\hline 122 & 67.851 & & & 0.013 & & LDL \\
\hline 123 & 68.162 & & 6.08 & 0.015 & & LDL \\
\hline 124 & 68.553 & & & 0.009 & & LDL \\
\hline 125 & 68.926 & & & 0.012 & & LDL \\
\hline 126 & 69.341 & & 5.89 & 0.010 & & LDL \\
\hline
\end{tabular}


Table 10 (Continued): Aluminum Oxide Transport Data - Study \#2_pH 6

Data results for aluminum oxide nanoparticle transport Study \#2_pH 6; samples 127-159.

\begin{tabular}{|c|c|c|c|c|c|c|}
\hline Sample & $\begin{array}{c}\text { Pore } \\
\text { Volume } \\
(\mathrm{mL})\end{array}$ & $\begin{array}{c}\text { Influent } \\
\mathrm{pH}\end{array}$ & $\begin{array}{c}\text { Effluent } \\
\mathrm{pH}\end{array}$ & $\begin{array}{c}\text { UV-Vis } \\
\text { Abs }\end{array}$ & $\mathrm{C} / \mathrm{C}_{\mathrm{o}}$ & \\
\hline 127 & 69.774 & & & 0.009 & & LDL \\
\hline 128 & 70.195 & & 5.80 & 0.012 & & LDL \\
\hline 129 & 71.178 & 6.09 & 5.94 & & & \\
\hline 130 & 72.096 & & & 0.014 & & LDL \\
\hline 131 & 73.037 & & 6.02 & & & \\
\hline 132 & 73.941 & & & 0.013 & & LDL \\
\hline 133 & 74.867 & 6.08 & 5.99 & & & \\
\hline 134 & 75.849 & & & 0.060 & 0.061 & \\
\hline 135 & 76.083 & & & & & \\
\hline 136 & 76.258 & & & 0.014 & & LDL \\
\hline 137 & 77.173 & & 6.08 & & & \\
\hline 138 & 78.127 & & & 0.015 & & LDL \\
\hline 139 & 79.109 & & 5.92 & & & \\
\hline 140 & 80.032 & & & 0.118 & 0.236 & \\
\hline 141 & 80.166 & & & & & \\
\hline 142 & 80.299 & & & 0.022 & & LDL \\
\hline 143 & 81.182 & 6.08 & 6.04 & & & \\
\hline 144 & 82.074 & & & 0.023 & & LDL \\
\hline 145 & 82.998 & & 6.05 & & & \\
\hline 146 & 83.921 & & & 0.012 & & LDL \\
\hline 147 & 84.863 & & 6.02 & & & \\
\hline 148 & 85.871 & & & 0.018 & & LDL \\
\hline 149 & 86.798 & 6.04 & 6.02 & & & \\
\hline 150 & 89.552 & & & 0.018 & & LDL \\
\hline 151 & 88.557 & & 6.04 & & & \\
\hline 152 & 89.387 & & & 0.011 & & LDL \\
\hline 153 & 90.290 & & 6.00 & & & \\
\hline 154 & 91.181 & & & 0.018 & & LDL \\
\hline 155 & 92.080 & & 5.99 & & & \\
\hline 156 & 92.985 & & & 0.020 & & LDL \\
\hline 157 & 93.899 & & 6.09 & & & \\
\hline 158 & 94.818 & & & 0.023 & & LDL \\
\hline 159 & 95.756 & & 6.00 & & & \\
\hline
\end{tabular}


Table 10 (Continued): Aluminum Oxide Transport Data - Study \#2_pH 6

Data results for aluminum oxide nanoparticle transport Study \#2_pH 6; samples 160-192.

\begin{tabular}{|c|c|c|c|c|c|c|}
\hline Sample & $\begin{array}{l}\text { Pore } \\
\text { Volume } \\
\text { (mL) }\end{array}$ & $\begin{array}{c}\text { Influent } \\
\mathrm{pH}\end{array}$ & $\begin{array}{l}\text { Effluent } \\
\text { pH }\end{array}$ & $\begin{array}{c}\text { UV-Vis } \\
\text { Abs }\end{array}$ & $\mathrm{C} / \mathrm{C}_{\mathrm{o}}$ & \\
\hline 160 & 96.730 & & & 0.021 & & LDL \\
\hline 161 & 97.730 & & 6.05 & & & \\
\hline 162 & 98.701 & & & 0.021 & & LDL \\
\hline 163 & 99.607 & & 6.08 & & & \\
\hline 164 & 100.515 & & & 0.025 & & LDL \\
\hline 165 & 101.424 & & 6.09 & & & \\
\hline 166 & 102.336 & & & 0.028 & & LDL \\
\hline 167 & 103.083 & & 6.13 & & & \\
\hline 168 & 103.808 & & & 0.174 & 0.371 & \\
\hline 169 & 104.073 & & & 0.068 & 0.070 & Stop Flow \\
\hline 170 & 104.279 & & & 0.052 & 0.033 & \\
\hline 171 & 104.477 & & & 0.044 & 0.014 & \\
\hline 172 & 104.674 & & & 0.533 & 1.348 & \\
\hline 173 & 104.882 & & & 0.028 & & LDL \\
\hline 174 & 105.083 & & 6.14 & 0.045 & & LDL \\
\hline 175 & 105.277 & & & 0.053 & 0.035 & \\
\hline 176 & 105.478 & & & 0.071 & 0.077 & \\
\hline 177 & 105.682 & & & 0.068 & 0.070 & \\
\hline 178 & 105.896 & & & 0.118 & 0.208 & \\
\hline 179 & 106.162 & & & 0.075 & 0.086 & \\
\hline 180 & 106.415 & & & 0.067 & 0.068 & \\
\hline 181 & 106.616 & & 5.84 & 0.051 & 0.030 & \\
\hline 182 & 106.823 & & & 0.073 & 0.082 & \\
\hline 183 & 107.125 & & & 0.078 & 0.093 & \\
\hline 184 & 107.570 & & & 0.049 & & LDL \\
\hline 185 & 108.050 & 5.88 & & 0.054 & 0.037 & \\
\hline 186 & 108.472 & 6.03 & 5.72 & 0.053 & 0.035 & \\
\hline 187 & 108.894 & & & 0.046 & & LDL \\
\hline 188 & 109.311 & & & 0.063 & 0.058 & \\
\hline 189 & 109.694 & & 5.66 & 0.094 & 0.140 & \\
\hline 190 & 110.248 & & 5.87 & & & \\
\hline 191 & 110.730 & & & 0.051 & 0.030 & \\
\hline 192 & 111.176 & & 5.84 & & & \\
\hline
\end{tabular}




\section{Table 10 (Continued): Aluminum Oxide Transport Data - Study \#2_pH 6}

Data results for aluminum oxide nanoparticle transport Study \#2_pH 6; samples 193-225.

\begin{tabular}{|c|c|c|c|c|c|c|}
\hline Sample & $\begin{array}{c}\text { Pore } \\
\text { Volume } \\
(\mathrm{mL})\end{array}$ & $\begin{array}{c}\text { Influent } \\
\mathrm{pH}\end{array}$ & $\begin{array}{c}\text { Effluent } \\
\mathrm{pH}\end{array}$ & $\begin{array}{c}\mathrm{UV}-\mathrm{V} \text { is } \\
\mathrm{Abs}\end{array}$ & $\mathrm{C} / \mathrm{C}_{\mathrm{o}}$ & \\
\hline 193 & 111.595 & & & 0.074 & 0.084 & \\
\hline 194 & 112.008 & 6.02 & 5.83 & & & \\
\hline 195 & 112.416 & & & 0.046 & & LDL \\
\hline 196 & 112.830 & & 5.83 & & & \\
\hline 197 & 113.250 & & & 0.045 & & LDL \\
\hline 198 & 113.988 & & 5.87 & & & \\
\hline 199 & 114.729 & & & 0.053 & 0.035 & \\
\hline 200 & 115.706 & & 5.90 & & & \\
\hline 201 & 116.711 & & & 0.089 & 0.126 & \\
\hline 202 & 117.065 & & 5.95 & & & \\
\hline 203 & 118.653 & & & 0.030 & & LDL \\
\hline 204 & 121.294 & & 6.00 & & & \\
\hline 205 & 123.922 & & & 0.092 & 0.134 & \\
\hline 206 & 126.636 & & 5.95 & & & \\
\hline 207 & 129.379 & & & 0.044 & & LDL \\
\hline 208 & 130.313 & 5.95 & 5.91 & & & \\
\hline 209 & 131.272 & & & 0.068 & 0.070 & \\
\hline 210 & 132.160 & & 5.91 & & & \\
\hline 211 & 133.052 & & & 0.071 & 0.077 & \\
\hline 212 & 134.307 & & 5.90 & & & \\
\hline 213 & 134.918 & & & 0.051 & 0.030 & \\
\hline 214 & 135.801 & & 5.86 & & & \\
\hline 215 & 136.646 & 5.96 & & 0.039 & & LDL \\
\hline 216 & 137.459 & & 5.87 & & & \\
\hline 217 & 138.307 & & & 0.054 & 0.037 & \\
\hline 218 & 139.143 & & 5.89 & & & \\
\hline 219 & 139.956 & & & 0.043 & & LDL \\
\hline 220 & 140.403 & 5.93 & 5.80 & & & \\
\hline 221 & 140.841 & & & 0.049 & & LDL \\
\hline 222 & 141.101 & & & 0.062 & 0.109 & \\
\hline 223 & 141.313 & & & 0.035 & 0.042 & Stop Flow \\
\hline 224 & 141.571 & & & 0.039 & 0.053 & \\
\hline 225 & 141.888 & & & 0.040 & 0.056 & \\
\hline
\end{tabular}


Table 10 (Continued): Aluminum Oxide Transport Data - Study \#2_pH 6

Data results for aluminum oxide nanoparticle transport Study \#2_pH 6; samples 226-258.

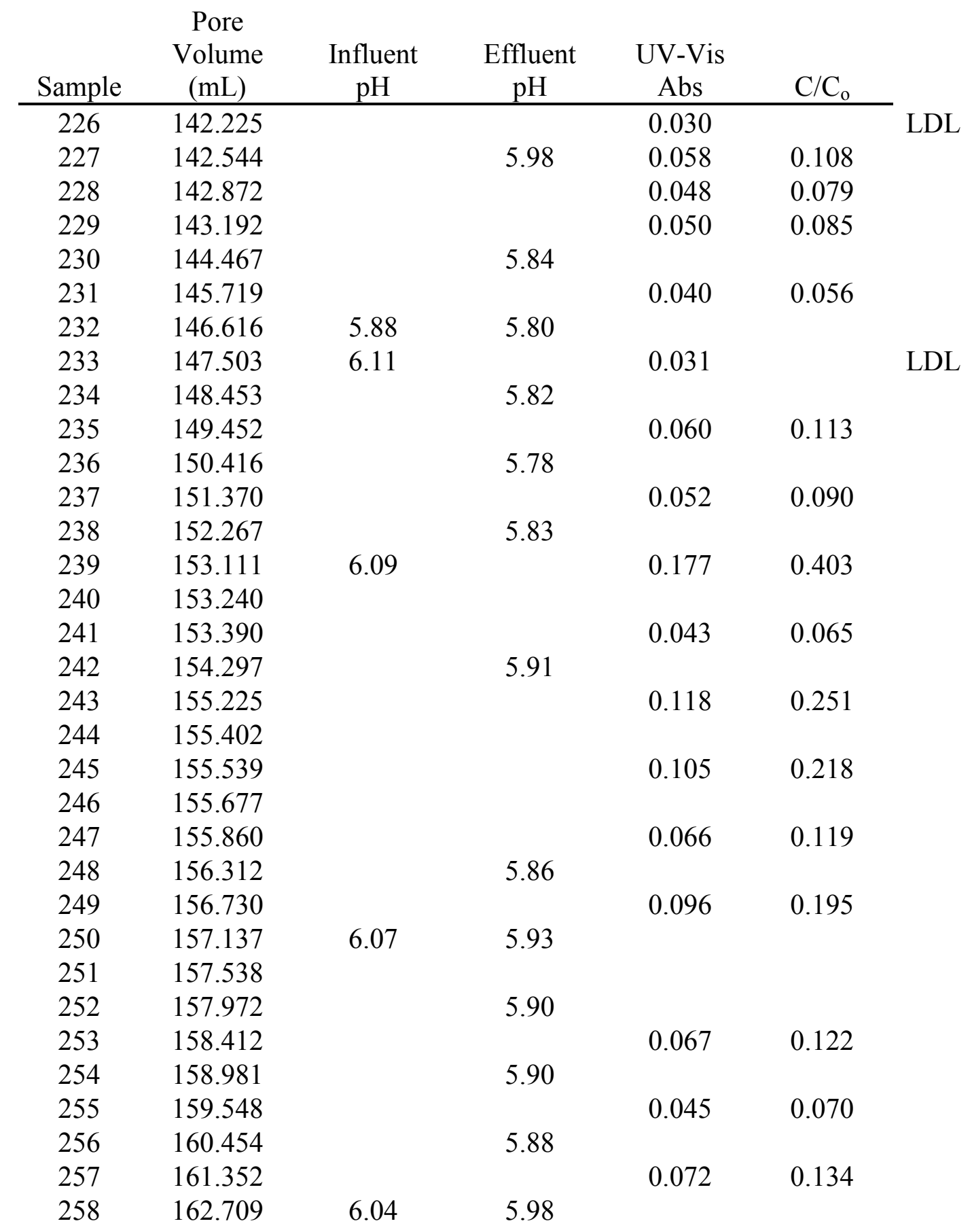




\section{Table 10 (Continued): Aluminum Oxide Transport Data - Study \#2_pH 6}

Data results for aluminum oxide nanoparticle transport Study \#2_pH 6; samples 259-291.

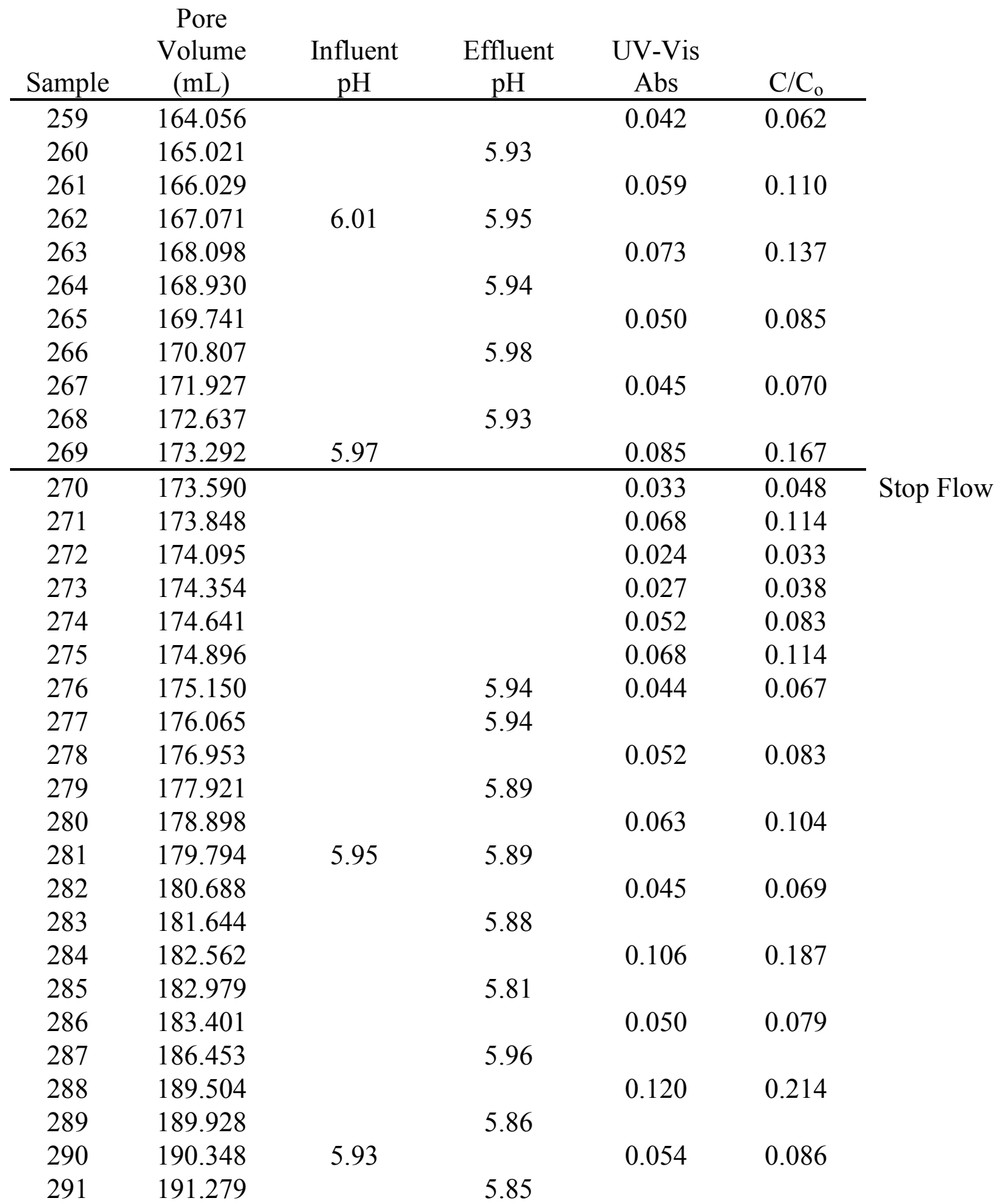




\section{Table 10 (Continued): Aluminum Oxide Transport Data - Study \#2_pH 6}

Data results for aluminum oxide nanoparticle transport Study \#2_pH 6; samples 292-324.

\begin{tabular}{|c|c|c|c|c|c|c|}
\hline Sample & $\begin{array}{c}\text { Pore } \\
\text { Volume } \\
\text { (mL) }\end{array}$ & $\begin{array}{c}\text { Influent } \\
\text { pH }\end{array}$ & $\begin{array}{c}\text { Effluent } \\
\mathrm{pH}\end{array}$ & $\begin{array}{c}\text { UV-Vis } \\
\text { Abs }\end{array}$ & $\mathrm{C} / \mathrm{C}_{\mathrm{o}}$ & \\
\hline 292 & 192.270 & & & 0.046 & 0.071 & \\
\hline 293 & 193.261 & & 5.81 & & & \\
\hline 294 & 194.208 & & & 0.056 & 0.090 & \\
\hline 295 & 195.183 & 5.93 & 5.86 & & & \\
\hline 296 & 196.215 & & & 0.059 & 0.096 & \\
\hline 297 & 197.113 & & 5.81 & & & \\
\hline 298 & 198.005 & & & 0.072 & 0.121 & \\
\hline 299 & 199.012 & & 5.89 & & & \\
\hline 300 & 199.978 & & & 0.062 & 0.102 & \\
\hline 301 & 201.060 & 5.88 & 5.84 & & & \\
\hline 302 & 202.132 & & & 0.067 & 0.112 & \\
\hline 303 & 203.112 & 5.94 & 5.84 & & & \\
\hline 304 & 204.116 & & & 0.081 & 0.139 & \\
\hline 305 & 205.004 & & 5.88 & & & \\
\hline 306 & 205.921 & & & 0.080 & 0.137 & \\
\hline 307 & 206.284 & & & 0.045 & 0.085 & Stop Flow \\
\hline 308 & 206.499 & & & 0.039 & 0.071 & \\
\hline 309 & 206.764 & & & 0.085 & 0.180 & \\
\hline 310 & 207.074 & & & 0.020 & 0.023 & \\
\hline 311 & 207.328 & & 5.88 & 0.043 & 0.081 & \\
\hline 312 & 207.550 & & & 0.049 & 0.095 & \\
\hline 313 & 207.759 & & & 0.075 & 0.157 & \\
\hline 314 & 207.969 & & & 0.090 & 0.192 & \\
\hline 315 & 208.253 & & 6.07 & 0.056 & 0.112 & \\
\hline 316 & 209.178 & & 5.92 & & & \\
\hline 317 & 210.034 & & & 0.070 & 0.145 & \\
\hline 318 & 210.936 & 5.98 & 5.87 & & & \\
\hline 319 & 211.859 & & & 0.078 & 0.164 & \\
\hline 320 & 212.797 & & 5.86 & & & \\
\hline 321 & 213.707 & & & 0.063 & 0.128 & \\
\hline 322 & 214.547 & 5.95 & 5.86 & & & \\
\hline 323 & 215.418 & & & 0.103 & 0.223 & \\
\hline 324 & 216.555 & & 5.86 & & & \\
\hline
\end{tabular}


Table 10 (Continued): Aluminum Oxide Transport Data - Study \#2_pH 6

Data results for aluminum oxide nanoparticle transport Study \#2_pH 6; samples 325-357.

\begin{tabular}{|c|c|c|c|c|c|c|}
\hline Sample & $\begin{array}{c}\text { Pore } \\
\text { Volume } \\
(\mathrm{mL})\end{array}$ & $\begin{array}{c}\text { Influent } \\
\mathrm{pH}\end{array}$ & $\begin{array}{c}\text { Effluent } \\
\mathrm{pH}\end{array}$ & $\begin{array}{c}\text { UV-Vis } \\
\text { Abs }\end{array}$ & $\mathrm{C} / \mathrm{C}_{\mathrm{o}}$ & \\
\hline 325 & 217.714 & & & 0.077 & 0.161 & \\
\hline 326 & 218.568 & 5.95 & 5.89 & & & \\
\hline 327 & 219.368 & & & 0.140 & 0.311 & \\
\hline 328 & 219.514 & & & & & \\
\hline 329 & 219.656 & & & 0.084 & 0.178 & \\
\hline 330 & 219.788 & & & & & \\
\hline 331 & 219.926 & & & 0.092 & 0.197 & \\
\hline 332 & 222.734 & & 5.92 & & & \\
\hline 333 & 225.599 & & & 0.062 & 0.126 & \\
\hline 334 & 226.639 & & 5.93 & & & \\
\hline 335 & 227.635 & & & 0.080 & 0.169 & \\
\hline 336 & 228.550 & & 5.89 & & & \\
\hline 337 & 229.456 & & & 0.078 & 0.164 & \\
\hline 338 & 230.313 & & 5.88 & & & \\
\hline 339 & 231.178 & & & 0.082 & 0.173 & \\
\hline 340 & 232.326 & 5.87 & 5.90 & & & \\
\hline 341 & 233.564 & 5.92 & & 0.082 & 0.173 & \\
\hline 342 & 232.671 & & 5.90 & & & \\
\hline 343 & 235.447 & & & 0.116 & 0.251 & \\
\hline 344 & 236.442 & & 5.96 & & & \\
\hline 345 & 237.508 & & & 0.106 & 0.230 & \\
\hline 346 & 238.071 & & 5.93 & & & \\
\hline 347 & 238.587 & & & 0.086 & 0.183 & \\
\hline 348 & 238.961 & & & 0.041 & & LDL,Stop Flow \\
\hline 349 & 239.277 & & & 0.041 & & LDL \\
\hline 350 & 239.529 & & & 0.023 & & LDL \\
\hline 351 & 239.818 & & & 0.053 & 0.091 & \\
\hline 352 & 240.079 & & & 0.068 & 0.127 & \\
\hline 353 & 240.266 & & & 0.138 & 0.305 & \\
\hline 354 & 240.488 & & 6.05 & 0.083 & 0.164 & \\
\hline 355 & 240.714 & & & 0.068 & 0.127 & \\
\hline 356 & 240.907 & & & 0.118 & 0.254 & \\
\hline 357 & 241.160 & & & 0.126 & 0.274 & \\
\hline
\end{tabular}


Table 10 (Continued): Aluminum Oxide Transport Data - Study \#2_pH 6

Data results for aluminum oxide nanoparticle transport Study \#2_pH 6; samples 358-390.

\begin{tabular}{|c|c|c|c|c|c|}
\hline Sample & $\begin{array}{c}\text { Pore } \\
\text { Volume } \\
(\mathrm{mL})\end{array}$ & $\begin{array}{c}\text { Influent } \\
\mathrm{pH}\end{array}$ & $\begin{array}{c}\text { Effluent } \\
\mathrm{pH}\end{array}$ & $\begin{array}{c}\text { UV-Vis } \\
\mathrm{Abs}\end{array}$ & $\mathrm{C} / \mathrm{C}_{\mathrm{o}}$ \\
\hline 358 & 241.409 & & & 0.082 & 0.162 \\
\hline 359 & 241.745 & & & 0.102 & 0.211 \\
\hline 360 & 242.093 & & & 0.091 & 0.184 \\
\hline 361 & 242.427 & & 5.85 & 0.147 & 0.327 \\
\hline 362 & 243.313 & & 5.95 & & \\
\hline 363 & 244.195 & 5.95 & & 0.086 & 0.171 \\
\hline 364 & 245.016 & & 5.93 & & \\
\hline 365 & 245.803 & & & 0.174 & 0.396 \\
\hline 366 & 246.328 & & 5.89 & & \\
\hline 367 & 246.816 & & & 0.225 & 0.525 \\
\hline 368 & 246.948 & & & & \\
\hline 369 & 247.090 & & & 0.101 & 0.208 \\
\hline 370 & 247.908 & & & 0.090 & 0.181 \\
\hline 371 & 248.637 & & 5.93 & & \\
\hline 372 & 249.431 & & & 0.118 & 0.254 \\
\hline 373 & 250.148 & 5.92 & 5.93 & & \\
\hline 374 & 250.867 & 5.94 & & 0.429 & 1.043 \\
\hline 375 & 250.974 & & & & \\
\hline 376 & 251.143 & & & 0.455 & 1.109 \\
\hline 377 & 251.271 & & & & \\
\hline 378 & 251.409 & & & 0.096 & 0.196 \\
\hline 379 & 251.693 & & & 0.089 & 0.179 \\
\hline 380 & 251.987 & & & 0.097 & 0.198 \\
\hline 381 & 252.968 & & 5.95 & & \\
\hline 382 & 253.988 & & & 0.092 & 0.186 \\
\hline 383 & 254.784 & & 5.98 & & \\
\hline 384 & 255.631 & 5.93 & & 0.091 & 0.184 \\
\hline 385 & 256.523 & & 5.90 & & \\
\hline 386 & 257.375 & & & 0.089 & 0.179 \\
\hline 387 & 258.309 & & 5.84 & & \\
\hline 388 & 259.251 & & & 0.115 & 0.246 \\
\hline 389 & 260.164 & & 5.92 & & \\
\hline 390 & 261.053 & 5.89 & & 0.097 & 0.198 \\
\hline
\end{tabular}


Table 10 (Continued): Aluminum Oxide Transport Data - Study \#2_pH 6

Data results for aluminum oxide nanoparticle transport Study \#2_pH 6; samples 391-423.

\begin{tabular}{|c|c|c|c|c|c|c|}
\hline Sample & $\begin{array}{c}\text { Pore } \\
\text { Volume } \\
(\mathrm{mL})\end{array}$ & $\begin{array}{c}\text { Influent } \\
\mathrm{pH}\end{array}$ & $\begin{array}{c}\text { Effluent } \\
\mathrm{pH}\end{array}$ & $\begin{array}{c}\text { UV-Vis } \\
\text { Abs }\end{array}$ & $\mathrm{C} / \mathrm{C}_{\mathrm{o}}$ & \\
\hline 391 & 261.941 & 5.99 & 5.88 & & & \\
\hline 392 & 262.820 & & & 0.093 & 0.189 & \\
\hline 393 & 263.895 & & 5.90 & & & \\
\hline 394 & 265.104 & & & 0.097 & 0.198 & \\
\hline 395 & 266.106 & & 5.92 & & & \\
\hline 396 & 267.044 & & & 0.097 & 0.198 & \\
\hline 397 & 268.109 & 5.96 & 5.99 & & & \\
\hline 398 & 269.162 & & & 0.098 & 0.201 & \\
\hline 399 & 270.529 & & 6.01 & & & \\
\hline 400 & 271.808 & & & 0.113 & 0.241 & \\
\hline 401 & 271.982 & & & & & \\
\hline 402 & 272.148 & & & 0.106 & 0.220 & \\
\hline 403 & 272.395 & & & 0.107 & & LDL,Stop Flow \\
\hline 404 & 272.606 & & & 0.086 & & LDL \\
\hline 405 & 272.811 & & & 0.057 & & LDL \\
\hline 406 & 273.019 & & & 0.047 & & LDL \\
\hline 407 & 273.255 & & & 0.037 & & LDL \\
\hline 408 & 273.503 & & 6.15 & 0.092 & & LDL \\
\hline 409 & 273.742 & & & 0.126 & 0.092 & \\
\hline 410 & 273.996 & & & 0.127 & 0.096 & \\
\hline 411 & 274.267 & 5.98 & & 0.127 & 0.096 & \\
\hline 412 & 274.516 & & & 0.122 & & LDL \\
\hline 413 & 274.826 & & 6.14 & 0.137 & 0.134 & \\
\hline 414 & 275.226 & & & 0.126 & 0.092 & \\
\hline 415 & 275.606 & & & 0.134 & 0.122 & \\
\hline 416 & 276.429 & & 5.41 & & & \\
\hline 417 & 277.207 & & & 0.137 & 0.134 & \\
\hline 418 & 278.213 & 5.98 & 5.71 & & & \\
\hline 419 & 279.223 & & & 0.135 & 0.126 & \\
\hline 420 & 281.619 & & 5.88 & & & \\
\hline 421 & 284.013 & & & 0.143 & 0.156 & \\
\hline 422 & 286.481 & & 5.91 & & & \\
\hline 423 & 288.975 & & & 0.150 & 0.183 & \\
\hline
\end{tabular}




\section{Table 10 (Continued): Aluminum Oxide Transport Data - Study \#2_pH 6}

Data results for aluminum oxide nanoparticle transport Study \#2_pH 6; samples 424-456.

\begin{tabular}{|c|c|c|c|c|c|c|}
\hline Sample & $\begin{array}{c}\text { Pore } \\
\text { Volume } \\
(\mathrm{mL})\end{array}$ & $\begin{array}{c}\text { Influent } \\
\text { pH }\end{array}$ & $\begin{array}{c}\text { Effluent } \\
\mathrm{pH}\end{array}$ & $\begin{array}{c}\text { UV-Vis } \\
\text { Abs }\end{array}$ & $\mathrm{C} / \mathrm{C}_{\mathrm{o}}$ & \\
\hline 424 & 290.864 & & 5.95 & & & \\
\hline 425 & 292.745 & & & 0.192 & 0.315 & \\
\hline 426 & 293.772 & 5.96 & 5.93 & & & \\
\hline 427 & 294.801 & & & 0.205 & 0.348 & \\
\hline 428 & 295.801 & & & & & \\
\hline 429 & 296.841 & & & 0.202 & 0.340 & \\
\hline 430 & 298.449 & & 5.96 & & & \\
\hline 431 & 300.025 & & & 0.206 & 0.350 & \\
\hline 432 & 300.962 & & 5.96 & & & \\
\hline 433 & 302.015 & 5.95 & & 0.206 & 0.350 & \\
\hline 434 & 303.306 & & 5.96 & & & \\
\hline 435 & 304.488 & & & 0.209 & 0.358 & \\
\hline 436 & 305.581 & & 5.96 & & & \\
\hline 437 & 306.734 & & & 0.218 & 0.380 & \\
\hline 438 & 307.786 & & 5.95 & & & \\
\hline 439 & 308.778 & & & 0.212 & 0.365 & \\
\hline 440 & 309.892 & & 5.64 & & & \\
\hline 441 & 311.007 & & & 0.218 & 0.380 & \\
\hline 442 & 313.175 & & & & & \\
\hline 443 & 315.389 & & & 0.227 & 0.403 & \\
\hline 444 & 317.231 & 6.01 & & 0.207 & 0.353 & Stop Flow \\
\hline 445 & 317.579 & & & 0.236 & 0.425 & \\
\hline 446 & 317.925 & & & 0.226 & 0.400 & \\
\hline 447 & 318.279 & & & 0.231 & 0.413 & \\
\hline 448 & 318.661 & & & 0.226 & 0.400 & \\
\hline 449 & 318.990 & & & 0.216 & 0.440 & \\
\hline 450 & 319.487 & & & 0.210 & 0.423 & \\
\hline 451 & 319.924 & & & 0.216 & 0.440 & \\
\hline 452 & 320.744 & & 4.79 & & & \\
\hline 453 & 321.507 & & & 0.220 & 0.452 & \\
\hline 454 & 322.516 & 6.00 & 5.99 & & & \\
\hline 455 & 323.285 & & & 0.203 & 0.402 & \\
\hline 456 & 324.448 & & 5.60 & & & \\
\hline
\end{tabular}


Table 10 (Continued): Aluminum Oxide Transport Data - Study \#2_pH 6

Data results for aluminum oxide nanoparticle transport Study \#2_pH 6; samples 457-488.

\begin{tabular}{|c|c|c|c|c|c|c|}
\hline Sample & $\begin{array}{c}\text { Pore } \\
\text { Volume } \\
(\mathrm{mL})\end{array}$ & $\begin{array}{l}\text { Influent } \\
\mathrm{pH}\end{array}$ & $\begin{array}{c}\text { Effluent } \\
\mathrm{pH}\end{array}$ & $\begin{array}{c}\mathrm{UV}-\mathrm{Vis} \\
\mathrm{Abs}\end{array}$ & $\mathrm{C} / \mathrm{C}_{\mathrm{o}}$ & \\
\hline 457 & 325.590 & & & 0.216 & 0.440 & \\
\hline 458 & 326.677 & & 5.77 & & & \\
\hline 459 & 327.788 & & & 0.218 & 0.446 & \\
\hline 460 & 328.464 & & 5.95 & & & \\
\hline 461 & 329.181 & & & 0.217 & 0.443 & \\
\hline 462 & 344.543 & & 5.07 & & & \\
\hline 462 & 345.613 & & & 0.208 & 0.417 & \\
\hline 463 & 346.691 & & & 0.244 & 0.523 & \\
\hline 464 & 347.485 & 5.98 & 4.95 & & & \\
\hline 465 & 348.194 & & & 0.251 & 0.543 & \\
\hline 466 & 350.382 & & 5.27 & & & \\
\hline 467 & 352.642 & & & 0.244 & 0.523 & \\
\hline 468 & 356.654 & & 5.84 & & & \\
\hline 469 & 360.638 & & & 0.236 & 0.499 & \\
\hline 470 & 362.467 & & 5.77 & & & \\
\hline 471 & 364.266 & 5.98 & & 0.266 & 0.588 & \\
\hline 472 & 365.829 & & 5.91 & & & \\
\hline 473 & 367.391 & & & 0.272 & 0.605 & \\
\hline 474 & 368.555 & & 5.66 & & & \\
\hline 475 & 369.706 & & & 0.267 & 0.590 & \\
\hline 476 & 369.956 & & & 0.079 & & LDL,Stop Flow \\
\hline 477 & 370.161 & & & 0.066 & & LDL \\
\hline 478 & 370.358 & & & 0.030 & & LDL \\
\hline 479 & 370.560 & & & 0.038 & & LDL \\
\hline 480 & 370.765 & & & 0.044 & & LDL \\
\hline 481 & 370.968 & & & 0.065 & & LDL \\
\hline 482 & 371.205 & & 5.96 & 0.138 & 0.213 & \\
\hline 483 & 371.449 & & & 0.218 & 0.276 & \\
\hline 484 & 371.674 & & & 0.262 & 0.432 & \\
\hline 485 & 371.906 & & & 0.256 & 0.411 & \\
\hline 486 & 372.132 & & & 0.262 & 0.432 & \\
\hline 487 & 372.354 & & & 0.253 & 0.400 & \\
\hline 488 & 372.572 & & & 0.264 & 0.440 & \\
\hline
\end{tabular}




\section{Table 10 (Continued): Aluminum Oxide Transport Data - Study \#2_pH 6}

Data results for aluminum oxide nanoparticle transport Study \#2_pH 6; samples 489-521.

\begin{tabular}{|c|c|c|c|c|c|}
\hline Sample & $\begin{array}{c}\text { Pore } \\
\text { Volume } \\
(\mathrm{mL})\end{array}$ & $\begin{array}{c}\text { Influent } \\
\mathrm{pH}\end{array}$ & $\begin{array}{c}\text { Effluent } \\
\mathrm{pH}\end{array}$ & $\begin{array}{c}\text { UV-Vis } \\
\text { Abs }\end{array}$ & $\mathrm{C} / \mathrm{C}_{\mathrm{o}}$ \\
\hline 489 & 372.793 & & & 0.256 & 0.411 \\
\hline 490 & 373.123 & & 5.39 & 0.265 & 0.443 \\
\hline 491 & 375.635 & & 5.85 & & \\
\hline 492 & 378.041 & & & 0.304 & 0.582 \\
\hline 493 & 378.678 & & & 0.283 & 0.507 \\
\hline 494 & 378.870 & & & 0.292 & 0.539 \\
\hline 495 & 379.068 & & & 0.298 & 0.560 \\
\hline 496 & 379.274 & & & 0.289 & 0.528 \\
\hline 497 & 379.490 & & 6.03 & 0.299 & 0.564 \\
\hline 498 & 379.905 & 6.04 & 6.02 & & \\
\hline 499 & 380.320 & & & 0.299 & 0.564 \\
\hline 500 & 380.743 & & 5.98 & & \\
\hline 501 & 381.169 & & & 0.291 & 0.536 \\
\hline 502 & 382.018 & & 5.91 & & \\
\hline 503 & 382.910 & & & 0.284 & 0.511 \\
\hline 504 & 383.737 & & 5.98 & & \\
\hline 505 & 384.530 & & & 0.291 & 0.536 \\
\hline 506 & 385.285 & & 6.04 & & \\
\hline 507 & 386.103 & & & 0.287 & 0.521 \\
\hline 508 & 387.205 & & 6.04 & & \\
\hline 509 & 388.287 & & & 0.292 & 0.539 \\
\hline 510 & 389.283 & 6.03 & 5.94 & & \\
\hline 511 & 390.247 & & & 0.298 & 0.560 \\
\hline 512 & 391.276 & & 6.02 & & \\
\hline 513 & 392.341 & & & 0.289 & 0.528 \\
\hline 514 & 393.075 & & 6.02 & & \\
\hline 515 & 394.054 & & & 0.056 & 0.084 \\
\hline 516 & 394.259 & & & 0.059 & 0.091 \\
\hline 517 & 394.462 & & & 0.076 & 0.134 \\
\hline 518 & 394.670 & & & 0.163 & 0.355 \\
\hline 519 & 394.873 & & & 0.101 & 0.197 \\
\hline 520 & 395.071 & & & 0.121 & 0.248 \\
\hline 521 & 395.278 & & & 0.152 & 0.327 \\
\hline
\end{tabular}


Table 10 (Continued): Aluminum Oxide Transport Data - Study \#2_pH 6

Data results for aluminum oxide nanoparticle transport Study \#2_pH 6; samples 522-554.

\begin{tabular}{|c|c|c|c|c|c|c|}
\hline Sample & $\begin{array}{c}\text { Pore } \\
\text { Volume } \\
(\mathrm{mL})\end{array}$ & Influent $\mathrm{pH}$ & Effluent $\mathrm{pH}$ & $\begin{array}{c}\text { UV-Vis } \\
\text { Abs }\end{array}$ & $\mathrm{C} / \mathrm{C}_{\mathrm{o}}$ & \\
\hline 522 & 395.517 & & & 0.232 & 0.539 & \\
\hline 523 & 395.781 & & 6.10 & 0.271 & 0.639 & \\
\hline 524 & 396.030 & & & 0.274 & 0.647 & \\
\hline 525 & 396.256 & & & 0.280 & 0.662 & \\
\hline 526 & 396.540 & & & 0.305 & 0.727 & \\
\hline 527 & 396.913 & & & 0.316 & 0.755 & \\
\hline 528 & 397.277 & 5.98 & 5.96 & 0.303 & 0.721 & \\
\hline 529 & 397.642 & 5.98 & 5.91 & 0.315 & 0.752 & \\
\hline 530 & 398.028 & & & 0.305 & 0.727 & \\
\hline 531 & 398.480 & & & 0.304 & 0.724 & \\
\hline 532 & 400.101 & & & 0.309 & 0.737 & \\
\hline 533 & 403.938 & & & 0.318 & 0.760 & \\
\hline 534 & 405.358 & & 5.81 & & & \\
\hline 535 & 406.745 & & & 0.317 & 0.757 & \\
\hline 536 & 408.501 & & 5.95 & & & \\
\hline 537 & 410.252 & & & 0.316 & 0.755 & \\
\hline 538 & 411.796 & & 5.95 & & & \\
\hline 539 & 413.347 & & & 0.324 & 0.775 & \\
\hline 540 & 415.315 & & 5.95 & & & \\
\hline 541 & 417.322 & & & 0.322 & 0.770 & \\
\hline 542 & 419.382 & & 5.96 & & & \\
\hline 543 & 421.389 & & & 0.322 & 0.770 & \\
\hline 544 & 423.428 & 5.96 & 5.96 & & & \\
\hline 545 & 425.478 & & & 0.314 & 0.750 & \\
\hline 546 & 427.562 & & & 0.313 & 0.747 & \\
\hline 547 & 427.819 & & & 0.064 & 0.086 & Stop Flow \\
\hline 548 & 428.098 & & & 0.108 & 0.188 & \\
\hline 549 & 428.392 & & & 0.137 & 0.255 & \\
\hline 550 & 428.596 & & & 0.123 & 0.223 & \\
\hline 551 & 428.809 & & & 0.147 & 0.290 & \\
\hline 552 & 429.019 & & & 0.182 & 0.384 & \\
\hline 553 & 429.258 & & 6.03 & 0.241 & 0.543 & \\
\hline 554 & 429.532 & & & 0.282 & 0.654 & \\
\hline
\end{tabular}




\section{Table 10 (Continued): Aluminum Oxide Transport Data - Study \#2_pH 6}

Data results for aluminum oxide nanoparticle transport Study \#2_pH 6; samples 555-587.

\begin{tabular}{|c|c|c|c|c|c|c|}
\hline Sample & $\begin{array}{c}\text { Pore } \\
\text { Volume } \\
(\mathrm{mL})\end{array}$ & $\begin{array}{c}\text { Influent } \\
\mathrm{pH}\end{array}$ & $\begin{array}{c}\text { Effluent } \\
\mathrm{pH}\end{array}$ & $\begin{array}{c}\text { UV-Vis } \\
\text { Abs }\end{array}$ & $\mathrm{C} / \mathrm{C}_{\mathrm{o}}$ & \\
\hline 555 & 429.770 & & & 0.296 & 0.691 & \\
\hline 556 & 430.026 & & & 0.303 & 0.710 & \\
\hline 557 & 430.324 & & & 0.305 & 0.716 & \\
\hline 558 & 430.587 & & & 0.308 & 0.724 & \\
\hline 559 & 430.834 & & 5.96 & 0.315 & 0.742 & \\
\hline 560 & 431.185 & & & 0.311 & 0.732 & \\
\hline 561 & 431.669 & & & 0.310 & 0.729 & \\
\hline 562 & 432.163 & & & 0.318 & 0.751 & \\
\hline 563 & 437.452 & & & 0.321 & 0.759 & \\
\hline 564 & 440.436 & 6.02 & 5.98 & & & \\
\hline 565 & 443.455 & & & 0.324 & 0.767 & \\
\hline 566 & 446.132 & & 5.89 & & & \\
\hline 567 & 448.773 & & & 0.330 & 0.783 & \\
\hline 568 & 450.645 & & 5.93 & & & \\
\hline 569 & 452.501 & & & 0.335 & 0.796 & \\
\hline 570 & 453.887 & 5.98 & 5.90 & & & \\
\hline 571 & 455.340 & & & 0.315 & 0.742 & \\
\hline 572 & 456.042 & & & 0.322 & 0.761 & \\
\hline 573 & 456.400 & & & 0.085 & 0.164 & Stop Flow \\
\hline 574 & 456.645 & & & 0.076 & 0.142 & \\
\hline 575 & 456.908 & & & 0.061 & 0.105 & \\
\hline 576 & 457.177 & & & 0.077 & 0.145 & \\
\hline 577 & 457.440 & & & 0.129 & 0.259 & \\
\hline 578 & 457.720 & & & 0.212 & 0.470 & \\
\hline 579 & 458.053 & & 6.01 & 0.293 & 0.677 & \\
\hline 580 & 458.377 & & & 0.313 & 0.728 & \\
\hline 581 & 458.657 & & & 0.323 & 0.753 & \\
\hline 582 & 458.922 & & & 0.333 & 0.778 & \\
\hline 583 & 459.199 & & & 0.332 & 0.776 & \\
\hline 584 & 459.541 & & & 0.334 & 0.781 & \\
\hline 585 & 459.949 & & & 0.332 & 0.776 & \\
\hline 586 & 461.129 & & 5.92 & & & \\
\hline 587 & 462.217 & & & 0.336 & 0.786 & \\
\hline
\end{tabular}




\section{Table 10 (Continued): Aluminum Oxide Transport Data - Study \#2_pH 6}

Data results for aluminum oxide nanoparticle transport Study \#2_pH 6; samples 588-620.

\begin{tabular}{|c|c|c|c|c|c|c|}
\hline Sample & $\begin{array}{c}\text { Pore } \\
\text { Volume } \\
(\mathrm{mL})\end{array}$ & $\begin{array}{c}\text { Influent } \\
\mathrm{pH}\end{array}$ & $\begin{array}{c}\text { Effluent } \\
\mathrm{pH}\end{array}$ & $\begin{array}{c}\text { UV-Vis } \\
\text { Abs }\end{array}$ & $\mathrm{C} / \mathrm{C}_{\mathrm{o}}$ & \\
\hline 588 & 463.926 & & 5.90 & & & \\
\hline 589 & 466.013 & & & 0.332 & 0.776 & \\
\hline 590 & 468.034 & & 5.99 & & & \\
\hline 591 & 470.082 & 6.00 & & 0.336 & 0.786 & \\
\hline 592 & 472.114 & & 5.97 & & & \\
\hline 593 & 474.104 & & & 0.346 & 0.812 & \\
\hline 594 & 476.253 & & 5.89 & & & \\
\hline 595 & 478.407 & & & 0.344 & 0.807 & \\
\hline 596 & 480.409 & 6.00 & 6.02 & & & \\
\hline 597 & 482.401 & & & 0.341 & 0.799 & \\
\hline 598 & 483.029 & & 6.01 & & & \\
\hline 599 & 483.653 & & & 0.343 & 0.804 & \\
\hline 600 & 483.901 & & & 0.115 & 0.109 & Stop Flow \\
\hline 601 & 484.110 & & & 0.135 & 0.138 & \\
\hline 602 & 484.328 & & & 0.096 & 0.081 & \\
\hline 603 & 484.539 & & & 0.102 & 0.090 & \\
\hline 604 & 484.736 & & & 0.114 & 0.107 & \\
\hline 605 & 484.941 & & & 0.143 & 0.149 & \\
\hline 606 & 485.202 & & & 0.248 & 0.458 & \\
\hline 607 & 485.486 & & 6.05 & 0.323 & 0.678 & \\
\hline 608 & 485.714 & & & 0.365 & 0.801 & \\
\hline 609 & 485.909 & & & 0.347 & 0.748 & \\
\hline 610 & 486.116 & & & 0.366 & 0.804 & \\
\hline 611 & 486.336 & & & 0.341 & 0.731 & \\
\hline 612 & 486.557 & & & 0.343 & 0.737 & \\
\hline 613 & 486.761 & & 5.86 & 0.456 & 1.067 & \\
\hline 614 & 487.033 & & & 0.385 & 0.859 & \\
\hline 615 & 487.357 & & & 0.380 & 0.845 & \\
\hline 616 & 487.570 & & & 0.347 & 0.748 & \\
\hline 617 & 487.811 & & & 0.364 & 0.798 & \\
\hline 618 & 488.053 & & & 0.370 & 0.816 & \\
\hline 619 & 488.339 & & 5.85 & 0.395 & 0.889 & \\
\hline 620 & 488.646 & & & 0.359 & 0.783 & \\
\hline
\end{tabular}


Table 10 (Continued): Aluminum Oxide Transport Data - Study \#2_pH 6

Data results for aluminum oxide nanoparticle transport Study \#2_pH 6; samples 621-653.

\begin{tabular}{|c|c|c|c|c|c|c|}
\hline Sample & $\begin{array}{c}\text { Pore } \\
\text { Volume } \\
(\mathrm{mL})\end{array}$ & $\begin{array}{l}\text { Influent } \\
\mathrm{pH}\end{array}$ & $\begin{array}{c}\text { Effluent } \\
\text { pH }\end{array}$ & $\begin{array}{c}\mathrm{UV}-\mathrm{Vis} \\
\mathrm{Abs}\end{array}$ & $\mathrm{C} / \mathrm{C}_{\mathrm{o}}$ & \\
\hline 621 & 488.903 & & & 0.392 & 0.880 & \\
\hline 622 & 489.221 & & & 0.378 & 0.839 & \\
\hline 623 & 489.622 & & 5.85 & 0.375 & 0.830 & \\
\hline 624 & 490.049 & & & 0.410 & 0.933 & \\
\hline 625 & 490.624 & & & 0.383 & 0.854 & \\
\hline 626 & 491.087 & & 4.91 & 0.363 & 0.795 & \\
\hline 627 & 493.361 & & 5.89 & & & \\
\hline 628 & 495.644 & & & 0.368 & 0.810 & \\
\hline 629 & 497.172 & & 6.01 & 0.378 & 0.839 & \\
\hline 630 & 498.741 & & & 0.366 & 0.804 & \\
\hline 631 & 501.964 & & 5.98 & & & \\
\hline 632 & 505.175 & & & 0.359 & 0.783 & \\
\hline 633 & 507.119 & & 6.00 & & & \\
\hline 634 & 509.061 & 5.95 & 5.95 & 0.370 & 0.816 & \\
\hline 635 & 513.286 & & & 0.356 & 0.775 & \\
\hline 636 & 513.505 & & & 0.355 & 0.772 & \\
\hline 637 & 513.815 & & & 0.135 & 0.232 & Stop Flow \\
\hline 638 & 514.071 & & & 0.248 & 0.544 & \\
\hline 639 & 514.304 & & & 0.197 & 0.410 & \\
\hline 640 & 514.525 & & & 0.225 & 0.484 & \\
\hline 641 & 514.737 & & & 0.240 & 0.523 & \\
\hline 642 & 514.946 & & & 0.306 & 0.697 & \\
\hline 643 & 515.150 & & 5.99 & 0.301 & 0.684 & \\
\hline 644 & 515.418 & & & 0.491 & 1.183 & \\
\hline 645 & 515.709 & & & 0.390 & 0.917 & \\
\hline 646 & 515.929 & & & 0.388 & 0.912 & \\
\hline 647 & 516.133 & & & 0.384 & 0.902 & \\
\hline 648 & 516.394 & & & 0.413 & 0.978 & \\
\hline 649 & 516.736 & & & 0.407 & 0.962 & \\
\hline 650 & 517.097 & & 5.96 & 0.390 & 0.917 & \\
\hline 651 & 517.469 & & & 0.413 & 0.978 & \\
\hline 652 & 517.846 & & & 0.374 & 0.875 & \\
\hline 653 & 518.247 & & & 0.372 & 0.870 & \\
\hline
\end{tabular}




\section{Table 10 (Continued): Aluminum Oxide Transport Data - Study \#2_pH 6}

Data results for aluminum oxide nanoparticle transport Study \#2_pH 6; samples 654-686.

\begin{tabular}{|c|c|c|c|c|c|c|}
\hline Sample & $\begin{array}{c}\text { Pore } \\
\text { Volume } \\
(\mathrm{mL})\end{array}$ & $\begin{array}{l}\text { Influent } \\
\text { pH }\end{array}$ & $\begin{array}{c}\text { Effluent } \\
\text { pH }\end{array}$ & $\begin{array}{c}\mathrm{UV}-\mathrm{Vis} \\
\mathrm{Abs}\end{array}$ & $\mathrm{C} / \mathrm{C}_{\mathrm{o}}$ & \\
\hline 654 & 518.760 & & 5.83 & 0.427 & 1.015 & \\
\hline 655 & 519.234 & & & 0.376 & 0.881 & \\
\hline 656 & 519.623 & & & 0.390 & 0.917 & \\
\hline 657 & 520.084 & & 5.83 & 0.383 & 0.899 & \\
\hline 658 & 520.638 & & & 0.373 & 0.873 & \\
\hline 659 & 521.125 & & & 0.383 & 0.899 & \\
\hline 660 & 521.515 & & 5.79 & 0.379 & 0.889 & \\
\hline 661 & 522.651 & & 5.79 & & & \\
\hline 662 & 523.698 & & & 0.381 & 0.894 & \\
\hline 663 & 525.764 & & 5.92 & & & \\
\hline 664 & 527.830 & & & 0.373 & 0.873 & \\
\hline 665 & 529.814 & 5.97 & 5.91 & & & \\
\hline 666 & 531.848 & & & 0.368 & 0.860 & \\
\hline 667 & 533.886 & & 5.89 & & & \\
\hline 668 & 535.893 & & & 0.370 & 0.865 & \\
\hline 669 & 537.962 & 5.96 & 5.91 & & & \\
\hline 670 & 540.012 & & & 0.364 & 0.849 & \\
\hline 671 & 540.585 & & 5.93 & & & \\
\hline 672 & 541.159 & & & 0.374 & 0.875 & \\
\hline 673 & 541.414 & & & 0.118 & 0.192 & Stop Flow \\
\hline 674 & 541.607 & & & 0.233 & 0.516 & \\
\hline 675 & 541.820 & & & 0.216 & 0.471 & \\
\hline 676 & 542.045 & & & 0.221 & 0.484 & \\
\hline 677 & 542.258 & & & 0.227 & 0.500 & \\
\hline 678 & 542.454 & & & 0.256 & 0.578 & \\
\hline 679 & 542.651 & & & 0.272 & 0.621 & \\
\hline 680 & 542.853 & & 5.91 & 0.304 & 0.707 & \\
\hline 681 & 543.054 & & & 0.378 & 0.905 & \\
\hline 682 & 543.258 & & & 0.341 & 0.806 & \\
\hline 683 & 543.551 & & & 0.358 & 0.852 & \\
\hline 684 & 543.926 & & & 0.379 & 0.908 & \\
\hline 685 & 544.294 & & & 0.405 & 0.978 & \\
\hline 686 & 544.604 & & 5.95 & 0.424 & 1.029 & \\
\hline
\end{tabular}


Table 10 (Continued): Aluminum Oxide Transport Data - Study \#2_pH 6

Data results for aluminum oxide nanoparticle transport Study \#2_pH 6; samples 687-719.

\begin{tabular}{|c|c|c|c|c|c|c|}
\hline Sample & $\begin{array}{c}\text { Pore } \\
\text { Volume } \\
\text { (mL) }\end{array}$ & $\begin{array}{l}\text { Influent } \\
\text { pH }\end{array}$ & $\begin{array}{c}\text { Effluent } \\
\mathrm{pH}\end{array}$ & $\begin{array}{c}\text { UV-Vis } \\
\text { Abs }\end{array}$ & $\mathrm{C} / \mathrm{C}_{\mathrm{o}}$ & \\
\hline 687 & 544.826 & & & 0.367 & 0.876 & \\
\hline 688 & 545.048 & & & 0.369 & 0.881 & \\
\hline 689 & 545.285 & & & 0.365 & 0.870 & \\
\hline 690 & 545.483 & & & 0.424 & 1.029 & \\
\hline 691 & 545.745 & & & 0.388 & 0.932 & \\
\hline 692 & 545.981 & & & 0.383 & 0.919 & \\
\hline 693 & 546.225 & & & 0.383 & 0.919 & \\
\hline 694 & 546.550 & & 5.84 & 0.396 & 0.954 & \\
\hline 695 & 546.933 & & & 0.375 & 0.897 & \\
\hline 696 & 547.348 & & & 0.383 & 0.919 & \\
\hline 697 & 547.775 & & & 0.376 & 0.900 & \\
\hline 698 & 548.255 & & & 0.386 & 0.927 & \\
\hline 699 & 548.828 & & 5.83 & 0.368 & 0.878 & \\
\hline 700 & 551.231 & & 5.93 & & & \\
\hline 701 & 553.468 & & & 0.384 & 0.921 & \\
\hline 702 & 556.047 & & 5.88 & & & \\
\hline 703 & 558.646 & & & 0.387 & 0.929 & \\
\hline 704 & 560.714 & & 5.93 & & & \\
\hline 705 & 562.766 & & & 0.367 & 0.876 & \\
\hline 706 & 564.899 & 5.97 & & & & \\
\hline 707 & 566.993 & & & 0.408 & 0.986 & \\
\hline 708 & 567.237 & & & & & \\
\hline 709 & 567.470 & & & 0.372 & 0.889 & \\
\hline 710 & 567.811 & 5.96 & 5.95 & & & \\
\hline 711 & 568.212 & & & 0.111 & 0.189 & Stop Flow \\
\hline 712 & 568.422 & & & 0.238 & 0.529 & \\
\hline 713 & 568.629 & & & 0.233 & 0.515 & \\
\hline 714 & 568.834 & & & 0.218 & 0.473 & \\
\hline 715 & 569.034 & & & 0.250 & 0.563 & \\
\hline 716 & 569.237 & & & 0.260 & 0.591 & \\
\hline 717 & 569.460 & & & 0.301 & 0.706 & \\
\hline 718 & 569.678 & & & 0.314 & 0.742 & \\
\hline 719 & 569.885 & & 5.93 & 0.352 & 0.849 & \\
\hline
\end{tabular}




\section{Table 10 (Continued): Aluminum Oxide Transport Data - Study \#2_pH 6}

Data results for aluminum oxide nanoparticle transport Study \#2_pH 6; samples 720-752.

\begin{tabular}{|c|c|c|c|c|c|c|}
\hline Sample & $\begin{array}{c}\text { Pore } \\
\text { Volume } \\
(\mathrm{mL})\end{array}$ & $\begin{array}{c}\text { Influent } \\
\mathrm{pH}\end{array}$ & $\begin{array}{c}\text { Effluent } \\
\mathrm{pH}\end{array}$ & $\begin{array}{c}\text { UV-Vis } \\
\text { Abs }\end{array}$ & $\mathrm{C} / \mathrm{C}_{\mathrm{o}}$ & \\
\hline 720 & 570.086 & & & 0.349 & 0.841 & \\
\hline 721 & 570.308 & & & 0.356 & 0.860 & \\
\hline 722 & 570.522 & & & 0.366 & 0.888 & \\
\hline 723 & 570.733 & & & 0.355 & 0.857 & \\
\hline 724 & 570.943 & & & 0.365 & 0.885 & \\
\hline 725 & 571.318 & & 5.94 & & & \\
\hline 726 & 571.730 & & & 0.385 & 0.942 & \\
\hline 727 & 572.119 & & & 0.350 & 0.843 & \\
\hline 728 & 572.639 & & & 0.372 & 0.905 & \\
\hline 729 & 572.994 & & & 0.365 & 0.885 & \\
\hline 730 & 573.288 & & 5.93 & 0.370 & 0.899 & \\
\hline 731 & 574.642 & & 5.91 & & & \\
\hline 732 & 575.902 & & & 0.363 & 0.880 & \\
\hline 733 & 575.652 & & 5.91 & & & \\
\hline 734 & 579.188 & & & 0.374 & 0.911 & \\
\hline 735 & 585.007 & & 5.95 & & & \\
\hline 736 & 587.081 & 5.96 & & 0.358 & 0.866 & \\
\hline 737 & 588.836 & & 6.02 & & & \\
\hline 738 & 590.655 & & & 0.379 & 0.925 & \\
\hline 739 & 592.560 & & 5.96 & & & \\
\hline 740 & 594.360 & & & 0.370 & 0.899 & \\
\hline 741 & 596.523 & & 5.96 & & & \\
\hline 742 & 598.691 & & & 0.355 & 0.857 & \\
\hline 743 & 599.245 & 5.95 & 6.03 & & & \\
\hline 744 & 599.805 & & & 0.352 & 0.849 & \\
\hline 745 & 600.091 & & & 0.104 & 0.187 & Stop Flow \\
\hline 746 & 600.339 & & & 0.124 & 0.240 & \\
\hline 747 & 600.690 & & & 0.120 & 0.229 & \\
\hline 748 & 601.121 & & & 0.167 & 0.353 & \\
\hline 749 & 601.555 & & & 0.285 & 0.717 & \\
\hline 750 & 601.892 & & & 0.316 & 0.811 & \\
\hline 751 & 602.204 & & 6.03 & 0.306 & 0.781 & \\
\hline 752 & 602.562 & & & 0.332 & 0.860 & \\
\hline
\end{tabular}




\section{Table 10 (Continued): Aluminum Oxide Transport Data - Study \#2_pH 6}

Data results for aluminum oxide nanoparticle transport Study \#2_pH 6; samples 753-768.

\begin{tabular}{cccccc} 
Sample & $\begin{array}{c}\text { Polume } \\
(\mathrm{mL})\end{array}$ & $\begin{array}{c}\text { Influent } \\
\mathrm{pH}\end{array}$ & $\begin{array}{c}\text { Effluent } \\
\mathrm{pH}\end{array}$ & $\begin{array}{c}\mathrm{UV}-\mathrm{V} \text { is } \\
\mathrm{Abs}\end{array}$ & ${\mathrm{C} / \mathrm{C}_{\mathrm{o}}}$ \\
\hline 753 & 602.857 & & & 0.326 & 0.842 \\
754 & 603.154 & & 5.91 & 0.325 & 0.839 \\
755 & 603.451 & & & 0.320 & 0.824 \\
756 & 603.773 & & & 0.319 & 0.821 \\
757 & 604.181 & & & 0.325 & 0.839 \\
758 & 604.581 & & & 0.332 & 0.860 \\
759 & 604.906 & & 5.92 & 0.339 & 0.881 \\
760 & 605.554 & & 5.90 & & 0.881 \\
761 & 608.579 & & & 0.340 & 0.884 \\
762 & 611.208 & & 5.93 & & \\
763 & 612.881 & & & 0.337 & 0.875 \\
764 & 614.577 & 5.98 & 5.90 & & \\
765 & 615.981 & & & 0.339 & 0.881 \\
766 & 617.461 & & 5.93 & & \\
767 & 619.605 & & & 0.328 & 0.848
\end{tabular}


Table 11: Non-Reactive Tracer Study Data - Study \#3_pH 6_NRT

Performed for $\mathrm{Al}_{2} \mathrm{O}_{3}$ Study \#3 $\mathrm{pH} 6$

Column: D

Darcy Velocity: $0.010 \mathrm{~cm} / \mathrm{min}$

Electrolyte: $\mathrm{KCl}$

Ionic Strength: $0.015 \mathrm{M}$

Data results for pentafluorobenzoic acid transport Study \#3_pH 6_NRT; Samples 1 - 27.

\begin{tabular}{cccccc} 
Sample & $\begin{array}{c}\text { Pore Volume } \\
(\mathrm{mL})\end{array}$ & $\begin{array}{c}\text { UV-Vis } \\
\text { Abs }\end{array}$ & $\begin{array}{c}\text { Dilution } \\
\text { C/C } \mathrm{C}_{\mathrm{o}}\end{array}$ & \\
\hline 1 & -0.514 & 0.014 & 1 & 0.000 & LDL \\
2 & -0.378 & 0.006 & 1 & -0.002 & LDL \\
3 & -0.219 & 0.003 & 1 & -0.002 & LDL \\
4 & -0.026 & 0.003 & 1 & -0.002 & LDL \\
5 & 0.189 & 0.011 & 1 & -0.001 & LDL \\
6 & 0.403 & 0.240 & 1 & 0.031 & \\
7 & 0.635 & 2.568 & 1 & 0.344 & \\
8 & 0.863 & 1.822 & 2.9 & 0.721 & \\
9 & 1.075 & 2.381 & 2.6 & 0.838 & \\
10 & 1.293 & 2.381 & 2.8 & 0.896 & \\
11 & 1.499 & 2.725 & 2.4 & 0.901 & \\
12 & 1.696 & 2.370 & 2.9 & 0.940 & \\
13 & 1.910 & 2.541 & 2.7 & 0.942 & \\
14 & 2.192 & 2.725 & 2.6 & 0.950 & \\
15 & 2.550 & 2.499 & 2.8 & 0.965 & \\
16 & 2.913 & 2.460 & 2.9 & 0.973 & \\
17 & 3.248 & 2.460 & 2.9 & 0.976 & \\
18 & 3.644 & 2.828 & 2.5 & 0.964 & \\
19 & 4.117 & 2.642 & 2.7 & 0.980 & \\
20 & 4.576 & 2.323 & 3.2 & 0.993 & \\
21 & 5.017 & 2.323 & 3.2 & 0.999 & \\
22 & 5.946 & 2.332 & 3.1 & 0.977 & \\
23 & 6.765 & 2.332 & 3.2 & 0.999 & \\
24 & 7.746 & 2.541 & 2.9 & 0.987 & \\
25 & 8.560 & 2.191 & 3.4 & 1.003 & \\
26 & 9.370 & 2.725 & 2.7 & 0.981 & \\
27 & 10.195 & 2.332 & 3.2 & 1.001 &
\end{tabular}


Table 11 (Continued): Non-Reactive Tracer Study Data - Study \#3_pH 6_NRT

Data results for pentafluorobenzoic acid transport Study \#3_pH 6_NRT; Samples 28 - 53.

\begin{tabular}{|c|c|c|c|c|c|}
\hline Sample & $\begin{array}{l}\text { Pore Volume } \\
\qquad(\mathrm{mL})\end{array}$ & $\begin{array}{c}\mathrm{UV}-\mathrm{Vis} \\
\mathrm{Abs}\end{array}$ & Dilution & $\mathrm{C} / \mathrm{C}_{\mathrm{o}}$ & \\
\hline 28 & 10.443 & 2.527 & 2.9 & 0.995 & Elution \\
\hline 29 & 10.668 & 2.436 & 3.0 & 0.997 & \\
\hline 30 & 10.874 & 2.381 & 3.1 & 1.001 & \\
\hline 31 & 11.088 & 2.662 & 2.7 & 0.979 & \\
\hline 32 & 11.322 & 2.589 & 2.8 & 0.976 & \\
\hline 33 & 11.546 & 1.752 & 2.9 & 0.696 & \\
\hline 34 & 11.765 & 0.791 & 3.0 & 0.315 & \\
\hline 35 & 11.951 & 1.285 & 1 & 0.169 & \\
\hline 36 & 12.141 & 0.868 & 1 & 0.112 & \\
\hline 37 & 12.359 & 0.623 & 1 & 0.082 & \\
\hline 38 & 12.581 & 0.476 & 1 & 0.062 & \\
\hline 39 & 12.799 & 0.391 & 1 & 0.051 & \\
\hline 40 & 13.099 & 0.314 & 1 & 0.041 & \\
\hline 41 & 13.477 & 0.251 & 1 & 0.032 & \\
\hline 42 & 13.866 & 0.214 & 1 & 0.027 & \\
\hline 43 & 14.332 & 0.178 & 1 & 0.022 & \\
\hline 44 & 14.816 & 0.154 & 1 & 0.019 & \\
\hline 45 & 15.875 & 0.119 & 1 & 0.014 & \\
\hline 46 & 16.825 & 0.100 & 1 & 0.012 & \\
\hline 47 & 17.809 & 0.080 & 1 & 0.009 & \\
\hline 48 & 18.849 & 0.062 & 1 & 0.006 & \\
\hline 49 & 20.071 & 0.048 & 1 & 0.004 & \\
\hline 50 & 20.961 & 0.042 & 1 & 0.004 & \\
\hline 51 & 21.985 & 0.034 & 1 & 0.002 & \\
\hline 52 & 22.922 & 0.027 & 1 & 0.001 & \\
\hline 53 & 23.787 & 0.018 & 1 & 0.000 & LDL \\
\hline
\end{tabular}


Table 12: Aluminum Oxide Transport Data - Study \#3_pH 6

Concentration: $100 \mathrm{mg} / \mathrm{L}$

Column: D

Darcy Velocity: $0.096 \mathrm{~cm} / \mathrm{min}$

Electrolyte: $\mathrm{KCl}$

Ionic Strength: $0.015 \mathrm{M}$

Data results for aluminum oxide nanoparticle transport Study \#3_pH 6; samples 1-27.

\begin{tabular}{|c|c|c|c|c|c|}
\hline Sample & $\begin{array}{l}\text { Pore } \\
\text { Volume } \\
(\mathrm{mL})\end{array}$ & Influent $\mathrm{pH}$ & Effluent $\mathrm{pH}$ & $\begin{array}{c}\text { UV-Vis } \\
\text { Abs }\end{array}$ & $\mathrm{C} / \mathrm{C}_{\mathrm{o}}$ \\
\hline 1 & -0.505 & & & 0.078 & 0.057 \\
\hline 2 & -0.308 & & 6.06 & 0.046 & 0.039 \\
\hline 3 & -0.125 & & & 0.035 & 0.033 \\
\hline 4 & 0.062 & & 6.24 & 0.078 & 0.057 \\
\hline 5 & 0.305 & & & 0.073 & 0.054 \\
\hline 6 & 0.557 & & 6.22 & 0.040 & 0.036 \\
\hline 7 & 0.825 & & & 0.061 & 0.047 \\
\hline 8 & 1.074 & & 6.27 & 0.081 & 0.059 \\
\hline 9 & 1.305 & & & 0.099 & 0.069 \\
\hline 10 & 1.573 & & 6.15 & 0.070 & 0.052 \\
\hline 11 & 1.887 & & & 0.065 & 0.050 \\
\hline 12 & 2.226 & & 6.20 & 0.090 & 0.064 \\
\hline 13 & 2.616 & & & 0.091 & 0.064 \\
\hline 14 & 3.040 & & 6.13 & 0.104 & 0.071 \\
\hline 15 & 3.433 & & & 0.098 & 0.068 \\
\hline 16 & 3.887 & & 5.95 & 0.092 & 0.065 \\
\hline 17 & 4.376 & & & 0.086 & 0.061 \\
\hline 18 & 4.846 & 6.07 & 6.08 & 0.084 & 0.060 \\
\hline 19 & 5.324 & & & 0.083 & 0.060 \\
\hline 20 & 5.786 & & 6.12 & 0.076 & 0.056 \\
\hline 21 & 6.241 & & & 0.085 & 0.061 \\
\hline 22 & 6.753 & & 6.02 & 0.081 & 0.059 \\
\hline 23 & 7.708 & & & 0.099 & 0.069 \\
\hline 24 & 8.638 & & 6.04 & 0.092 & 0.065 \\
\hline 25 & 9.799 & 6.10 & & 0.103 & 0.071 \\
\hline 26 & 11.065 & & 6.05 & 0.090 & 0.064 \\
\hline 27 & 12.156 & & & 0.096 & 0.067 \\
\hline
\end{tabular}


Table 12 (Continued): Aluminum Oxide Transport Data - Study \#3_pH 6

Data results for aluminum oxide nanoparticle transport Study \#3_pH 6; samples 28 - 60.

\begin{tabular}{|c|c|c|c|c|c|}
\hline Sample & $\begin{array}{l}\text { Pore Volume } \\
\text { (mL) }\end{array}$ & Influent $\mathrm{pH}$ & Effluent $\mathrm{pH}$ & $\begin{array}{c}\text { UV-Vis } \\
\text { Abs }\end{array}$ & $\mathrm{C} / \mathrm{C}_{\mathrm{o}}$ \\
\hline 28 & 13.260 & 6.13 & 6.09 & 0.113 & 0.076 \\
\hline 29 & 14.543 & & & 0.128 & 0.085 \\
\hline 30 & 15.671 & & 6.01 & 0.118 & 0.079 \\
\hline 31 & 19.871 & & & 0.142 & 0.093 \\
\hline 32 & 21.506 & 6.10 & 5.99 & 0.171 & 0.109 \\
\hline 33 & 23.614 & & & 0.122 & 0.081 \\
\hline 34 & 24.119 & & & 0.115 & 0.077 \\
\hline 35 & 25.832 & & & 0.145 & 0.093 \\
\hline 36 & 27.415 & & 6.03 & 0.154 & 0.098 \\
\hline 37 & 29.247 & 6.13 & & 0.188 & 0.117 \\
\hline 38 & 30.682 & & 5.86 & 0.164 & 0.104 \\
\hline 39 & 34.102 & & & 0.181 & 0.113 \\
\hline 40 & 38.220 & 6.13 & 6.10 & 0.213 & 0.131 \\
\hline 41 & 40.396 & & & 0.261 & 0.158 \\
\hline 42 & 42.859 & & 5.89 & 0.294 & 0.160 \\
\hline 43 & 44.943 & & & 0.311 & 0.170 \\
\hline 44 & 47.388 & & 6.07 & 0.313 & 0.172 \\
\hline 45 & 49.016 & 6.02 & & 0.350 & 0.195 \\
\hline 46 & 51.446 & & 6.09 & 0.321 & 0.177 \\
\hline 47 & 53.790 & & & 0.384 & 0.219 \\
\hline 48 & 55.574 & 6.01 & 5.83 & 0.416 & 0.239 \\
\hline 49 & 59.305 & & & 0.445 & 0.258 \\
\hline 50 & 64.454 & 5.98 & 5.97 & 0.563 & 0.332 \\
\hline 51 & 66.605 & & & 0.583 & 0.345 \\
\hline 52 & 68.980 & 6.07 & & 0.677 & 0.404 \\
\hline 53 & 69.294 & & & 0.653 & 0.389 \\
\hline 54 & 75.835 & & & 0.800 & 0.479 \\
\hline 55 & 77.986 & & & 0.805 & 0.482 \\
\hline 56 & 81.824 & 5.99 & 5.88 & 0.863 & 0.518 \\
\hline 57 & 85.527 & & & 0.874 & 0.525 \\
\hline 58 & 87.662 & 5.98 & & 0.915 & 0.551 \\
\hline 59 & 90.354 & & & 1.027 & 0.617 \\
\hline 60 & 92.319 & & 5.93 & 1.042 & 0.626 \\
\hline
\end{tabular}


Table 12 (Continued): Aluminum Oxide Transport Data - Study \#3_pH 6

Data results for aluminum oxide nanoparticle transport Study \#3_pH 6; samples 61 - 93.

\begin{tabular}{|c|c|c|c|c|c|c|}
\hline Sample & $\begin{array}{c}\text { Pore } \\
\text { Volume } \\
(\mathrm{mL})\end{array}$ & Influent $\mathrm{pH}$ & $\begin{array}{c}\text { Effluent } \\
\mathrm{pH}\end{array}$ & $\begin{array}{c}\text { UV-Vis } \\
\text { Abs }\end{array}$ & $\mathrm{C} / \mathrm{C}_{\mathrm{o}}$ & \\
\hline 61 & 95.105 & & & 1.081 & 0.655 & \\
\hline 62 & 95.470 & 5.95 & & 0.259 & 0.139 & Stop Flow \\
\hline 63 & 95.749 & & 5.92 & 0.393 & 0.223 & \\
\hline 64 & 96.073 & & & 0.543 & 0.317 & \\
\hline 65 & 96.406 & & 5.91 & 0.768 & 0.459 & \\
\hline 66 & 96.761 & & & 0.994 & 0.600 & \\
\hline 67 & 97.171 & & 5.95 & 1.058 & 0.641 & \\
\hline 68 & 97.626 & & & 1.079 & 0.654 & \\
\hline 69 & 98.064 & & 5.90 & 1.077 & 0.653 & \\
\hline 70 & 98.439 & & & 1.077 & 0.653 & \\
\hline 71 & 98.810 & & 5.90 & 1.096 & 0.664 & \\
\hline 72 & 100.736 & & & 1.116 & 0.677 & \\
\hline 73 & 104.697 & & 5.95 & 1.163 & 0.707 & \\
\hline 74 & 108.430 & & & 1.177 & 0.715 & \\
\hline 75 & 111.688 & 5.95 & & 1.173 & 0.713 & \\
\hline 76 & 112.729 & & 6.15 & 1.203 & 0.742 & \\
\hline 77 & 116.907 & & & 1.217 & 0.751 & \\
\hline 78 & 120.650 & & 6.07 & 1.237 & 0.764 & \\
\hline 79 & 123.260 & 5.95 & & 1.270 & 0.785 & \\
\hline 80 & 126.623 & & & 1.361 & 0.812 & \\
\hline 81 & 129.917 & & & 1.397 & 0.834 & \\
\hline 82 & 133.933 & & & 1.393 & 0.832 & \\
\hline 83 & 135.981 & & 5.99 & 1.429 & 0.854 & \\
\hline 84 & 136.906 & 5.96 & & 1.392 & 0.831 & \\
\hline 85 & 139.547 & & & 1.414 & 0.845 & \\
\hline 86 & 142.123 & 6.05 & & 1.433 & 0.856 & \\
\hline 87 & 147.471 & & & 1.450 & 0.863 & \\
\hline 88 & 151.863 & & & 1.446 & 0.861 & \\
\hline 89 & 156.125 & & & 1.450 & 0.863 & \\
\hline 90 & 160.049 & & & 1.450 & 0.863 & \\
\hline 91 & 160.383 & 5.98 & & 1.404 & 0.835 & Elution \\
\hline 92 & 160.641 & & 6.07 & 1.381 & 0.821 & \\
\hline 93 & 160.897 & & & 1.415 & 0.842 & \\
\hline
\end{tabular}


Table 12 (Continued): Aluminum Oxide Transport Data - Study \#3_pH 6

Data results for aluminum oxide nanoparticle transport Study \#3_pH 6; samples 94 - 106.

\begin{tabular}{cccccc} 
Sample & $\begin{array}{c}\text { Pore Volume } \\
(\mathrm{mL})\end{array}$ & Influent $\mathrm{pH}$ & Effluent $\mathrm{pH}$ & $\mathrm{UV}-\mathrm{Abs}$ & $\mathrm{C} / \mathrm{C}_{\mathrm{o}}$ \\
\hline 94 & 161.144 & & 6.12 & 1.388 & 0.825 \\
95 & 161.536 & & & 0.486 & 0.274 \\
96 & 161.977 & & 6.05 & 0.177 & 0.109 \\
97 & 162.384 & & 0.062 & 0.047 \\
98 & 162.777 & 6.01 & 0.044 & 0.037 \\
99 & 163.155 & & 0.044 & 0.037 \\
100 & 163.449 & 5.95 & 0.064 & 0.048 \\
101 & 164.494 & & 0.060 & 0.046 \\
102 & 165.415 & 5.88 & 0.034 & 0.032 \\
103 & 166.408 & & 0.034 & 0.032 \\
104 & 167.804 & & & 0.024 & 0.026 \\
105 & 169.249 & & & 0.013 & 0.020 \\
106 & 170.497 & & & 0.010 & 0.019
\end{tabular}


Table 13: Non-Reactive Tracer Study Data - Study \#4_pH 9_NRT

Performed for $\mathrm{Al}_{2} \mathrm{O}_{3}$ Study \#4_pH 9

Column: A

Darcy Velocity: $0.097 \mathrm{~cm} / \mathrm{min}$

Electrolyte: $\mathrm{K}_{2} \mathrm{HPO}_{4} / \mathrm{K}_{3} \mathrm{HPO}_{4}$

Ionic Strength: $0.015 \mathrm{M}$

Data results for pentafluorobenzoic acid transport Study \#4_pH 9_NRT; Samples 1 - 26.

\begin{tabular}{|c|c|c|c|c|c|}
\hline Sample & Pore Volume (mL) & UV-Vis Abs & Dilution & $\mathrm{C} / \mathrm{C}_{\mathrm{o}}$ & \\
\hline 1 & -0.315 & 0.023 & 1 & 0.001 & LDL \\
\hline 2 & 0.014 & 0.020 & 1 & 0.001 & LDL \\
\hline 3 & 0.335 & 0.226 & 1 & 0.027 & \\
\hline 4 & 0.681 & 2.199 & 1 & 0.284 & \\
\hline 5 & 1.020 & 1.968 & 3 & 0.786 & \\
\hline 6 & 1.353 & 2.392 & 3 & 0.958 & \\
\hline 7 & 1.688 & 2.500 & 3 & 1.002 & \\
\hline 8 & 2.032 & 2.500 & 3 & 1.002 & \\
\hline 9 & 2.393 & 2.487 & 3 & 0.996 & \\
\hline 10 & 2.737 & 2.487 & 3 & 0.996 & \\
\hline 11 & 3.074 & 2.528 & 3 & 1.013 & \\
\hline 12 & 3.539 & 2.542 & 3 & 1.019 & \\
\hline 13 & 4.146 & 2.528 & 3 & 1.013 & \\
\hline 14 & 4.730 & 2.487 & 3 & 0.996 & \\
\hline 15 & 5.451 & 2.487 & 3 & 0.996 & \\
\hline 16 & 6.356 & 2.514 & 3 & 1.007 & \\
\hline 17 & 7.291 & 2.514 & 3 & 1.007 & \\
\hline 18 & 8.214 & 2.487 & 3 & 0.996 & \\
\hline 19 & 9.132 & 2.487 & 3 & 0.996 & \\
\hline 20 & 10.076 & 2.324 & 3 & 0.930 & \\
\hline 21 & 11.217 & 2.487 & 3 & 0.996 & \\
\hline 22 & 12.382 & 2.542 & 3 & 1.019 & \\
\hline 23 & 13.087 & 2.500 & 3 & 1.002 & Elution \\
\hline 24 & 13.443 & 2.487 & 3 & 0.996 & \\
\hline 25 & 13.781 & 2.414 & 3 & 0.967 & \\
\hline 26 & 14.084 & 1.823 & 3 & 0.727 & \\
\hline
\end{tabular}


Table 13 (Continued): Non-Reactive Tracer Study Data - Study \#4_pH 9_NRT

Data results for pentafluorobenzoic acid transport Study \#4_pH 9_NRT; Samples 27 - 44.

\begin{tabular}{|c|c|c|c|c|}
\hline Sample & Pore Volume (mL) & UV-Vis Abs & Dilution & $\mathrm{C} / \mathrm{C}_{\mathrm{o}}$ \\
\hline 27 & 14.422 & 2.114 & 1 & 0.273 \\
\hline 28 & 14.793 & 0.544 & 1 & 0.060 \\
\hline 29 & 15.154 & 0.251 & 1 & 0.031 \\
\hline 30 & 15.489 & 0.170 & 1 & 0.020 \\
\hline 31 & 15.835 & 0.131 & 1 & 0.015 \\
\hline 32 & 16.257 & 0.103 & 1 & 0.012 \\
\hline 33 & 16.723 & 0.081 & 1 & 0.009 \\
\hline 34 & 17.117 & 0.071 & 1 & 0.008 \\
\hline 35 & 17.822 & 0.055 & 1 & 0.006 \\
\hline 36 & 18.881 & 0.046 & 1 & 0.005 \\
\hline 37 & 19.910 & 0.036 & 1 & 0.003 \\
\hline 38 & 20.886 & 0.036 & 1 & 0.003 \\
\hline 39 & 21.807 & 0.036 & 1 & 0.003 \\
\hline 40 & 22.797 & 0.030 & 1 & 0.003 \\
\hline 41 & 23.874 & 0.025 & 1 & 0.002 \\
\hline 42 & 24.964 & 0.029 & 1 & 0.002 \\
\hline 43 & 26.030 & 0.023 & 1 & 0.002 \\
\hline 44 & 27.009 & 0.025 & 1 & 0.002 \\
\hline
\end{tabular}


Table 14: Aluminum Oxide Transport Data - Study \#4_pH 9

Concentration: $100 \mathrm{mg} / \mathrm{L}$

Column: A

Darcy Velocity: $0.098 \mathrm{~cm} / \mathrm{min}$

Electrolyte: $\mathrm{K}_{2} \mathrm{HPO}_{4} / \mathrm{K}_{3} \mathrm{HPO}_{4}$

Ionic Strength: $0.015 \mathrm{M}$

Data results for aluminum oxide nanoparticle transport Study \#4_pH 9; samples 1 - 27.

\begin{tabular}{|c|c|c|c|c|c|}
\hline Sample & Pore Volume (mL) & Influent $\mathrm{pH}$ & Effluent $\mathrm{pH}$ & UV-Vis Abs & $\mathrm{C} / \mathrm{C}_{\mathrm{o}}$ \\
\hline 1 & -0.443 & & & 0.053 & 0.025 \\
\hline 2 & -0.246 & & & 0.063 & 0.031 \\
\hline 3 & -0.054 & & & 0.058 & 0.028 \\
\hline 4 & 0.151 & & & 0.070 & 0.035 \\
\hline 5 & 0.358 & & & 0.097 & 0.052 \\
\hline 6 & 0.581 & 9.44 & & 0.232 & 0.119 \\
\hline 7 & 0.806 & & 8.86 & 0.608 & 0.347 \\
\hline 8 & 1.089 & & & 0.826 & 0.479 \\
\hline 9 & 1.476 & & 9.09 & 1.178 & 0.693 \\
\hline 10 & 1.856 & & & 1.363 & 0.805 \\
\hline 11 & 2.224 & & 9.20 & 1.418 & 0.838 \\
\hline 12 & 2.588 & & & 1.508 & 0.893 \\
\hline 13 & 2.997 & 9.48 & 9.17 & 1.547 & 0.916 \\
\hline 14 & 3.449 & & & 1.567 & 0.928 \\
\hline 15 & 3.881 & & 9.19 & 1.634 & 0.969 \\
\hline 16 & 4.286 & & & 1.688 & 1.002 \\
\hline 17 & 4.666 & & & 1.677 & 0.995 \\
\hline 18 & 4.952 & & & 1.749 & 1.039 \\
\hline 19 & 5.362 & & 9.11 & & \\
\hline 20 & 5.771 & 9.42 & & 1.705 & 1.012 \\
\hline 21 & 6.168 & & 9.23 & & \\
\hline 22 & 6.583 & & & 1.716 & 1.019 \\
\hline 23 & 7.006 & & 9.25 & & \\
\hline 24 & 7.416 & & & 1.739 & 1.033 \\
\hline 25 & 7.834 & 9.34 & 9.23 & & \\
\hline 26 & 8.198 & & & 1.766 & 1.049 \\
\hline 27 & 8.630 & & 9.20 & & \\
\hline
\end{tabular}


Table 14 (Continued): Aluminum Oxide Transport Data - Study \#4_pH 9

Data results for aluminum oxide nanoparticle transport Study \#4_pH 9; samples 28 - 61 .

\begin{tabular}{|c|c|c|c|c|c|c|}
\hline Sample & Pore Volume (mL) & Influent $\mathrm{pH}$ & Effluent $\mathrm{pH}$ & UV-Vis Abs & $\mathrm{C} / \mathrm{C}_{\mathrm{o}}$ & \\
\hline 28 & 9.057 & & & 1.661 & 0.985 & \\
\hline 29 & 9.493 & & 9.17 & & & \\
\hline 30 & 9.921 & & & 1.661 & 0.985 & \\
\hline 31 & 10.404 & & 9.19 & & & \\
\hline 32 & 10.898 & 9.30 & & 1.782 & 1.059 & \\
\hline 33 & 11.362 & & 9.17 & & & \\
\hline 34 & 11.882 & & & 1.673 & 0.993 & \\
\hline 35 & 12.139 & & & 1.806 & 1.073 & \\
\hline 36 & 12.353 & & & 1.927 & 1.147 & \\
\hline 37 & 12.540 & & & 1.909 & 1.136 & \\
\hline 38 & 12.819 & & & 1.322 & 0.780 & \\
\hline 39 & 13.159 & & 8.95 & 0.690 & 0.397 & \\
\hline 40 & 13.504 & & & 0.202 & 0.101 & \\
\hline 41 & 13.893 & & & 0.128 & 0.071 & \\
\hline 42 & 14.278 & & 9.01 & 0.091 & 0.048 & \\
\hline 43 & 14.739 & 9.25 & & 0.084 & 0.044 & \\
\hline 44 & 15.239 & & & 0.138 & 0.077 & Elution \\
\hline 45 & 15.664 & & 8.93 & 0.196 & 0.113 & \\
\hline 46 & 16.038 & & & 0.080 & 0.042 & \\
\hline 47 & 16.410 & & & 0.091 & 0.048 & \\
\hline 48 & 16.724 & & 8.90 & 0.139 & 0.078 & \\
\hline 49 & 17.148 & & 9.14 & & & \\
\hline 50 & 17.562 & & & 0.067 & 0.034 & \\
\hline 51 & 17.962 & & 9.04 & & & \\
\hline 52 & 18.351 & & & 0.156 & 0.088 & \\
\hline 53 & 18.732 & 9.20 & 9.06 & & & \\
\hline 54 & 19.126 & & & 0.051 & 0.024 & \\
\hline 55 & 19.531 & & 9.05 & & & \\
\hline 56 & 19.923 & & & 0.287 & 0.169 & \\
\hline 57 & 20.317 & & 9.04 & & & \\
\hline 58 & 20.709 & & & 0.163 & 0.093 & \\
\hline 59 & 21.183 & & 9.04 & & & \\
\hline 60 & 21.666 & & & 0.234 & 0.120 & \\
\hline 61 & 22.065 & & 9.02 & & & \\
\hline
\end{tabular}


Table 14 (Continued): Aluminum Oxide Transport Data - Study \#4_pH 9

Data results for aluminum oxide nanoparticle transport Study \#4 pH 9; samples 62 - 74.

\begin{tabular}{cccccc} 
Sample & Pore Volume $(\mathrm{mL})$ & Influent $\mathrm{pH}$ & Effluent $\mathrm{pH}$ & $\mathrm{UV}-\mathrm{Vis} \mathrm{Abs}$ & ${\mathrm{C} / \mathrm{C}_{\mathrm{o}}}^{\mathrm{N}}$ \\
\hline 62 & 22.458 & & & 0.191 & 0.094 \\
63 & 22.912 & & 9.04 & & \\
64 & 23.364 & & & 0.131 & 0.073 \\
65 & 23.759 & & 9.03 & & \\
66 & 24.163 & 9.14 & & 0.142 & 0.080 \\
67 & 24.549 & & 8.86 & & \\
68 & 24.931 & & & 0.114 & 0.063 \\
69 & 25.341 & 9.10 & 8.98 & & \\
70 & 25.747 & & & 0.128 & 0.071 \\
71 & 26.150 & & 9.01 & & \\
72 & 26.559 & & & 0.037 & 0.015 \\
73 & 26.952 & & 8.98 & & \\
74 & 27.352 & & & 0.827 & 0.502
\end{tabular}




\section{Table 15: Non-Reactive Tracer Study Data - Study \#5_pH 9_NRT}

Performed for $\mathrm{Al}_{2} \mathrm{O}_{3}$ Study \#5_pH 9

Column: A

Darcy Velocity: $0.098 \mathrm{~cm} / \mathrm{min}$

Electrolyte: $\mathrm{K}_{2} \mathrm{HPO}_{4} / \mathrm{K}_{3} \mathrm{HPO}_{4}$

Ionic Strength: $0.015 \mathrm{M}$

Data results for pentafluorobenzoic acid transport Study \#5_pH 9_NRT; Samples 1 - 29.

\begin{tabular}{|c|c|c|c|c|c|}
\hline Sample & Pore Volume (mL) & UV-Vis Abs & Dilution & $\mathrm{C} / \mathrm{C}_{\mathrm{o}}$ & \\
\hline 1 & -0.315 & 0.011 & 1 & -0.006 & LDL \\
\hline 2 & -0.134 & 0.005 & 1 & -0.007 & LDL \\
\hline 3 & 0.042 & 0.002 & 1 & -0.001 & LDL \\
\hline 4 & 0.225 & 0.002 & 1 & -0.004 & LDL \\
\hline 5 & 0.420 & 0.028 & 1 & -0.001 & LDL \\
\hline 6 & 0.634 & 1.189 & 1 & 0.158 & \\
\hline 7 & 0.857 & 1.682 & 2.9 & 0.674 & \\
\hline 8 & 1.133 & 2.328 & 2.9 & 0.919 & \\
\hline 9 & 1.488 & 2.699 & 2.6 & 0.958 & \\
\hline 10 & 1.841 & 2.745 & 2.6 & 0.974 & \\
\hline 11 & 2.188 & 2.568 & 2.8 & 0.989 & \\
\hline 12 & 2.536 & 2.553 & 2.8 & 0.989 & \\
\hline 13 & 2.895 & 2.602 & 2.8 & 0.984 & \\
\hline 14 & 3.244 & 2.328 & 3.1 & 0.991 & \\
\hline 15 & 3.504 & 2.432 & 3.0 & 0.998 & \\
\hline 16 & 4.236 & 2.745 & 2.7 & 0.995 & \\
\hline 17 & 4.966 & 2.620 & 2.8 & 0.990 & \\
\hline 18 & 5.726 & 2.602 & 2.8 & 0.990 & \\
\hline 19 & 6.515 & 2.168 & 3.4 & 1.011 & \\
\hline 20 & 7.341 & 2.319 & 3.2 & 1.007 & \\
\hline 21 & 8.114 & 2.420 & 3.0 & 1.006 & \\
\hline 22 & 8.864 & 2.482 & 3.0 & 1.006 & \\
\hline 24 & 10.307 & 2.301 & 3.2 & 1.010 & \\
\hline 25 & 10.533 & 2.523 & 2.9 & 0.997 & Elution \\
\hline 26 & 10.713 & 2.377 & 3.1 & 1.004 & \\
\hline 27 & 10.896 & 2.456 & 3.0 & 1.000 & \\
\hline 28 & 11.077 & 2.444 & 3.0 & 0.999 & \\
\hline 29 & 11.267 & 2.282 & 3.0 & 1.002 & \\
\hline
\end{tabular}


Table 15 (Continued): Non-Reactive Tracer Study Data - Study \#5_pH 9_NRT

Data results for pentafluorobenzoic acid transport Study \#5_pH 9_NRT; Samples 30 - 48.

\begin{tabular}{cccccc} 
Sample & Pore Volume $(\mathrm{mL})$ & UV-Vis Abs & Dilution & ${\mathrm{C} / \mathrm{C}_{\mathrm{o}}}$ & \\
\hline 30 & 11.457 & 2.071 & 3.2 & 0.914 & \\
31 & 11.641 & 1.169 & 3.0 & 0.480 & \\
32 & 11.816 & 0.396 & 3.2 & 0.167 & \\
33 & 12.075 & 0.436 & 1 & 0.057 & \\
34 & 12.424 & 0.197 & 1 & 0.025 & \\
35 & 12.776 & 0.117 & 1 & 0.014 & \\
36 & 13.127 & 0.082 & 1 & 0.010 & \\
37 & 13.470 & 0.065 & 1 & 0.008 & \\
38 & 13.794 & 0.056 & 1 & 0.005 & \\
39 & 14.040 & 0.053 & 1 & 0.005 & \\
40 & 14.790 & 0.043 & 1 & 0.002 & \\
41 & 15.546 & 0.032 & 1 & -0.001 & LDL \\
42 & 16.405 & 0.027 & 1 & -0.002 & LDL \\
43 & 17.164 & 0.025 & 1 & -0.002 & LDL \\
44 & 17.920 & 0.021 & 1 & -0.003 & LDL \\
45 & 18.679 & 0.021 & 1 & -0.003 & LDL \\
46 & 19.443 & 0.023 & 1 & -0.003 & LDL \\
47 & 20.191 & 0.021 & 1 & -0.003 & LDL \\
48 & 20.902 & 0.012 & 1 & -0.006 & LDL
\end{tabular}


Table 16: Aluminum Oxide Transport Data - Study \#5_pH 9

Concentration: $100 \mathrm{mg} / \mathrm{L}$

Column: A

Darcy Velocity: $0.098 \mathrm{~cm} / \mathrm{min}$

Electrolyte: $\mathrm{K}_{2} \mathrm{HPO}_{4} / \mathrm{K}_{3} \mathrm{HPO}_{4}$

Ionic Strength: $0.015 \mathrm{M}$

Data results for aluminum oxide nanoparticle transport Study \#5_pH 9; samples 1 - 27.

\begin{tabular}{|c|c|c|c|c|c|c|}
\hline Sample & $\begin{array}{c}\text { Pore } \\
\text { Volume } \\
(\mathrm{mL})\end{array}$ & $\begin{array}{c}\text { Influent } \\
\mathrm{pH}\end{array}$ & $\begin{array}{c}\text { Effluent } \\
\mathrm{pH}\end{array}$ & $\begin{array}{c}\text { UV-Vis } \\
\mathrm{Abs}\end{array}$ & $\mathrm{C} / \mathrm{C}_{\mathrm{o}}$ & \\
\hline 1 & -0.312 & & & 0.024 & -0.001 & LDL \\
\hline 2 & -0.126 & & & 0.005 & -0.012 & LDL \\
\hline 3 & 0.063 & & & 0.007 & -0.011 & LDL \\
\hline 4 & 0.243 & & & 0.002 & -0.013 & LDL \\
\hline 5 & 0.415 & & & 0.019 & -0.004 & LDL \\
\hline 6 & 0.592 & & & 0.124 & 0.055 & \\
\hline 7 & 0.782 & & & 0.319 & 0.160 & \\
\hline 8 & 0.967 & & 8.55 & 0.489 & 0.258 & \\
\hline 9 & 1.134 & & & 0.611 & 0.337 & \\
\hline 10 & 1.322 & & & 0.742 & 0.422 & \\
\hline 11 & 1.518 & & & 0.885 & 0.514 & \\
\hline 12 & 1.722 & & & 1.011 & 0.595 & \\
\hline 13 & 1.925 & & & 1.118 & 0.664 & \\
\hline 14 & 2.110 & & & 1.192 & 0.712 & \\
\hline 15 & 2.378 & & 8.84 & 1.285 & 0.772 & \\
\hline 16 & 2.744 & 9.34 & & 1.359 & 0.820 & \\
\hline 17 & 3.108 & & & 1.400 & 0.846 & \\
\hline 18 & 3.440 & & 8.87 & 1.447 & 0.876 & \\
\hline 19 & 3.764 & & & 1.470 & 0.891 & \\
\hline 20 & 4.093 & & & 1.506 & 0.914 & \\
\hline 21 & 4.442 & & 8.88 & 1.504 & 0.913 & \\
\hline 22 & 4.803 & & & 1.530 & 0.930 & \\
\hline 24 & 5.461 & & 8.93 & & & \\
\hline 25 & 5.850 & & & 1.548 & 0.942 & \\
\hline 26 & 6.262 & & 8.9 & & & \\
\hline 27 & 6.687 & & & 1.559 & 0.949 & \\
\hline
\end{tabular}


Table 16 (Continued): Aluminum Oxide Transport Data - Study \#5_pH 9

Data results for aluminum oxide nanoparticle transport Study \#5_pH 9; samples 28 - 60.

\begin{tabular}{|c|c|c|c|c|c|}
\hline Sample & $\begin{array}{c}\text { Pore } \\
\text { Volume } \\
(\mathrm{mL})\end{array}$ & $\begin{array}{c}\text { Influent } \\
\mathrm{pH}\end{array}$ & $\begin{array}{c}\text { Effluent } \\
\mathrm{pH}\end{array}$ & $\begin{array}{c}\text { UV-Vis } \\
\text { Abs }\end{array}$ & $\mathrm{C} / \mathrm{C}_{\mathrm{o}}$ \\
\hline 28 & 7.125 & 9.29 & 8.85 & & \\
\hline 29 & 7.548 & & & 1.585 & 0.965 \\
\hline 30 & 7.998 & & 8.84 & & \\
\hline 31 & 8.404 & & & 1.595 & 0.972 \\
\hline 32 & 8.843 & 9.25 & & & \\
\hline 33 & 9.272 & & & 1.595 & 0.972 \\
\hline 34 & 9.668 & & 8.8 & & \\
\hline 35 & 10.096 & & & 1.595 & 0.972 \\
\hline 36 & 10.507 & & 8.84 & & \\
\hline 37 & 10.903 & & & 1.595 & 0.972 \\
\hline 38 & 11.303 & & 8.86 & & \\
\hline 39 & 11.703 & & & 1.609 & 0.981 \\
\hline 40 & 12.106 & & 8.84 & & \\
\hline 41 & 12.506 & & & 1.597 & 0.973 \\
\hline 42 & 12.903 & & 8.84 & & \\
\hline 43 & 13.333 & 9.2 & & 1.609 & 0.981 \\
\hline 44 & 13.758 & & 8.76 & & \\
\hline 45 & 14.174 & & & 1.609 & 0.981 \\
\hline 46 & 14.592 & & 8.8 & & \\
\hline 47 & 14.995 & & & 1.609 & 0.981 \\
\hline 48 & 15.629 & & 8.8 & & \\
\hline 49 & 16.253 & & & 1.614 & 0.984 \\
\hline 50 & 16.504 & & & 1.595 & 0.972 \\
\hline 51 & 16.684 & & & 1.600 & 0.975 \\
\hline 52 & 16.860 & & & 1.607 & 0.980 \\
\hline 53 & 17.056 & & & 1.590 & 0.969 \\
\hline 54 & 17.264 & & & 1.540 & 0.936 \\
\hline 55 & 17.452 & & & 1.186 & 0.708 \\
\hline 56 & 17.623 & & & 0.670 & 0.375 \\
\hline 57 & 17.799 & 9.3 & & 0.327 & 0.154 \\
\hline 58 & 17.983 & & 8.74 & 0.168 & 0.079 \\
\hline 59 & 18.159 & & & 0.110 & 0.048 \\
\hline 60 & 18.330 & & & 0.077 & 0.028 \\
\hline
\end{tabular}


Table 16 (Continued): Aluminum Oxide Transport Data - Study \#5_pH 9

Data results for aluminum oxide nanoparticle transport Study \#5_pH 9; samples 61 - 96.

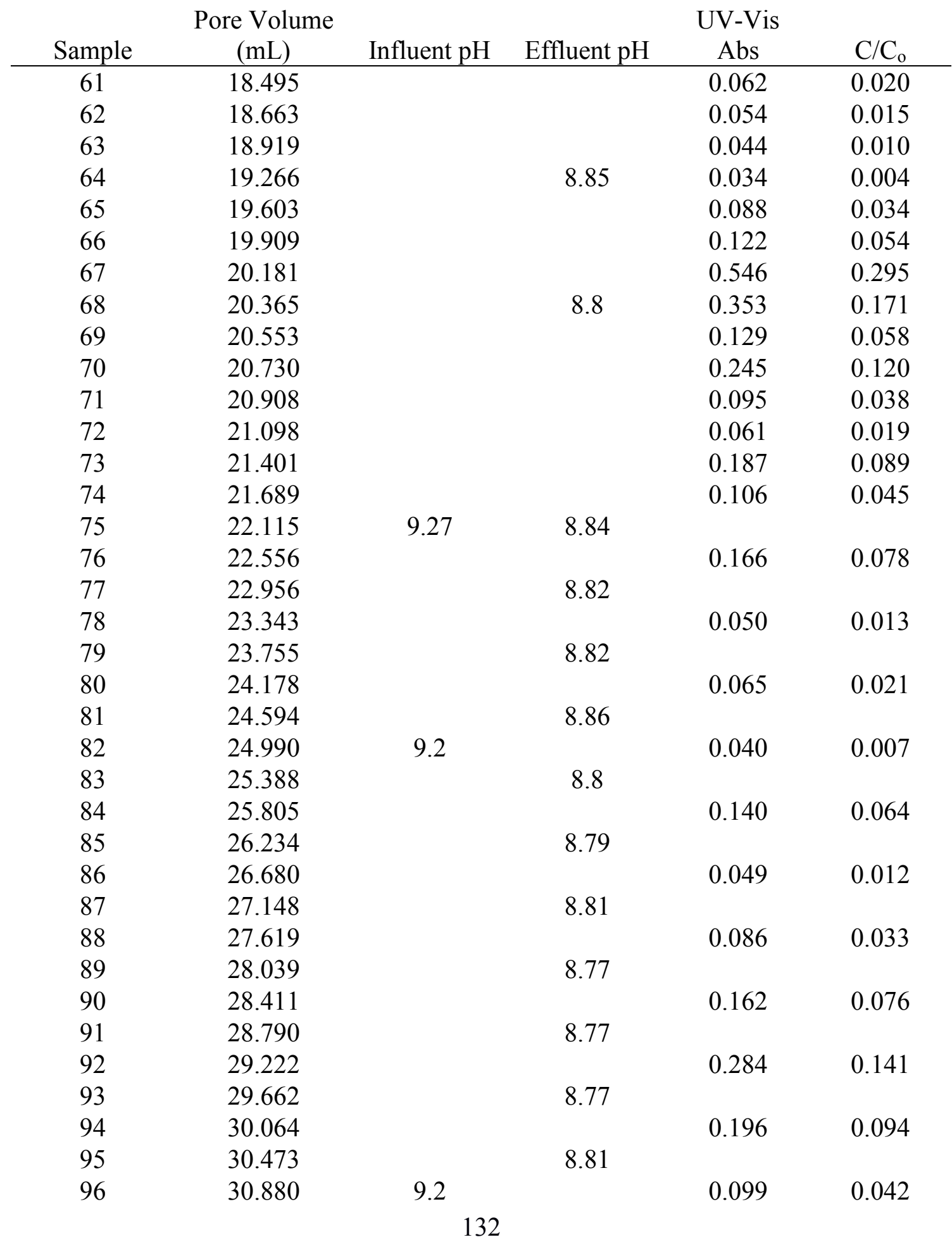


Table 17: Non-Reactive Tracer Study Data - Study \#6_pH 9_NRT

Performed for $\mathrm{Al}_{2} \mathrm{O}_{3}$ Study \#6_pH 9

Column: A

Darcy Velocity: $0.098 \mathrm{~cm} / \mathrm{min}$

Electrolyte: $\mathrm{K}_{2} \mathrm{HPO}_{4} / \mathrm{K}_{3} \mathrm{HPO}_{4}$

Ionic Strength: $0.015 \mathrm{M}$

Data results for pentafluorobenzoic acid transport Study \#6_pH 9_NRT; Samples 1 - 28.

\begin{tabular}{cccccc} 
Sample & Pore Volume $(\mathrm{mL})$ & UV-Vis Abs & Dilution & ${\mathrm{C} / \mathrm{C}_{\mathrm{o}}}$ & \\
\cline { 1 - 4 } 1 & -0.359 & 0.019 & 1 & 0.001 & LDL \\
2 & -0.146 & 0.010 & 1 & 0.000 & LDL \\
3 & 0.058 & 0.007 & 1 & -0.001 & LDL \\
4 & 0.291 & 0.033 & 1 & 0.002 & \\
5 & 0.528 & 0.190 & 1 & 0.020 & \\
6 & 0.731 & 1.807 & 1 & 0.241 & \\
7 & 0.945 & 1.625 & 3.0 & 0.666 & \\
8 & 1.183 & 2.194 & 3.0 & 0.891 & \\
9 & 1.497 & 2.347 & 3.0 & 0.956 & \\
10 & 1.877 & 2.387 & 3.0 & 0.970 & \\
11 & 2.258 & 2.409 & 3.0 & 0.982 & \\
12 & 2.634 & 2.409 & 3.0 & 0.979 & \\
13 & 3.000 & 2.444 & 3.0 & 0.991 & \\
14 & 3.434 & 2.444 & 3.0 & 0.991 & \\
15 & 3.784 & 2.420 & 3.0 & 0.985 & \\
16 & 4.645 & 2.420 & 3.0 & 0.984 & \\
17 & 5.508 & 2.468 & 3.0 & 0.999 & \\
18 & 6.371 & 2.468 & 3.0 & 1.000 & \\
19 & 7.168 & 2.495 & 3.0 & 1.007 & \\
20 & 7.980 & 2.468 & 3.0 & 0.999 & \\
21 & 8.830 & 2.468 & 3.0 & 0.996 & \\
22 & 9.708 & 2.301 & 3.2 & 1.007 & \\
\cline { 1 - 2 } 24 & 10.827 & 2.769 & 2.6 & 0.990 & \multirow{2}{*}{ Elution } \\
25 & 11.040 & 2.824 & 2.7 & 0.979 & \\
26 & 11.264 & 2.495 & 2.7 & 1.001 & \\
27 & 11.481 & 2.409 & 2.7 & 1.013 & \\
28 & 11.678 & 2.131 & 2.7 & 0.989 &
\end{tabular}


Table 17 (Continued): Non-Reactive Tracer Study Data - Study \#6_pH 9_NRT

Data results for pentafluorobenzoic acid transport Study \#6_pH 9_NRT; Samples 29 - 48.

\begin{tabular}{|c|c|c|c|c|}
\hline Sample & Pore Volume $(\mathrm{mL})$ & UV-Vis Abs & Dilution & $\mathrm{C} / \mathrm{C}_{\mathrm{o}}$ \\
\hline 29 & 11.905 & 2.046 & 2.7 & 0.797 \\
\hline 30 & 12.222 & 0.943 & 2.6 & 0.298 \\
\hline 31 & 12.597 & 0.279 & 2.5 & 0.069 \\
\hline 32 & 12.962 & 0.282 & 1 & 0.036 \\
\hline 33 & 13.330 & 0.202 & 1 & 0.025 \\
\hline 34 & 13.705 & 0.161 & 1 & 0.019 \\
\hline 35 & 14.091 & 0.131 & 1 & 0.015 \\
\hline 36 & 14.378 & 0.119 & 1 & 0.014 \\
\hline 37 & 15.187 & 0.102 & 1 & 0.011 \\
\hline 38 & 16.003 & 0.065 & 1 & 0.006 \\
\hline 39 & 16.862 & 0.067 & 1 & 0.006 \\
\hline 40 & 17.753 & 0.045 & 1 & 0.004 \\
\hline 41 & 18.637 & 0.034 & 1 & 0.002 \\
\hline 42 & 19.528 & 0.039 & 1 & 0.003 \\
\hline 43 & 20.469 & 0.125 & 1 & 0.015 \\
\hline 44 & 20.891 & 0.024 & 1 & 0.001 \\
\hline 45 & 21.795 & 0.018 & 1 & 0.001 \\
\hline 46 & 22.637 & 0.029 & 1 & 0.002 \\
\hline 47 & 23.565 & 0.017 & 1 & 0.000 \\
\hline 48 & 24.408 & 0.011 & 1 & 0.000 \\
\hline
\end{tabular}


Table 18: Aluminum Oxide Transport Data - Study \#6_pH 9

Concentration: $100 \mathrm{mg} / \mathrm{L}$

Column: A

Darcy Velocity: $0.098 \mathrm{~cm} / \mathrm{min}$

Electrolyte: $\mathrm{K}_{2} \mathrm{HPO}_{4} / \mathrm{K}_{3} \mathrm{HPO}_{4}$

Ionic Strength: $0.015 \mathrm{M}$

Data results for aluminum oxide nanoparticle transport Study \#6_pH 9; samples 1 - 27.

\begin{tabular}{|c|c|c|c|c|c|c|}
\hline Sample & $\begin{array}{c}\text { Pore } \\
\text { Volume } \\
(\mathrm{mL})\end{array}$ & Influent $\mathrm{pH}$ & $\begin{array}{c}\text { Effluent } \\
\mathrm{pH}\end{array}$ & $\begin{array}{c}\text { UV-Vis } \\
\text { Abs }\end{array}$ & $\mathrm{C} / \mathrm{C}_{\mathrm{o}}$ & \\
\hline 1 & -0.380 & & & 0.008 & -0.010 & LDL \\
\hline 2 & -0.165 & & & -0.008 & -0.018 & LDL \\
\hline 3 & 0.027 & & & -0.008 & -0.018 & LDL \\
\hline 4 & 0.231 & & & -0.003 & -0.015 & LDL \\
\hline 5 & 0.430 & & & 0.007 & -0.010 & LDL \\
\hline 6 & 0.631 & & & 0.071 & 0.024 & \\
\hline 7 & 0.826 & & & 0.161 & 0.073 & \\
\hline 8 & 1.026 & & & 0.283 & 0.137 & \\
\hline 9 & 1.230 & & & 0.422 & 0.209 & \\
\hline 10 & 1.443 & & & 0.608 & 0.325 & \\
\hline 11 & 1.653 & & & 0.795 & 0.442 & \\
\hline 12 & 1.857 & & 8.70 & 0.986 & 0.561 & \\
\hline 13 & 2.069 & & & 1.093 & 0.628 & \\
\hline 14 & 2.364 & 9.15 & & 1.273 & 0.741 & \\
\hline 15 & 2.722 & & & 1.337 & 0.781 & \\
\hline 16 & 3.098 & & & 1.485 & 0.873 & \\
\hline 17 & 3.487 & & & 1.447 & 0.849 & \\
\hline 18 & 3.854 & & 8.80 & 1.477 & 0.868 & \\
\hline 19 & 4.244 & & & 1.529 & 0.901 & \\
\hline 20 & 4.634 & & & 1.525 & 0.898 & \\
\hline 21 & 5.003 & & & 1.543 & 0.909 & \\
\hline 22 & 5.361 & 9.13 & 8.89 & 1.560 & 0.920 & \\
\hline 23 & 5.731 & & & 1.597 & 0.943 & \\
\hline 24 & 6.098 & & & 1.564 & 0.922 & \\
\hline 25 & 6.464 & & & 1.726 & 1.024 & \\
\hline 26 & 6.825 & & 8.89 & 1.596 & 0.942 & \\
\hline 27 & 7.098 & & & 1.611 & 0.952 & \\
\hline
\end{tabular}


Table 18 (Continued): Aluminum Oxide Transport Data - Study \#6_pH 9

Data results for aluminum oxide nanoparticle transport Study \#6_pH 9; samples 28 - 60.

\begin{tabular}{|c|c|c|c|c|c|c|}
\hline Sample & $\begin{array}{l}\text { Pore } \\
\text { Volume } \\
\text { (mL) }\end{array}$ & Influent $\mathrm{pH}$ & $\begin{array}{c}\text { Effluent } \\
\mathrm{pH}\end{array}$ & $\begin{array}{c}\text { UV-Vis } \\
\text { Abs }\end{array}$ & $\mathrm{C} / \mathrm{C}_{\mathrm{o}}$ & \\
\hline 28 & 7.495 & & 8.89 & & & \\
\hline 29 & 7.915 & & & 1.597 & 0.943 & \\
\hline 30 & 8.338 & & 8.86 & & & \\
\hline 31 & 8.737 & & & 1.633 & 0.966 & \\
\hline 32 & 9.138 & 9.09 & 8.84 & & & \\
\hline 33 & 9.539 & & & 1.660 & 0.982 & \\
\hline 34 & 9.938 & & 8.88 & & & \\
\hline 35 & 10.335 & & & 1.615 & 0.954 & \\
\hline 36 & 10.732 & & 8.84 & & & \\
\hline 37 & 11.063 & & & 1.611 & 0.952 & \\
\hline 38 & 11.582 & & 8.89 & & & \\
\hline 39 & 11.981 & & & 1.615 & 0.954 & \\
\hline 40 & 12.379 & & 8.89 & & & \\
\hline 41 & 12.780 & & & 1.611 & 0.952 & \\
\hline 42 & 12.985 & 9.06 & & 1.611 & 0.952 & \\
\hline 43 & 13.226 & 9.14 & & 1.564 & 0.922 & Elution \\
\hline 44 & 13.450 & & & 1.576 & 0.930 & \\
\hline 45 & 13.701 & & & 1.589 & 0.938 & \\
\hline 46 & 13.936 & & & 1.584 & 0.935 & \\
\hline 47 & 14.175 & & & 1.394 & 0.816 & \\
\hline 48 & 14.395 & & & 0.912 & 0.515 & \\
\hline 49 & 14.591 & & 8.78 & 0.481 & 0.245 & \\
\hline 50 & 14.783 & & & 0.247 & 0.118 & \\
\hline 51 & 14.988 & & & 0.138 & 0.061 & \\
\hline 52 & 15.190 & & & 0.093 & 0.036 & \\
\hline 53 & 15.388 & & & 0.079 & 0.028 & \\
\hline 54 & 15.685 & & & 0.064 & 0.020 & \\
\hline 55 & 16.055 & & & 0.055 & 0.015 & LDL \\
\hline 56 & 16.445 & & 8.83 & 0.072 & 0.024 & \\
\hline 57 & 16.843 & 9.13 & & 0.042 & 0.008 & LDL \\
\hline 58 & 17.218 & & & 0.036 & 0.005 & LDL \\
\hline 59 & 17.636 & & & 0.042 & 0.008 & LDL \\
\hline 60 & 17.959 & & & 0.024 & -0.001 & LDL \\
\hline
\end{tabular}


Table 18 (Continued): Aluminum Oxide Transport Data - Study \#6_pH 9

Data results for aluminum oxide nanoparticle transport Study \#6_pH 9; samples 61 - 74.

\begin{tabular}{|c|c|c|c|c|c|c|}
\hline Sample & $\begin{array}{c}\text { Pore } \\
\text { Volume } \\
(\mathrm{mL})\end{array}$ & Influent $\mathrm{pH}$ & $\begin{array}{c}\text { Effluent } \\
\mathrm{pH}\end{array}$ & $\begin{array}{c}\mathrm{UV}-\mathrm{V} \text { is } \\
\mathrm{Abs}\end{array}$ & $\mathrm{C} / \mathrm{C}_{\mathrm{o}}$ & \\
\hline 61 & 18.365 & & 8.89 & & & LDL \\
\hline 62 & 18.768 & & & 0.018 & -0.004 & LDL \\
\hline 63 & 19.182 & & 8.83 & & & LDL \\
\hline 64 & 19.607 & & & 0.012 & -0.007 & LDL \\
\hline 65 & 20.001 & & 8.79 & & & LDL \\
\hline 66 & 20.396 & & & 0.010 & -0.009 & LDL \\
\hline 67 & 20.790 & 9.10 & 8.81 & & & LDL \\
\hline 68 & 21.175 & & & 0.007 & -0.010 & LDL \\
\hline 69 & 21.562 & & 8.82 & & & LDL \\
\hline 70 & 21.966 & & & 0.005 & -0.011 & LDL \\
\hline 71 & 22.405 & & 8.84 & & & LDL \\
\hline 72 & 22.868 & & & 0.003 & -0.012 & LDL \\
\hline 73 & 23.274 & & 8.82 & & & LDL \\
\hline 74 & 23.648 & & & 0.004 & -0.012 & LDL \\
\hline
\end{tabular}


Table 19: Non-Reactive Tracer Study Data - Study \#7_pH 9_NRT

Performed for $\mathrm{Al}_{2} \mathrm{O}_{3}$ Study \#7_pH 9

Column: A

Darcy Velocity: $0.025 \mathrm{~cm} / \mathrm{min}$

Electrolyte: $\mathrm{K}_{2} \mathrm{HPO}_{4} / \mathrm{K}_{3} \mathrm{HPO}_{4}$

Ionic Strength: $0.015 \mathrm{M}$

Data results for pentafluorobenzoic acid transport Study \#7_pH 9_NRT; Samples 1 - 28.

\begin{tabular}{cccccc} 
Sample & Pore Volume $(\mathrm{mL})$ & UV-Vis Abs & Dilution & ${\mathrm{C} / \mathrm{C}_{\mathrm{o}}}$ & \\
\cline { 1 - 4 } 2 & -0.447 & 0.012 & 1 & 0.000 & LDL \\
2 & -0.148 & 0.005 & 1 & -0.001 & LDL \\
3 & 0.179 & 0.006 & 1 & 0.000 & LDL \\
4 & 0.483 & 0.965 & 1 & 0.131 & \\
5 & 0.790 & 1.726 & 2.9 & 0.695 & \\
6 & 1.102 & 2.377 & 2.8 & 0.905 & \\
7 & 1.377 & 2.319 & 3.0 & 0.942 & \\
8 & 1.633 & 2.310 & 3.0 & 0.964 & \\
9 & 1.901 & 2.468 & 2.9 & 0.970 & \\
10 & 2.195 & 2.468 & 2.9 & 0.969 & \\
11 & 2.568 & 2.337 & 3.1 & 0.980 & \\
12 & 2.978 & 2.268 & 3.2 & 0.983 & \\
13 & 3.346 & 1.836 & 4.0 & 1.004 & \\
14 & 3.719 & 2.319 & 3.1 & 0.997 & \\
15 & 4.061 & 1.963 & 3.7 & 0.990 & \\
16 & 4.392 & 2.620 & 2.8 & 0.990 & \\
17 & 4.781 & 2.456 & 2.7 & 0.925 & \\
18 & 5.033 & 2.174 & 3.2 & 0.977 & \\
19 & 5.278 & 2.420 & 2.9 & 0.991 & \\
20 & 5.544 & 2.310 & 3.0 & 0.979 & \\
21 & 5.822 & 2.174 & 3.3 & 0.995 & \\
22 & 6.111 & 2.260 & 3.2 & 1.031 & \\
23 & 6.378 & 2.537 & 2.8 & 1.015 & \\
24 & 6.705 & 2.620 & 2.7 & 1.013 & \\
25 & 7.097 & 2.620 & 2.8 & 1.022 & \\
26 & 7.506 & 2.387 & 3.0 & 1.024 & \\
27 & 8.717 & 2.237 & 3.3 & 1.046 & \\
28 & 9.874 & 2.456 & 3.0 & 1.024 &
\end{tabular}


Table 19 (Continued): Non-Reactive Tracer Study Data - Study \#7_pH 9_NRT

Data results for pentafluorobenzoic acid transport Study \#7_pH 9_NRT; Samples 29 - 62.

\begin{tabular}{|c|c|c|c|c|c|}
\hline Sample & Pore Volume (mL) & UV-Vis Abs & Dilution & $\mathrm{C} / \mathrm{C}_{\mathrm{o}}$ & \\
\hline 29 & 11.137 & 2.854 & 2.4 & 0.975 & \\
\hline 30 & 11.717 & 2.468 & 3.0 & 1.026 & \\
\hline 31 & 12.050 & 2.537 & 2.9 & 1.040 & Elution \\
\hline 32 & 12.332 & 2.432 & 3.0 & 1.025 & \\
\hline 33 & 12.640 & 2.409 & 3.0 & 1.034 & \\
\hline 34 & 12.945 & 2.194 & 2.9 & 0.898 & \\
\hline 35 & 13.253 & 0.959 & 3.1 & 0.411 & \\
\hline 36 & 13.549 & 0.349 & 2.8 & 0.132 & \\
\hline 37 & 13.826 & 0.547 & 1 & 0.071 & \\
\hline 38 & 14.117 & 0.388 & 1 & 0.052 & \\
\hline 39 & 14.456 & 0.286 & 1 & 0.038 & \\
\hline 40 & 14.799 & 0.215 & 1 & 0.028 & \\
\hline 41 & 15.098 & 0.191 & 1 & 0.025 & \\
\hline 42 & 15.409 & 0.158 & 1 & 0.020 & \\
\hline 43 & 15.759 & 0.889 & 1 & 0.116 & \\
\hline 44 & 16.028 & 0.454 & 1 & 0.060 & \\
\hline 45 & 16.290 & 0.235 & 1 & 0.031 & \\
\hline 46 & 16.521 & 0.374 & 1 & 0.049 & \\
\hline 47 & 16.786 & 0.468 & 1 & 0.062 & \\
\hline 48 & 17.120 & 0.179 & 1 & 0.023 & \\
\hline 49 & 17.430 & 0.084 & 1 & 0.011 & \\
\hline 50 & 17.727 & 0.058 & 1 & 0.007 & \\
\hline 51 & 18.057 & 0.047 & 1 & 0.006 & \\
\hline 52 & 18.374 & 0.048 & 1 & 0.006 & \\
\hline 53 & 18.705 & 0.045 & 1 & 0.005 & \\
\hline 54 & 19.026 & 0.043 & 1 & 0.005 & \\
\hline 55 & 19.300 & 0.036 & 1 & 0.004 & \\
\hline 56 & 19.574 & 0.037 & 1 & 0.004 & \\
\hline 57 & 19.861 & 0.035 & 1 & 0.004 & \\
\hline 58 & 20.208 & 0.029 & 1 & 0.003 & \\
\hline 59 & 20.579 & 0.033 & 1 & 0.004 & \\
\hline 60 & 20.916 & 0.034 & 1 & 0.004 & \\
\hline 61 & 21.322 & 0.045 & 1 & 0.005 & \\
\hline 62 & 21.707 & 0.032 & 1 & 0.004 & \\
\hline
\end{tabular}


Table 19 (Continued): Non-Reactive Tracer Study Data - Study \#7_pH 9_NRT

Data results for pentafluorobenzoic acid transport Study \#7_pH 9_NRT; Samples 63 - 70.

\begin{tabular}{cccccc} 
Sample & Pore Volume $(\mathrm{mL})$ & UV-Vis Abs & Dilution & C/C $_{o}$ & \\
\cline { 1 - 5 } 63 & 22.013 & 0.041 & 1 & 0.005 & \\
64 & 22.316 & 0.043 & 1 & 0.005 & \\
65 & 22.620 & 0.041 & 1 & 0.005 & \\
66 & 22.937 & 0.021 & 1 & 0.002 & LDL \\
67 & 23.216 & 0.022 & 1 & 0.002 & LDL \\
68 & 23.454 & 0.023 & 1 & 0.002 & LDL \\
69 & 23.685 & 0.025 & 1 & 0.003 & LDL \\
70 & 23.894 & 0.019 & 1 & 0.002 & LDL
\end{tabular}


Table 20: Aluminum Oxide Transport Data - Study \#7_pH 9

Concentration: $100 \mathrm{mg} / \mathrm{L}$

Column: A

Darcy Velocity: $0.025 \mathrm{~cm} / \mathrm{min}$

Electrolyte: $\mathrm{K}_{2} \mathrm{HPO}_{4} / \mathrm{K}_{3} \mathrm{HPO}_{4}$

Ionic Strength: $0.015 \mathrm{M}$

Data results for aluminum oxide nanoparticle transport Study \#7_pH 9; samples 1 - 28.

\begin{tabular}{|c|c|c|c|c|c|c|}
\hline Sample & $\begin{array}{c}\text { Pore } \\
\text { Volume } \\
(\mathrm{mL})\end{array}$ & $\begin{array}{c}\text { Influent } \\
\mathrm{pH}\end{array}$ & $\begin{array}{c}\text { Effluent } \\
\mathrm{pH}\end{array}$ & $\begin{array}{c}\text { UV-Vis } \\
\text { Abs }\end{array}$ & $\mathrm{C} / \mathrm{C}_{\mathrm{o}}$ & \\
\hline 1 & -0.432 & & & -0.032 & -0.031 & LDL \\
\hline 2 & -0.133 & & 8.61 & 0.015 & -0.006 & LDL \\
\hline 3 & 0.169 & & & -0.004 & -0.016 & LDL \\
\hline 4 & 0.448 & & & 0.020 & -0.003 & LDL \\
\hline 5 & 0.708 & & 8.68 & 0.107 & 0.042 & \\
\hline 6 & 0.977 & 9.01 & & 0.196 & 0.097 & \\
\hline 7 & 1.246 & & 8.77 & 0.447 & 0.258 & \\
\hline 8 & 1.513 & & & 0.659 & 0.393 & \\
\hline 9 & 1.790 & & 8.63 & 0.902 & 0.553 & \\
\hline 10 & 2.067 & & & 1.078 & 0.654 & \\
\hline 11 & 2.372 & & 8.85 & 1.248 & 0.753 & \\
\hline 12 & 2.675 & & & 1.359 & 0.817 & \\
\hline 13 & 2.938 & 9.04 & 8.84 & 1.408 & 0.845 & \\
\hline 14 & 3.218 & & & 1.499 & 0.898 & \\
\hline 15 & 3.517 & & 8.77 & 1.545 & 0.925 & \\
\hline 16 & 3.829 & & & 1.518 & 0.909 & \\
\hline 18 & 4.421 & 8.99 & & 1.565 & 0.936 & \\
\hline 19 & 4.685 & & 8.77 & 1.588 & 0.949 & \\
\hline 20 & 4.965 & & & 1.588 & 0.949 & \\
\hline 21 & 5.252 & & 8.77 & 1.596 & 0.954 & \\
\hline 22 & 5.528 & 9.37 & & 1.576 & 0.942 & \\
\hline 23 & 5.811 & & 8.8 & 1.591 & 0.951 & \\
\hline 24 & 6.119 & & & 1.625 & 0.971 & \\
\hline 25 & 6.434 & & 8.78 & 1.621 & 0.969 & \\
\hline 26 & 6.760 & & & 1.591 & 0.951 & \\
\hline 27 & 7.153 & & 8.72 & 1.552 & 0.929 & \\
\hline 28 & 7.522 & & & 1.518 & 0.909 & \\
\hline
\end{tabular}


Table 20 (Continued): Aluminum Oxide Transport Data - Study \#7_pH 9

Data results for aluminum oxide nanoparticle transport Study \#7_pH 9; samples 29 - 61.

\begin{tabular}{|c|c|c|c|c|c|c|}
\hline Sample & $\begin{array}{l}\text { Pore } \\
\text { Volume } \\
\text { (mL) }\end{array}$ & $\begin{array}{c}\text { Influent } \\
\mathrm{pH}\end{array}$ & $\begin{array}{c}\text { Effluent } \\
\mathrm{pH}\end{array}$ & $\begin{array}{c}\text { UV-Vis } \\
\text { Abs }\end{array}$ & $\mathrm{C} / \mathrm{C}_{\mathrm{o}}$ & \\
\hline 29 & 7.837 & & & 1.528 & 0.914 & \\
\hline 30 & 8.103 & & 8.74 & 1.525 & 0.913 & \\
\hline 31 & 8.363 & & & 1.542 & 0.922 & \\
\hline 32 & 8.621 & & 8.86 & 1.554 & 0.929 & \\
\hline 33 & 8.897 & & & 1.707 & 1.018 & \\
\hline 34 & 9.139 & & 8.8 & 1.580 & 0.944 & \\
\hline 35 & 9.421 & 9.05 & & 1.586 & 0.948 & \\
\hline 37 & 10.004 & 9.15 & & 1.607 & 0.960 & \\
\hline 38 & 10.270 & & 8.89 & 1.598 & 0.955 & \\
\hline 39 & 10.542 & & & 1.608 & 0.961 & \\
\hline 40 & 10.768 & & 8.86 & 1.608 & 0.961 & \\
\hline 41 & 10.995 & & & 1.612 & 0.963 & \\
\hline 42 & 11.241 & & 8.78 & 1.628 & 0.972 & \\
\hline 43 & 11.490 & & & 1.641 & 0.980 & \\
\hline 44 & 11.741 & & 8.75 & 1.612 & 0.963 & \\
\hline 45 & 11.971 & & & 1.626 & 0.971 & \\
\hline 46 & 12.194 & 9.26 & 8.85 & 1.645 & 0.982 & \\
\hline 47 & 12.530 & 9.06 & & 0.528 & 0.281 & $\begin{array}{l}6 \text { day stop } \\
\text { flow }\end{array}$ \\
\hline 48 & 12.820 & & 7.87 & 0.691 & 0.381 & \\
\hline 49 & 13.089 & & & 0.968 & 0.552 & \\
\hline 50 & 13.399 & & 7.94 & 1.332 & 0.776 & \\
\hline 51 & 13.714 & & & 1.427 & 0.835 & \\
\hline 52 & 14.009 & & 8.16 & 1.464 & 0.857 & \\
\hline 53 & 14.324 & & & 1.585 & 0.932 & \\
\hline 54 & 14.670 & 9.05 & 8.5 & 1.671 & 0.985 & \\
\hline 55 & 15.032 & & & 1.653 & 0.974 & \\
\hline 56 & 15.376 & & 8.57 & 1.667 & 0.982 & \\
\hline 57 & 15.714 & & & 1.655 & 0.975 & \\
\hline 58 & 16.056 & & 8.63 & 1.639 & 0.965 & \\
\hline 59 & 16.430 & & & 1.623 & 0.955 & \\
\hline 60 & 16.781 & & 8.66 & 1.649 & 0.971 & \\
\hline 61 & 17.072 & & & 1.645 & 0.969 & \\
\hline
\end{tabular}


Table 20 (Continued): Aluminum Oxide Transport Data - Study \#7_pH 9

Data results for aluminum oxide nanoparticle transport Study \#7_pH 9; samples 62 - 94.

\begin{tabular}{|c|c|c|c|c|c|}
\hline Sample & $\begin{array}{l}\text { Pore } \\
\text { Volume } \\
\text { (mL) }\end{array}$ & $\begin{array}{c}\text { Influent } \\
\mathrm{pH}\end{array}$ & $\begin{array}{c}\text { Effluent } \\
\mathrm{pH}\end{array}$ & $\begin{array}{c}\text { UV-Vis } \\
\text { Abs }\end{array}$ & $\mathrm{C} / \mathrm{C}_{\mathrm{o}}$ \\
\hline 62 & 17.397 & & 8.63 & 1.653 & 0.974 \\
\hline 63 & 17.772 & & & 1.655 & 0.975 \\
\hline 64 & 18.162 & & 8.63 & 1.687 & 0.995 \\
\hline 65 & 18.549 & & & 1.677 & 0.989 \\
\hline 66 & 18.866 & & 8.64 & 1.641 & 0.966 \\
\hline 67 & 19.162 & & & 1.641 & 0.966 \\
\hline 68 & 19.516 & & & 1.667 & 0.982 \\
\hline 69 & 19.795 & & 8.59 & 1.667 & 0.982 \\
\hline 70 & 20.055 & & & 1.627 & 0.958 \\
\hline 71 & 20.318 & & 8.62 & 1.632 & 0.961 \\
\hline 72 & 20.557 & & & 1.039 & 0.596 \\
\hline 73 & 20.832 & & 8.6 & 0.522 & 0.277 \\
\hline 74 & 21.142 & & & 0.231 & 0.107 \\
\hline 75 & 21.441 & & 8.66 & 0.150 & 0.065 \\
\hline 76 & 21.742 & & & 0.118 & 0.048 \\
\hline 77 & 22.029 & & 8.7 & 0.097 & 0.037 \\
\hline 78 & 22.291 & & & 0.090 & 0.033 \\
\hline 79 & 22.552 & & 8.7 & 0.096 & 0.036 \\
\hline 80 & 22.851 & & & 0.139 & 0.059 \\
\hline 81 & 23.169 & & 8.71 & 0.077 & 0.026 \\
\hline 82 & 23.438 & & & 0.093 & 0.035 \\
\hline 83 & 23.697 & & 8.68 & 0.091 & 0.034 \\
\hline 84 & 23.951 & & & 0.086 & 0.031 \\
\hline 85 & 24.179 & & 8.72 & 0.085 & 0.031 \\
\hline 86 & 24.492 & & & 0.333 & 0.164 \\
\hline 87 & 24.764 & & 7.94 & 0.210 & 0.088 \\
\hline 88 & 25.031 & & & 0.197 & 0.080 \\
\hline 89 & 25.293 & & 7.98 & 0.221 & 0.095 \\
\hline 90 & 25.562 & & & 0.243 & 0.108 \\
\hline 91 & 25.854 & & 8.05 & 0.171 & 0.068 \\
\hline 92 & 26.128 & & & 0.125 & 0.044 \\
\hline 93 & 26.457 & & 8.41 & 0.107 & 0.034 \\
\hline 94 & 26.857 & & & 0.062 & 0.017 \\
\hline
\end{tabular}


Table 20 (Continued): Aluminum Oxide Transport Data - Study \#7_pH 9

Data results for aluminum oxide nanoparticle transport Study \#7_pH 9; samples 95 - 114.

\begin{tabular}{ccccccc} 
Sample & $\begin{array}{c}\text { Pore } \\
\text { Volume } \\
(\mathrm{mL})\end{array}$ & $\begin{array}{c}\text { Influent } \\
\mathrm{pH}\end{array}$ & $\begin{array}{c}\text { Effluent } \\
\mathrm{pH}\end{array}$ & $\begin{array}{c}\text { UV-Vis } \\
\text { Abs }\end{array}$ & $\begin{array}{c}\text { C/C } \\
\text { o }\end{array}$ & \\
\hline 95 & 27.199 & & 8.54 & 0.062 & 0.017 & \\
96 & 27.479 & & & 0.105 & 0.033 & \\
97 & 27.733 & & 8.56 & 0.065 & 0.019 & \\
98 & 27.989 & & & 0.074 & 0.023 & \\
99 & 28.252 & & 8.6 & 0.050 & 0.011 & \\
100 & 28.516 & & & 0.075 & 0.023 & \\
101 & 28.750 & 8.57 & 0.058 & 0.015 & \\
102 & 29.003 & & & 0.041 & 0.007 & \\
103 & 29.272 & 8.55 & 0.061 & 0.017 & \\
104 & 29.538 & & & 0.054 & 0.013 & \\
105 & 29.815 & & 8.61 & 0.050 & 0.011 & \\
106 & 30.163 & & & 0.047 & 0.010 & \\
107 & 30.443 & & & 0.060 & 0.016 & \\
108 & 30.725 & & & 0.133 & 0.048 & \\
109 & 31.017 & & 8.61 & 0.018 & -0.014 & LDL \\
110 & 31.269 & & & 0.071 & 0.021 & LDL \\
111 & 31.520 & & & 0.046 & 0.009 & LDL \\
112 & 31.848 & & 8.66 & 0.049 & 0.011 & LDL \\
113 & 32.205 & & & 0.048 & 0.010 & LDL \\
114 & 32.490 & & 8.61 & 0.063 & 0.018 & LDL
\end{tabular}




\section{Table 21: Non-Reactive Tracer Study Data - Study \#8_pH 9_NRT}

Performed for $\mathrm{Al}_{2} \mathrm{O}_{3}$ Study \#8_pH 9

Column: A

Darcy Velocity: $1.9 \mathrm{~cm} / \mathrm{min}$

Electrolyte: $\mathrm{K}_{2} \mathrm{HPO}_{4} / \mathrm{K}_{3} \mathrm{HPO}_{4}$

Ionic Strength: $0.015 \mathrm{M}$

Data results for pentafluorobenzoic acid transport Study \#8_pH 9_NRT; Samples 1 - 28.

\begin{tabular}{|c|c|c|c|c|}
\hline Sample & Pore Volume (mL) & UV-Vis Abs & Dilution & $\mathrm{C} / \mathrm{C}_{\mathrm{o}}$ \\
\hline 1 & -0.449 & 0.034 & 1 & 0.005 \\
\hline 2 & -0.285 & 0.020 & 1 & 0.004 \\
\hline 3 & -0.092 & 0.004 & 1 & 0.001 \\
\hline 4 & 0.101 & 0.010 & 1 & 0.002 \\
\hline 5 & 0.293 & 0.062 & 1 & 0.009 \\
\hline 6 & 0.486 & 0.789 & 1 & 0.108 \\
\hline 7 & 0.689 & 1.002 & 3.1 & 0.430 \\
\hline 8 & 0.901 & 1.883 & 2.8 & 0.738 \\
\hline 9 & 1.113 & 2.347 & 2.8 & 0.889 \\
\hline 10 & 1.325 & 2.432 & 2.8 & 0.937 \\
\hline 11 & 1.633 & 2.678 & 2.6 & 0.949 \\
\hline 12 & 2.038 & 2.398 & 3.0 & 0.975 \\
\hline 13 & 2.443 & 2.432 & 2.9 & 0.970 \\
\hline 14 & 2.848 & 2.456 & 2.9 & 0.976 \\
\hline 15 & 3.272 & 2.420 & 3.0 & 0.988 \\
\hline 16 & 3.677 & 2.310 & 3.1 & 0.996 \\
\hline 17 & 4.563 & 2.161 & 2.1 & 0.622 \\
\hline 18 & 5.411 & 2.284 & 3.2 & 0.994 \\
\hline 19 & 6.183 & 2.537 & 2.9 & 1.008 \\
\hline 20 & 6.983 & 2.260 & 3.3 & 1.011 \\
\hline 21 & 7.783 & 2.678 & 2.7 & 0.979 \\
\hline 22 & 8.554 & 2.678 & 2.7 & 0.992 \\
\hline 23 & 9.325 & 2.745 & 2.6 & 0.999 \\
\hline 24 & 10.105 & 2.620 & 2.8 & 0.996 \\
\hline 25 & 10.886 & 2.337 & 3.1 & 1.005 \\
\hline 26 & 11.638 & 2.293 & 3.2 & 1.011 \\
\hline 27 & 11.850 & 2.509 & 2.9 & 1.010 \\
\hline 28 & 12.062 & 2.456 & 3.0 & 1.009 \\
\hline
\end{tabular}


Table 21 (Continued): Non-Reactive Tracer Study Data - Study \#8_pH 9_NRT

Data results for pentafluorobenzoic acid transport Study \#8_pH 9_NRT; Samples 29 - 52.

\begin{tabular}{|c|c|c|c|c|}
\hline Sample & Pore Volume (mL) & UV-Vis Abs & Dilution & $\mathrm{C} / \mathrm{C}_{\mathrm{o}}$ \\
\hline 29 & 12.274 & 2.357 & 3.1 & 1.012 \\
\hline 30 & 12.486 & 2.092 & 3.3 & 0.936 \\
\hline 31 & 12.698 & 1.786 & 2.6 & 0.645 \\
\hline 32 & 12.910 & 0.884 & 2.7 & 0.327 \\
\hline 33 & 13.122 & 0.437 & 2.6 & 0.159 \\
\hline 34 & 13.334 & 0.600 & 1 & 0.082 \\
\hline 35 & 13.546 & 0.397 & 1 & 0.054 \\
\hline 36 & 13.855 & 0.284 & 1 & 0.039 \\
\hline 37 & 14.269 & 0.224 & 1 & 0.030 \\
\hline 38 & 14.684 & 0.191 & 1 & 0.026 \\
\hline 39 & 15.089 & 0.164 & 1 & 0.022 \\
\hline 40 & 15.493 & 0.143 & 1 & 0.019 \\
\hline 41 & 15.898 & 0.125 & 1 & 0.017 \\
\hline 42 & 16.785 & 0.093 & 1 & 0.012 \\
\hline 43 & 17.633 & 0.065 & 1 & 0.009 \\
\hline 44 & 18.424 & 0.053 & 1 & 0.007 \\
\hline 45 & 19.339 & 0.037 & 1 & 0.005 \\
\hline 46 & 20.236 & 0.034 & 1 & 0.004 \\
\hline 47 & 21.045 & 0.031 & 1 & 0.004 \\
\hline 48 & 21.855 & 0.027 & 1 & 0.003 \\
\hline 49 & 22.665 & 0.025 & 1 & 0.003 \\
\hline 50 & 23.416 & 0.021 & 1 & 0.003 \\
\hline 51 & 24.226 & 0.021 & 1 & 0.003 \\
\hline 52 & 25.093 & 0.020 & 1 & 0.002 \\
\hline
\end{tabular}


Table 22: Aluminum Oxide Transport Data - Study \#8_pH 9

Concentration: $100 \mathrm{mg} / \mathrm{L}$

Column: A

Darcy Velocity: $1.9 \mathrm{~cm} / \mathrm{min}$

Electrolyte: $\mathrm{K}_{2} \mathrm{HPO}_{4} / \mathrm{K}_{3} \mathrm{HPO}_{4}$

Ionic Strength: $0.015 \mathrm{M}$

Data results for aluminum oxide nanoparticle transport Study \#8_pH 9; samples 1 - 27.

\begin{tabular}{|c|c|c|c|c|c|}
\hline Sample & $\begin{array}{c}\text { Pore Volume } \\
(\mathrm{mL})\end{array}$ & Influent $\mathrm{pH}$ & Effluent $\mathrm{pH}$ & $\begin{array}{c}\text { UV-Vis } \\
\text { Abs }\end{array}$ & $\mathrm{C} / \mathrm{C}_{\mathrm{o}}$ \\
\hline 1 & -0.385 & 9.19 & & 0.113 & 0.071 \\
\hline 2 & -0.136 & & & 0.027 & 0.024 \\
\hline 3 & 0.114 & & 8.35 & 0.011 & 0.015 \\
\hline 4 & 0.364 & & & 0.144 & 0.089 \\
\hline 5 & 0.614 & & & 0.540 & 0.307 \\
\hline 6 & 0.863 & & 8.63 & 0.933 & 0.527 \\
\hline 7 & 1.113 & & & 1.155 & 0.659 \\
\hline 8 & 1.363 & & & 1.293 & 0.741 \\
\hline 9 & 1.603 & & 8.73 & 1.329 & 0.763 \\
\hline 10 & 1.872 & & & 1.400 & 0.805 \\
\hline 11 & 2.228 & & & 1.508 & 0.869 \\
\hline 12 & 2.708 & & 8.8 & 1.535 & 0.885 \\
\hline 13 & 3.188 & & & 1.585 & 0.915 \\
\hline 14 & 3.669 & & & 1.568 & 0.905 \\
\hline 15 & 4.149 & & & 1.611 & 0.931 \\
\hline 16 & 4.514 & & 8.82 & 1.515 & 0.873 \\
\hline 17 & 4.706 & & 8.89 & & \\
\hline 18 & 5.811 & & 8.95 & & \\
\hline 19 & 6.301 & & & 1.568 & 0.905 \\
\hline 20 & 6.753 & & 8.93 & & \\
\hline 21 & 7.204 & & & 1.640 & 0.948 \\
\hline 22 & 7.646 & & 8.93 & & \\
\hline 23 & 8.088 & & & 1.674 & 0.968 \\
\hline 24 & 8.530 & & 8.95 & & \\
\hline 25 & 8.972 & & & 1.682 & 0.973 \\
\hline 26 & 9.414 & & 8.95 & & \\
\hline 27 & 9.846 & & & 1.720 & 0.996 \\
\hline
\end{tabular}


Table 22 (Continued): Aluminum Oxide Transport Data - Study \#8_pH 9

Data results for aluminum oxide nanoparticle transport Study \#8_pH 9; samples 28 - 46.

\begin{tabular}{|c|c|c|c|c|c|}
\hline Sample & $\begin{array}{c}\text { Pore Volume } \\
(\mathrm{mL})\end{array}$ & Influent $\mathrm{pH}$ & Effluent $\mathrm{pH}$ & $\begin{array}{c}\mathrm{UV}-\mathrm{V} \text { is } \\
\mathrm{Abs}\end{array}$ & $\mathrm{C} / \mathrm{C}_{\mathrm{o}}$ \\
\hline 28 & 10.288 & & 8.96 & & \\
\hline 29 & 10.720 & & & 1.739 & 1.007 \\
\hline 30 & 11.210 & & 8.91 & & \\
\hline 31 & 11.719 & & & 1.670 & 0.966 \\
\hline 32 & 12.190 & & 8.93 & & \\
\hline 33 & 12.680 & & & 1.691 & 0.978 \\
\hline 34 & 13.276 & & & 1.581 & 0.913 \\
\hline 35 & 13.718 & & & & \\
\hline 36 & 14.169 & & & 1.706 & 0.987 \\
\hline 37 & 14.621 & & 8.94 & & \\
\hline 38 & 15.101 & & & 1.753 & 1.015 \\
\hline 39 & 15.581 & & 8.93 & & \\
\hline 40 & 16.043 & & & 1.739 & 1.007 \\
\hline 41 & 16.484 & & 8.9 & & \\
\hline 42 & 16.907 & & & 1.729 & 1.001 \\
\hline 43 & 17.190 & & & 1.729 & 1.001 \\
\hline 44 & 17.706 & & 8.91 & & \\
\hline 45 & 18.223 & & & 1.700 & 0.984 \\
\hline 46 & 18.557 & & 8.9 & & \\
\hline
\end{tabular}


Table 23: Non-Reactive Tracer Study Data - Study \#9_pH 9_NRT

Performed for $\mathrm{Al}_{2} \mathrm{O}_{3}$ Study \#9_pH 9

Column: A

Darcy Velocity: $1.8 \mathrm{~cm} / \mathrm{min}$

Electrolyte: $\mathrm{K}_{2} \mathrm{HPO}_{4} / \mathrm{K}_{3} \mathrm{HPO}_{4}$

Ionic Strength: $0.015 \mathrm{M}$

Data results for pentafluorobenzoic acid transport Study \#9_pH 9_NRT; Samples 1 - 28.

\begin{tabular}{cccccc} 
Sample & $\begin{array}{c}\text { Pore Volume } \\
(\mathrm{mL})\end{array}$ & UV-Vis Abs & Dilution & ${\mathrm{C} / \mathrm{C}_{\mathrm{o}}}$ & \\
\cline { 1 - 3 } 2 & -0.143 & 0.020 & 1 & 0.002 & LDL \\
2 & 0.054 & 0.019 & 1 & 0.001 & LDL \\
3 & 0.252 & 0.039 & 1 & 0.004 & \\
4 & 0.449 & 0.738 & 1 & 0.099 & \\
5 & 0.647 & 1.131 & 3.0 & 0.463 & \\
6 & 0.844 & 1.940 & 3.0 & 0.797 & \\
7 & 1.041 & 2.244 & 3.0 & 0.921 & \\
8 & 1.239 & 2.310 & 3.0 & 0.953 & \\
9 & 1.436 & 2.337 & 3.0 & 0.967 & \\
10 & 1.634 & 2.366 & 3.0 & 0.976 & \\
11 & 1.831 & 2.357 & 3.0 & 0.974 & \\
12 & 2.029 & 2.357 & 3.0 & 0.976 & \\
13 & 2.316 & 2.377 & 3.0 & 0.982 & \\
14 & 2.693 & 2.377 & 3.0 & 0.979 & \\
15 & 3.070 & 2.377 & 3.0 & 0.985 & \\
16 & 3.447 & 2.409 & 3.0 & 0.990 & \\
17 & 3.824 & 2.377 & 3.0 & 0.982 & \\
18 & 4.560 & 2.377 & 3.0 & 0.963 & \\
19 & 5.332 & 2.409 & 3.0 & 0.995 & \\
20 & 6.086 & 2.420 & 3.0 & 1.000 & \\
21 & 6.786 & 2.444 & 3.0 & 1.004 & \\
22 & 7.558 & 2.409 & 3.0 & 1.003 & \\
23 & 8.294 & 2.420 & 3.0 & 1.000 & \\
24 & 9.048 & 2.745 & 2.6 & 0.994 & \\
25 & 9.784 & 2.420 & 3.0 & 0.998 & \\
26 & 10.537 & 2.658 & 2.8 & 1.008 & \\
27 & 11.309 & 2.420 & 3.0 & 1.006 & \\
28 & 11.902 & 2.444 & 3.0 & 1.007 &
\end{tabular}


Table 23 (Continued): Non-Reactive Tracer Study Data - Study \#9_pH 9_NRT

Data results for pentafluorobenzoic acid transport Study \#9_pH 9_NRT; Samples 29 - 63.

\begin{tabular}{|c|c|c|c|c|c|}
\hline Sample & $\begin{array}{l}\text { ore Volume } \\
\qquad(\mathrm{mL})\end{array}$ & $\mathrm{UV}-\mathrm{V}$ is $\mathrm{Abs}$ & Dilution & $\mathrm{C} / \mathrm{C}_{\mathrm{o}}$ & \\
\hline 29 & 12.665 & 2.444 & 3.0 & 1.003 & \\
\hline 30 & 13.428 & 2.444 & 3.0 & 1.007 & \\
\hline 31 & 13.616 & 2.444 & 3.0 & 1.016 & Elution \\
\hline 32 & 13.805 & 2.444 & 3.0 & 1.007 & \\
\hline 33 & 13.984 & 2.456 & 3.0 & 1.013 & \\
\hline 34 & 14.181 & 2.456 & 3.0 & 1.012 & \\
\hline 35 & 14.379 & 2.420 & 3.0 & 1.005 & \\
\hline 36 & 14.576 & 2.229 & 3.0 & 0.927 & \\
\hline 37 & 14.783 & 1.366 & 3.0 & 0.562 & \\
\hline 38 & 14.989 & 0.545 & 3.0 & 0.222 & \\
\hline 39 & 15.187 & 0.673 & 1 & 0.090 & \\
\hline 40 & 15.384 & 0.398 & 1 & 0.052 & \\
\hline 41 & 15.671 & 0.265 & 1 & 0.034 & \\
\hline 42 & 16.048 & 0.198 & 1 & 0.025 & \\
\hline 43 & 16.425 & 0.172 & 1 & 0.022 & \\
\hline 44 & 16.802 & 0.157 & 1 & 0.020 & \\
\hline 45 & 17.179 & 0.141 & 1 & 0.017 & \\
\hline 46 & 17.556 & 0.129 & 1 & 0.016 & \\
\hline 47 & 18.382 & 0.116 & 1 & 0.014 & \\
\hline 48 & 19.154 & 0.103 & 1 & 0.012 & \\
\hline 49 & 19.908 & 0.096 & 1 & 0.011 & \\
\hline 50 & 20.662 & 0.089 & 1 & 0.010 & \\
\hline 51 & 21.425 & 0.086 & 1 & 0.010 & \\
\hline 52 & 22.188 & 0.065 & 1 & 0.007 & \\
\hline 53 & 22.942 & 0.073 & 1 & 0.008 & \\
\hline 54 & 23.704 & 0.060 & 1 & 0.007 & \\
\hline 55 & 24.485 & 0.052 & 1 & 0.006 & \\
\hline 56 & 25.239 & 0.044 & 1 & 0.005 & \\
\hline 57 & 25.975 & 0.041 & 1 & 0.004 & \\
\hline 58 & 26.729 & 0.044 & 1 & 0.005 & \\
\hline 59 & 27.483 & 0.040 & 1 & 0.004 & \\
\hline 60 & 28.237 & 0.044 & 1 & 0.005 & \\
\hline 61 & 28.973 & 0.023 & 1 & 0.002 & \\
\hline 62 & 29.727 & 0.033 & 1 & 0.003 & \\
\hline 63 & 30.481 & 0.026 & 1 & 0.002 & \\
\hline
\end{tabular}


Table 24: Aluminum Oxide Transport Data - Study \#9_pH 9

Concentration: $100 \mathrm{mg} / \mathrm{L}$

Column: A

Darcy Velocity: $1.9 \mathrm{~cm} / \mathrm{min}$

Electrolyte: $\mathrm{K}_{2} \mathrm{HPO}_{4} / \mathrm{K}_{3} \mathrm{HPO}_{4}$

Ionic Strength: $0.015 \mathrm{M}$

Data results for aluminum oxide nanoparticle transport Study \#9_pH 9; samples 1 - 27.

\begin{tabular}{|c|c|c|c|c|c|c|}
\hline Sample & $\begin{array}{c}\text { Pore } \\
\text { Volume } \\
(\mathrm{mL})\end{array}$ & $\begin{array}{l}\text { Influent } \\
\text { pH }\end{array}$ & $\begin{array}{l}\text { Effluent } \\
\text { pH }\end{array}$ & $\begin{array}{c}\mathrm{UV}-\mathrm{V} \text { is } \\
\mathrm{Abs}\end{array}$ & $\mathrm{C} / \mathrm{C}_{\mathrm{o}}$ & \\
\hline 1 & -0.536 & 9.44 & & 0.069 & 0.051 & \\
\hline 2 & -0.336 & & & 0.034 & 0.031 & \\
\hline 3 & -0.136 & & 8.38 & 0.067 & 0.050 & \\
\hline 4 & 0.064 & & & 0.043 & 0.036 & \\
\hline 5 & 0.264 & & & 0.072 & 0.053 & \\
\hline 6 & 0.455 & & 8.69 & 0.245 & 0.156 & \\
\hline 7 & 0.646 & & & 0.517 & 0.314 & \\
\hline 8 & 0.847 & & & 0.738 & 0.449 & \\
\hline 9 & 1.047 & & 8.64 & 0.873 & 0.531 & \\
\hline 10 & 1.238 & & & 0.951 & 0.578 & \\
\hline 11 & 1.429 & & & 0.997 & 0.606 & \\
\hline 12 & 1.629 & & 8.73 & 1.056 & 0.642 & \\
\hline 13 & 1.829 & & & 1.112 & 0.676 & \\
\hline 14 & 2.029 & & & 1.154 & 0.702 & \\
\hline 15 & 2.229 & & 8.76 & 1.169 & 0.711 & \\
\hline 16 & 2.429 & & & 1.204 & 0.732 & \\
\hline 17 & 2.629 & & & 1.237 & 0.752 & \\
\hline 18 & 2.830 & & 8.76 & 1.283 & 0.780 & \\
\hline 19 & 3.030 & & & 1.321 & 0.803 & \\
\hline 20 & 3.239 & & & 1.286 & 0.782 & \\
\hline 21 & 3.430 & & & 1.103 & 0.671 & 5-10 min. stop flow \\
\hline 22 & 3.721 & & 8.86 & 1.179 & 0.717 & \\
\hline 23 & 4.103 & & & 1.224 & 0.744 & \\
\hline 24 & 4.476 & & 8.93 & 1.210 & 0.736 & \\
\hline 25 & 4.867 & & & 1.414 & 0.860 & \\
\hline 26 & 5.267 & & 8.88 & 1.489 & 0.905 & \\
\hline 27 & 5.740 & & 8.99 & & & \\
\hline
\end{tabular}


Table 24 (Continued): Aluminum Oxide Transport Data - Study \#9_pH 9

Data results for aluminum oxide nanoparticle transport Study \#9_pH 9; samples 28 - 59.

\begin{tabular}{|c|c|c|c|c|c|c|}
\hline Sample & $\begin{array}{c}\text { Pore } \\
\text { Volume } \\
(\mathrm{mL})\end{array}$ & $\begin{array}{c}\text { Influent } \\
\mathrm{pH}\end{array}$ & $\begin{array}{c}\text { Effluent } \\
\mathrm{pH}\end{array}$ & $\begin{array}{c}\text { UV-Vis } \\
\text { Abs }\end{array}$ & $\mathrm{C} / \mathrm{C}_{\mathrm{o}}$ & \\
\hline 28 & 6.122 & & & 1.554 & 0.945 & \\
\hline 29 & 6.504 & & 9.01 & & & \\
\hline 30 & 6.886 & & & 1.614 & 0.981 & \\
\hline 31 & 7.268 & & 8.94 & & & \\
\hline 32 & 7.705 & & & 1.547 & 0.940 & \\
\hline 33 & 8.142 & & 8.9 & & & \\
\hline 34 & 8.524 & & & 1.605 & 0.976 & \\
\hline 35 & 8.706 & & & 1.455 & 0.885 & 5-10 min. stop flow \\
\hline 36 & 9.088 & & 8.94 & & & \\
\hline 37 & 9.470 & & & 1.489 & 0.905 & \\
\hline 38 & 9.852 & & 8.93 & & & \\
\hline 39 & 10.234 & & & 1.560 & 0.948 & \\
\hline 40 & 10.616 & & 8.92 & & & \\
\hline 41 & 10.998 & & & 1.609 & 0.978 & \\
\hline 42 & 11.407 & & 8.95 & & & \\
\hline 43 & 11.817 & & & 1.621 & 0.985 & \\
\hline 44 & 12.199 & & 8.9 & & & \\
\hline 45 & 12.581 & & & 1.646 & 1.001 & \\
\hline 46 & 12.972 & & 8.91 & & & \\
\hline 47 & 13.363 & & & 1.646 & 1.001 & \\
\hline 48 & 13.736 & & 8.88 & & & \\
\hline 49 & 14.109 & & & 1.664 & 1.012 & \\
\hline 50 & 14.345 & 9.14 & & 1.540 & 0.936 & Elution \\
\hline 51 & 14.545 & & & 1.593 & 0.968 & \\
\hline 52 & 14.746 & & & 1.543 & 0.938 & \\
\hline 53 & 14.946 & & & 1.571 & 0.955 & \\
\hline 54 & 15.146 & & 8.8 & 1.560 & 0.948 & \\
\hline 55 & 15.346 & & & 1.282 & 0.779 & \\
\hline 56 & 15.546 & & & 0.789 & 0.480 & \\
\hline 57 & 15.737 & & 8.77 & 0.442 & 0.269 & \\
\hline 58 & 15.928 & & & 0.229 & 0.146 & \\
\hline 59 & 16.128 & & & 0.134 & 0.090 & \\
\hline
\end{tabular}


Table 24 (Continued): Aluminum Oxide Transport Data - Study \#9_pH 9

Data results for aluminum oxide nanoparticle transport Study \#9_pH 9; samples 60 - 93.

\begin{tabular}{|c|c|c|c|c|c|}
\hline Sample & $\begin{array}{l}\text { Pore Volume } \\
\text { (mL) }\end{array}$ & Influent $\mathrm{pH}$ & Effluent $\mathrm{pH}$ & $\begin{array}{c}\text { UV-Vis } \\
\text { Abs }\end{array}$ & $\mathrm{C} / \mathrm{C}_{\mathrm{o}}$ \\
\hline 60 & 16.337 & & 8.76 & 0.074 & 0.054 \\
\hline 61 & 16.547 & & & 0.092 & 0.065 \\
\hline 62 & 16.747 & & & 0.066 & 0.049 \\
\hline 63 & 16.947 & & 8.74 & 0.079 & 0.057 \\
\hline 64 & 17.147 & & & 0.083 & 0.059 \\
\hline 65 & 17.347 & & & 0.076 & 0.055 \\
\hline 66 & 17.547 & & 8.75 & 0.080 & 0.058 \\
\hline 67 & 17.747 & & & 0.042 & 0.036 \\
\hline 68 & 17.947 & & & 0.056 & 0.044 \\
\hline 69 & 18.175 & & 8.74 & 0.088 & 0.062 \\
\hline 70 & 18.493 & & & 0.056 & 0.044 \\
\hline 71 & 18.875 & & 8.86 & 0.058 & 0.045 \\
\hline 72 & 19.266 & & & 0.033 & 0.031 \\
\hline 73 & 19.548 & & 8.74 & 0.119 & 0.081 \\
\hline 74 & 19.930 & & 8.81 & & \\
\hline 75 & 20.312 & & & 0.052 & 0.041 \\
\hline 76 & 20.667 & & 8.81 & & \\
\hline 77 & 21.040 & & & 0.031 & 0.029 \\
\hline 78 & 21.422 & & 8.77 & & \\
\hline 79 & 21.804 & & & 0.050 & 0.040 \\
\hline 80 & 22.186 & & 8.79 & & \\
\hline 81 & 22.595 & & & 0.040 & 0.035 \\
\hline 82 & 23.005 & & 8.81 & & \\
\hline 83 & 23.387 & & & 0.031 & 0.029 \\
\hline 84 & 23.769 & & 8.81 & & \\
\hline 85 & 24.160 & & & 0.060 & 0.046 \\
\hline 86 & 24.397 & & & 0.037 & 0.033 \\
\hline 87 & 24.760 & & 8.74 & & \\
\hline 88 & 25.079 & & & 0.067 & 0.050 \\
\hline 89 & 25.461 & & 8.81 & & \\
\hline 90 & 25.843 & & & 0.044 & 0.037 \\
\hline 91 & 26.225 & & 8.79 & & \\
\hline 92 & 26.607 & & & 0.046 & 0.038 \\
\hline 93 & 26.989 & & 8.8 & & \\
\hline
\end{tabular}


Table 24 (Continued): Aluminum Oxide Transport Data - Study \#9_pH 9

Data results for aluminum oxide nanoparticle transport Study \#9_pH 9; samples 94 - 115.

\begin{tabular}{|c|c|c|c|c|c|c|}
\hline Sample & $\begin{array}{c}\text { Pore } \\
\text { Volume } \\
(\mathrm{mL})\end{array}$ & $\begin{array}{c}\text { Influent } \\
\mathrm{pH}\end{array}$ & $\begin{array}{c}\text { Effluent } \\
\mathrm{pH}\end{array}$ & $\begin{array}{c}\text { UV-Vis } \\
\text { Abs }\end{array}$ & $\mathrm{C} / \mathrm{C}_{\mathrm{o}}$ & \\
\hline 94 & 27.398 & & & 0.042 & 0.036 & \\
\hline 95 & 27.808 & & 8.79 & & & \\
\hline 96 & 28.208 & & & 0.056 & 0.044 & \\
\hline 97 & 28.617 & & 8.77 & & & \\
\hline 98 & 29.008 & & & 0.106 & 0.073 & \\
\hline 99 & 29.372 & & 8.77 & & & \\
\hline 100 & 29.736 & & & 0.036 & 0.032 & \\
\hline 101 & 29.918 & & & 0.015 & 0.020 & \\
\hline 102 & 30.300 & & 8.81 & & & \\
\hline 103 & 30.682 & & & 0.007 & 0.016 & LDL \\
\hline 104 & 30.873 & & & 0.011 & 0.018 & \\
\hline 105 & 31.100 & & & 0.097 & 0.068 & \\
\hline 106 & 31.537 & & 8.79 & & & \\
\hline 107 & 31.983 & & & 0.089 & 0.063 & \\
\hline 108 & 32.410 & & 8.77 & & & \\
\hline 109 & 32.792 & & & -0.008 & 0.007 & LDL \\
\hline 110 & 33.183 & & 8.73 & & & \\
\hline 111 & 33.575 & & & -0.006 & 0.009 & LDL \\
\hline 112 & 33.993 & & 8.76 & & & \\
\hline 113 & 34.430 & & & -0.011 & 0.006 & LDL \\
\hline 114 & 34.812 & & 8.75 & & & \\
\hline 115 & 35.203 & & & -0.014 & 0.004 & LDL \\
\hline
\end{tabular}

